\title{
Design of Bending Moment and Load Capacity Test for FRP Sheet Piles
}

Joshua Larry Wilt Mr.

West Virginia University, jlwilt@mix.wvu.edu

Follow this and additional works at: https://researchrepository.wvu.edu/etd

\section{Recommended Citation}

Wilt, Joshua Larry Mr., "Design of Bending Moment and Load Capacity Test for FRP Sheet Piles" (2021). Graduate Theses, Dissertations, and Problem Reports. 10201.

https://researchrepository.wvu.edu/etd/10201

This Thesis is protected by copyright and/or related rights. It has been brought to you by the The Research Repository @ WVU with permission from the rights-holder(s). You are free to use this Thesis in any way that is permitted by the copyright and related rights legislation that applies to your use. For other uses you must obtain permission from the rights-holder(s) directly, unless additional rights are indicated by a Creative Commons license in the record and/ or on the work itself. This Thesis has been accepted for inclusion in WVU Graduate Theses, Dissertations, and Problem Reports collection by an authorized administrator of The Research Repository @ WVU. For more information, please contact researchrepository@mail.wvu.edu. 


\title{
Design of Bending Moment and Load Capacity Test for FRP
}

\section{Sheet Piles}

\author{
Joshua Larry Wilt
}

\author{
Thesis Submitted to the \\ Benjamin M. Statler College of Engineering and Mineral Resources \\ at \\ West Virginia University \\ in \\ Partial Fulfillment of the Requirements \\ for the Degree of \\ Master of Science \\ in \\ Civil and Environmental Engineering
}

\author{
Hota V.S. GangaRao, Ph.D., P.E., Chair \\ John D. Quaranta, Ph.D., P.E. \\ Ruifeng R. Liang, Ph.D.
}

Wadsworth Department of Civil and Environmental Engineering

Morgantown, West Virginia

December 2021

Keywords: Fiber Reinforced Polymer, Sheet Piles, Flexural Behavior, Experimental Evaluation, Pre-standard Test

Copyright 2021 Joshua Wilt 


\title{
DESIGN OF BENDING MOMENT AND LOAD CAPACITY TEST METHOD FOR FRP SHEET PILES
}

\begin{abstract}
Joshua Larry Wilt
Sheet piles consist of numerous interlocked segments that form temporary or permanent support walls and serve as the primary foundational component across a variety of civil infrastructural applications, such as below-grade parking structures or sea walls. The installation of sheet piles is particularly advantageous in coastal areas, as dewatering of the site is unnecessary. Steel is commonly used for sheet piles due to its strength and ease of manufacturing; however, in the presence of saltwater steel begins to rust. Contrary to steel and concrete, fiber reinforced polymer (FRP) composite sheet piles are resistant to chlorides and have considerably higher corrosion resistance. However, varying mechanical properties of FRP composite sheet piles in length and width direction as well as stress risers at the corners of the corrugations cause the soil-structure interaction to be a challenging design issue.
\end{abstract}

The purpose of this study is to develop a standardized test procedure to determine moment capacity of composite sheet piles. Specifically, the moment incurred at any given point on a sheet pile is proportional to the stress experienced in conjunction(interaction) with soil pressures and a function of failure mode. Testing is conducted using an MTS actuator or winch that is connected to 1 inch diameter threaded rods centered on a wale section that is attached to the sheet pile components at its top. The pile is fixed at the bottom with a sand-concrete mixture of $\sim 70$ psi compressive strength (shear strength of $\sim 35 \mathrm{psi}$ ) that extends to a height of 3 feet, while the free-standing section of the sheet pile extends an additional 10 feet above mud line. Strain gages and LVDTs are installed strategically on pile surface at both the above and below mud line to monitor its condition during testing and to collect data to establish load vs strain response.

This report concludes that failure occurs along the weak axis of the sheet pile when flexural stress is incurred on the test specimen. A net pressure distribution diagram is created using strain data obtained in laboratory testing and compared with diagrams shown in literature. The diagrams indicate pressure along the depth of the sheet pile, which is used to determine the bending moment. Several sheet piles have been tested with consistent results that correlate well with theoretical sheet pile design calculations. The results from each test were also compared with field test data and are found to correlate well. Results from this study suggest that this test can become a useful resource for engineers and will assist in designing the most economically feasible and structurally efficient sheet pile structure. The test procedure developed herein will be a basis to propose ASTM test procedure to establish load capacity of sheet piles as a function of soil properties and embedment length. 


\section{Acknowledgements}

I would like to thank my research advisor and committee chairman, Dr. Hota V.S. GangaRao, for providing guidance and support throughout the course of this project. I would also like to thank Dr. John Quaranta for his assistance with the project as well as encouragement throughout the past semesters. Appreciation is also extended to Dr. Ruifieng Liang for reviewing my work and assisting at a moment's notice, whenever needed in the laboratory.

There Is an extensive list of individuals that I owe sincere gratitude towards for helping me accomplish this task. To Hana, who has helped in numerous ways and provided encouragement from the first day of graduate school. There is no one that I would rather survive the arduous nature of graduate school with. To my parents, Jonathan L. and Amy R. Wilt for whom I am forever indebted. The thousands of sacrifices that have been made to provide me with the greatest upbringing one could ask for is treasured. The love and support received from my grandparents, Edward and Lorraine Schintzius, and Larry and Diana Wilt has been greatly appreciated. I am very grateful for the many visits and trips to the grocery store throughout my time spent in college. To my brother, Jarod Wilt, for his persitance and friendship. I would like to thank all of my friends and colleauges whom have helped out at various stages of this project. Amir Houschmandyar, Drew Damich, Robert Tennant, and several others have been crucial in the completion of this project. Additionally, I would like to thank Douglas Dunko and Justin Kile for their willingness to teach me as much as possible over the course of a short summer internship, and inspiring me to continue my education.

This project was funded by Creative Composites Group. I would like to thank all of the personell that I have worked with along the way. Jeremy Mostoller and Dustin Troutman have been extremely cooperative and understanding over the span of this project. 


\section{CONTENTS}

\section{Contents}

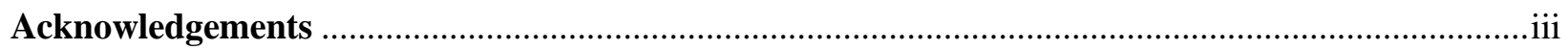

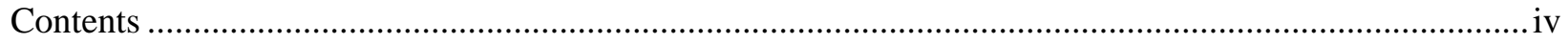

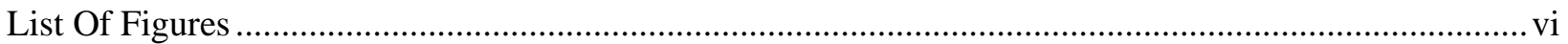

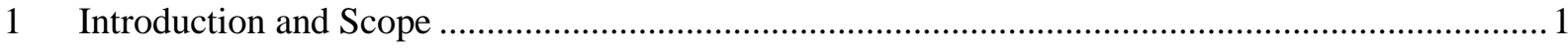

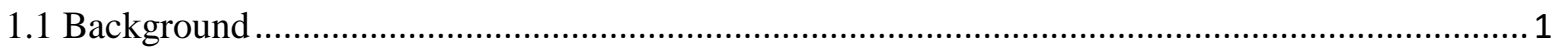

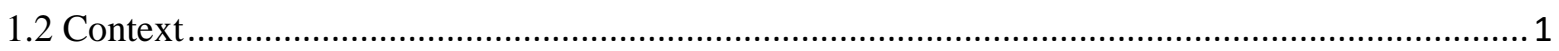

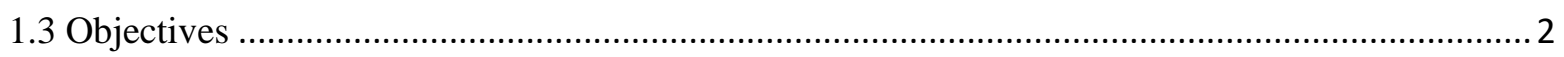

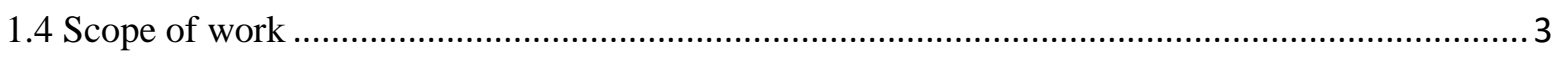

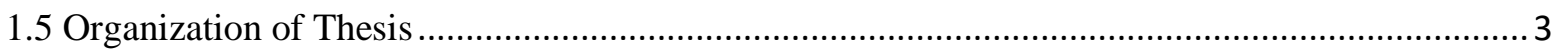

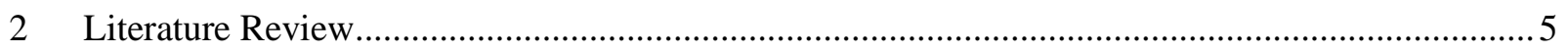

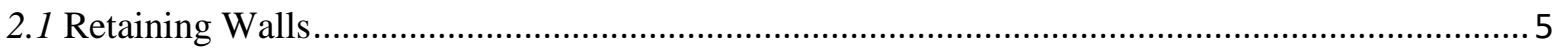

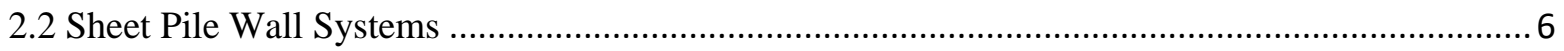

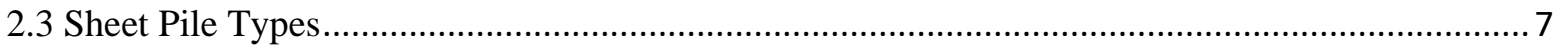

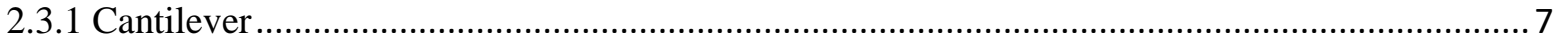

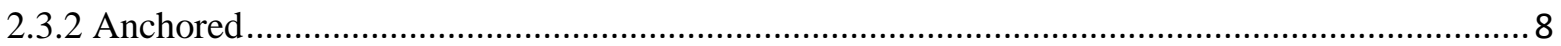

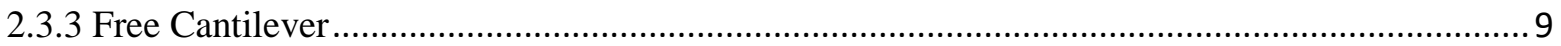

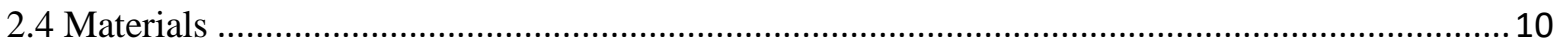

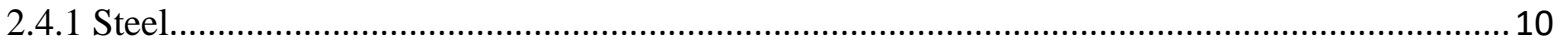

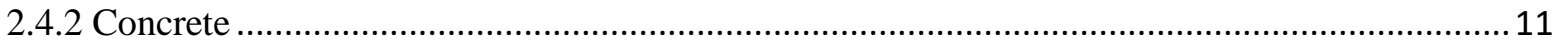

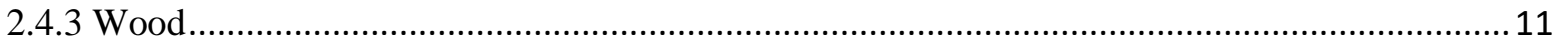

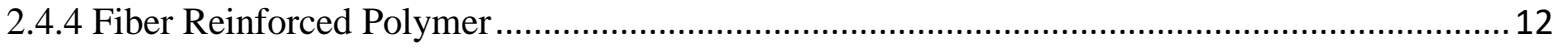

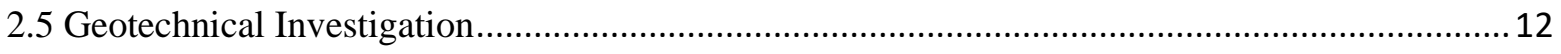

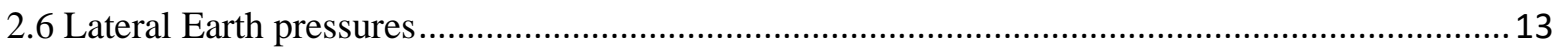

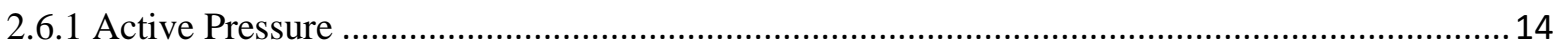

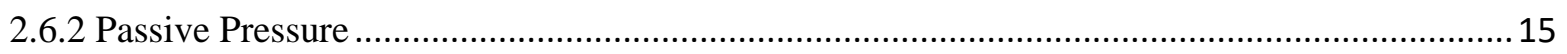

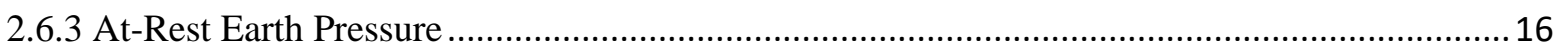

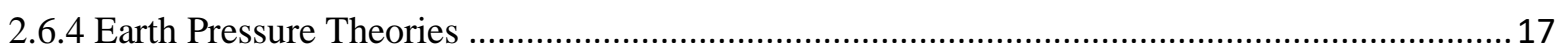

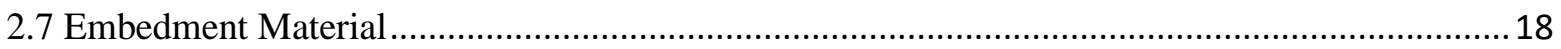

2.7.1 Loading in Coarse Grained (cohesionless) Soil .................................................................. 18

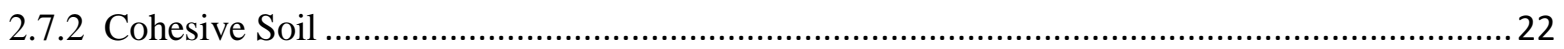

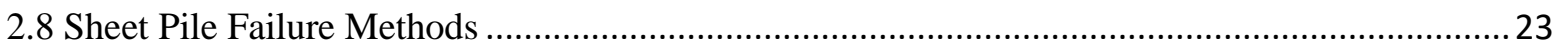

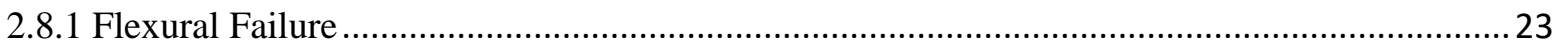

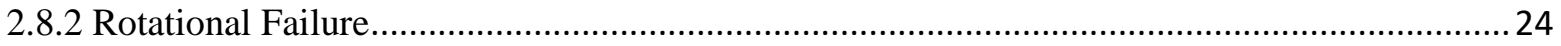




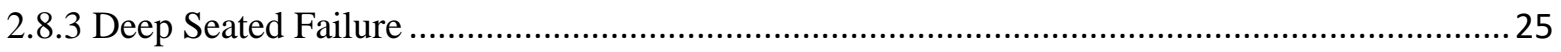

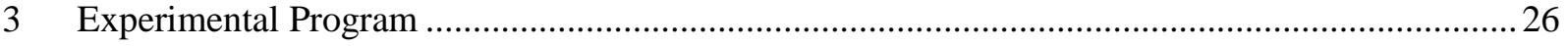

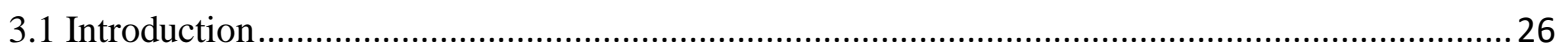

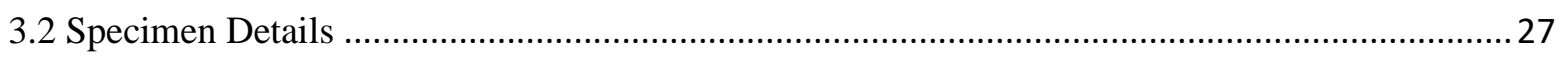

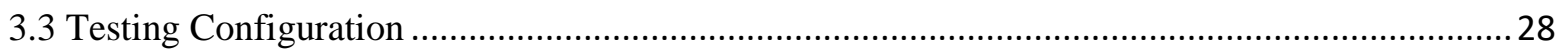

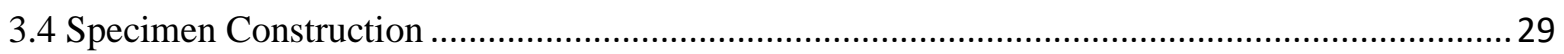

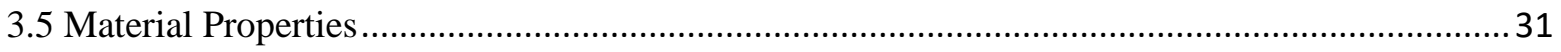

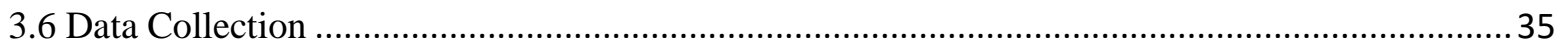

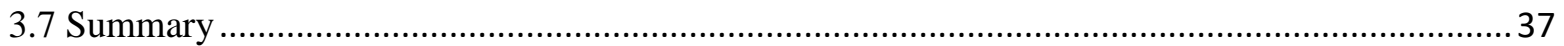

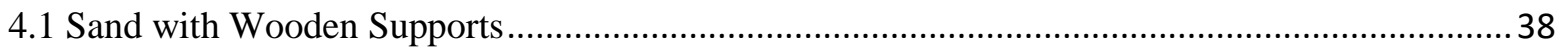

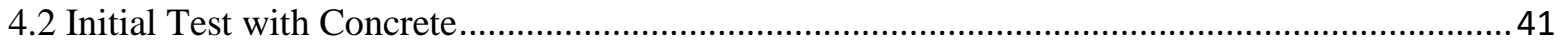

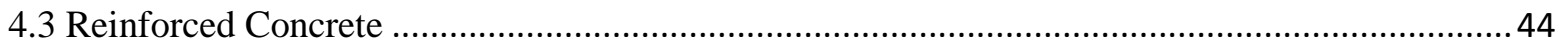

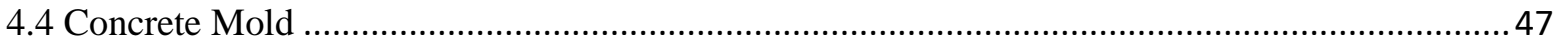

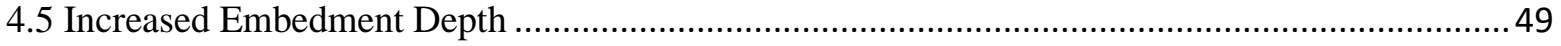

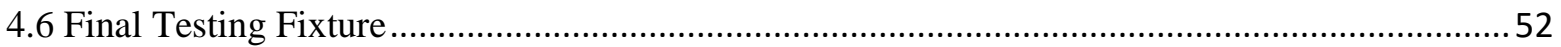

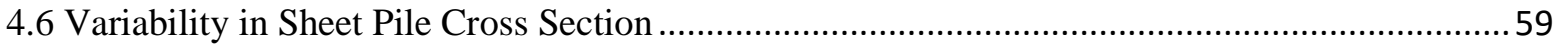

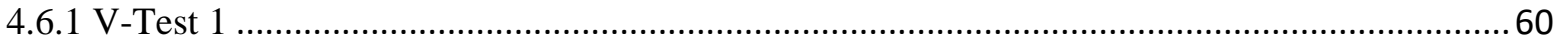

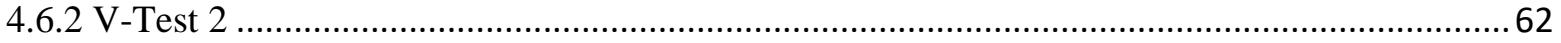

4.7 Summary

$5 \quad$ Theoretical and Experimental Evaluation of Sheet Pile Capacity ….......................................... 70

5.1 Theoretical Evaluation of Ultimate Moment Capacity …........................................................ 70

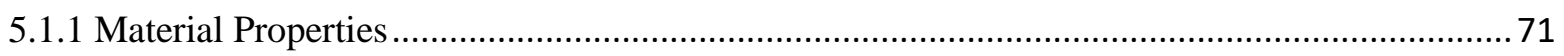

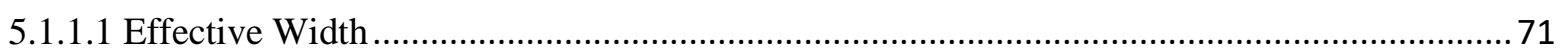

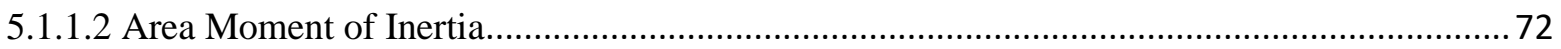

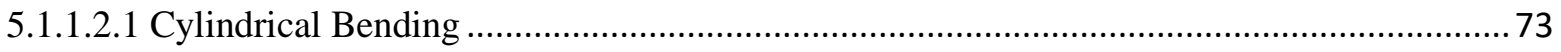

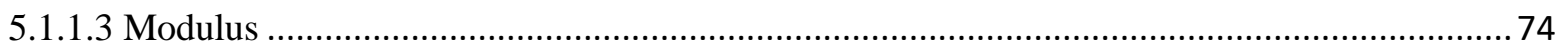

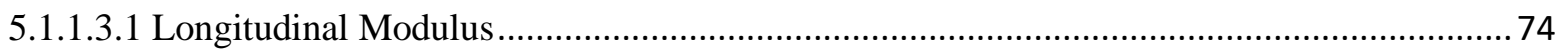

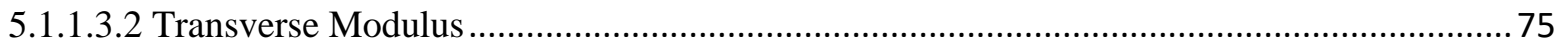

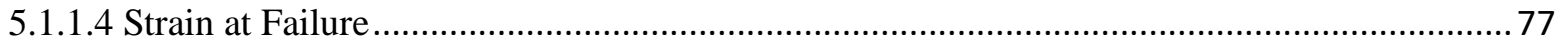

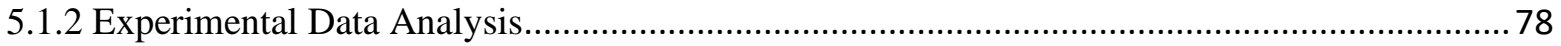

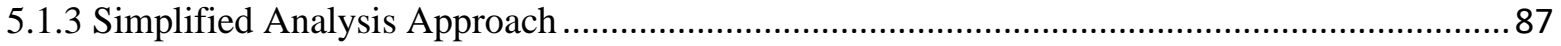

5.2 Theoretical Evaluation of Different Failure Modes ................................................................. 89

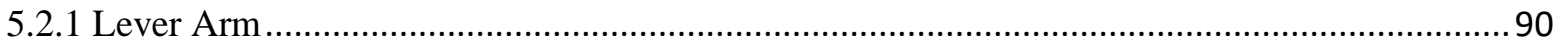

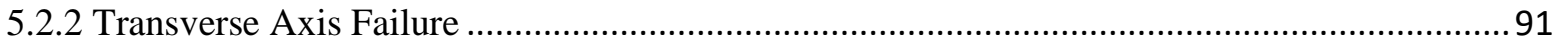

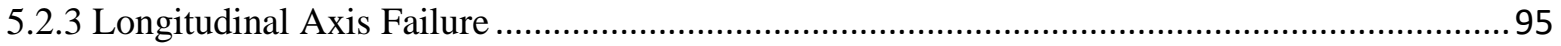




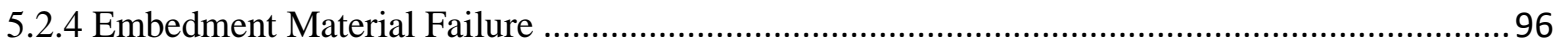

5.2.4.1 Final Test Embedment Material................................................................................... 97

5.2.4.2 Alternative Material Shear Strength Properties ........................................................... 100

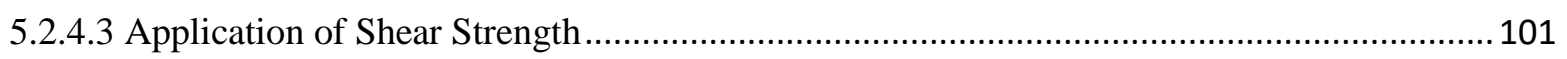

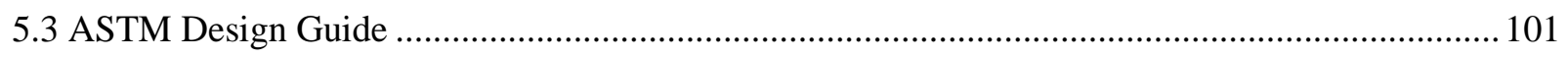

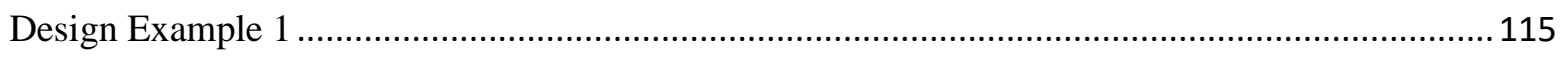

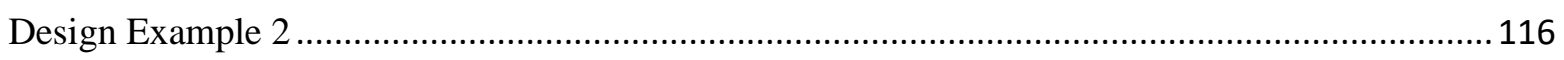

Design Example 3 (US Steel Sheet Pile Design Manual, 1984) .................................................119

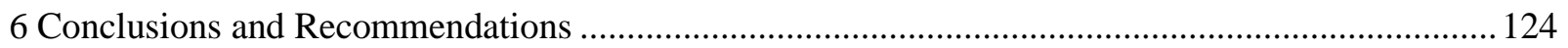

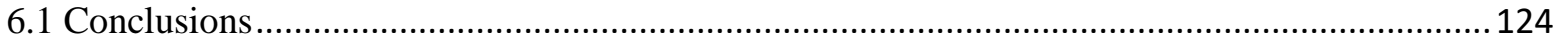

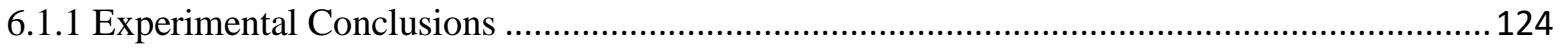

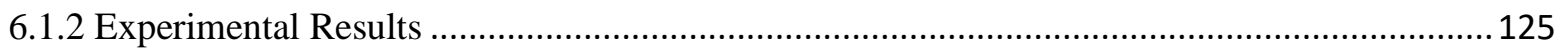

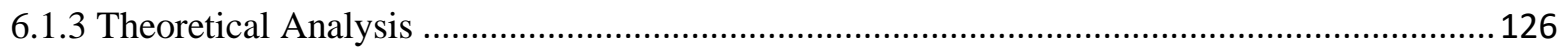

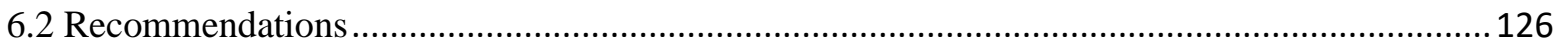

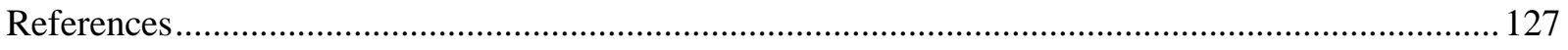

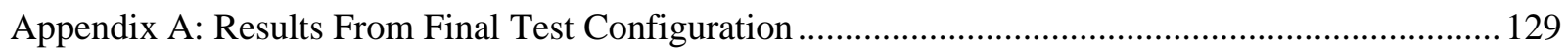

Appendix B: Referenced Documents .............................................................................. 133

\section{LIST OF FIGURES}

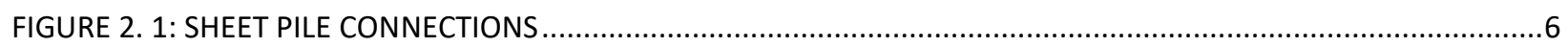

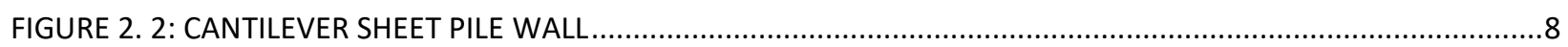

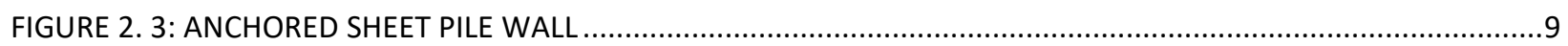

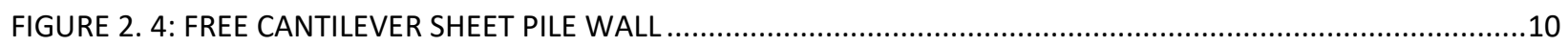

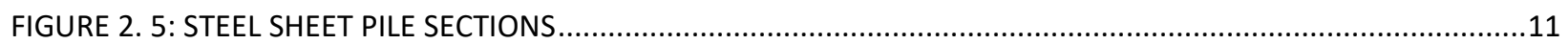

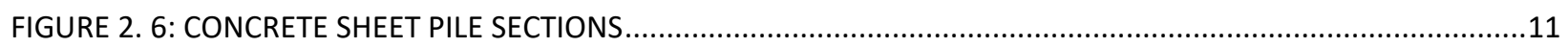

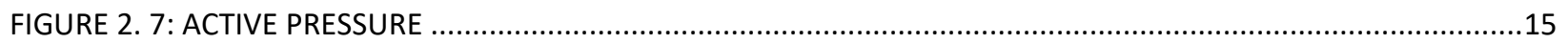

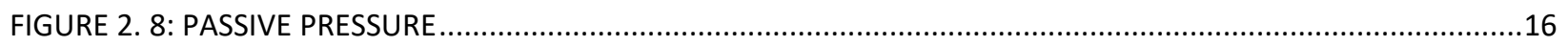

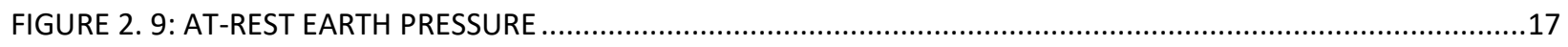

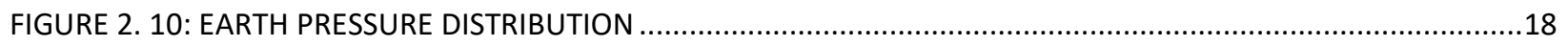

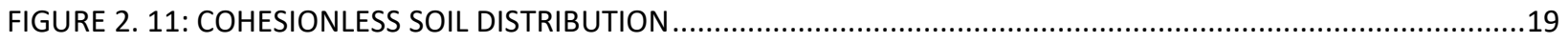

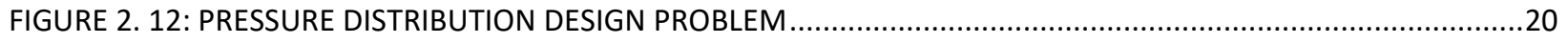

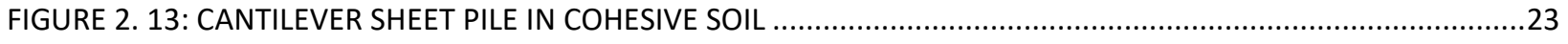

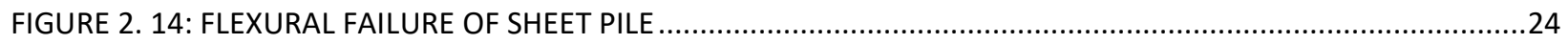

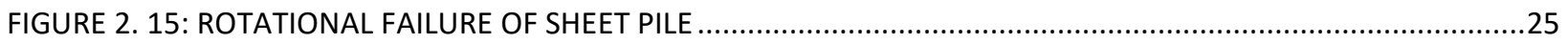

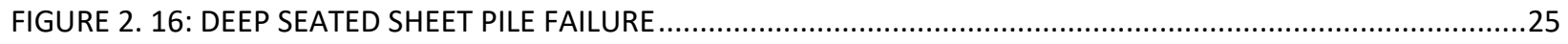

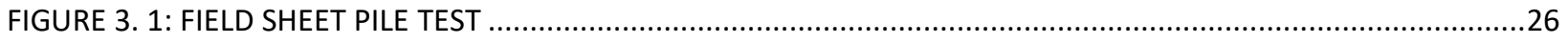

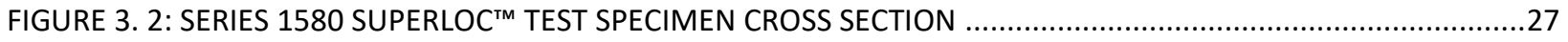

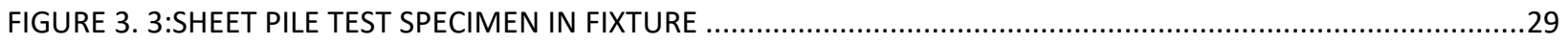

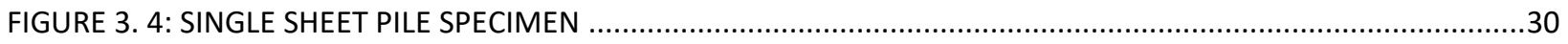

FIGURE 3. 5: SHEET PILE SPECIMEN UNDER CONSTRUCTION WITH WALE SECTION .............................................. 


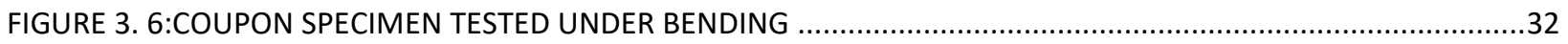

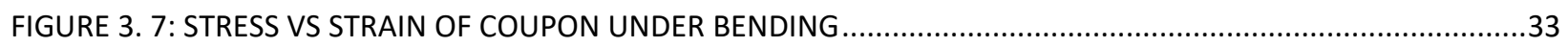

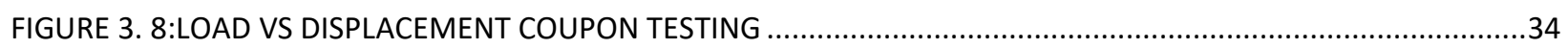

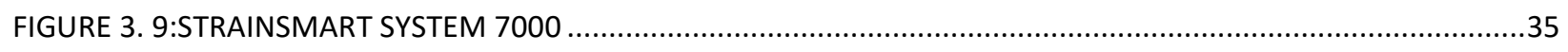

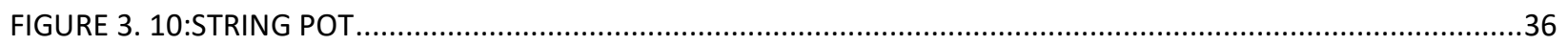

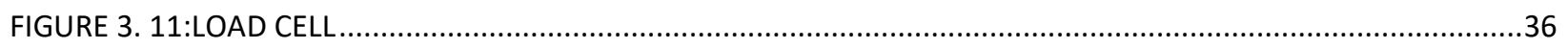

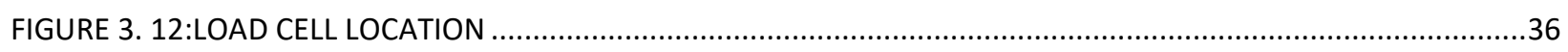

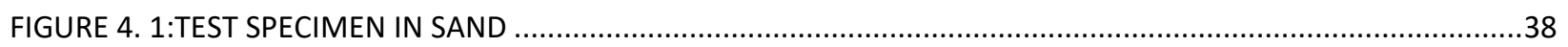

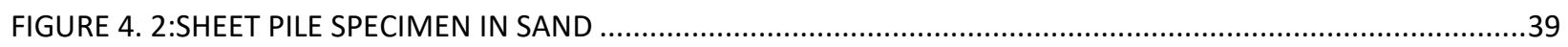

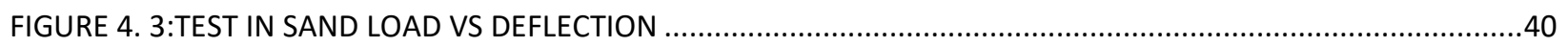

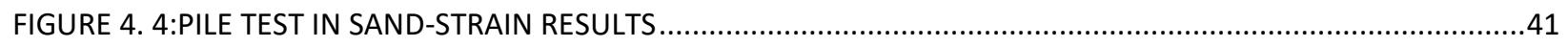

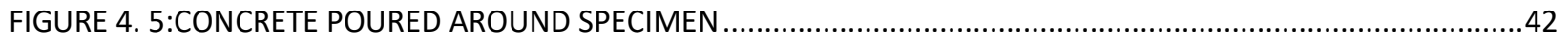

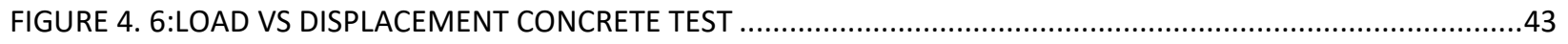

FIGURE 4. 7:CRACKED CONCRETE BASE

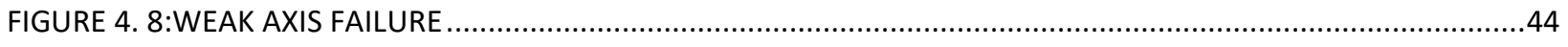

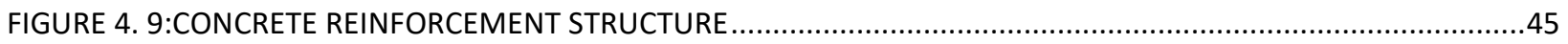

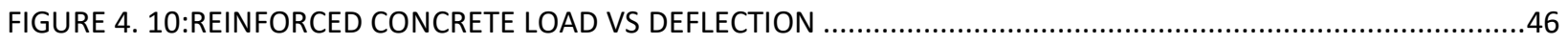

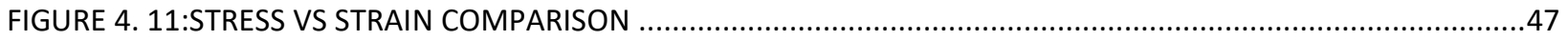

FIGURE 4. 12:RESTRAINING STRUCTURE WITH ELASTOMERIC PADDING ............................................................48

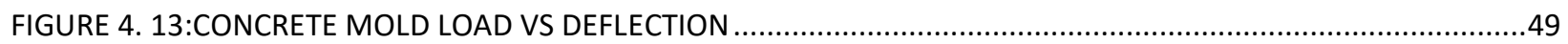

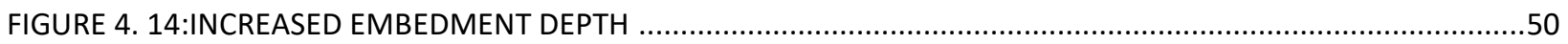

FIGURE 4. 15:INCREASED EMBEDMENT DEPTH LOAD VS DEFLECTION ……..................................................

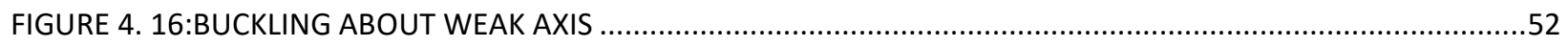

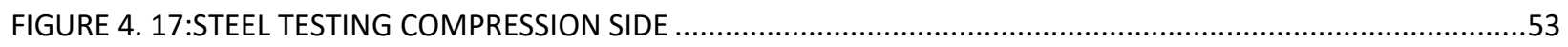

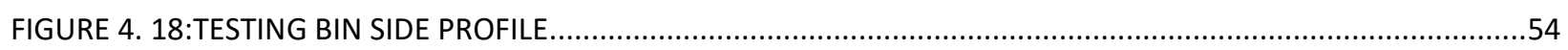

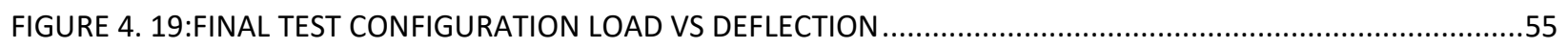

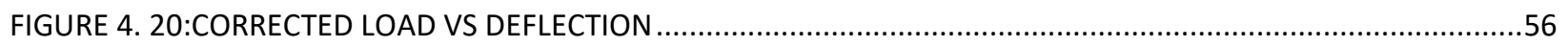

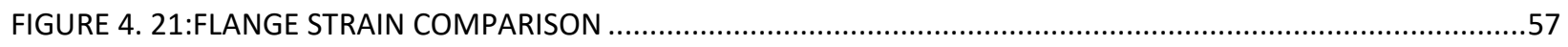

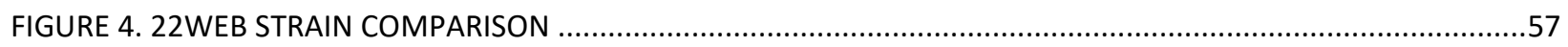

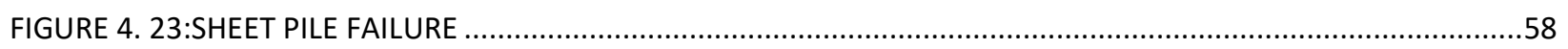

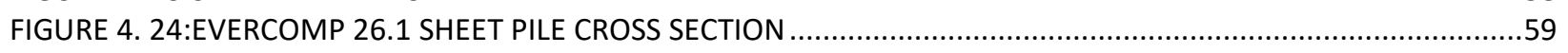

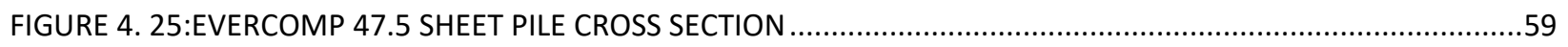

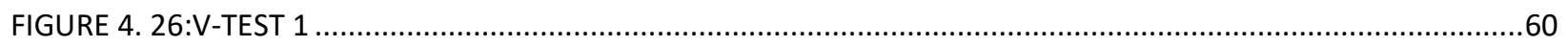

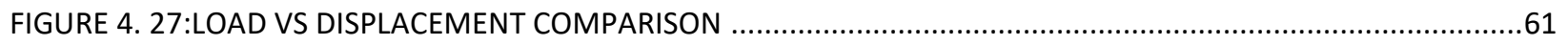

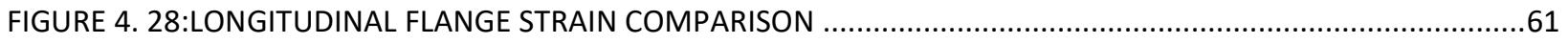

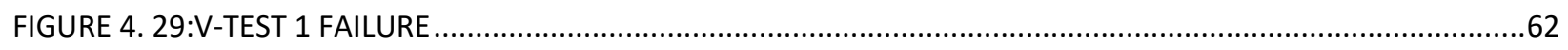

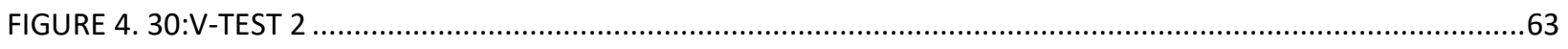

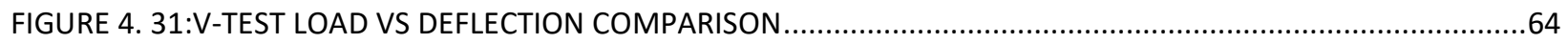

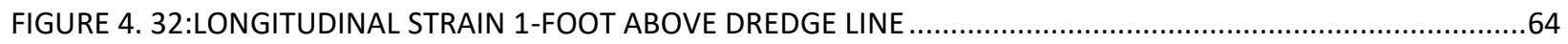

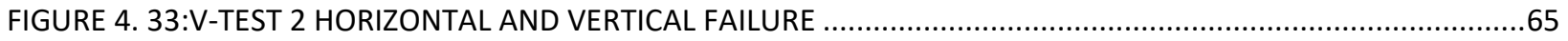

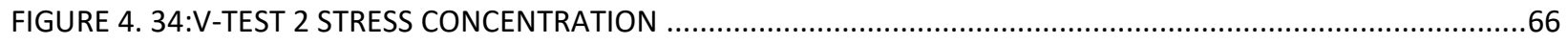

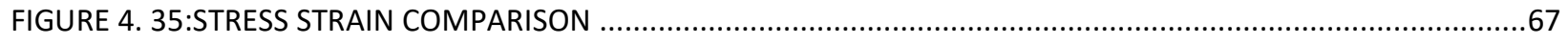

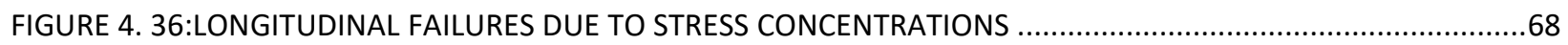

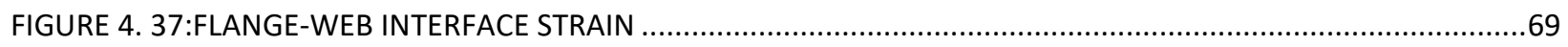

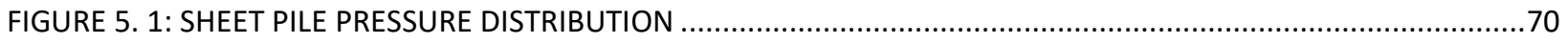

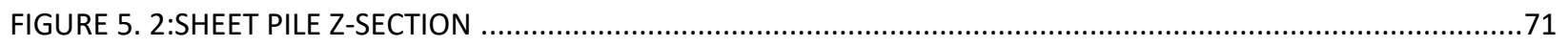

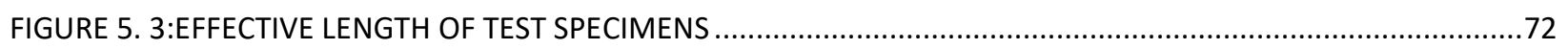

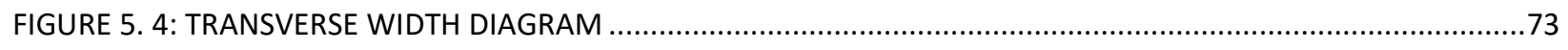

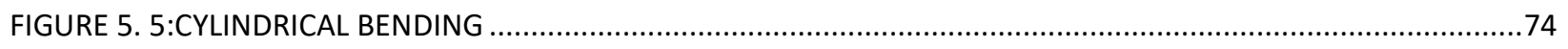

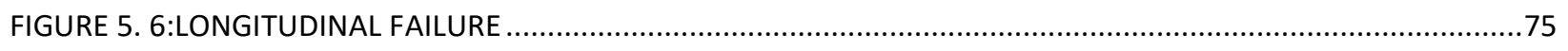

FIGURE 5. 7:SHEET PILE UNDER LONGITUDINAL BENDING ABOUT TRANSVERSE AXIS ..........................................76 


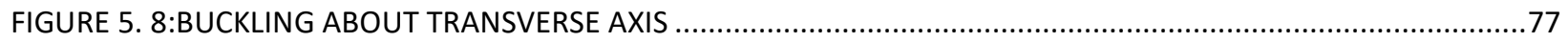

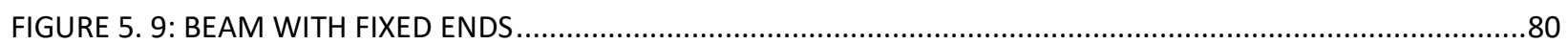

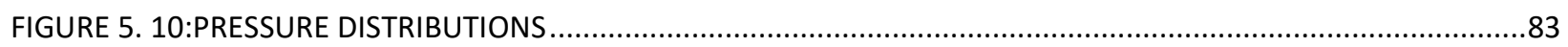

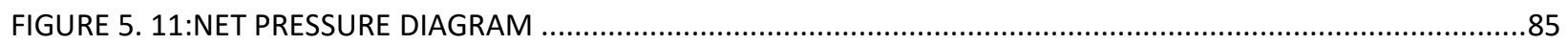

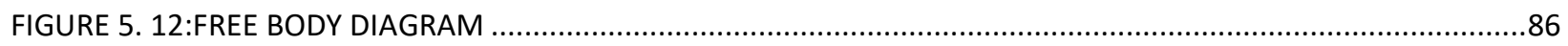

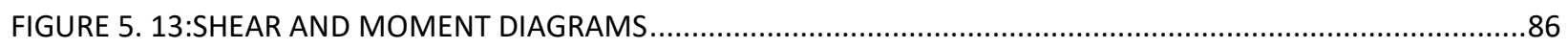

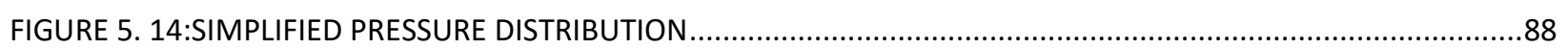

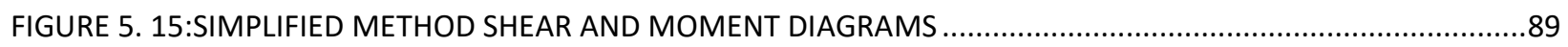

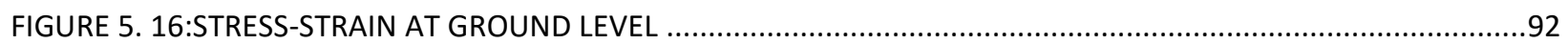

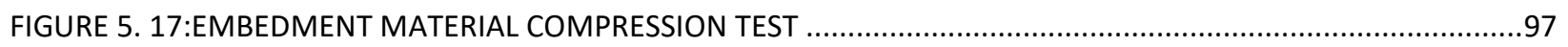

FIGURE 5. 18:CEMENTED SAND TEST RESULTS (EL-HANAFY AND ABDELAZIZ, 2021) …......................................98

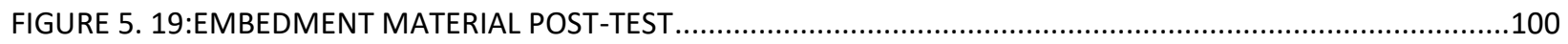

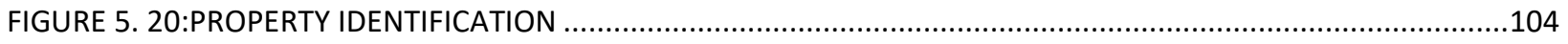

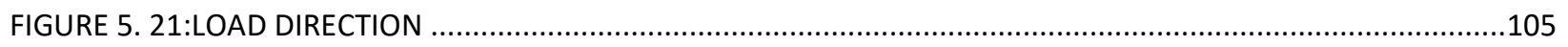

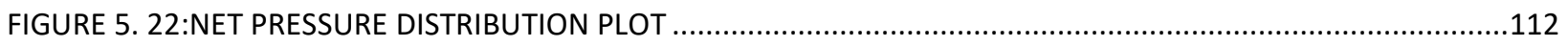

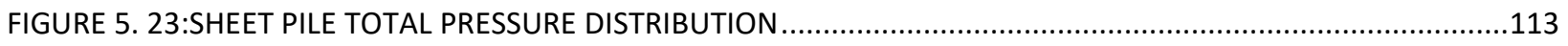

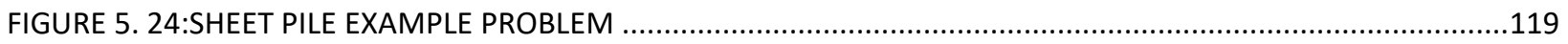

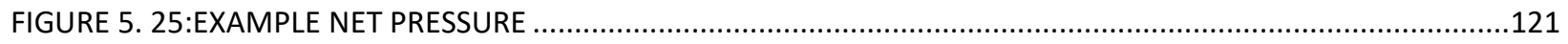

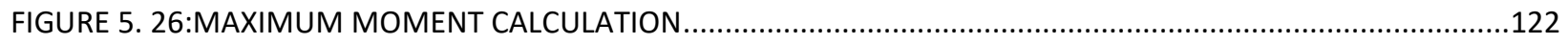

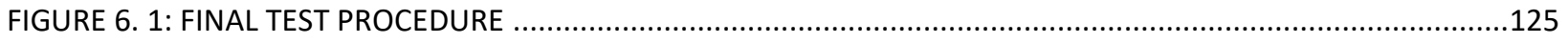

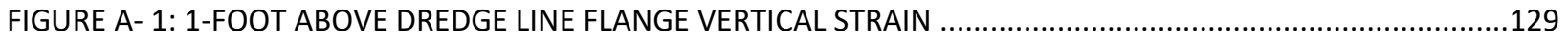

FIGURE A- 2:1-FOOT ABOVE DREDGE LINE WEB HORIZONTAL STRAIN ..........................................................129

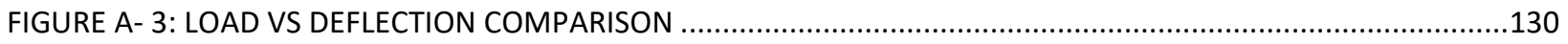

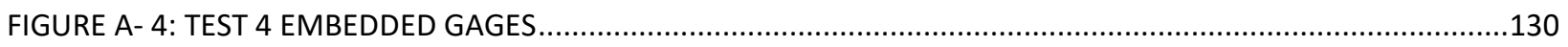

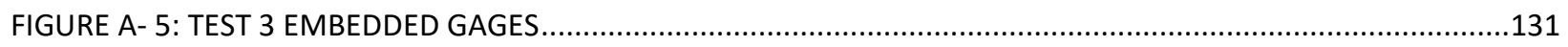

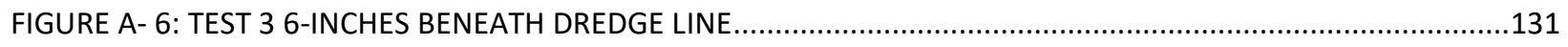

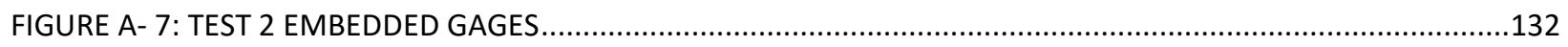

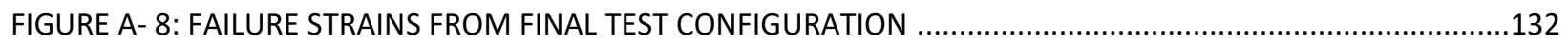

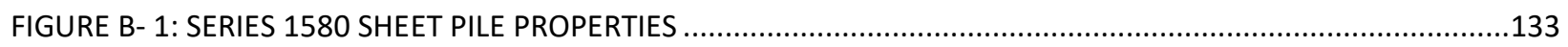

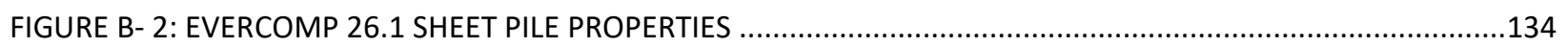

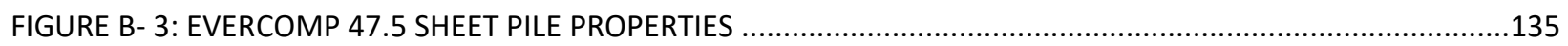

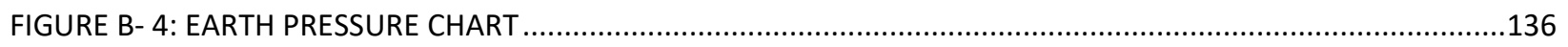

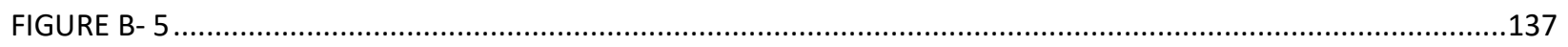

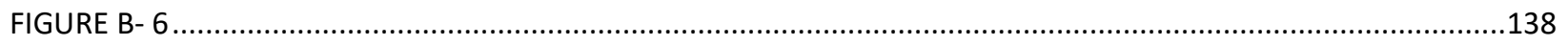

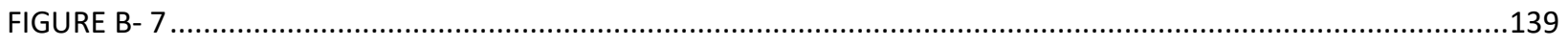

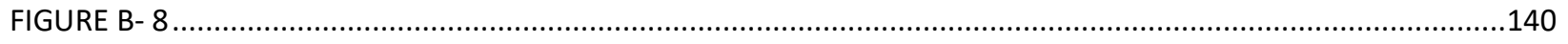




\section{Introduction and Scope}

\subsection{Background}

Infrastructure projects conducted using FRP composites can take place with the use of pultruded products. Pultrusion creates consistent cross sections and can be done in a continuous process to rapidly produce a high number of products. During the pultrusion process, strands of continuous fibers are pulled through a resin bath, then into a dye where heating and consolidation occur (Rajak and et al. 2019). Surplus resin is squeezed out by the mold to obtain an optimal fiber volume fraction. Upon curing, the final product is a composite member featuring strength comparable to steel, excellent corrosion resistance, and a longer service life than traditional materials.

Typically, composite materials consist of fiber or fabrics wetted with polymer resins. The most popular fibers used are glass, carbon, and aramid (GangaRao, 2021). Constituent materials such as fire retardants or colorants may also be added as desired. The advantageous tailor-made thermomechanical properties have made FRP composites more acceptable for constructing waterfront structures. Sheet pile walls are deployed within coastal environments due to the absence of dewatering needed prior to deployment. Composite technology has lent itself well for use of sheet piles because of their non-corrosive property. Due to a low life-cycle cost, composite sheet piles are commonly constructed from glass fiber reinforced polymer (GFRP) composites. As with any sheet pile, GFRP sheet piles feature thin-walled sections resulting in a low elastic modulus, causing any designs to be regulated by deflection and local buckling.

\subsection{Context}

The potential emanating from the use of FRP in infrastructure is limitless. Only a few hinderances have continued to prevent widespread application of FRP throughout the civil engineering industry. Designers have been hesitant to construct new specimens from FRP, primarily due to:

- Lack of design codes or guidelines 
- Lower stiffnesses that require altered design codes to meet deflection requirements

- Higher initial costs due to the implementation of a new material

- Much greater availability of traditional materials such as steel and concrete

Several studies have been conducted demonstrating the benefits and properties of FRP infrastructure applications. Researchers have also hybridized different segments using various fabric orientations and resins to reduce brittleness and inherently increase strength. Giroux and Shao (2003) created a multiple-span test method to determine the flexural stiffness of a sheet pile, but there are currently no standard tests for determining the moment capacity of FRP sheet piles. Although several composite sheet piles have been tested (Wang et al. 2016) the sheet piles were tested under four-point bending condition. This led to the pile experiencing failure modes different from the failure modes observed with cantilever loading. To create a standardized test for bending moment capacity, one of the focal objectives is for the pile to fail in a similar manner to field failures. Most FRP sheet piles are subject to a local buckling failure. It is typical for FRP materials to demonstrate the elastic instability behavior and experience global or local buckling prior to the materials crushing.

\subsection{Objectives}

The objectives of this study for fiberglass reinforced sheet piles are:

- Evaluate the feasibility of testing FRP sheet pile segments in a confined, laboratory environment.

- Create a procedure to test the maximum bending moment for FRP sheet pile walls replicating field conditions.

- Experimentally evaluate test specimen under static bending load.

- Provide clear instructions for replicating test procedure.

- Ensure that finalized procedure allows for the testing of sheet piles that possess differing cross sections and sizes. 


\subsection{Scope of work}

The scope of this study is limited to evaluation of Creative Composites' Series 1580 Seawall Profile sheet piles. A total of 18 tests were conducted. Each test featured the sheet pile placed as a cantilever beam in an embedment material and pulled from the top of the section, inducing a bending moment. Over the course of testing, two separate load application methods were used. A winch system and a hydraulic actuator. Parameters measured during testing included load, deflection, and strain from strain gages bonded to the sheet pile at several different locations.

\subsection{Organization of Thesis}

Chapter 1 devotes to the background, objectives, and scope of this study.

Chapter 2 is a review of published literature that is relevant to the research objectives. A review of sheet-piles is presented, including materials, failure methods, and uses.

Chapter 3 illustrates the experimental program. The test specimen construction process is documented, as well as the material properties of the specimen. The complex nature of an FRP sheet pile is discussed. Testing equipment is also documented in this section.

Chapter 4 discusses the mechanical testing process. The final test procedure differed greatly from the initial test. This chapter will chronologically show the evolution of testing procedures. Figures will be used to illustrate the results from each test. The data from each figure was analyzed so that the sheet pile behavior could be understood. Appropriate changes were then made to the test procedure. 
Chapter 5 is a theoretical analysis of the results from multiple tests, followed by a design guideline for future tests. This section describes the method of obtaining maximum bending moment capacity in a straight forward manner so that the reader can replicate a test and find use with the results.

Chapter $\mathbf{6}$ is the concluding section of this paper. Here will be a final discussion of results, uses of this study, and how the study can be improved upon. 


\section{Literature Review}

The following literature review was conducted to aid in the creation of a standardized method for testing the bending moment of sheet piles. Specifically, an investigation of the behavior of sheet piles walls with respect to sheet pile material, the material properties of the soil surrounding the pile, and the embedment depth of the sheet pile was conducted to obtain an understanding of relevant information prior to testing was conducted.

\subsection{Retaining Walls}

Structures used to retain material and the stresses brought about by that material are known as retaining walls. The walls form a near vertical face, confining soil or water and can act as lateral support for steep hillsides, a temporary braced wall for ongoing construction, or to create a more rigid coastline. Regardless of the application, the primary intent of retaining walls is to make maximum use from a limited right away (WSDOT Manual). Conventional retaining walls are classified under four categories: gravity retaining walls, semi-gravity retaining walls, cantilever retaining walls, and counterfort retaining walls (Das and Sivakugan, 2018). Gravity retaining walls rely on a self-weight property to resist lateral loads and are constructed from plain concrete or stone masonry. Some gravity walls feature steel reinforcement to reduce the size of the wall, these are known as semi-gravity retaining walls. Cantilever walls are thin walls that act as a vertical cantilever beam. These walls are either driven to a depth that allows for a rigid connection to the ground, or they are attached to a base that allows for a fixed connection underneath the surface. Cantilever walls are economically feasible until a height above 8 meters is reached. Counterfort retaining walls are nearly identical to cantilever walls with the exception of added counterforts that connect the slab to the wall in additional locations. The addition of counterforts allows for an increased shear and bending moment capacity. Cantilever walls that lack horizontal slabs at the 
base of the wall rely entirely on the passive pressures that exist within the material the pile has been placed in. When the passive pressure developed is not sufficient to resist the active pressure, cantilever walls need to be anchored. Anchored walls derive their lateral capacity through anchors embedded in stable soil or rock below or behind any potential soil failure surface (WSDOT Manual). In some cases, anchors are placed within concrete or grout to ensure that there is no movement.

The differential properties of the retaining walls purport the establishment of specific wall types depending on the intention and existing conditions, so that an efficient and safe retaining wall can be constructed.

\subsection{Sheet Pile Wall Systems}

A sheet pile wall is a specific type of retaining wall constructed from interlocking, vertical pile segments that are driven into the ground to form a straight wall (USACE Sheet Pile Design manual) Figure 2.1 depicts two sheet pile cross sections with different interlocking mechanisms.

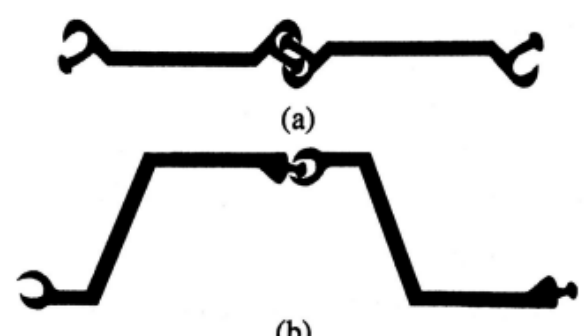

(b)

Figure 2. 1: Sheet Pile Connections

These interlocking mechanisms allow for continuous construction of walls to a desired length, however lack moment transfer capabilities. Upon installation, the sheet piles derive their stability from the surrounding soil. If the soil does not offer enough support, the piles can be driven deeper, 
or an anchor can be applied to the section. Due to their thin, flexible nature of the pile segments, sheet pile walls have a relatively low system stiffness which leads to larger deformations when compared to other retaining wall types (Bilgin, 2009). The flexibility and ease of installation has caused sheet piles to become extremely popular in waterfront environments. Connected sheet piles are commonly used to build continuous walls for waterfront structures that range from small pleasure boat launching facilities to large dock facilities (Das and Sivakugan, 2018).

\subsection{Sheet Pile Types}

\subsubsection{Cantilever}

Cantilever sheet pile walls are driven into the ground and act as a series of interconnected vertical cantilever wide-flanged beam. The lateral support needed to resist the active pressure exists in the form of passive earth pressure that is exerted onto the embedded portion of the pile. Depending on the quantity of active pressure, sufficient embedment depths may be needed, resulting in excessive stresses and may lead to failure. For this reason, cantilever sheet piles are typically restricted to a maximum height of 5 to 6 meters. The design of a cantilever sheet pile wall is primarily based on the stability of the entire retaining system and the pile's ability to resist moment (Murthy, 2002), (GuhaRay and Baidya, 2015). Figure 2.2 shows a common scenario in which cantilever sheet pile walls are utilized. 


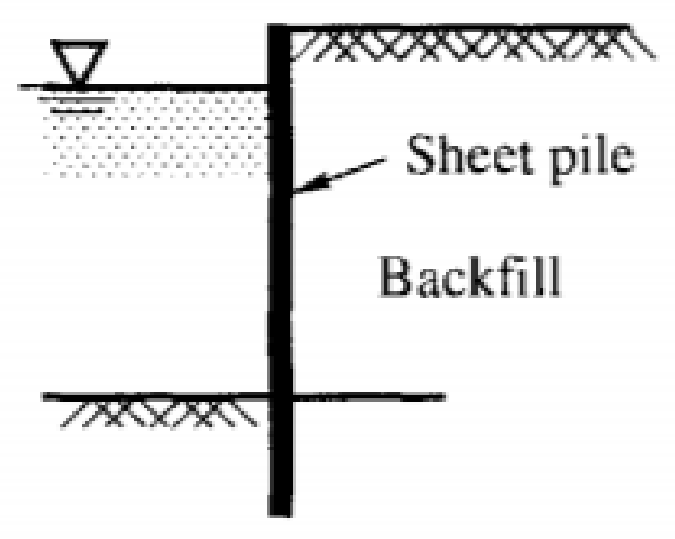

Figure 2. 2: Cantilever Sheet Pile Wall

\subsubsection{Anchored}

Walls that are designed to be deeper than 20-feet require an anchor due to an increase in loading. The loading incurred creates a larger bending moment that will cause a flexural failure in a standard sized sheet pile. To combat a bending moment failure, the section modulus of the sheet pile could be increased, however in most cases this is not economical. The use of an anchor counteracts the active force applied on the section of sheet pile above the dredge line. This reduces lateral deflection, bending moment, and depth of penetration of the pile (Das and Sivakugan, 2018). Anchored sheet pile walls are especially common adjoining railway lines and dock structures. The anchor supports the pile when load is increased from a passing train or a large cargo ship tying directly to the sheet pile wall (Murthy, 2002). Figure 2.3 shows a sheet pile wall with an anchor rod attached. 


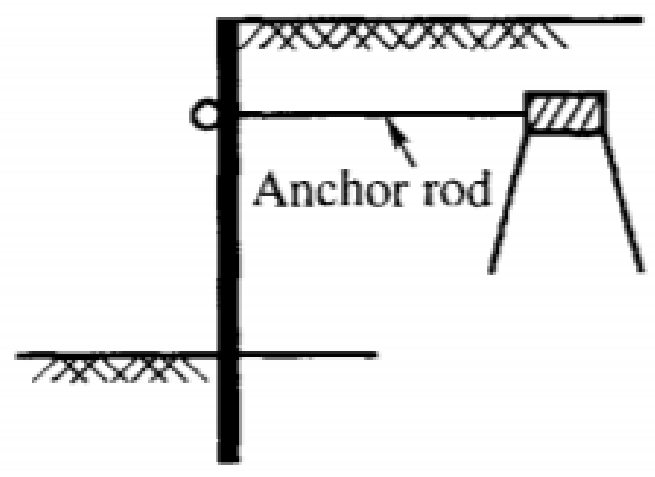

Figure 2. 3: Anchored Sheet Pile Wall

\subsubsection{Free Cantilever}

Free cantilever sheet piling is a unique version of a cantilever sheet pile. In this instance, the sheet pile is driven into the ground until a desired depth is reached, but a portion of the pile remains freestanding above the ground-line, with no backfill or soil present. Instead of a pressure exerted from soil, a horizontal line load is exerted at specified height. The walls derive their stability from the lateral resistance of the soil from the region driven into the soil. This sheet pile type is an example of laboratory testing that was done. The sheet pile was placed in a testing bin and fixed at the base of the pile. A horizontal line load was applied at the top of the pile until failure was reached. A depiction of a free cantilever sheet pile is shown in Figure 2.4. Free cantilever sheet piles are commonly found as seawalls and other various marine structures (Choudhury and Singh, 2011). 


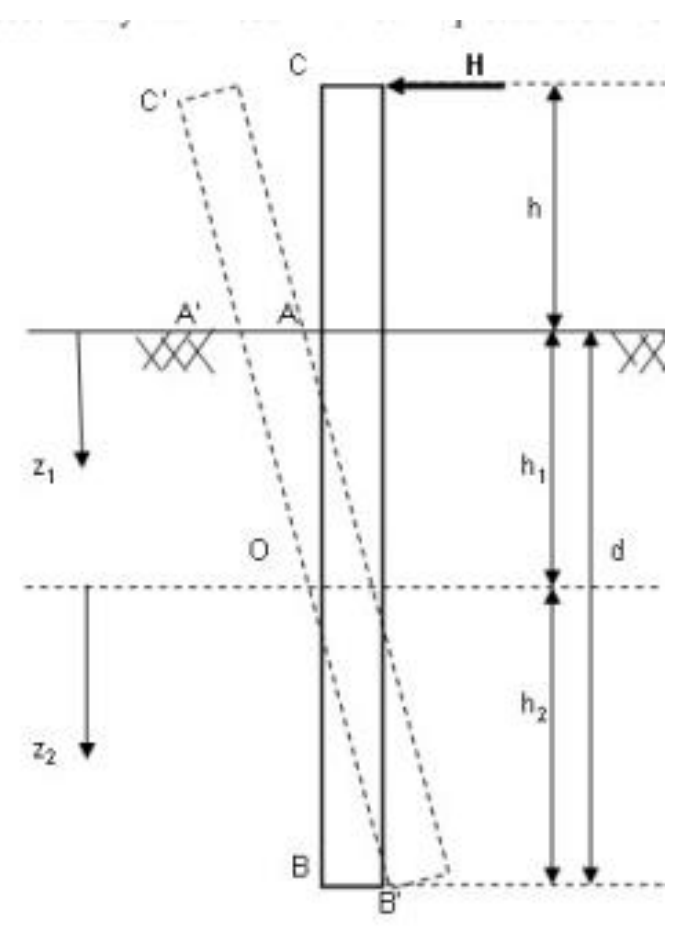

Figure 2. 4: Free Cantilever Sheet Pile Wall

\subsection{Materials}

\subsubsection{Steel}

It is common for sheet pile walls to be constructed from steel due to its resistance to the high driving stresses that present themselves upon installation. Steel is also relatively lightweight when compared with concrete and has a long service life. Steel sheet pile sections are available in various shapes, sizes, weights, and steel grades. Piles may be hot-rolled or cold-rolled as shown in Figure 2.5. Hot-rolled piles feature stronger interlocks and greater resistance to stresses when being driven into the soil (USDA, 2007). 


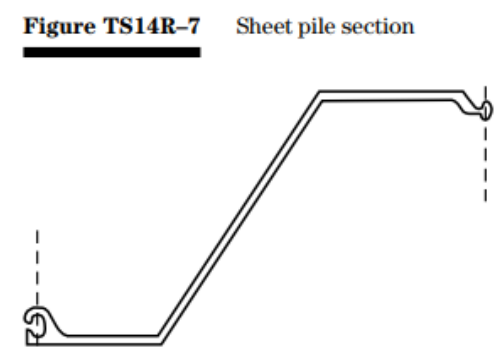

a. Hot-rolled Z-section

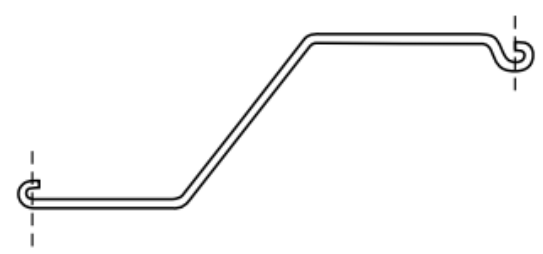

b. Cold-rolled Z-section

Figure 2. 5: Steel Sheet Pile Sections

\subsubsection{Concrete}

Concrete sheet piles are precast and heavier than counterparts and typically designed with reinforcement. Each pile can range from 6 to 12 inches thick and 30 to 48 inches wide. Piles can either be connected through "tongue and groove" connections or be grouted in between each pile as shown in Figure 2.6. These piles can withstand relatively high stresses and are effective at withstanding stresses produced during and after construction.

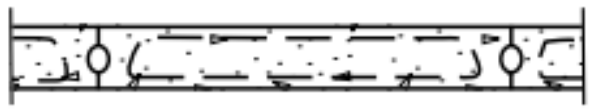

Grouted

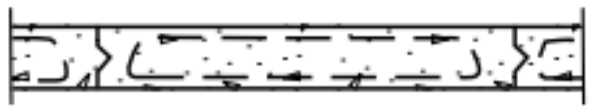

Tongue and groove

Figure 2. 6: Concrete Sheet Pile Sections

\subsubsection{Wood}

Wooden sheet piles are typically in the form of planks (2"x12") that are driven edge to edge into the ground. The strength created by a wooden sheet pile wall is only sufficient for loading created by light, temporary structures. These piles are susceptible to damage created by wood-destroying- 
insects and rot from water, therefore they must be chemically treated and only used above the water table.

\subsubsection{Fiber Reinforced Polymer}

Fiber Reinforced Polymer (FRP) sheet piles are constructed from at least two constituent materials (e.g. glass or carbon fiber combined with epoxy or polyester resin) that differ in thermomechanical properties (GangaRao, 2022). In most cases where FRP is utilized in infrastructure applications, glass fibers are used, which have relatively low mechanical properties when compared to carbon, and aramid fibers. The low cost of glass combined with excellent corrosion resistance and high tensile strength make it optimal for large-scale infrastructure projects. Carbon fibers are typically used for more advanced applications, especially within the aerospace industry. Carbon fibers feature a high temperature, fatigue, corrosion, and chemical resistance. Glass fiber reinforced polymers (GFRP) are an attractive option for sheet pile use in coastal environments where water, salts, and chemicals can be present because of corrosion resistance of a FRP. In chemical environments, steel sheet piles can rust and corrode, concrete piles may crack and allow the reinforcement to rust, and wooden piles can rot under the issues posed by the mentioned environmental factors. A synthetic material such as FRP that consists of fiber reinforcement and polymer resin matrix is resistant to these degrading/deteriorating effects while demonstrating a high strength to weight ratio.

\subsection{Geotechnical Investigation}

Prior to the installation of a sheet pile wall, several factors must be considered. The thin nature of sheet piles causes them to be especially susceptible to flexural failure caused by a large bending moment. To avoid a failure while maintaining an economical design, it is beneficial to conduct a geotechnical investigation of the proposed site. The purpose of the investigation is to identify the 
type and distribution of foundation materials, identify sources and characteristics of backfill materials, and determine material parameters for use in design/analyses (USACE, 1994). Material must be collected from the site at various locations and depths that will be encountered by the sheet pile. The material will be tested for its engineering parameters, including but not limited to, unit weight, specific gravity, moisture content, and angle of friction. The standard for determining a sample's engineering properties is set by the United Soil Classification System, "Upon recognizing a USCS symbol of a classification group or understanding the description. Using the Earth Manual Standard, one can immediately deduce the approximate permeability, shear strength, and volume change potential of a soil and how it may be affected by water, frost, and other physical conditions" (U.S. Bureau of Reclamation, 1998). Upon examination of the soil properties, the distribution of resisting load on the pile can be used to characterize a more economical design.

\subsection{Lateral Earth pressures}

Retaining structures are typically constructed to support slopes of earthen material. A welldesigned retaining wall requires knowledge of the lateral pressures acting on a structure. Lateral earth pressure is dependent on several factors including the shear strength parameters of the retained soil, the inclination of the surface of the backfill, the height and inclination of the retaining wall at the wall-backfill interface, the nature of wall movement under lateral pressure, and the adhesion and friction angle at the wall-backfill interface. A lateral pressure coefficient can be established as given in Equation 2.1 below (Das, 1979).

$$
K=\frac{\sigma_{h}^{\prime}}{\sigma_{o}^{\prime}}
$$

where,

$\sigma_{h}^{\prime}=$ horizontal effective pressure

$\sigma_{o}^{\prime}=$ vertical effective pressure 


\subsubsection{Active Pressure}

A sheet pile wall design must consider active pressure, or the "limiting pressure between the wall and soil produced when the relative wall/soil motion tends to allow the soil to expand horizontally" (USACE, 1994). Active pressures are the minimum possible values of earth pressure and can be developed at any depth when the wall begins to move or rotate away from the soil. An example of this can be seen in Figure 2.7. The wall in position A-B rotates to position A'-B as a result of the pressure generated from the soil mass in triangle A-B-C'. After rotation is finished, the existing pressure on the wall is considered active pressure and the soil mass will be in plastic equilibrium (Das and Sobhan, 2017). The active pressure coefficient can be established (Equation 2.2). This formula is particularly useful because vertical stress is a function of soil material and depth, therefore by multiplying the vertical stress with the pressure coefficient, horizontal stress may be known.

$$
K=K_{a}=\frac{\sigma_{h}^{\prime}}{\sigma_{o}^{\prime}}=\frac{\sigma_{a}^{\prime}}{\sigma_{o}^{\prime}}
$$




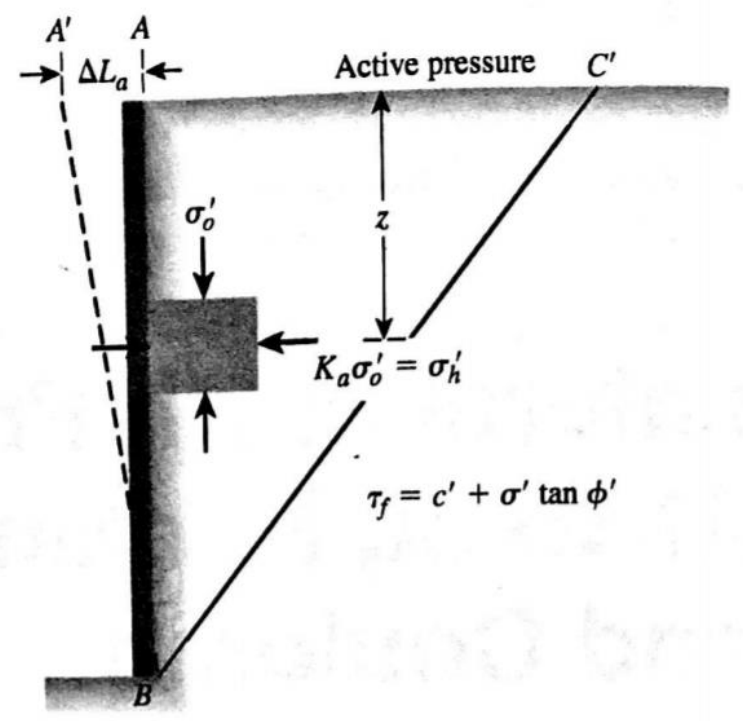

Figure 2. 7: Active Pressure

\subsubsection{Passive Pressure}

Passive pressure is the maximum possible horizontal soil pressure caused by the wall rotating toward or into the soil, compressing it horizontally (USACE,1994). About ten times the movement required to reach the maximum passive pressure is needed to reach the maximum active pressure. Maximum passive pressures are less likely to be developed, therefore in certain instances a factor of safety may be used to conservatively design a sheet pile wall. Figure 2.8 shown below demonstrates the effect of passive pressure. When a wall rotates about the bottom to the position A"-B, the triangular mass of soil A"-B-C" will reach the plastic equilibrium state. The horizontal stress will be present in the form of passive pressure. The coefficient of passive pressure is given in Equation 2.3.

$$
K=K_{p}=\frac{\sigma_{h}^{\prime}}{\sigma_{o}^{\prime}}=\frac{\sigma_{p}^{\prime}}{\sigma_{o}^{\prime}}
$$




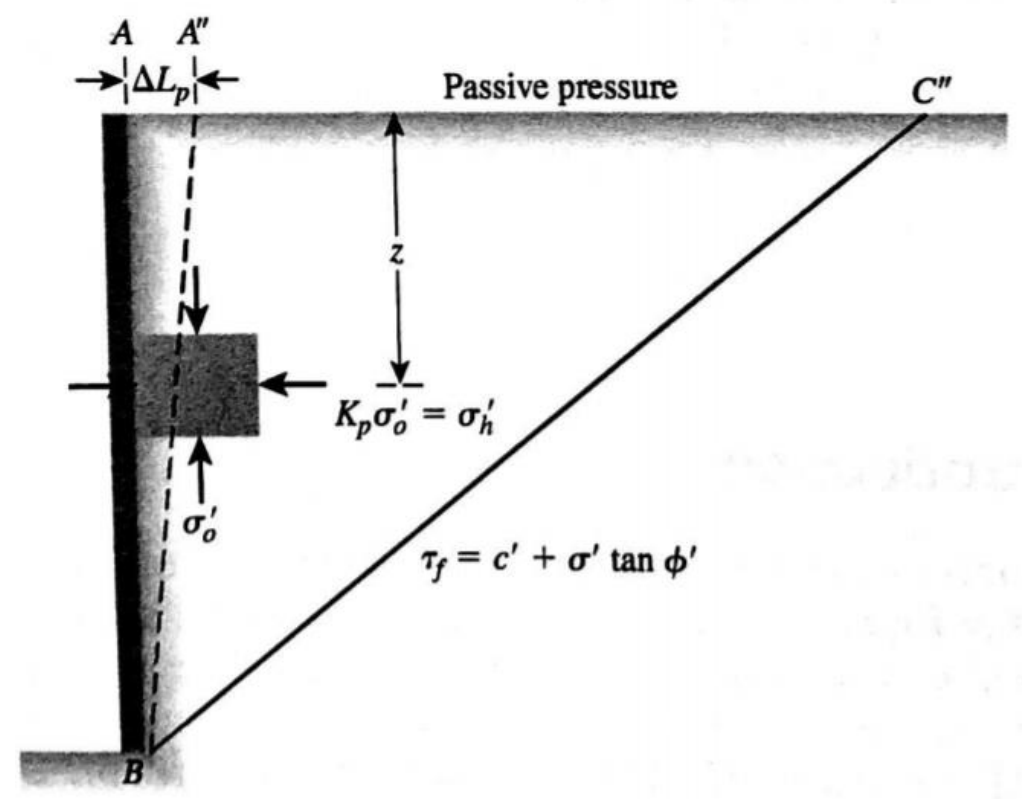

Figure 2. 8: Passive Pressure

\subsubsection{At-Rest Earth Pressure}

A constant horizontal pressure is applied to the pile even when there is no deformation. This pressure is known as at-rest earth pressure (USACE). At-rest-earth pressure is a condition in which the wall is static. Figure 2.9 shows that there is no movement of the wall or soil mass. The equation for the at-rest-earth pressure coefficient is identical to Equation 2.1. 


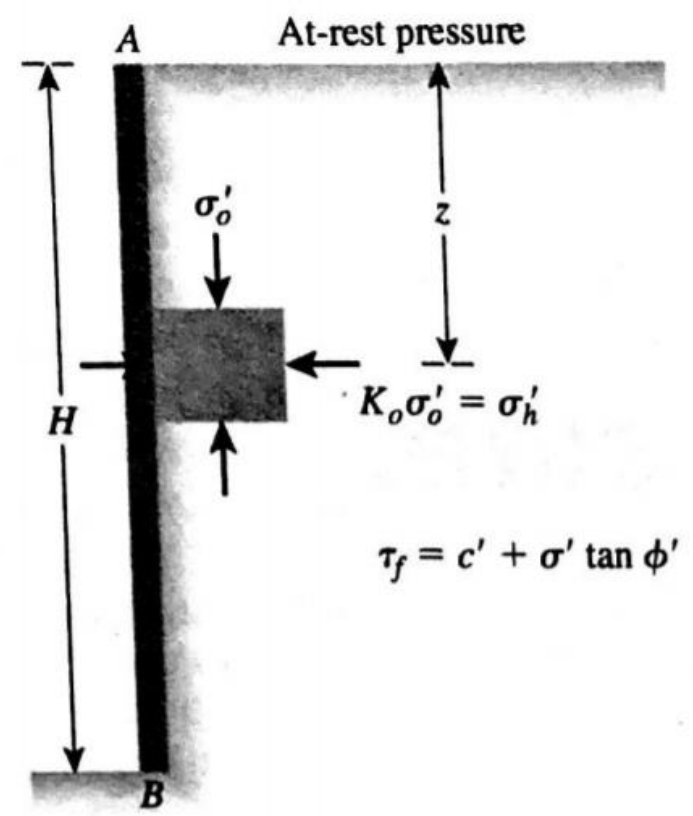

Figure 2. 9: At-Rest Earth Pressure

\subsubsection{Earth Pressure Theories}

Two popular earth pressure theories are the Rankine and Coulomb theories. They each can be used to calculate active and passive pressures for a soil mass at the state of failure. The Coulomb wedge theory (1776) analyzes the equilibrium of forces acting on a soil wedge, however it fails to consider the state of stresses within the soil, as well as the friction between the wall and backfill (Das and Sivakugan, 2017). Under these circumstances, it is assumed that a linear slip plane will occur with the full mobilization of the shear strength which will occur along the failure surface. The Rankine theory of earth pressures for active and passive conditions (1857) considers the state of the pressure as defined in previous sections to estimate the state of stress within a soil mass (Das and Sivakugan, 2017). The Rankine theory assumes that the wall being designed is frictionless. Coulomb's theory takes friction into consideration when designing a retaining wall. Rankine and Coulomb's theories 
for earth pressure, yields similar values when the friction angle between the wall and backfill is assumed to be zero. As the friction angle increases, Coulomb's theory remains accurate in terms of active pressure, however, in terms of passive pressure it can deviate from accuracy at significant depths (U.S. Bureau of Reclamation, 2019).

\subsection{Embedment Material}

A soil system is comprised of particulates, liquids, and gases, rendering it a multiphase (Lambe and Whitman, 1991). Several phase relationships play major roles in determining soil response to loading including: porosity, void ratio, and saturation. Figure 2.10 shows a comparison of how active and passive pressures respond in different materials.

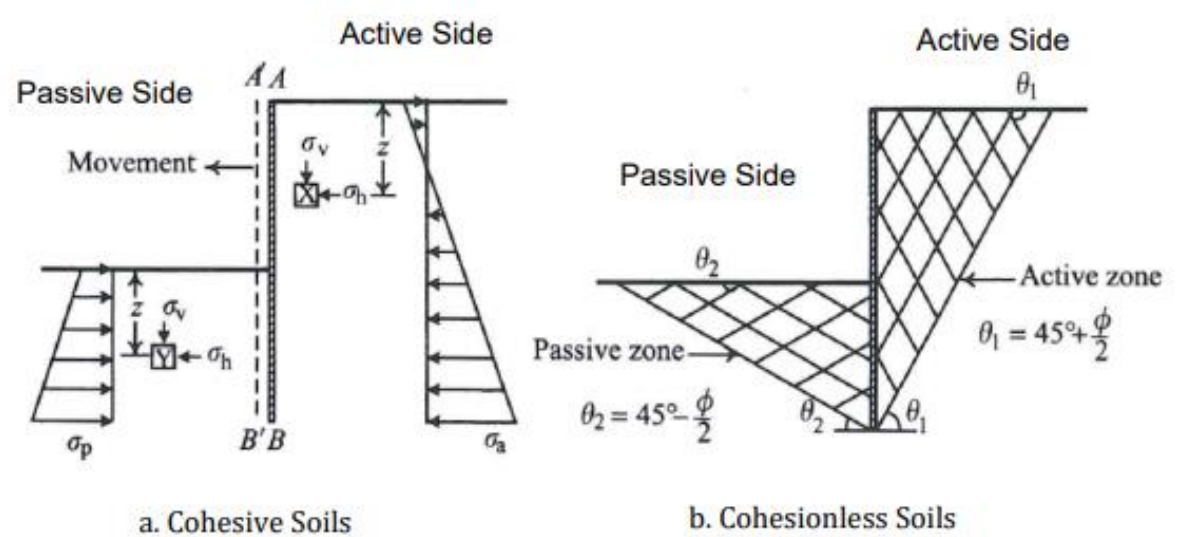

Figure 2. 10: Earth Pressure Distribution

\subsubsection{Loading in Coarse Grained (cohesionless) Soil}

The distribution of grain size characterizes how a material may interact with imposed loads. According to ASTM D422-Particle Size Analysis of Soils, material with a particle size ranging from $0.0075 \mathrm{~mm}$ to $4.75 \mathrm{~mm}$ in diameter is considered granular soil. Lateral earth pressure increases linearly with depth when a sheet pile is penetrating coarse grained soil. The introduction of water can change the rate; however, the pressure will continue to increase linearly on each side 
of the pile where soil exists. Coarse grained soils feature enough perviousness so that excess pore pressures that may alter stress conditions do not develop. The internal angle of friction controls the shear strength and primarily depends on shape, gradation, and relative density with a range of 25 to 45 degrees (USACE, 1994). Figure 2.11 illustrates commonly used pressure diagrams that are applied to the pile when it is embedded in granular soil. Figure 2.11 (a) shows a pile experiencing lateral loading, while Figures 2.11 (b) and 2.11(c) plot pressure distributions along the pile. Figure 2.11 (b) is the actual pressure distribution, however a simplified version (Figure 2.11(c)) is used for design purposes. A proper sheet pile wall design is complete when the depth of penetration provides an equivalent amount of horizontal passive and active pressures. The depth of penetration is obtained by creating a diagram with a force and moment equilibrium. (King, 1995)

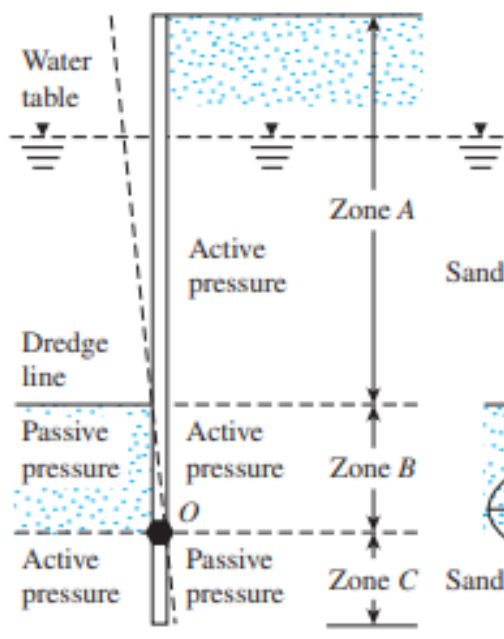

(a)

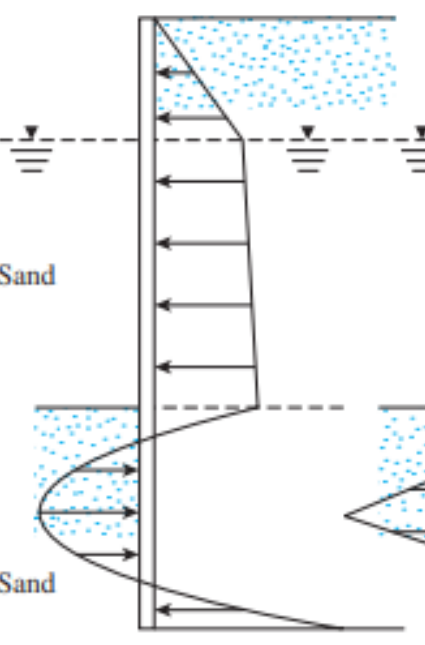

(b)

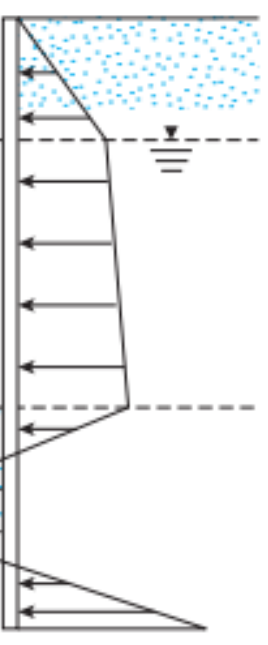

(c)

Figure 2. 11: Cohesionless Soil Distribution

Pressure diagrams similar to the ones shown in Figure 2.11 are essential in understanding the forces and reactions occurring throughout a sheet pile. King(1995) presents multiple simplified limit state design methods accepted across Europe and the United States. Referring to the simplified plot in Figure 2.12 
method B proposed by King is a clear and concise way of creating a pressure distribution plot for a sheet pile wall.

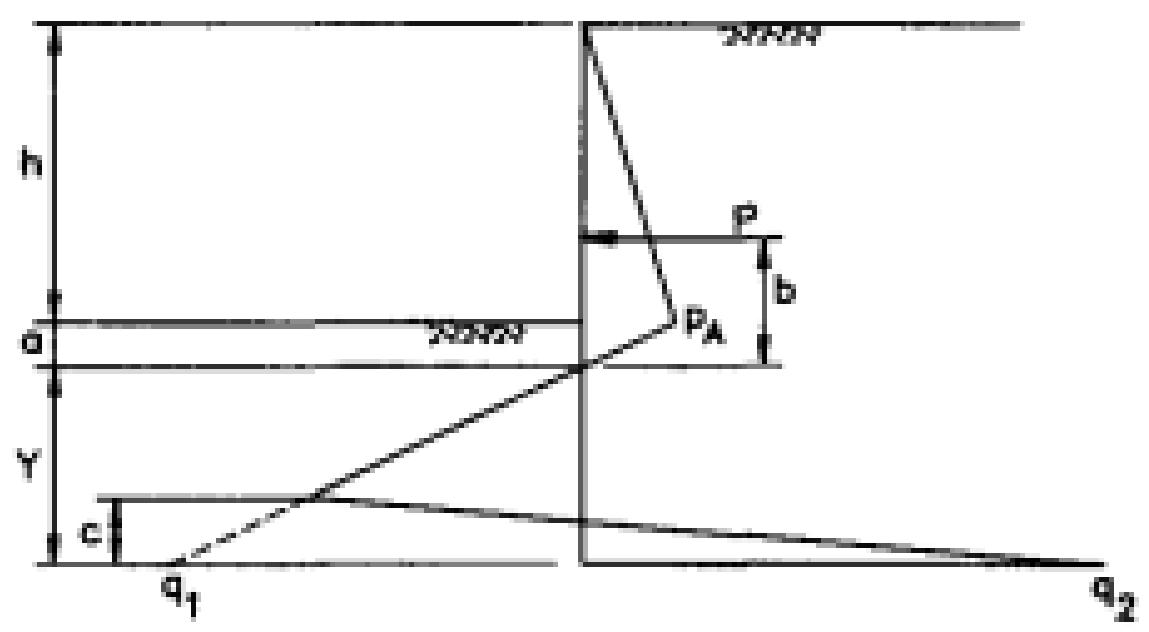

Figure 2. 12: Pressure Distribution Design Problem

The active pressure at dredge level is calculated as (King, 1995):

$$
P_{A}=K_{A} \gamma h
$$

The rate of increase of net pressure is then defined as:

$$
m=\left(K_{P}-K_{A}\right) \gamma
$$

Limit state pressures can then be assumed to be

$$
\begin{gathered}
q_{1}=m Y \\
q_{2}=q+m Y \\
q=K_{P} \gamma(h+a)-K_{A} \gamma a
\end{gathered}
$$

where,

$K_{A}=$ Rankine active pressure coefficient

$\gamma=$ unit weight of soil 
$\mathrm{h}=$ Height of sheet pile wall above dredge line (ground surface)

$P_{A}=$ Active pressure

$a=$ Distance from dredge line to pivot point

$\mathrm{Y}=$ Distance from pivot point to bottom of pile

From the above equations, depth to zero net pressure can be calculated as

$$
a=p_{A} / m
$$

The area of the two triangles representing active pressure above (Figure 2.12) and at the groundline is then calculated

$$
P=\left(\frac{1}{2}\right) K_{A} \gamma(h+a)
$$

This pressure then acts at a height represented by

$$
b=\frac{h+2 a}{3}
$$

A fourth order equation can be created by eliminating the dimension $\mathrm{c}$ when considering force and moment equilibrium

$$
Y^{4}+\left(\frac{q}{m}\right) Y^{3}-\left(\frac{8}{P}\right) Y^{2}-\left(\frac{6 P}{m^{2}}\right)(2 m b+q) Y-\left(\frac{P}{m^{2}}\right)(6 b q+4 P)=0
$$

The results of the equilibrium equation can now provide with the required depth of penetration prior to any safety factors being added

$$
d=Y+a
$$

Depth of penetration is increased by 20 to 30 percent to increase the safety factor. (Das and Sivakugan, 2018) 


\subsubsection{Cohesive Soil}

According to ASTM D422-Particle Size Analysis of Soils, fine grained, cohesive soils are characterized as being smaller than the $0.005 \mathrm{~mm}$ holes on the No. 200 sieve. Clays experience cohesion, or shear strength in excess of that generated by frictional resistance to sliding between particles, the rearrangement of particles, and particle crushing (Das and Sobhan, 2017). True cohesion exists due to the adherence of adjacent particles caused by chemical bonding, electromagnetic attractions, and primary valence bonding. A sheet pile driven into a saturated clay will encounter undrained cohesion $\left(\varphi^{\prime}=0\right)$ due to the low permeability and higher ratio of voids caused by clays cohesive nature. The higher void ratio results in less contact surfaces of particles and less interlocking causes reduction in shear strength. The soil must derive the entirety of its strength from cohesion. This is the case immediately after installation, as time increases, the internal angle of friction will increase to a range of 20 to 30 degrees and the lateral pressure distribution can be analyzed similarly to a granular soil due to pore pressure dissapation. Figure 2.13 shows the pressure distribution within cohesive soil. Similarly to cohesionless soil, a limit equilibrium method can be used to determine the depth of the sheet pile wall. 


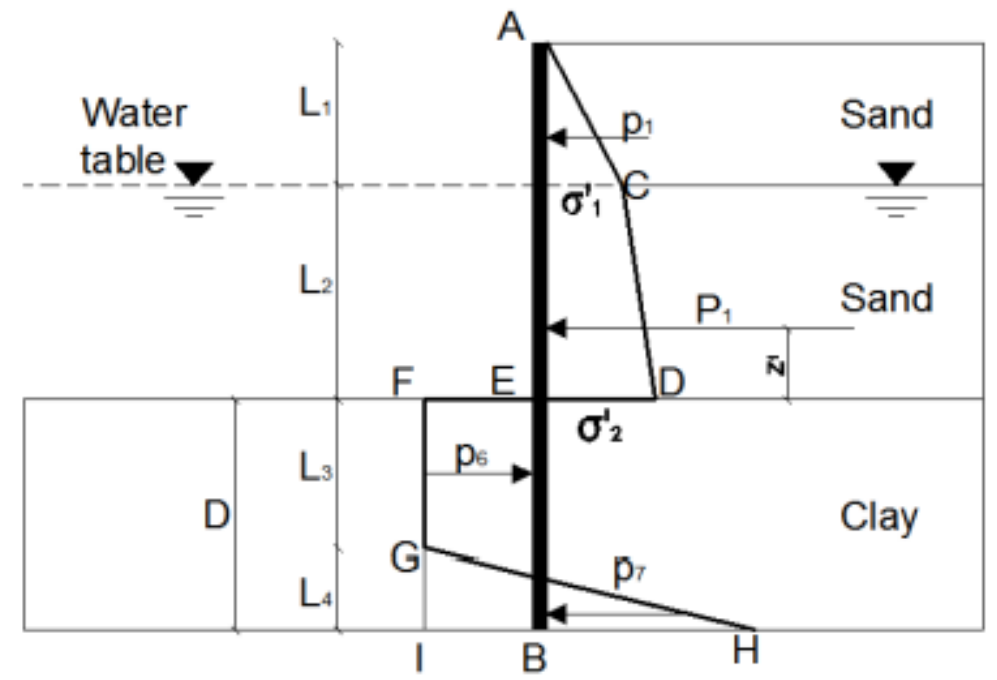

Figure 2. 13: Cantilever Sheet Pile in Cohesive Soil

\subsection{Sheet Pile Failure Methods}

\subsubsection{Flexural Failure}

A flexural failure occurring in both a cantilever and anchored sheet pile wall can be seen in Figure 2.14. The pile is failing about a plastic hinge where maximum moment is induced along the span of the pile. Flexural bending from soil thrust behind sheet pile generates a moment on the pile. The point at which maximum moment occurs is the hinge or location of failure. Terzaghi, 1934 stated that it is important to note that a structural hinge can carry a reaction force and no such reaction force can be carried in the case of a sheet pile wall rotating about a point without any lateral displacement. Therefore, the use of "pivot point" is preferred to understand the behavior of sheet pile sunder soil thrust. When designing a sheet pile, the maximum moment induced by soil thrust must be considered so that a pile with a sufficient section modulus can be chosen to resist the moment. 

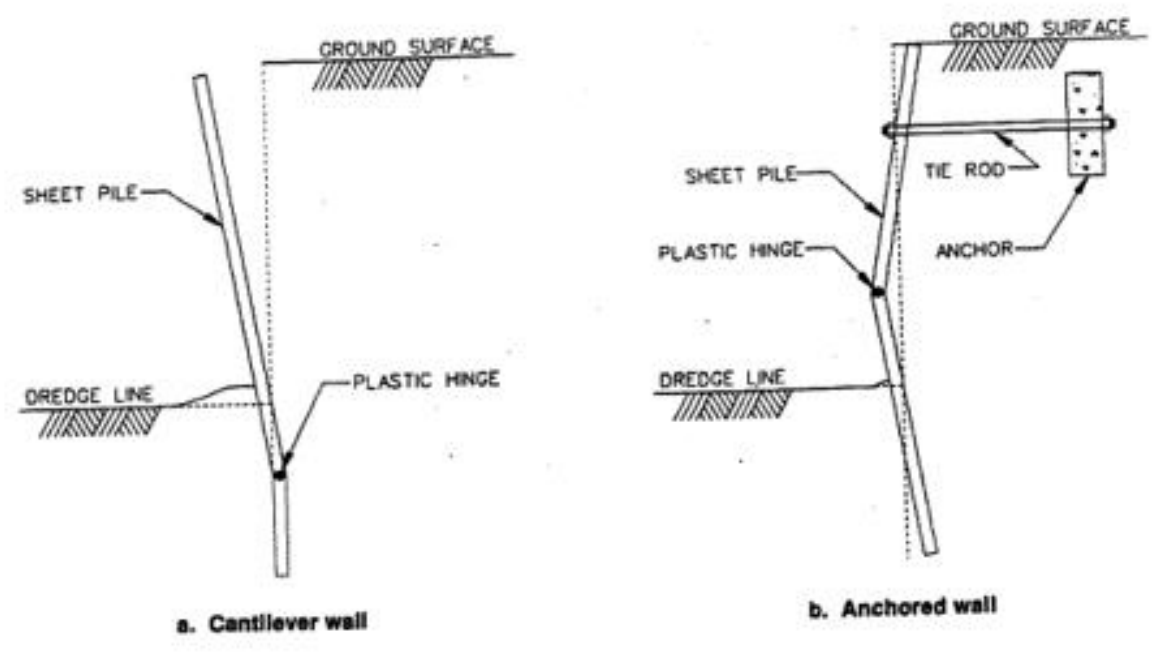

Figure 2. 14: Flexural Failure of Sheet Pile

\subsubsection{Rotational Failure}

Figure 2.15 shows a rotational failure taking place in a cantilever and an anchored sheet pile wall. For a rotational failure to occur, the sheet pile in question must be relatively stiff. (Madabhushi and Chandrasekaran, 2005) If the pile is not stiff, flexural failure would occur about a pivot point discussed in section 2.8.1. Cantilever walls with sufficient stiffness result in rotation about a pivot point. A lack of adequate passive force will result in rotation of the entire specimen. An increase in penetration depth of the pile will increase the region of passive pressure and further prevent any rotation. 


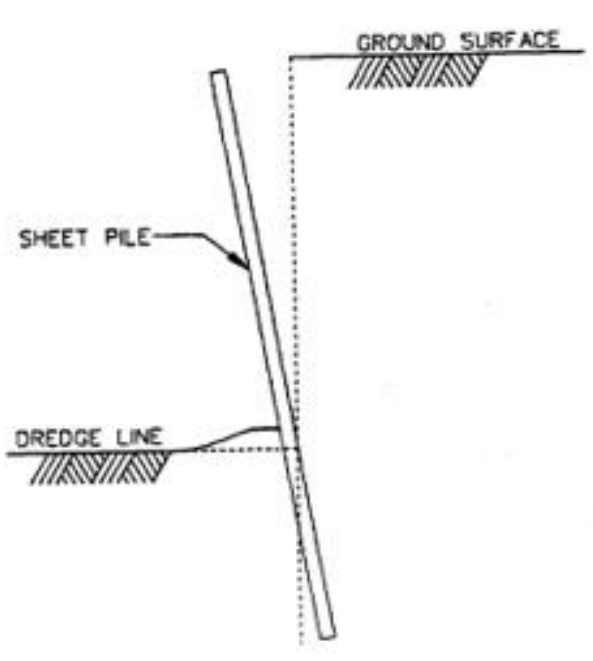

a. Cantilever wall

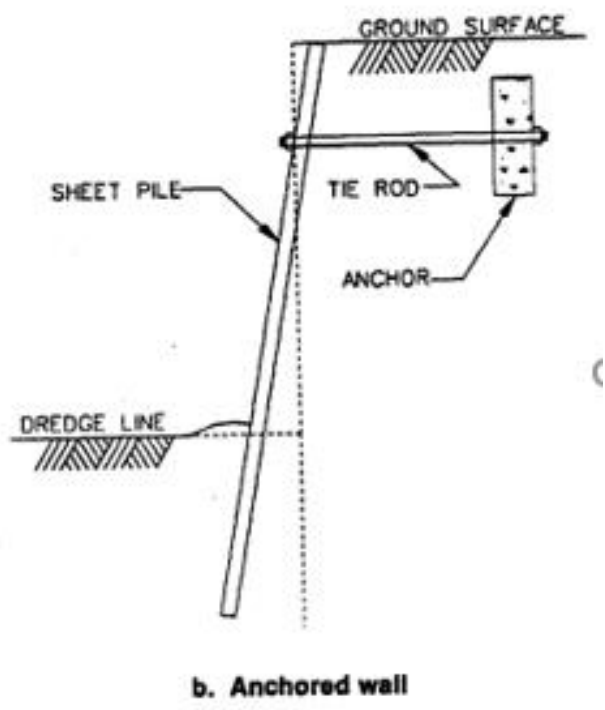

Figure 2. 15: Rotational Failure of Sheet Pile

\subsubsection{Deep Seated Failure}

A deep-seated failure shown in Figure 2.16 occurs within an entire soil mass containing a sheet pile wall. This failure mode does not occur as a result of inadequate structural design. Slope stability must be analyzed and actions such as the addition of structural fill or dewatering of a slope must be done to prevent any future rotation.
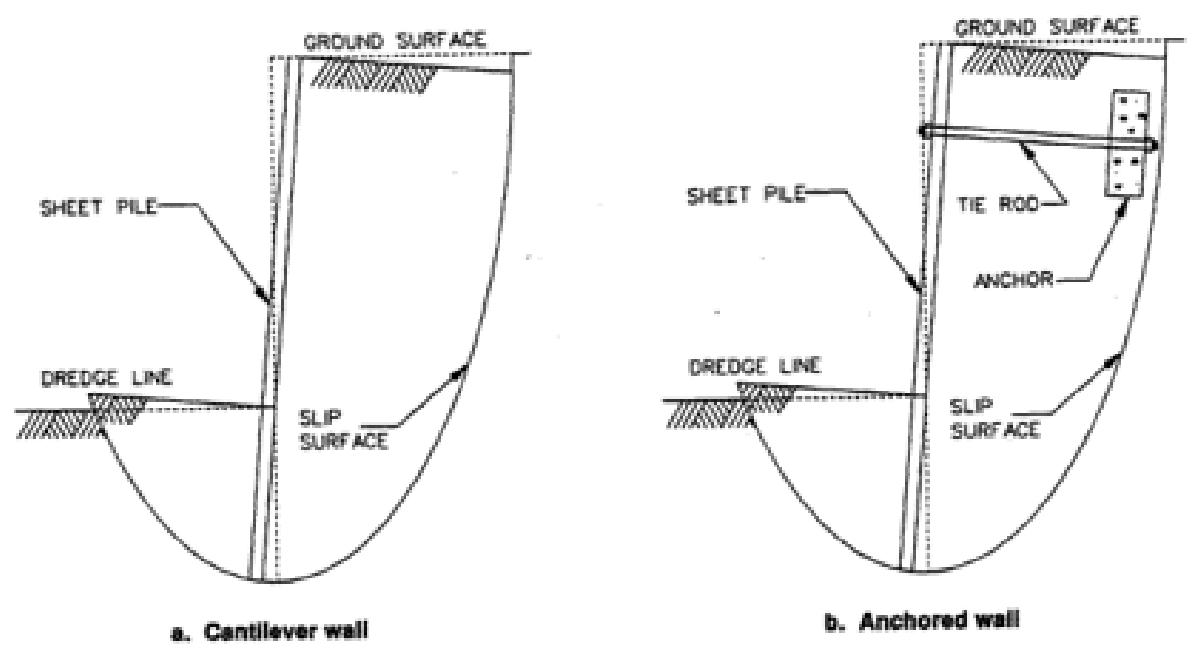

Figure 2. 16: Deep Seated Sheet Pile Failure 


\section{EXPERIMENTAL PROGRAM}

\subsection{Introduction}

This chapter provides information about the experimental program conducted in this study on FRP sheet pile segments under static flexural loading, including the material properties, the testing protocols, and the data procurement. Research for this project took place in the Constructed Facilities Center (CFC) at West Virginia University (WVU-CFC). Each of the testing configurations was proposed and designed prior to execution. The experiments conducted consisted of four glass fiber reinforced polymer (GFRP) composite sheet pile modules (18 inches wide) acting as a vertically placed, thin-walled cantilever beam. It is common for sheet piles to be utilized as cantilever retaining walls in the field and its positioning was deemed appropriate. Load was applied at the top of the sheet pile to simulate pressures that can be exhibited on retaining walls in field conditions. Figure 3.1 shows an image of the test specimen undergoing a test in field conditions at Creative Composites Group's (CCG) facility in Alum Bank, PA.

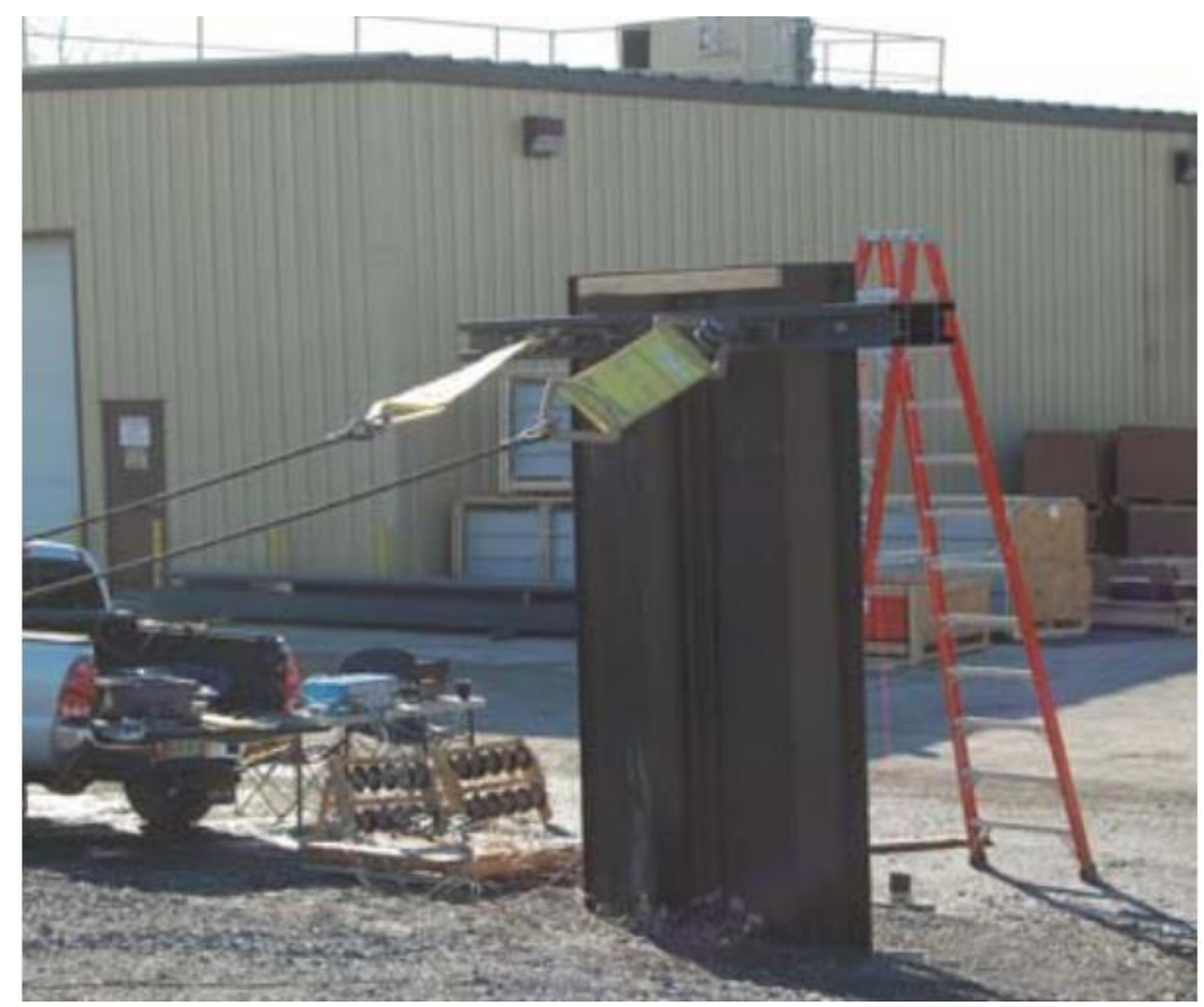

Figure 3. 1: Field Sheet Pile Test 


\subsection{Specimen Details}

Four pultruded sections of Series 1580 SuperLoc $^{\mathrm{TM}}$ Seawall Profile sheet piles sections of CCG were used for each test. Each section was interlocked with one another to form a 72 inch section. The SuperLoc ${ }^{\mathrm{TM}}$ line of sheet piles from CCG are manufactured using either vinyl ester or polyster matrix, reinforced with glass fibers. The particular section in use is pultruded with polyester resin. Four connected sections with the exact specifications of each test specimen are shown in Figure 3.2 Two wale sections were attached at the height of the applied load, on each side of the sheet pile with four $3 / 4-$ inch bolts near the cantilever end, when applied load was exerted to failure.

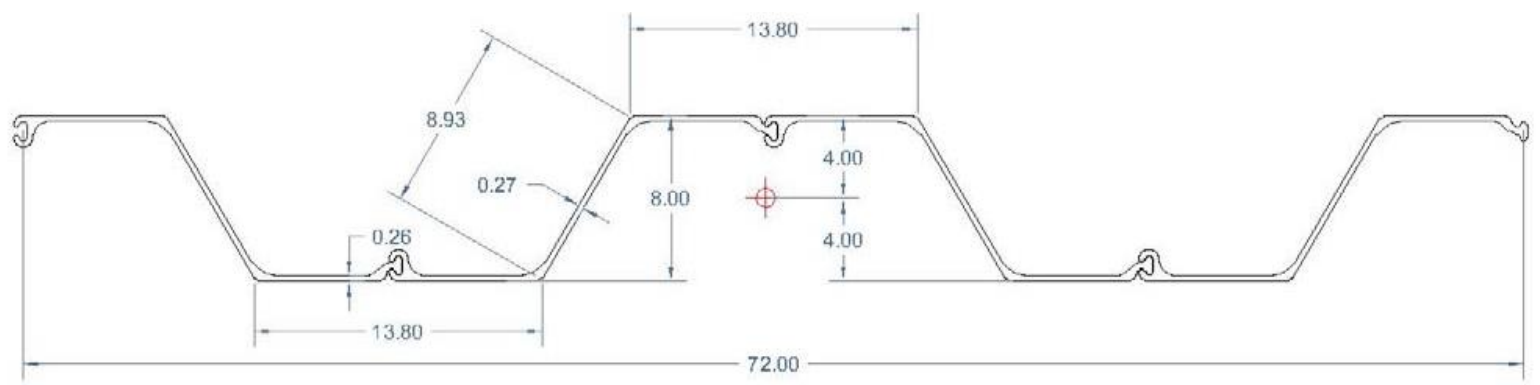

Figure 3. 2: Series 1580 SuperLoc $^{\mathrm{TM}}$ Test Specimen Cross Section

Several variations of the sheet pile testing were carried out with variations in, embedment material, and height of load application. These variations are addressed in Table 3.1. 
Table 3. 1: Sheet Pile Experiments

\begin{tabular}{|l|c|c|c|c|}
\hline Base material & $\begin{array}{l}\text { Number of Tests } \\
\text { Conducted }\end{array}$ & Height of Load & $\begin{array}{l}\text { Load } \\
\text { Application }\end{array}$ & $\begin{array}{l}\text { Embedment } \\
\text { Depth }\end{array}$ \\
\hline Sand & 2 & 9.5 & Actuator & $5^{\prime}$ \\
\hline $\begin{array}{l}\text { Standard Concrete, No } \\
\text { reinforcement }\end{array}$ & 1 & 9.5 & Actuator & $2^{\prime}$ \\
\hline Reinforced Concrete & 1 & 9.5 & Actuator & $2^{\prime}$ \\
\hline $\begin{array}{l}\text { Concrete Mold with } \\
\text { Elastomeric Padding }\end{array}$ & 5 & $9.5-12.5$ & $\begin{array}{l}\text { Actuator and } \\
\text { Winch }\end{array}$ & 2 \\
\hline $\begin{array}{l}\text { Concrete Mold with } \\
\text { Added Steel Channel }\end{array}$ & 1 & 10.5 & Winch & $3.5^{\prime}$ \\
\hline $\begin{array}{l}\text { Steel Bin filled with } \\
\text { Sand-Concrete } \\
\text { Mixture }\end{array}$ & 4 & 12.5 & Winch & $3^{\prime}$ \\
\hline V-Test 1 & 1 & 12.5 & Winch & 3 \\
\hline \begin{tabular}{l} 
V-Test 2 \\
\hline
\end{tabular} & 1 & 12.5 & Winch & 3 \\
\hline
\end{tabular}

\subsection{Testing Configuration}

Each experiment featured a test specimen as shown in Figure 3.1 which is placed vertically in the confines of the constructed testing bin as shown in Figure 3.3. The wale sections were attached at the top of the section so that load can be applied. The load acts in the form of a distributed line load due to a steel plate placed within the confines of the wale section on the opposing side of the load application. Figure 3.3 shows the test specimen within the apparatus. The pile was connected to the load source and load was applied to the pile, pulling it towards the actuator or winch. 


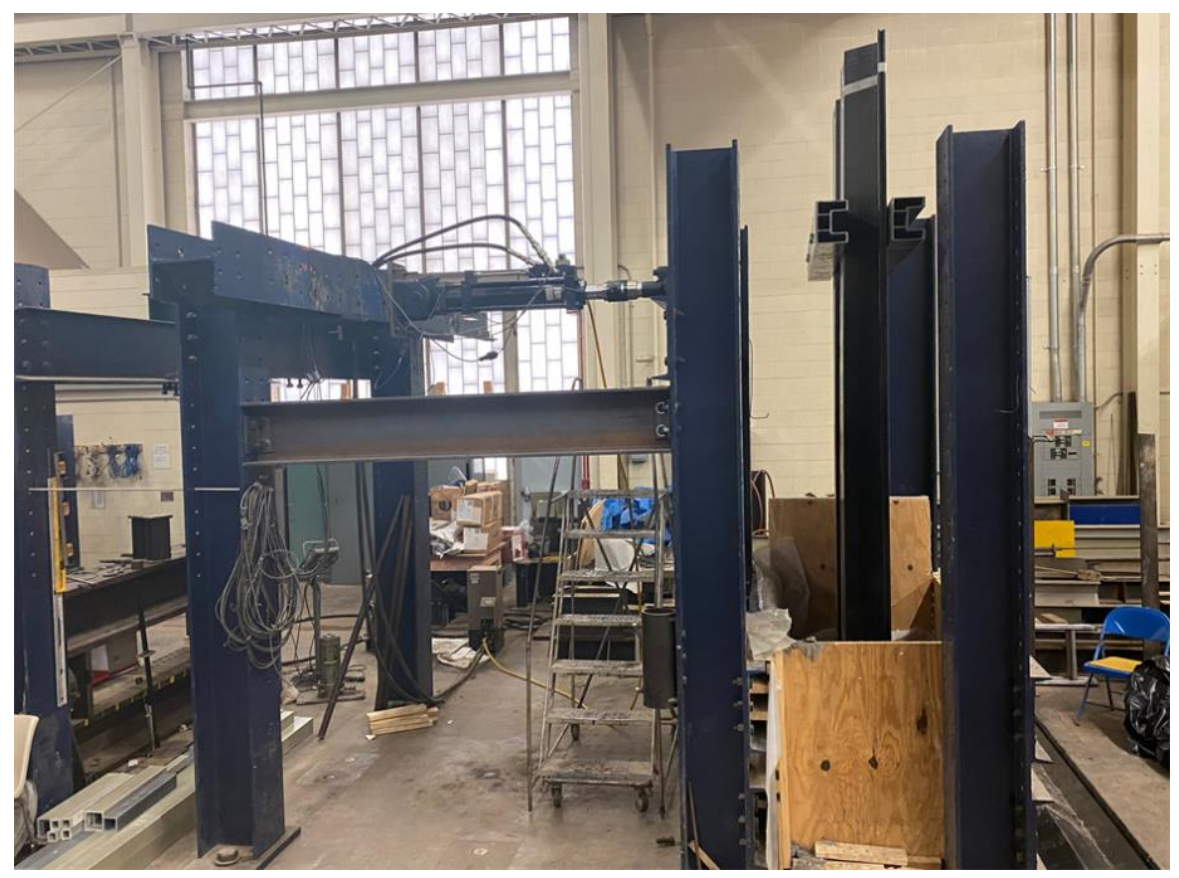

Figure 3. 3:Sheet Pile Test Specimen in Fixture

The vertically installed test pile has no horizontal supports above the embedment material. Sheet piles installed in this manner are considered cantilever sheet pile walls as shown in Figure 3.3. The surface of the material in which the sheet pile is embedded is known as the "dredge line." The lack of material above the dredge line causes this sheet pile to be characterized as a free cantilever. Stability is derived from the pressure resistance on either side of the sheet pile beneath the dredge line in the form of active and passive pressures.

\subsection{Specimen Construction}

The sheet pile segments were received as individual 18-inch segments. Each segment profile is a Z-section with a web angle of $120^{\circ}$ or $60^{\circ}$ to the horizontal axis. The test specimen had a thickness of 0.265 -inches. Figure 3.4 shows an image of the test specimen immediately after the wale section was attached. Four of these segments were joined by sliding the male end into the female end of the interlocking mechanism (groove and tongue). The wale sections were mounted at the desired load application heights.Figure 3.4 
and Figure 3.5 show the wale sections mounted to the sheet pile. Four 3/4-inch bolts were used to mount each wale section to its respective side of the sheet pile. When drilling occurred to create the holes for the threaded rods, temporary wooden supports were added beneath the section to prevent the pile from deflecting towards the floor under the weight of the wale section and drill. Two 1 inch bolts were inserted through both wale sections, spaced 4 inches on either side of the center of the wale section. The threaded 1 inch bolts were mounted to the load application device and secured with fasteners.

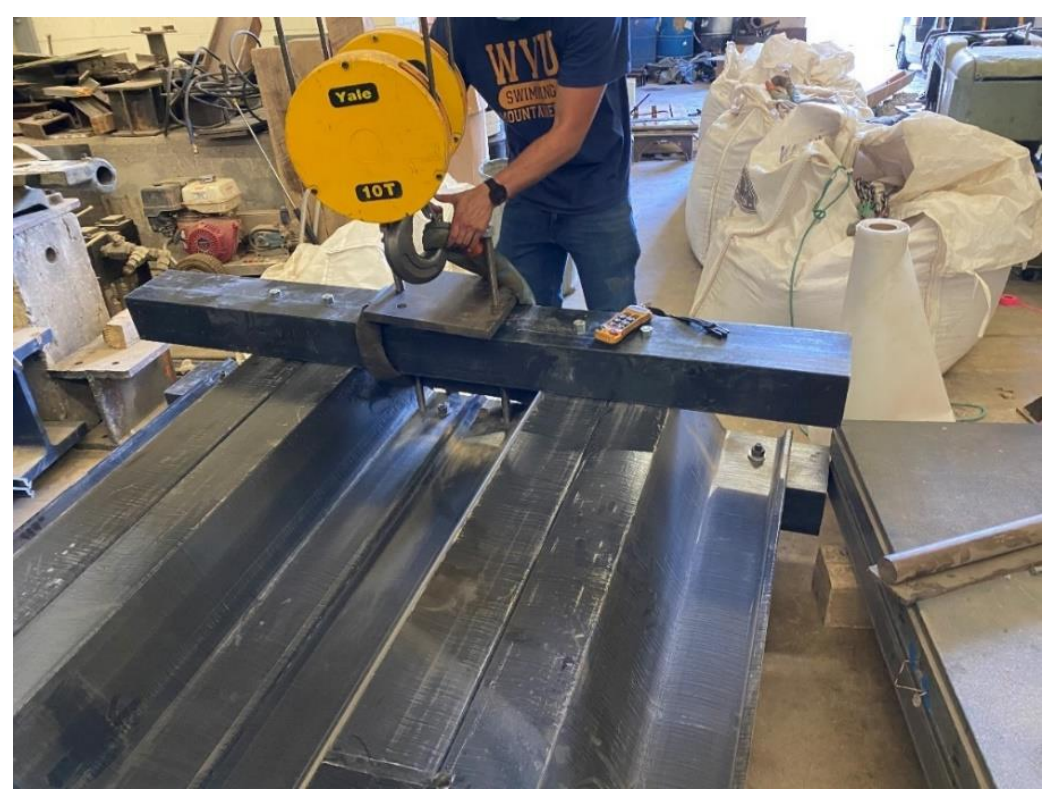

Figure 3. 4: Single Sheet Pile Specimen 


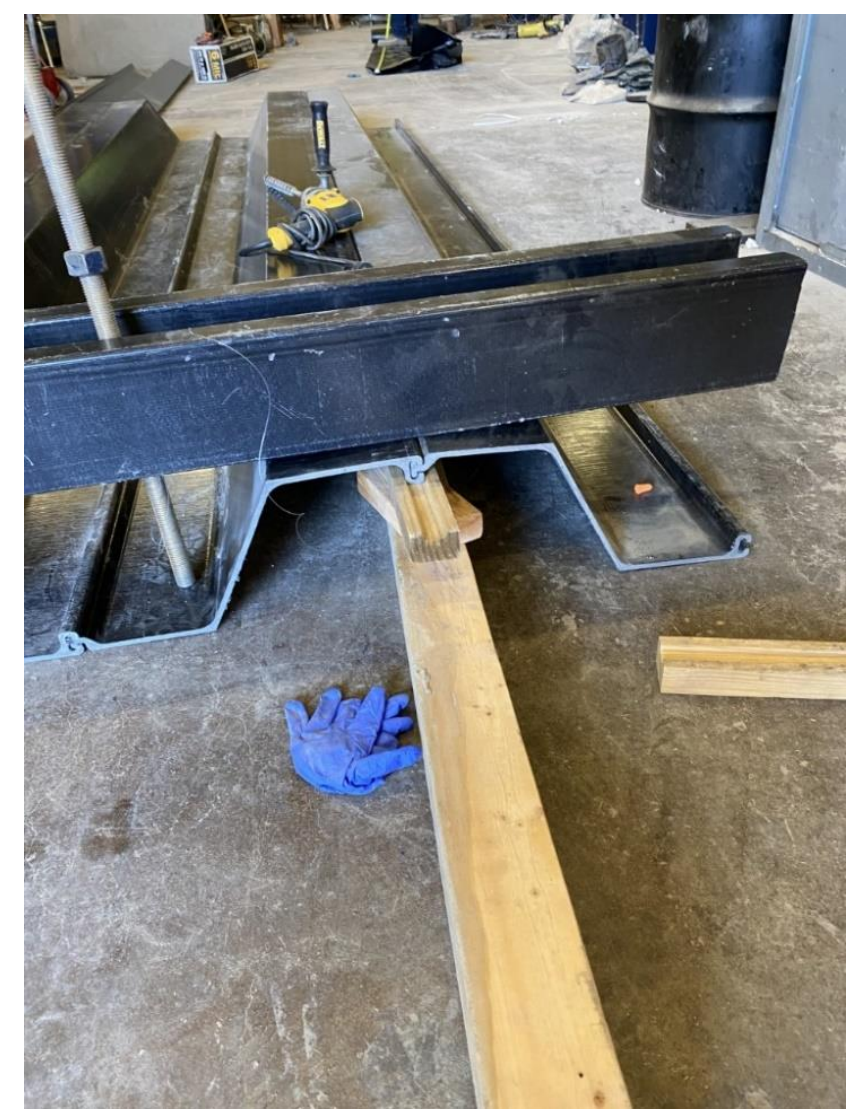

Figure 3. 5: Sheet Pile Specimen Under Construction with Wale Section

\subsection{Material Properties}

Table 3.2 shows section property values provided by Creative Composites Group.

Table 3. 2: Manufacturer Specimen Properties

\begin{tabular}{|c|c|}
\hline Moment of Inertia & $54.01 \frac{\mathrm{in}^{4}}{\mathrm{ft}}$ \\
\hline Section Modulus & $13.08 \frac{\mathrm{in}^{3}}{\mathrm{ft}}$ \\
\hline Longitudinal Modulus & $4250 \mathrm{ksi}$ \\
\hline Transverse Modulus & $1300 \mathrm{ksi}$ \\
\hline In-plane Shear Modulus & $500 \mathrm{ksi}$ \\
\hline Longitudinal Poisson's Ratio & 0.3 \\
\hline
\end{tabular}


All of the tests conducted showed evidence of buckling about the weak axis of the sheet pile. As a result testing ensued to confirm the weak transverse modulus values provided. Procedure from ASTM D790-17 was followed carefully on samples cut from the sheet pile. Figure 3.6 shows one of the tested specimens. The specimen was slightly over 4 inches so that a span length of 4 inches could be used, 0.75 inches in width, and had a thickness of 0.26 inches. The specimen was cut so that the span length of 4 inches was across the transverse axis. A strain gage was placed at the center of the specimen on the bottom (tension) side. The gage was oriented so that It measured the strain across the transverse axis. Equation 3.1 was used to calculate flexural stress. Figure 3.7 shows the stress and strain observed during testing.

$$
\sigma_{f}=\frac{3 P L}{2 b d^{2}}
$$

Where,

$\mathrm{P}=$ Applied Load (kips)

$\mathrm{L}=$ Span Length (inches)

$\mathrm{b}=$ width (inches)

$\mathrm{d}=$ Thickness (inches)

$\sigma_{f}=$ Flexural Stress (ksi)

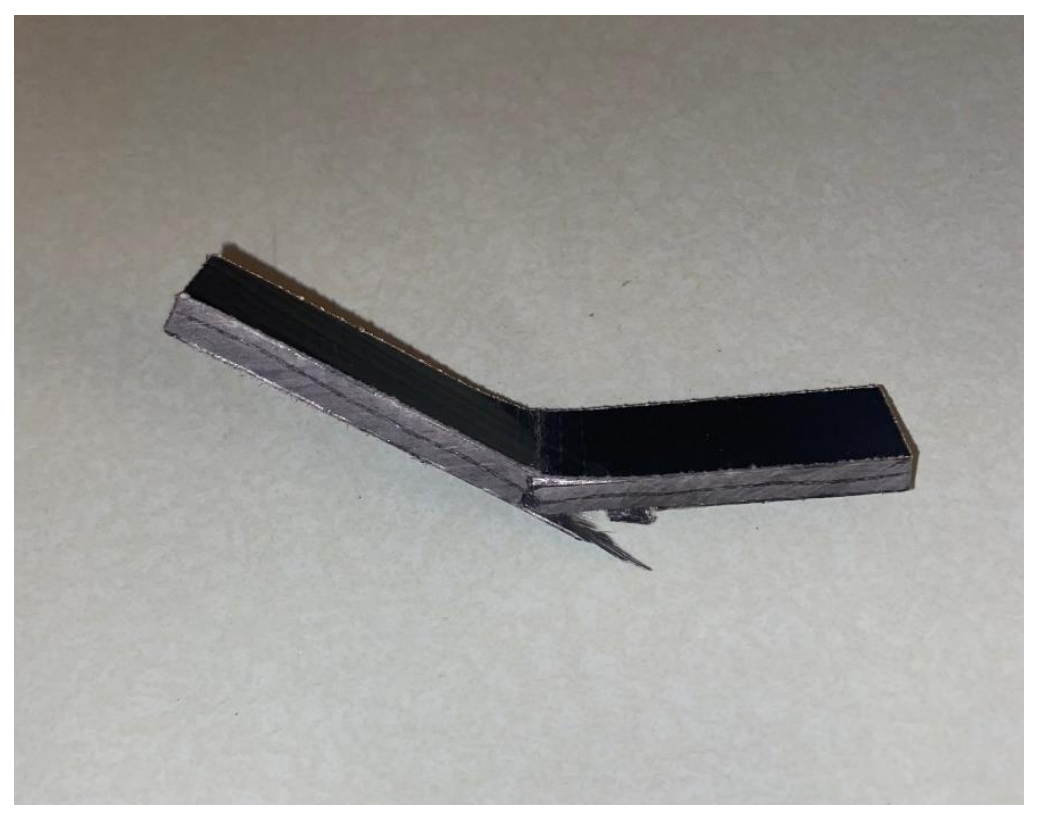

Figure 3. 6:Coupon Specimen Tested Under Bending 


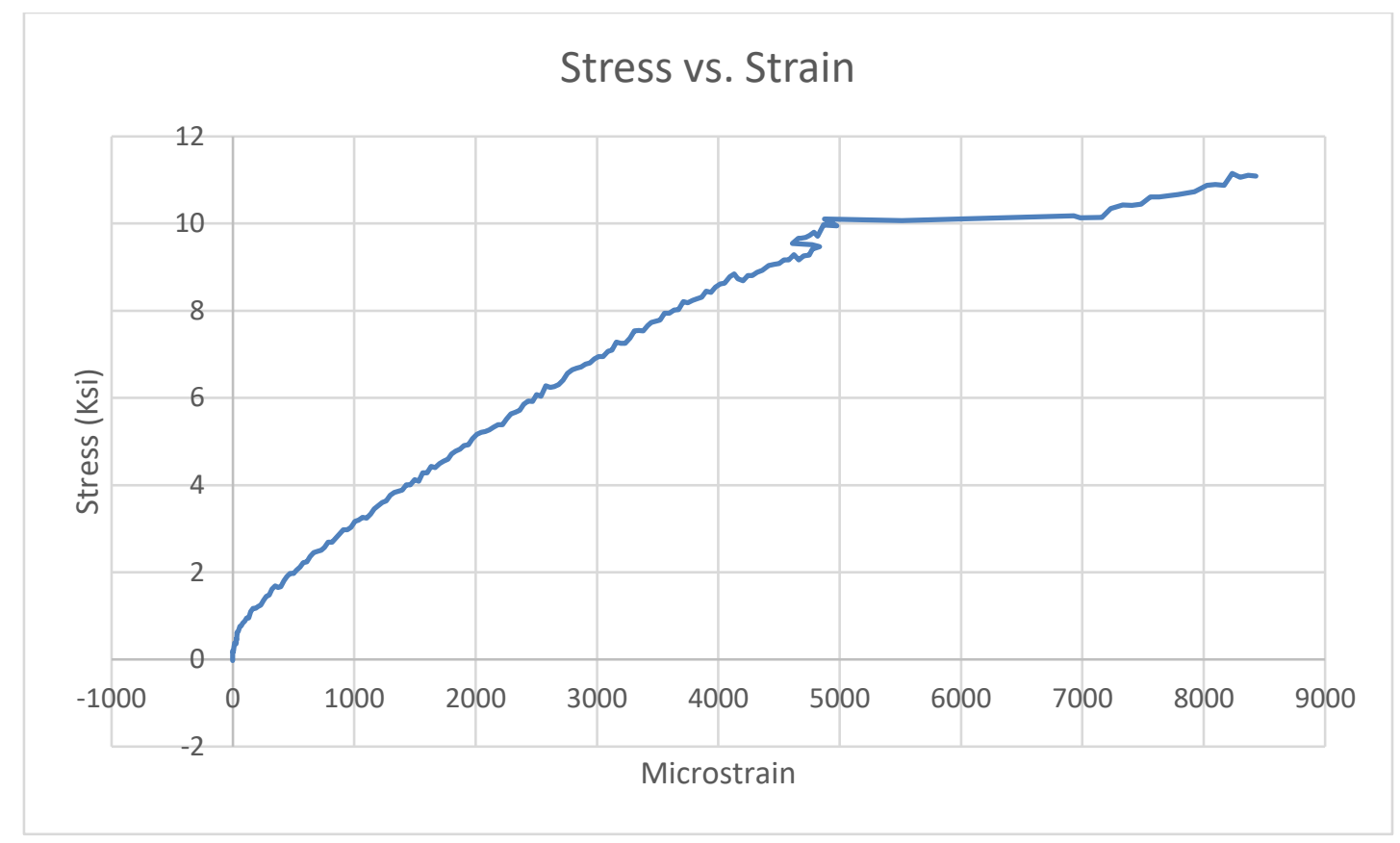

Figure 3. 7: Stress vs Strain of Coupon Under Bending

Equation 3.2 was used with values taken from the linear zone of Figure 3.7 Two data points representing stress and strain were taken and a bending modulus of $1.85 \times 10^{6} \mathrm{psi}$ was established along the weak axis.

$$
E_{f}=\frac{\sigma_{f 2}-\sigma_{f 1}}{\varepsilon_{f 2}-\varepsilon_{f 1}}
$$

Where,

$\sigma_{f 2}, \sigma_{f 1}=$ Stresses at selected points (ksi)

$\varepsilon_{f 2}, \varepsilon_{f 1}=$ Strains at selected points

$E_{f}=$ Flexural Modulus (ksi)

A bending modulus was also found using load and deflection data. Equation 3.3 was used to solve for the modulus. A bending modulus of $1.4 \times 10^{6}$ psi was established from Equation 3.3. Taking shear influence into account, a shear correction factor of $12 \%$ (Nagaraj and GangaRao) can be applied to the longitudinal modulus of the compression flange. In this instance, the longitudinal modulus of the compression flange is 
the transverse modulus of the sheet pile specimen which is perpendicular to the pull direction of a sheet pile. Therefore, from Equation 3.3 the transverse modulus is $1.6 \times 10^{6} \mathrm{psi}$

$$
\Delta=\frac{P L^{3}}{48 E I}
$$

Where,

$\mathrm{P}=$ Load (kips)

$\mathrm{L}=$ Span Length (inches)

$\mathrm{E}=$ Bending Modulus (ksi)

$\mathrm{I}=$ Moment of Inertia $\left(\right.$ inches $\left.^{4}\right)$

$\Delta=$ Displacement (inches)

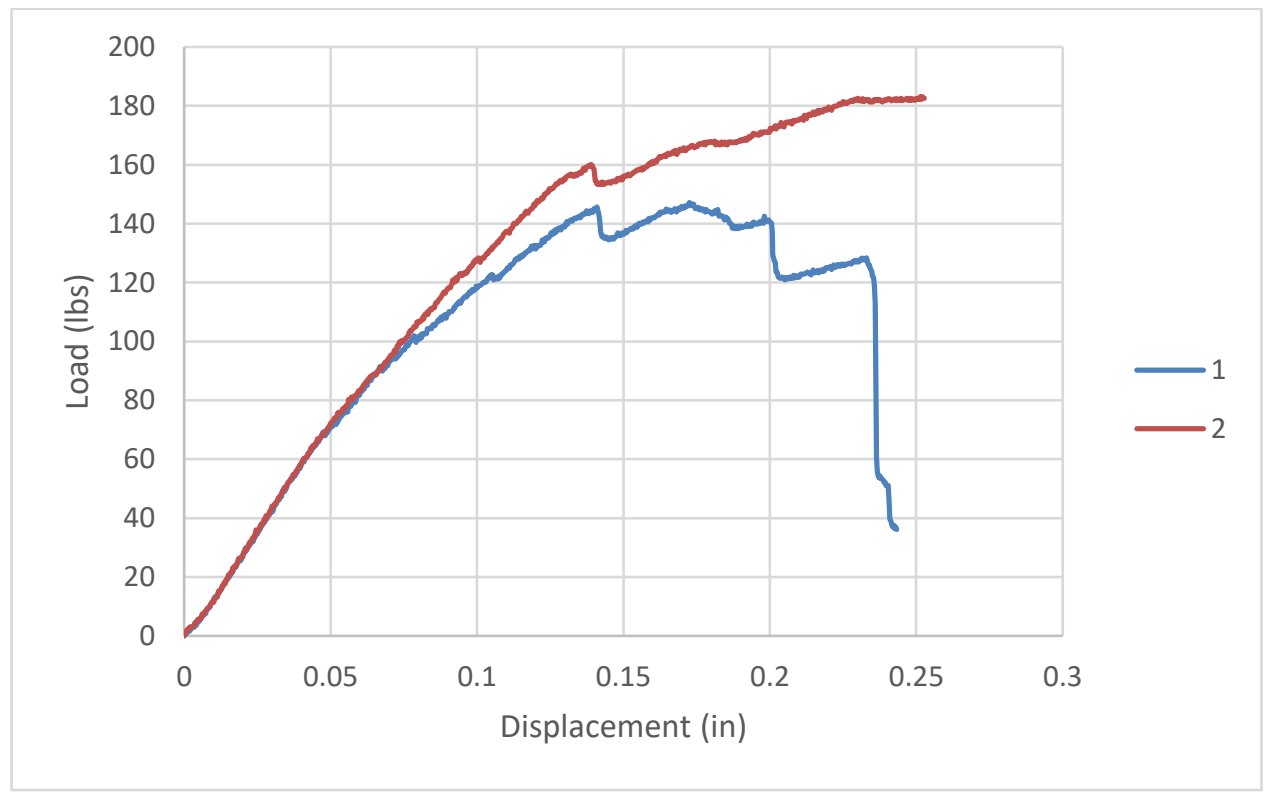

Figure 3. 8:Load vs Displacement Coupon Testing

In total, three different approaches were used to find the transverse modulus of the test section. Table 3.3 displays approximate values for each of the moduli calculated. A value of $1.6 \times 10^{6}$ psi ksi was used as the transverse modulus for calculation purposes in Chapter 5. 
Table 3. 3:Transverse Moduli

\begin{tabular}{|c|c|c|}
\hline Provided from Manufacturer & Deflection Based Approach & Stress-Strain Approach \\
\hline $1.3 \times 10^{6} \mathrm{psi}$ & $1.6 \times 10^{6} \mathrm{psi}$ & $1.8 \times 10^{6} \mathrm{psi}$ \\
\hline
\end{tabular}

\subsection{Data Collection}

Test data were collected from strain gages, load cells and a string pot using the Vishay data acquisition system 7000 (Figure 3.9) Using Strain Smart Software, data was processed and exported to Microsoft excel for further evaluation.

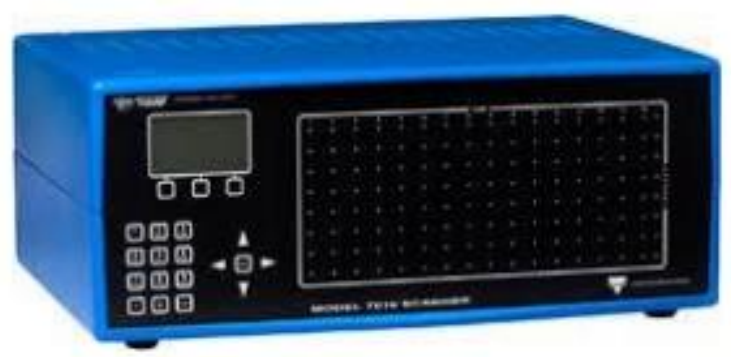

Figure 3. 9:Strainsmart System 7000

The acquisition of deflection was recorded using a Celsco SP3-50 Compact String Pot (Figure 3.10). The string pot had a stroke range of 50 inches which was sufficient for testing applications. Load was initially recorded using the MTS actuator, however when load application was transferred to the winch an Omega LC103B-20K load cell was used. The load cell was an S-Beam load cell shown in Figure 3.11. Figure 3.12 shows the placement of the load cell in relation to the sheet pile and load application. Designed for recording load in tension and compression, the S-Beam category of load cell was deemed fit for the method of loading. 


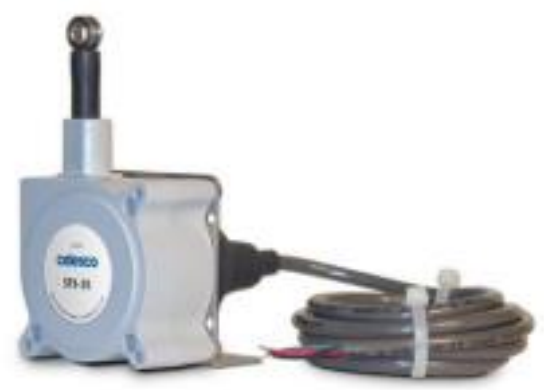

Figure 3. 10:String Pot

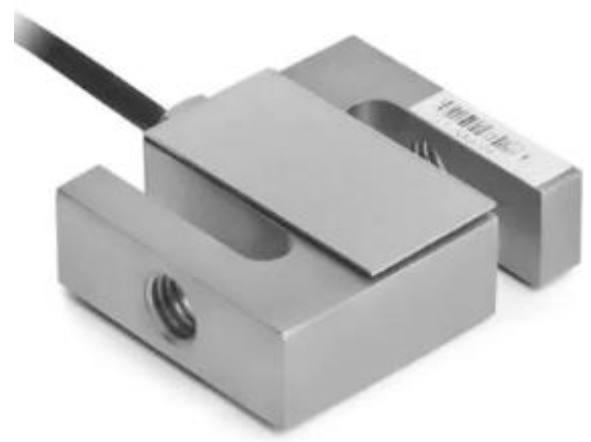

Figure 3. 11:Load Cell

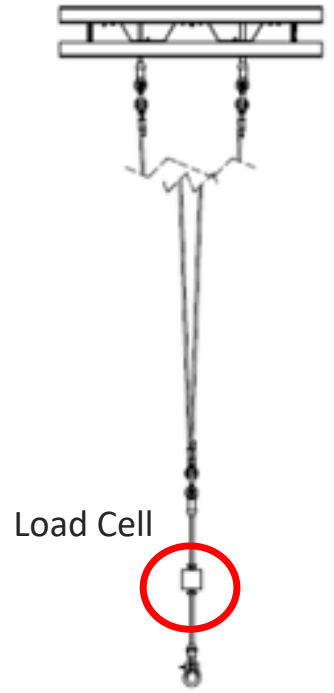

Figure 3. 12:Load Cell Location 


\subsection{Summary}

Research for this project took place in the Constructed Facilities Center (CFC) at West Virginia University. A team of graduate students and employees of the university constructed each of the testing apparatuses and conducted each test. The experiment conducted consisted of four fiber reinforced polymer sheet pile segments acting as a vertically placed cantilever beam. Load was applied at the top of the sheet pile to simulate pressures that can be exhibited on retaining walls in field conditions. Strain from each test was collected and studied meticulously to understand the sheet pile's behavior at different depths or locations on the cross-section. Load and deflection were measured and studied to compute bending stresses at different locations along the length of the sheet pile and compare the sheet pile's response to field testing results and to other experimental trials. Most tests featured variations in material that the sheet pile was embedded in or load application. The results of these tests are reported in Chapters 4 and 5 .

\section{EXPERIMENTAL RESULTS}

Over the course of this project, a total of 16 tests have been conducted. For each test, strain data were documented at several different locations to monitor the sheet pile's behavior, load applied to the pile was measured, displacement of the sheet pile was recorded, and the failure mode of each test specimen were documented. As a result of limited supply, strain gages were placed strategically, to provide the most useful information for the respective test, hence, strain gage location may vary throughout tests. The final testing apparatus and procedure differed greatly from the initial procedure and apparatus. The test results and pile failure behavior are documented in this chapter. 


\subsection{Sand with Wooden Supports}

Initially it was hypothesized that dry sand would suffice, surrounding the sheet pile and provide enough restraint for the pile. Sand replicated field conditions within reason. A wooden box (7 foot length by 4 foot width by 5 foot depth) was constructed around the base of the test specimen so that approximately 12,000 pounds of sand could be poured to surround the pile. Five feet of the sheet pile was beneath the sand and approximately 5 feet of the sheet pile was free above the dredge line. Additional wooden restraints were installed at the bottom of the bin to ensure that the sheet pile was as fixed as possible. Figure 4.1 shows the bottom of the specimen after it had been tested.

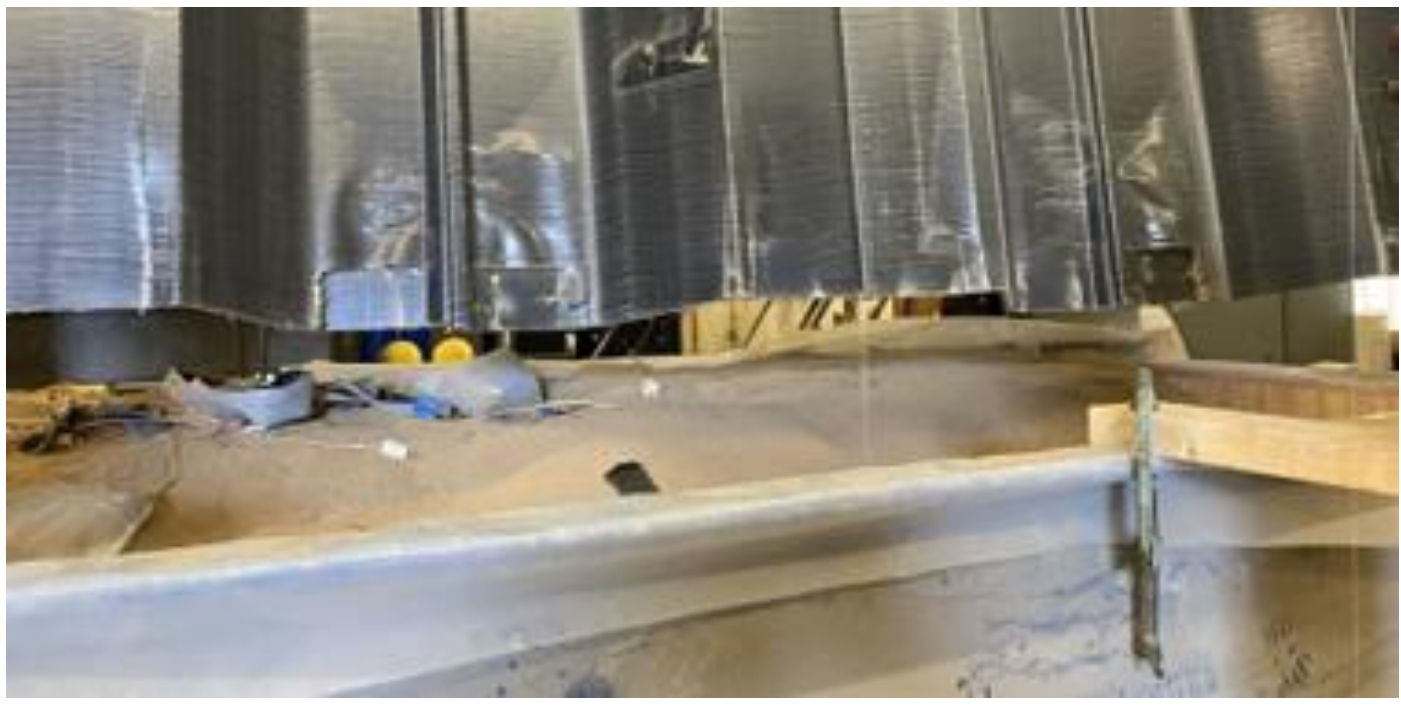

Figure 4. 1:Test Specimen in Sand

The wooden members used to restrain the specimen caused local crushing of the pile (deformations can be seen in Figure 4.1. Upon removal of the wooden members, the pile was tested once more in sand. When horizontal load was applied to the pile, a large bending moment was generated and caused the pile to rotate, forcing the sand to heave. The relatively small amount of sand (depth of 5 feet compared to $10+$ feet in field conditions) could not generate the active and passive forces to restrain the pile. Figure 4.2 shows the test specimen after load was applied. There is no buckling or failures to be seen on the FRP sheet pile, but a large amount of deformation in the sand. When load was removed from the pile, the pile had remained 
slanted because of the permanently deformed soil media. It should be noted that the sand behind the pile was elevated while the sand in front of the pile had sunk into the box.

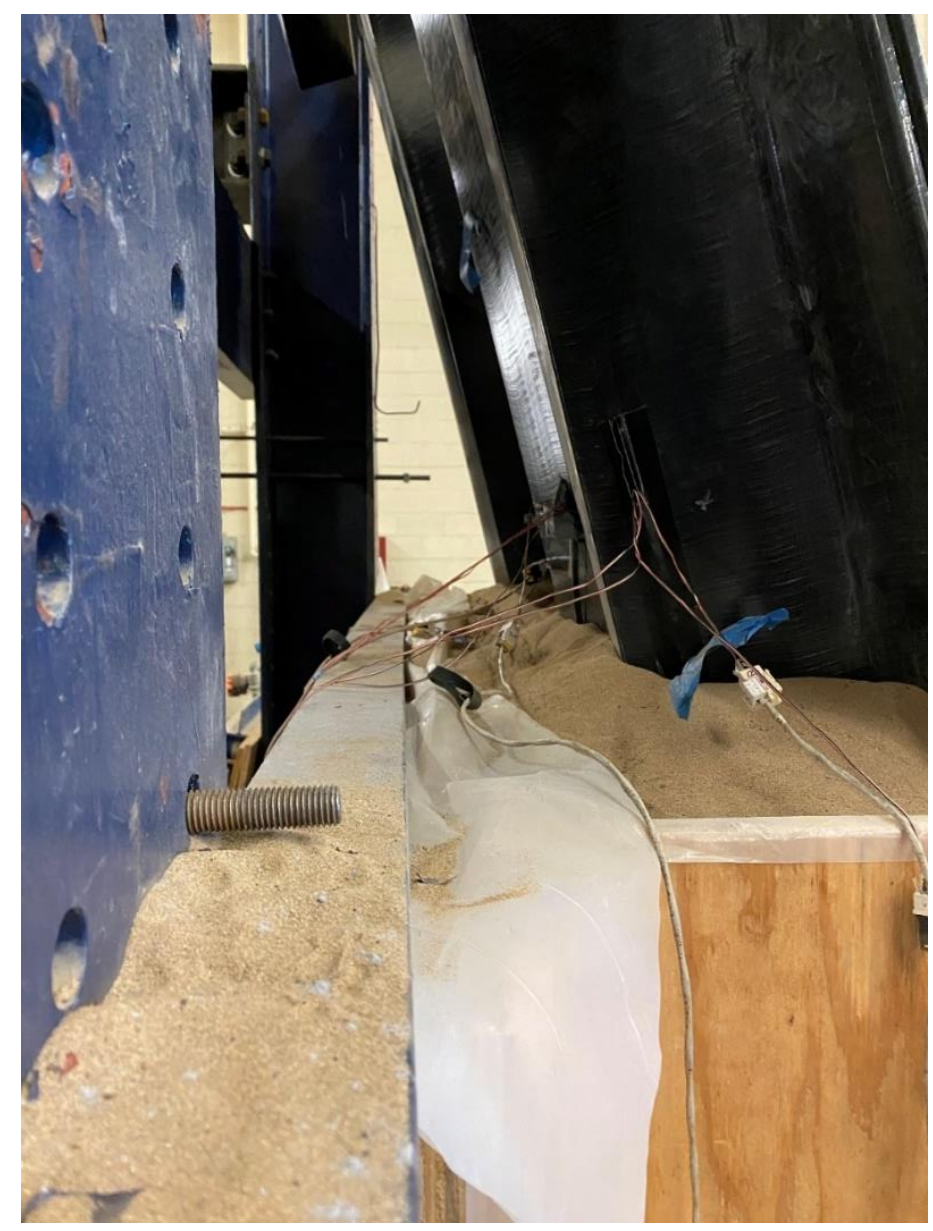

Figure 4. 2:Sheet Pile Specimen in Sand

Load was applied with the MTS actuator at a load rate of 350 pounds per second until the actuator had run out of stroke. A significant amount of movement can be seen in the direction of the load application in Figure 4.2. This is a clear indication that the shear resistance of the sand was not nearly enough to support the flexural moment generated by load. Figure 4.3 shows a load deflection curve for the test conducted in sand. 


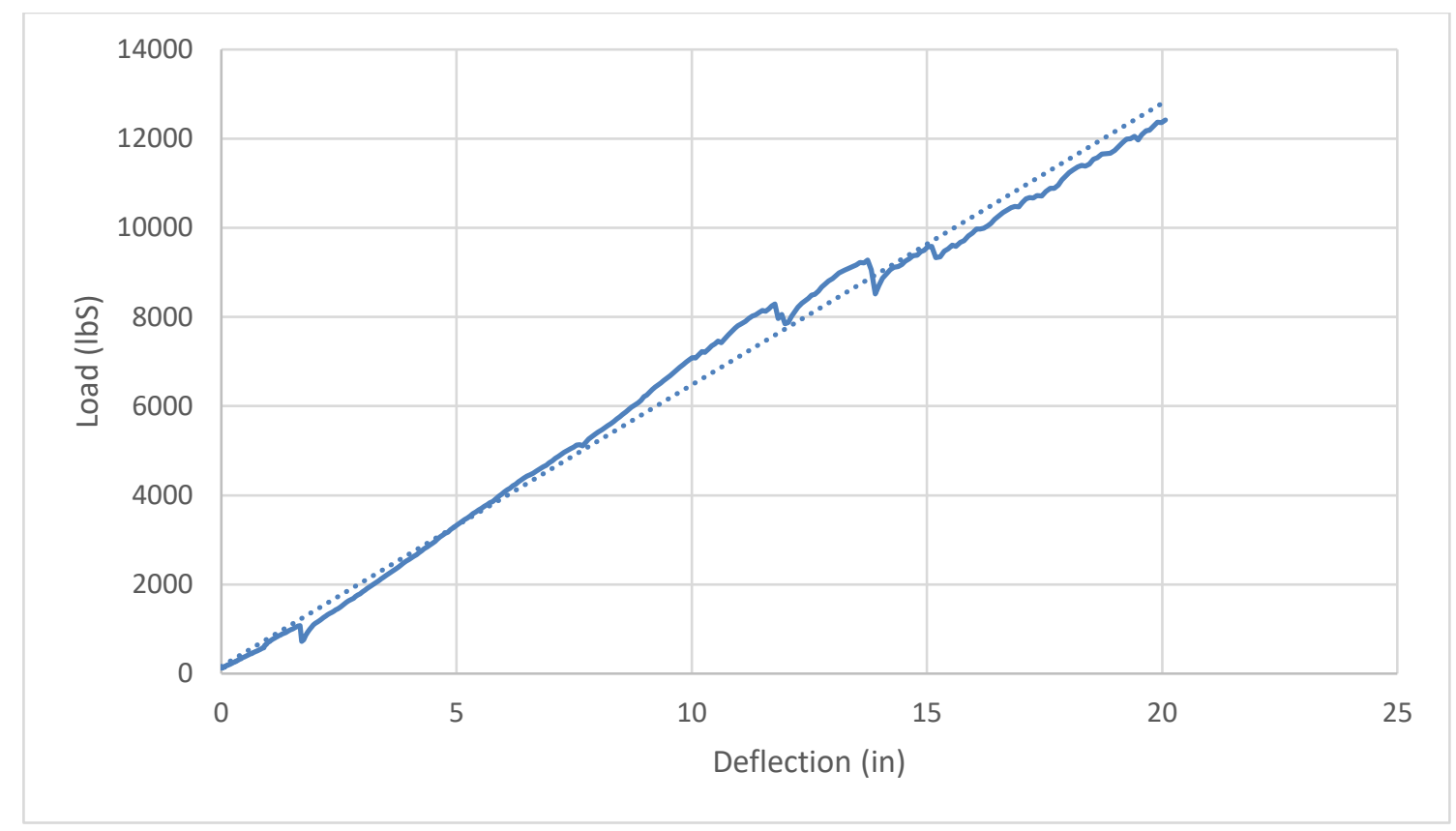

Figure 4. 3:Test in Sand Load vs Deflection

The rate of loading and deflection is linear until the load dropped at 8,291, 9,277, and 9,408 pounds of load. Prior to the drop at 8,291 lbs of load, the slope of the response had increased. It is thought that the horizontal movement at this point had caused some of the load to transfer to the gantry crane that was supporting the actuator via a sling. The drop then occurred as the actuator had moved close to 8 inches, potentially causing a slip in the sling.

The drop in the load deflection curve that is shown at 9,277 lbs can also be observed in strain data. Figure 4.4 shows the strains occurring beneath the sand on the sheet pile. The dashed line indicates the point at which strains changed, indicating that yielding had begun. The gage designation indicated the depth beneath the dredge line at which the gage is located. A drastic change in strain was noticed at 4 feet beneath the dredge line. Slight changes were observed at other locations, but the most prevalent strain gage located at 4 feet below the dredge line indicates that yielding began at a depth of 4 feet or greater. This data confirms the failure documented in Figure 4.1 where the pile showed signs of rupture where wooden supports were placed. 


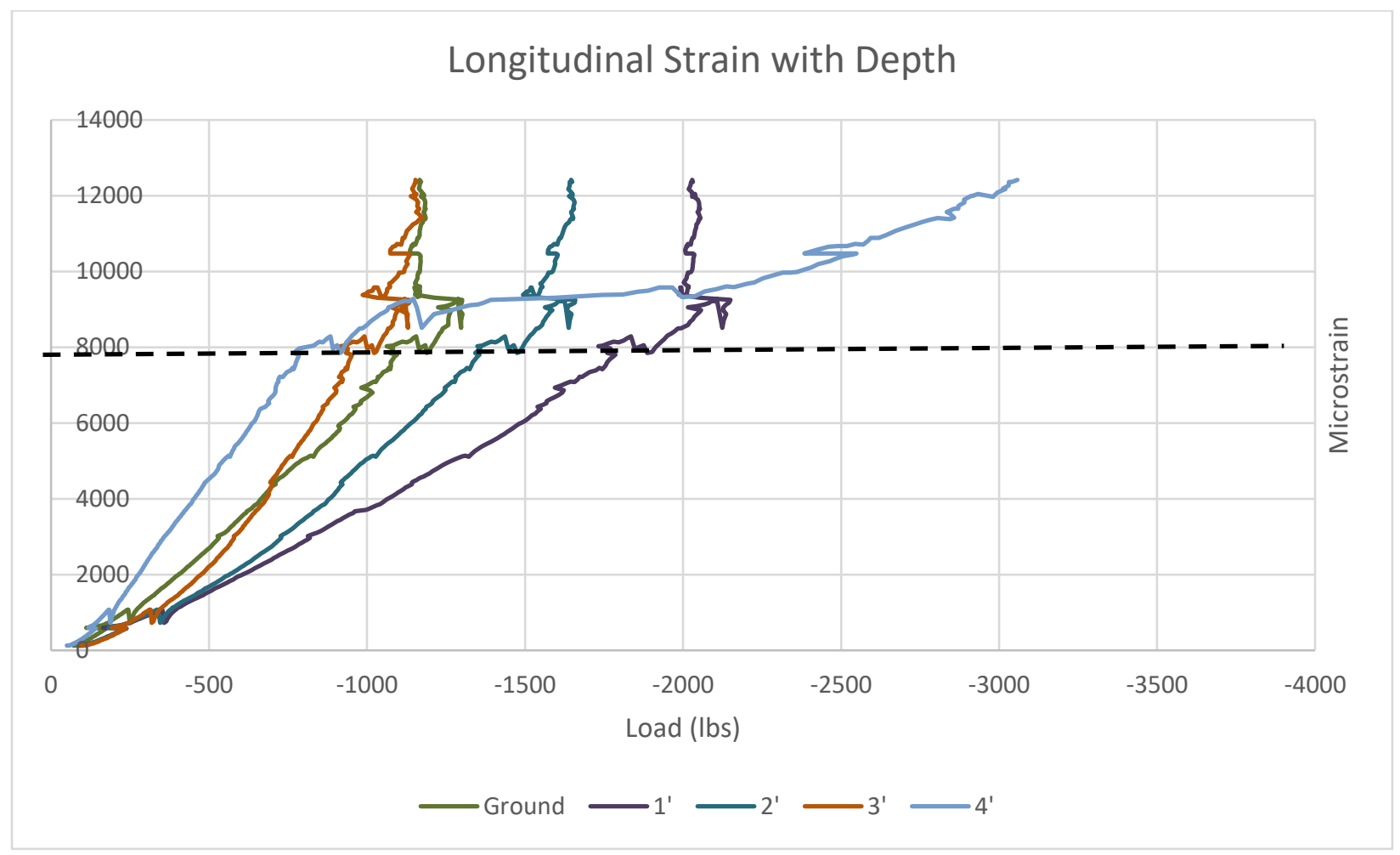

Figure 4. 4:Pile Test in Sand-Strain Results

\subsection{Initial Test with Concrete}

Following the experimental trial featuring the implementation of sand, concrete was chosen as a replacement. A denser material with a greater compressive strength was needed to resist (reactionary) load from the test specimen. The test specimen was placed in the box that was initially constructed to contain the sand, and concrete was poured around the test specimen unital a height of two feet was reached. Figure 4.5 shows the concrete immediately after it was poured around the test specimen. A curing time of 7 days was allotted so that the concrete could generate a sufficient amount of strength to resist any reactionary forces. Compressive tests were conducted on concrete cylinders on the same day of testing (7-days post pour) and had an average strength of 2,850 psi. 


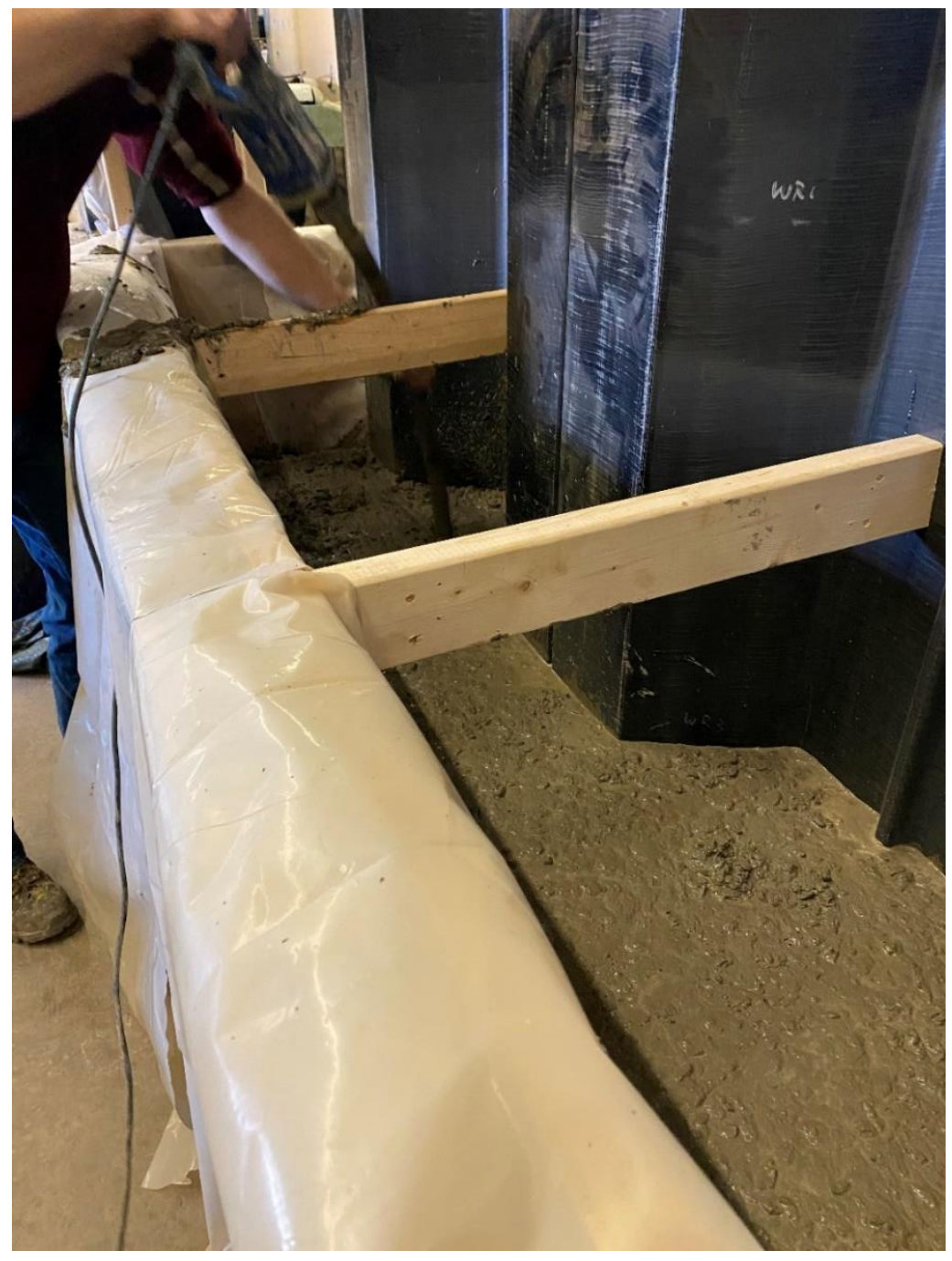

Figure 4. 5:Concrete Poured Around Specimen

Figure 4.6 shows load versus deflection curve that resulted from the initial concrete test. The pile began to deflect linearly util a small negative spike near 1 kip of load. The spike was attributed to the concrete at the base cracking, as it was observed during the test. As loading continued, a more pronounced crack occurred near 6.8 kips of load. After the crack had occurred, loading continued until the sheet pile showed signs of failure at 7.76 kips of load. 


\section{Test 1 Concrete}

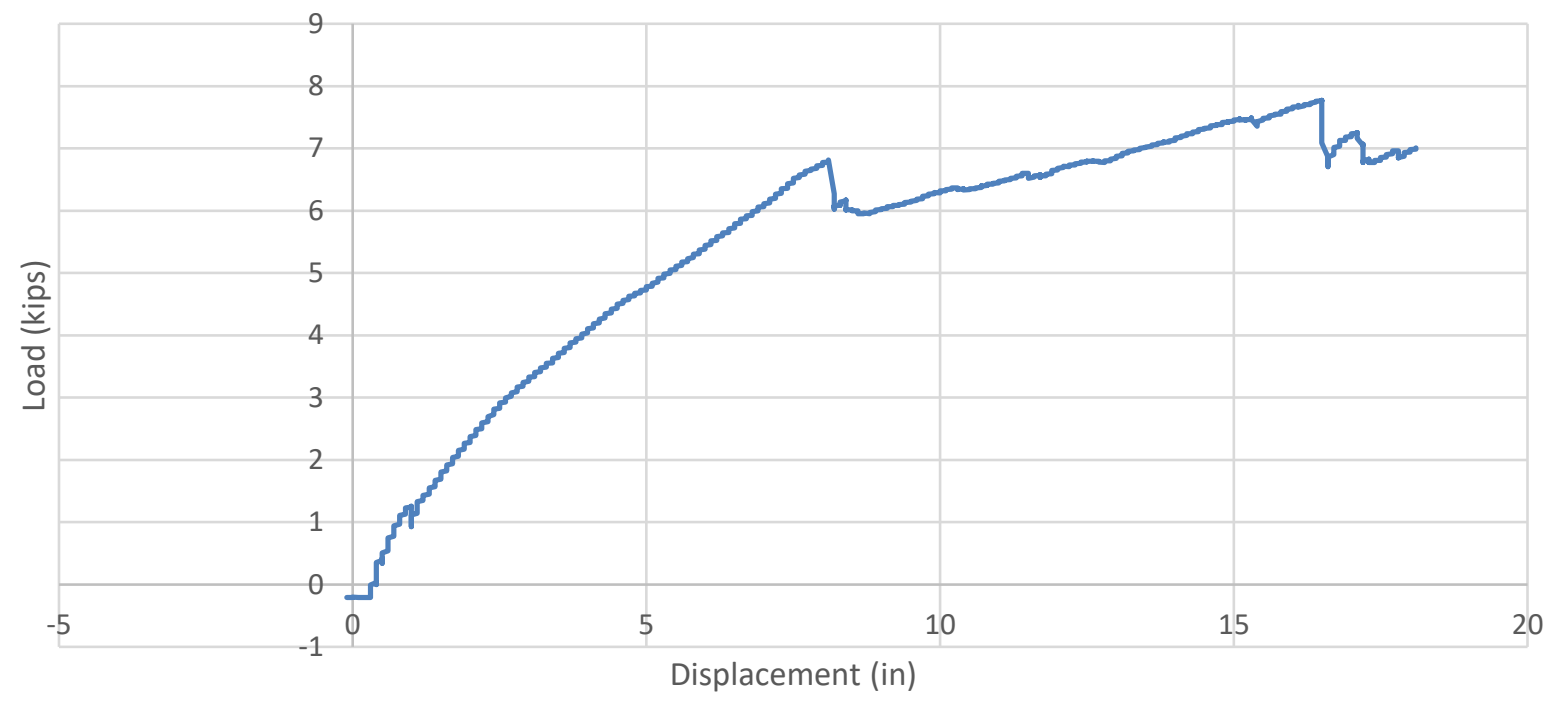

Figure 4. 6:Load vs Displacement Concrete Test

The concrete was able to provide a base that was significantly more fixed than the sand; however; the base concrete had no reinforcement and split into two parts prior any noticeable failure had occurred within the sheet pile. An image of the cracked concrete specimen is shown in Figure 4.7.

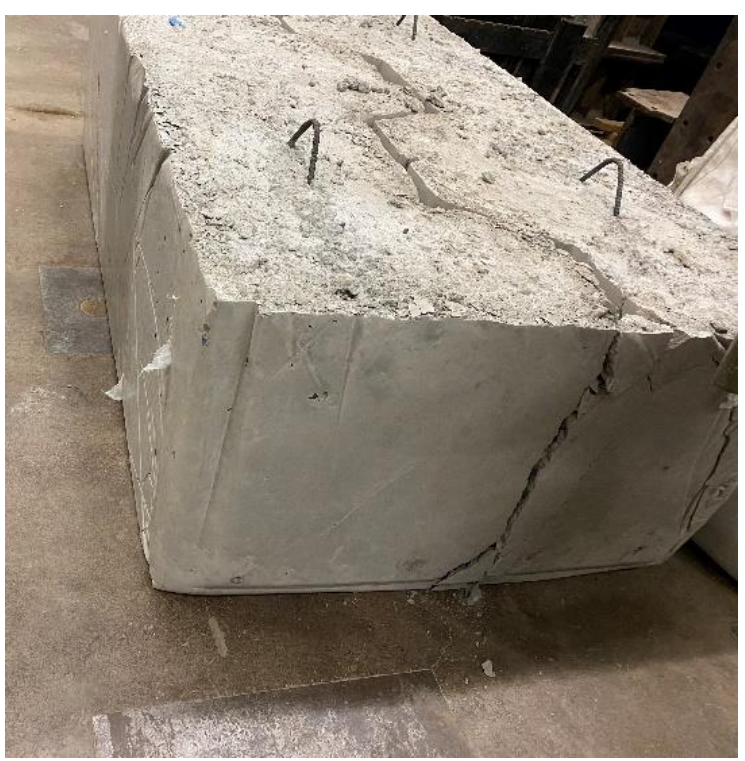

Figure 4. 7:Cracked Concrete Base 
Despite the large crack in concrete, the test continued until the specimen showed signs of failure. Figure 4.8 shows buckling that occurred about the weak axis, directly at the surface of the concrete.

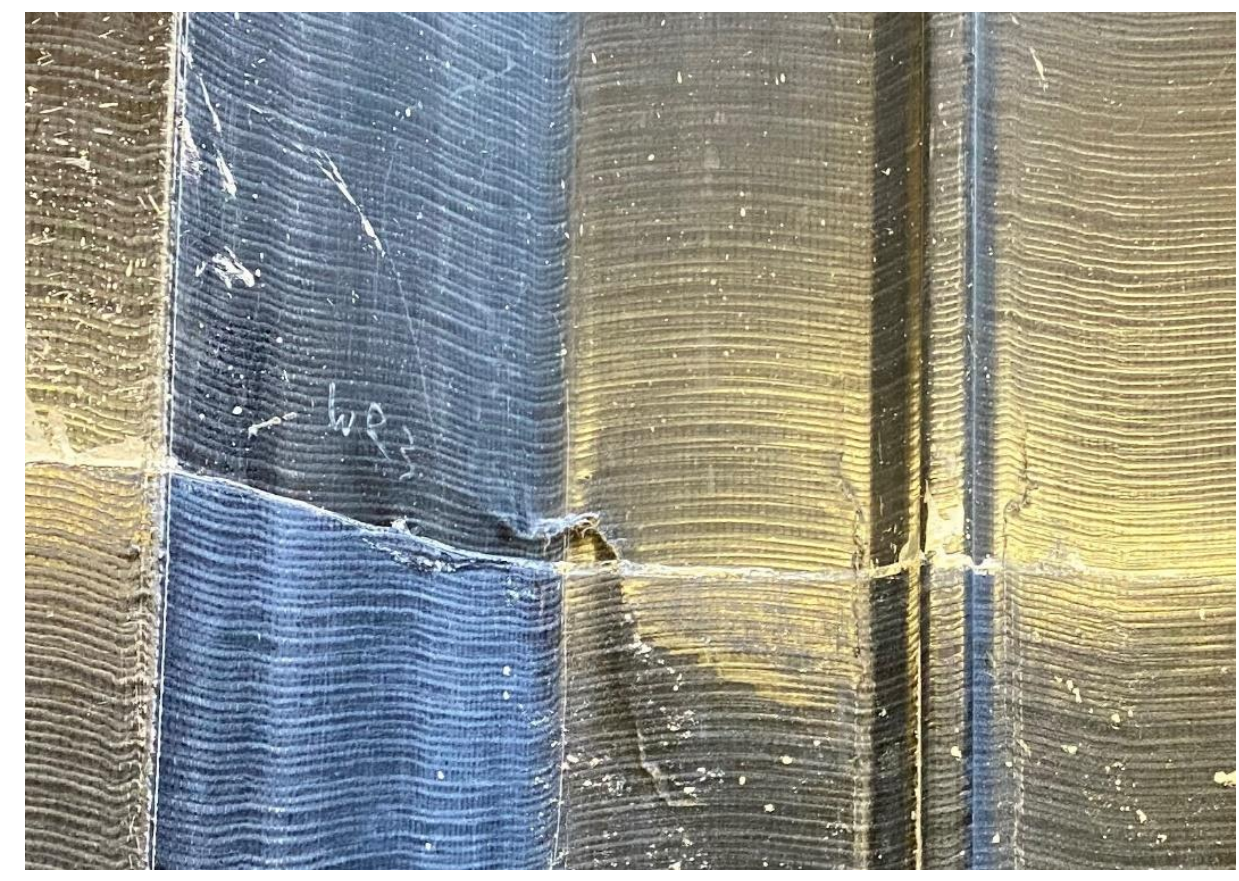

Figure 4. 8:Weak Axis Failure

\subsection{Reinforced Concrete}

Steel reinforcement was constructed (Figure 4.9) to prevent any cracking of concrete base (i.e. prevent concrete splitting as stated in Section 4.3) and placed inside of a new concrete base along with a sheet pile test specimen. The steel rebar structure was placed inside of the testing bin, followed by the test specimen, and then concrete was poured around the base of the sheet pile once more. 


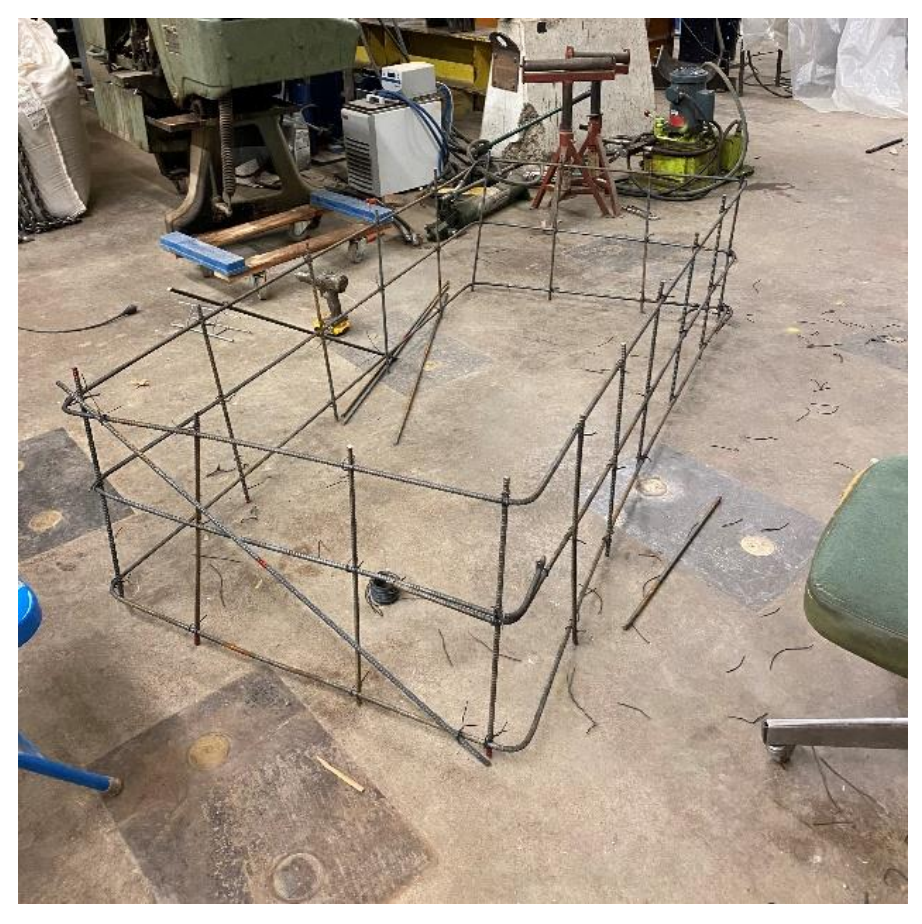

Figure 4. 9:Concrete Reinforcement Structure

The reinforced concrete media surrounding the pile had enough compression and tensile strength to resist reactionary loads at the base of the pile. Figure 4.10 shows a load versus deflection curve, indicating that the test was stopped at a load of 8.7 kips. 


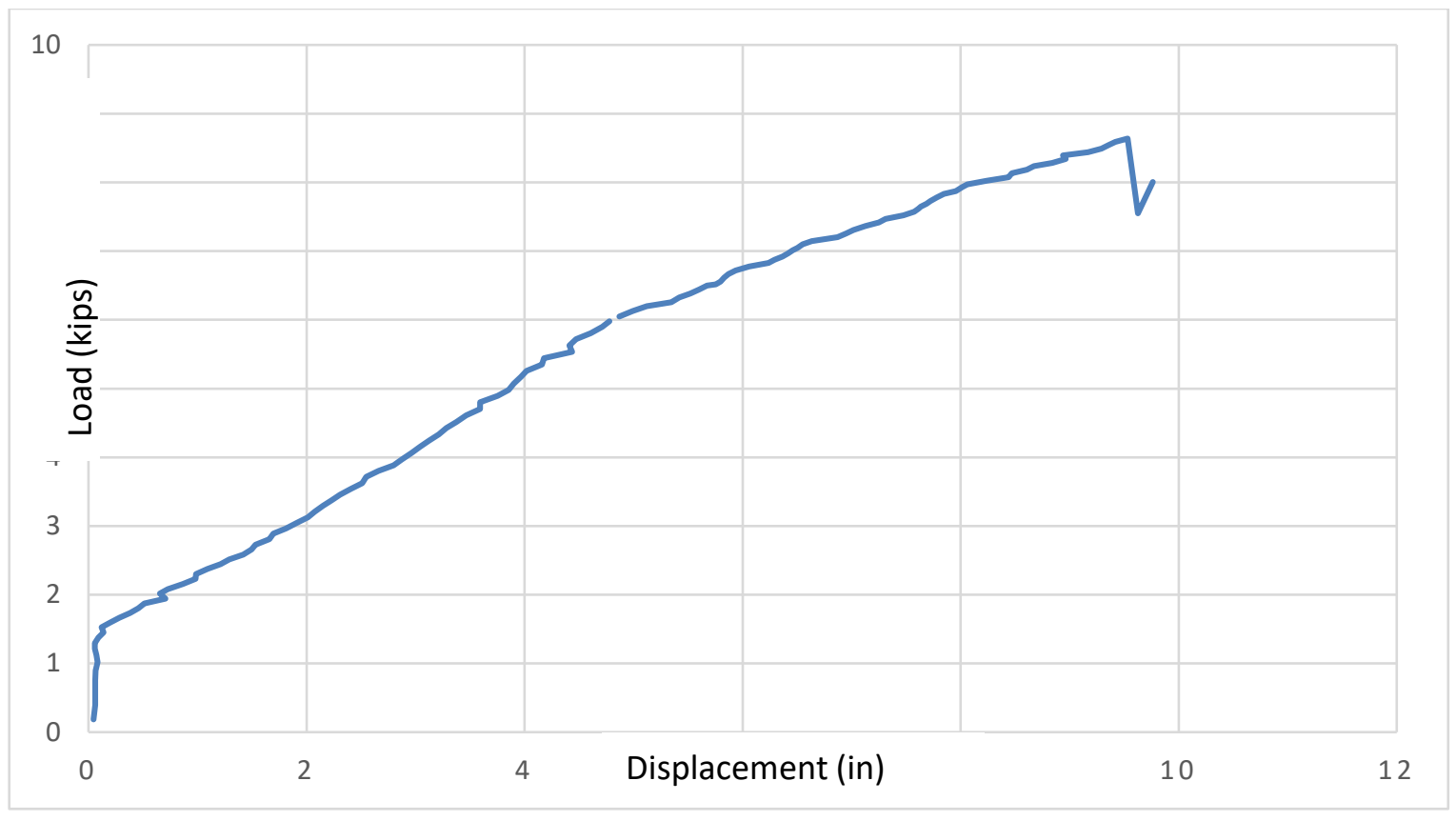

Figure 4. 10:Reinforced Concrete Load vs Deflection

Sheet pile response was observed only after the application of $1.5 \mathrm{kips}$ of load. This is because the concrete, sheet pile, and actuator require some load to become fully engaged, and this trend is seen in several trials. A linear response in terms of deflection was observed as a result of load application to the test specimen. Initially, it was believed that this test was promising. After continued research, it was acknowledged that the media of reinforced concrete created a fully fixed base for the cantilever sheet pileunlike the field scenarios with compacted sands and clays. This level of fixity does not allow for the sheet pile to react beneath the surface of the concrete, which is not realistic in terms of field response of a sheet pile surrounded by soil. Sheet piles derive their stability from active and passive pressures beneath the surface and the inability to do so in this test procedure was unacceptable Figure 4.11 compares strain data 1 foot above the concrete with results from field testing. The variation in stress- strain results (modulus) on the same exact sheet pile profile in separate conditions show that the concrete used to restrain the sheet pile at the base is much more fixed than in-situ soil. 


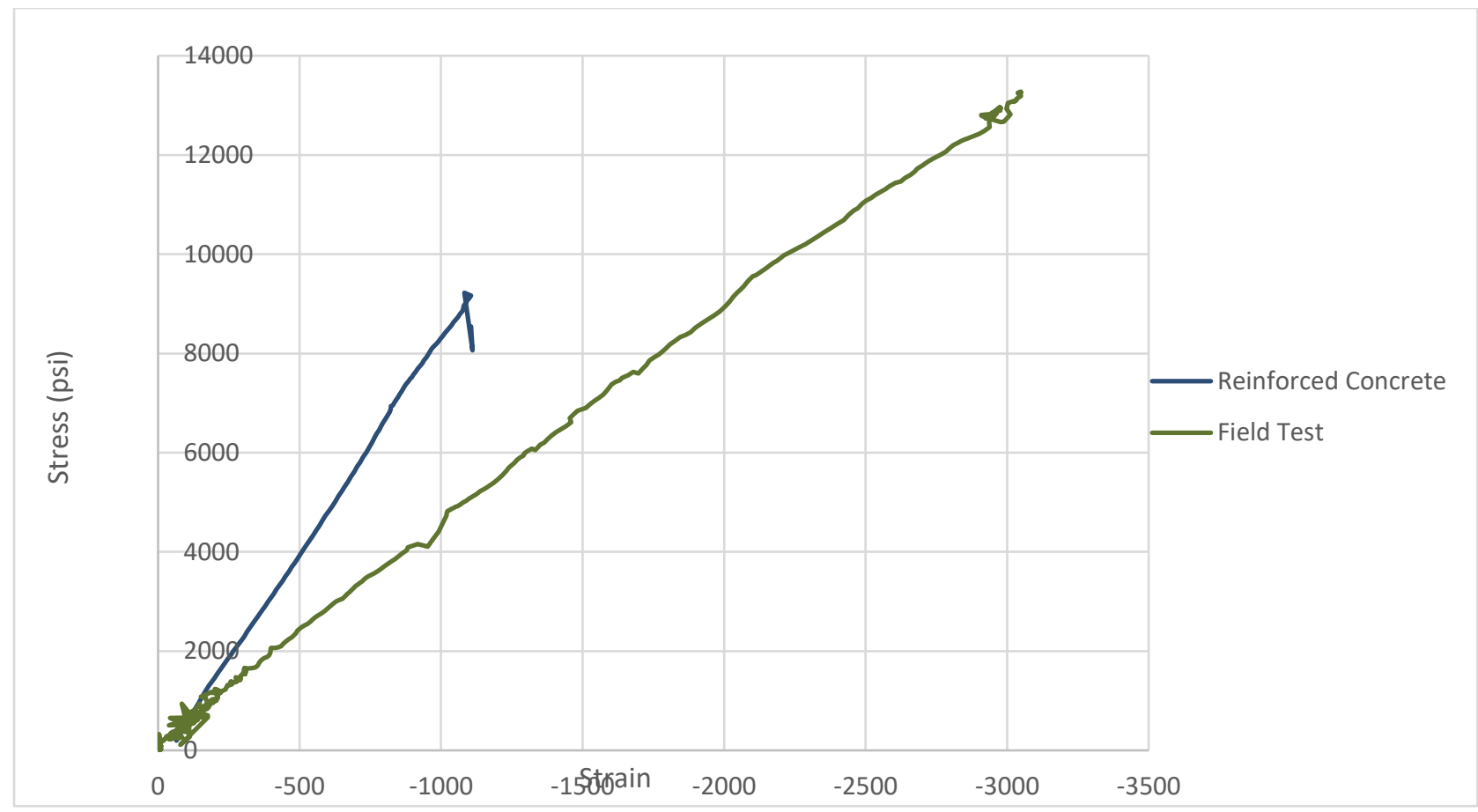

Figure 4. 11:Stress vs Strain Comparison

\subsection{Concrete Mold}

After the reinforced concrete properly resisted load but created a fixed connection that was not in agreement with expectations for this purpose, a material was needed so that fixity of the connection could be reduced to a value similar to that observed in the field. Elastomeric padding was used due to its ability to reduce stiffness at the base of the sheet pile. A reduction in fixity would allow the sheet pile to rotate about a pivot point below the dredge line as it would in field conditions. Figure 4.12 shows the mold that was used to restrain the test specimen at the bottom. Several tests were conducted inside of the mold with varying amounts of rubber padding added to decrease the fixity of the bin. Slight variations with different rubber padding in testing had negligible effects. 

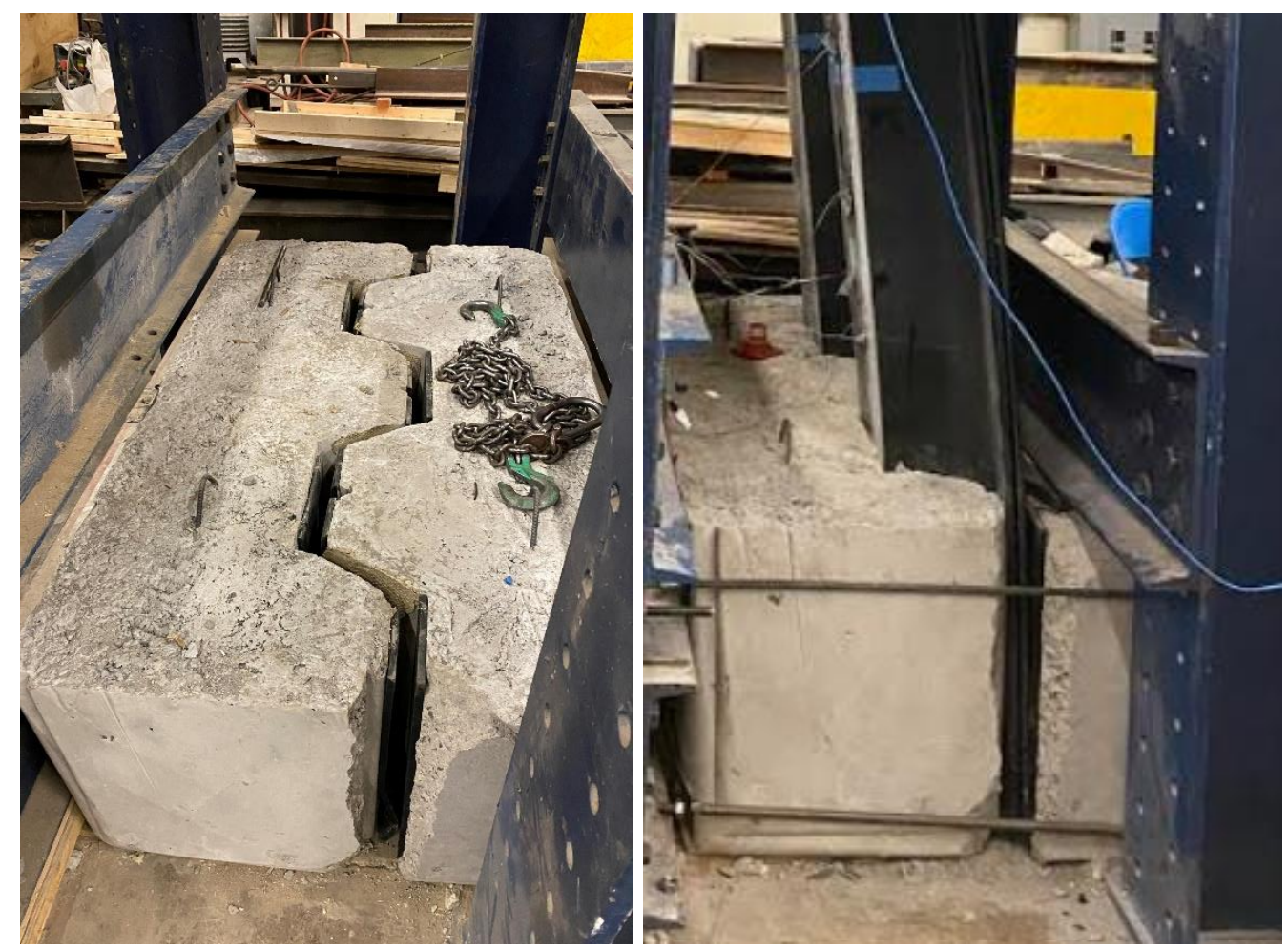

Figure 4. 12:Restraining Structure with Elastomeric Padding

Figure 4.13 documents three tests that had taken place utilizing the concrete mold. The initial slope of all tests begins with a linear nature when the initial load was applied. Between 1 to 2 kips of load application, the FRP specimen becomes engaged with the concrete mold. The FRP and concrete acted in unison as a composite section, causing each plot's load versus deflection (slope) to drastically increase from its initial trend. The slope change is representative of changes in stiffness that is not observed in sheet piles under loading conditions are needed to arrive at more realistic experimental response in relations to field response. 


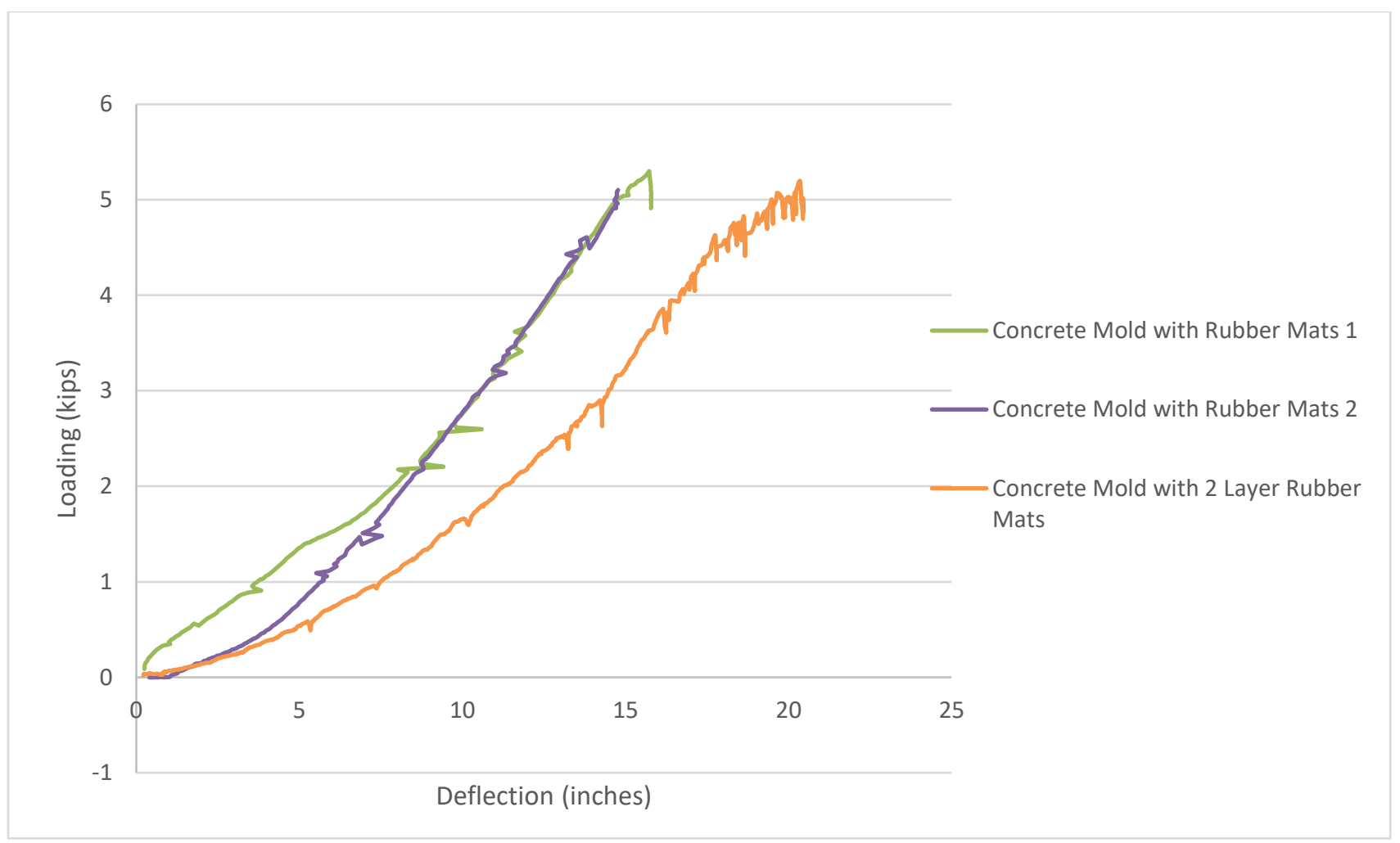

Figure 4. 13: Concrete Mold Load vs Deflection

An additional issue observed with testing conducted in the concrete mold was relatively low failure loads when compared with previous tests. The inability to completely prevent the concrete mold from moving during testing allowed for a large degree of rotation within the sheet pile. The test specimen was not able to derive any support from active or passive forces due to a low embedment depth and lack of fixity, and the load applied to the sheet pile created a bending moment of around $40 \mathrm{ft}$. kips to be exerted at the top of the concrete mold in each test. Several adjustments were made to prevent the concrete from moving during testing however, similar results were observed with each test.

\subsection{Increased Embedment Depth}

Several tests were conducted inside of the mold with varying amounts of rubber padding added to decrease the fixity of the bin. Slight variations in testing had negligible effects on the ultimate load capacity of the sheet pile system and a sufficient amount of loading to failure was never achieved with this setup. The 
slight degree of freedom offered by the mold and the 2 foot embedment depth did not provide the proper support for the sheet pile base to resist the moment induced by the applied load. Further improvements, especially an increase in embedment depth is needed to be made to arrive at more realistic experimental response in relation to field response.

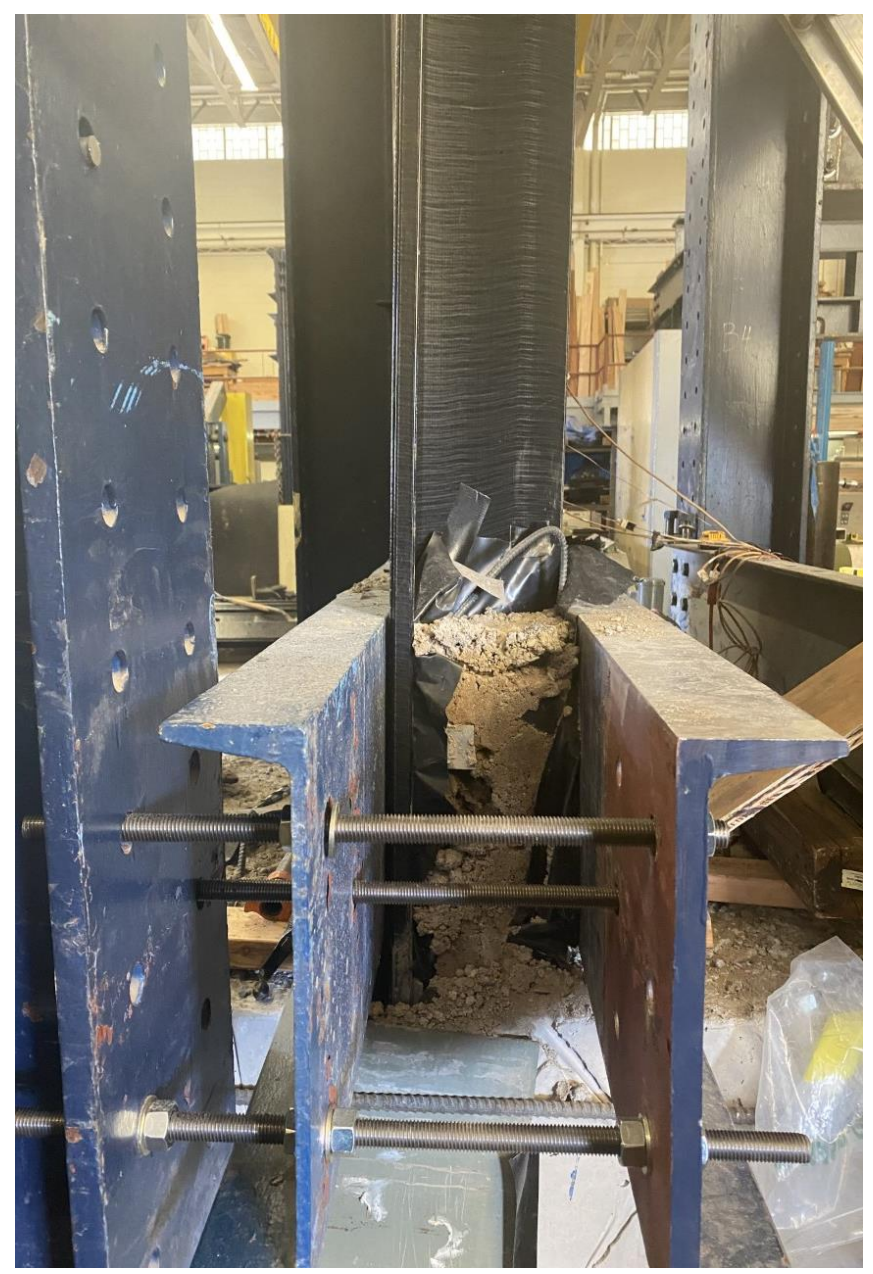

Figure 4. 14:Increased Embedment Depth

To increase embedment depth, two 15-inch-tall steel channels were placed on either side of the sheet pile, on top of the 25 inch concrete mold. This increased the embedment depth to 40 inches. Figure 4.14 shows the test fixture. The channels were bolted to the wide-flange structural columns adjacent to the fixture and remained in-place for the entire test. Concrete with added sand was used to fill the voids in between the channel and the sheet pile. This test procedure was conducted to increase the understanding of the depth 
needed to achieve sufficient loading and appropriate failure modes. Figure 4.15 shows the load versus deflection plot from two tests conducted with the channels added.

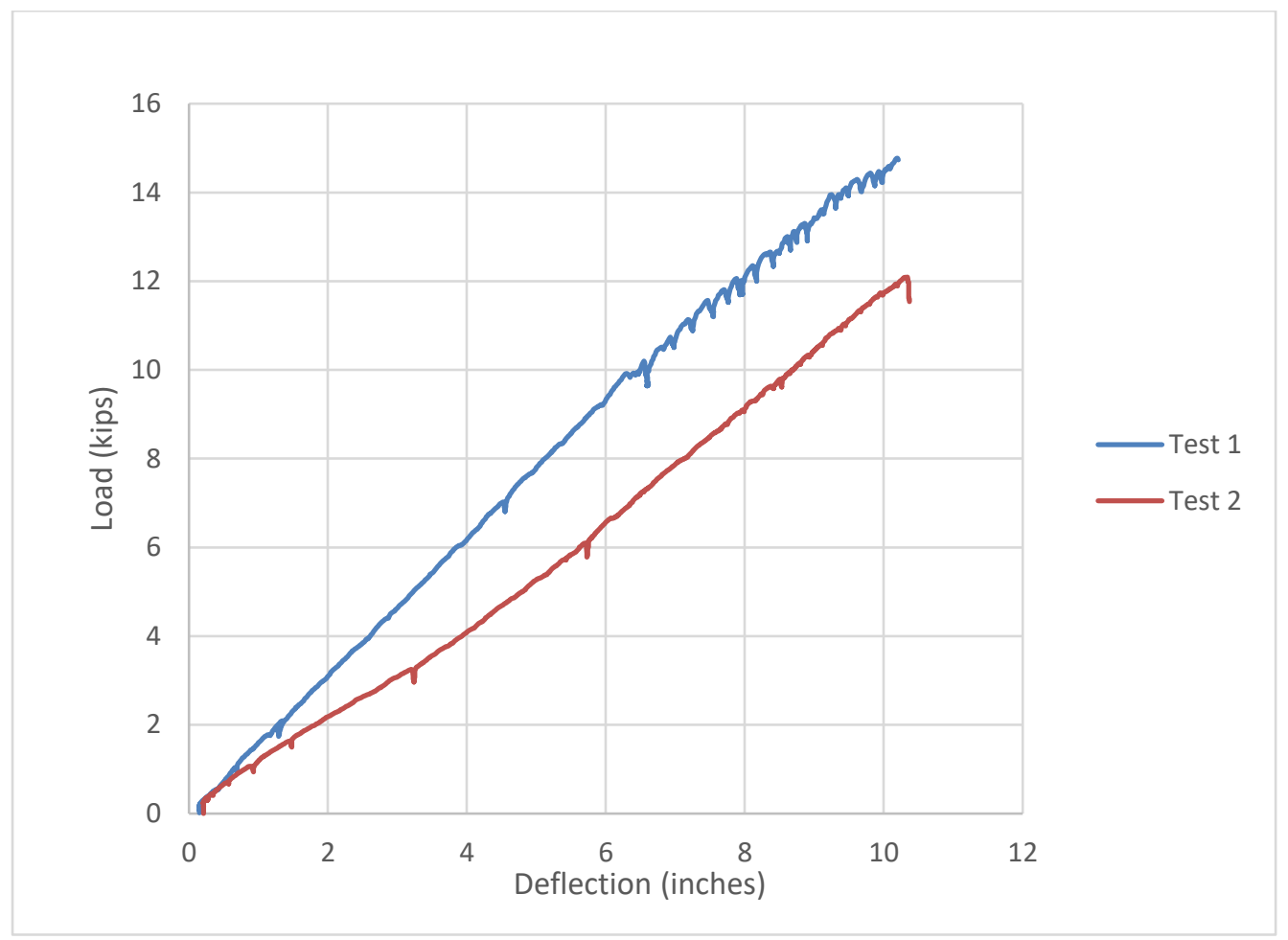

Figure 4. 15:Increased Embedment Depth Load vs Deflection

Test one was conducted with a lever arm of about 7.5 feet (distance from load application to pivot point). With the increased embedment depth, the test specimen was able to withstand 14 kips of load prior to the test specimen reaching its ultimate value. No indications of failure were observed, and the test was stopped because the winch used to apply the load was approaching its maximum capacity. In an effort to reduce the required load needed to fail the specimen, the lever arm was increased to 9.5 feet above the top of the concrete (dredge line) in Test 2. This trial was conducted without any issues arising from the testing configuration and the specimen failed at just over 12 kips of load. Strain data were measured from this test as well, but the primary focus was to understand the influence of embedment depth on the pile. The test specimen showed signs that it was beginning to buckle about the weak axis as shown in Figure 4.16.. 


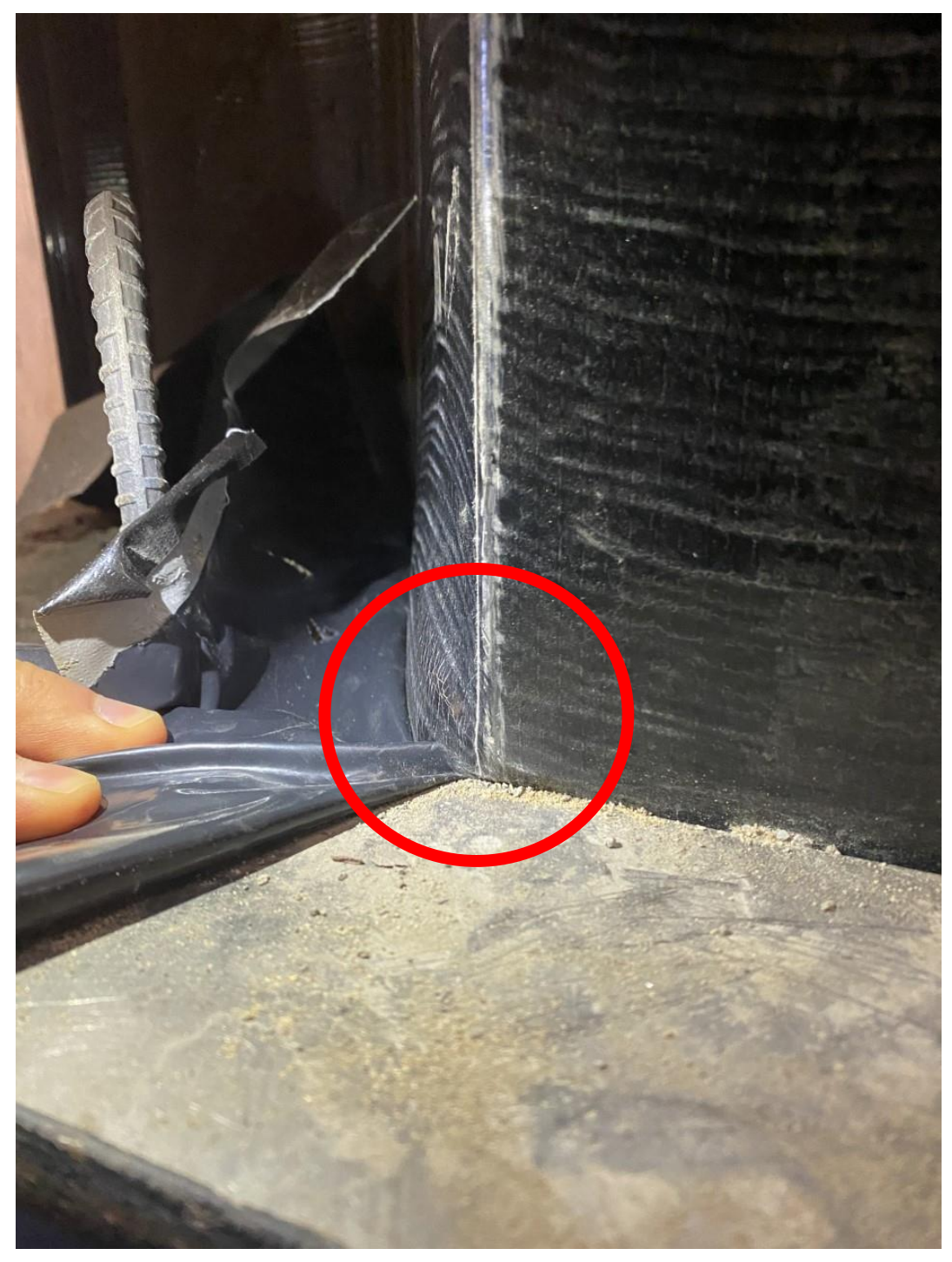

Figure 4. 16:Buckling about Weak Axis

\subsection{Final Testing Fixture}

Several factors went into the creation of the final test fixture. The fixture had to be large enough to contain a 6' wide, 8" deep sheet pile, rigid enough to resist up to 15 kips of load, while being extremely durable so that the fixture can be utilized several times. Previous tests have proven that an embedment depth greater than 24" was required to reach the desired load. Therefore, a customized steel angle (extending to a height of 3 feet) was manufactured to provide support on the compression side of the sheet pile via connecting to the lab foundation thru bolting (screw) to the lab base plates (Figure 4.17). Three steel channels were bolted 
to the adjacent structural columns to form a wall on the tension side of the sheet pile. A $1 / 2$ " thick sheet of metal was welded to the channels to create a continuous and much stiffer (shear) wall. (Figure 4.18). The bin created a rectangle with a length of $96 "$ and a width of $36 "$ " With nearly fixed end supports along the length being accounted for with the fabricated steel sections, the thickness of the rectangular mold was enclosed with wooden panels. Once fully enclosed, a sheet pile section can be placed in the center of this rectangle and fill material can encapsulate it. The fill material used consisted of 2 parts sand, 0.75 part 3000 psi concrete. This material provided adequate resistance until sheet pile failure and did not disintegrate at any point in time.

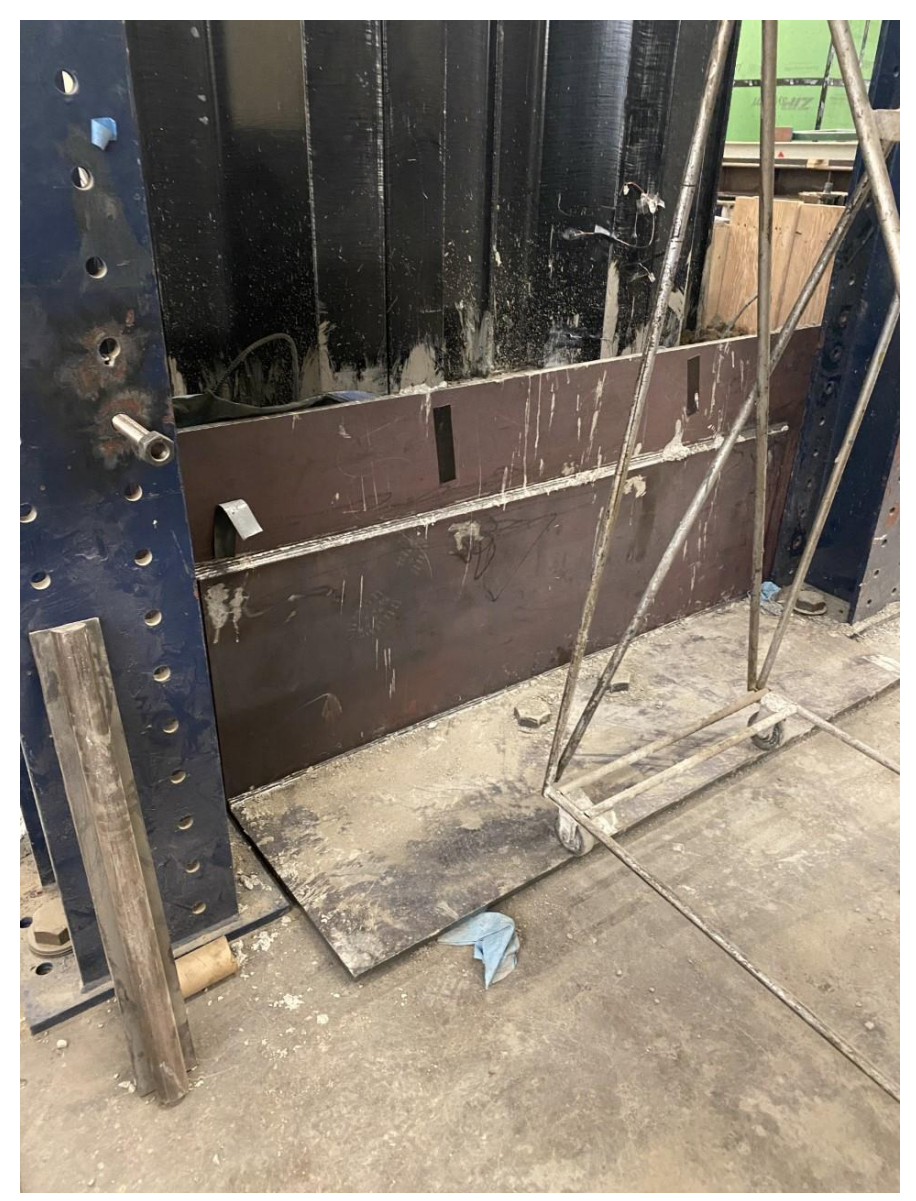

Figure 4. 17:Steel Testing Compression Side 


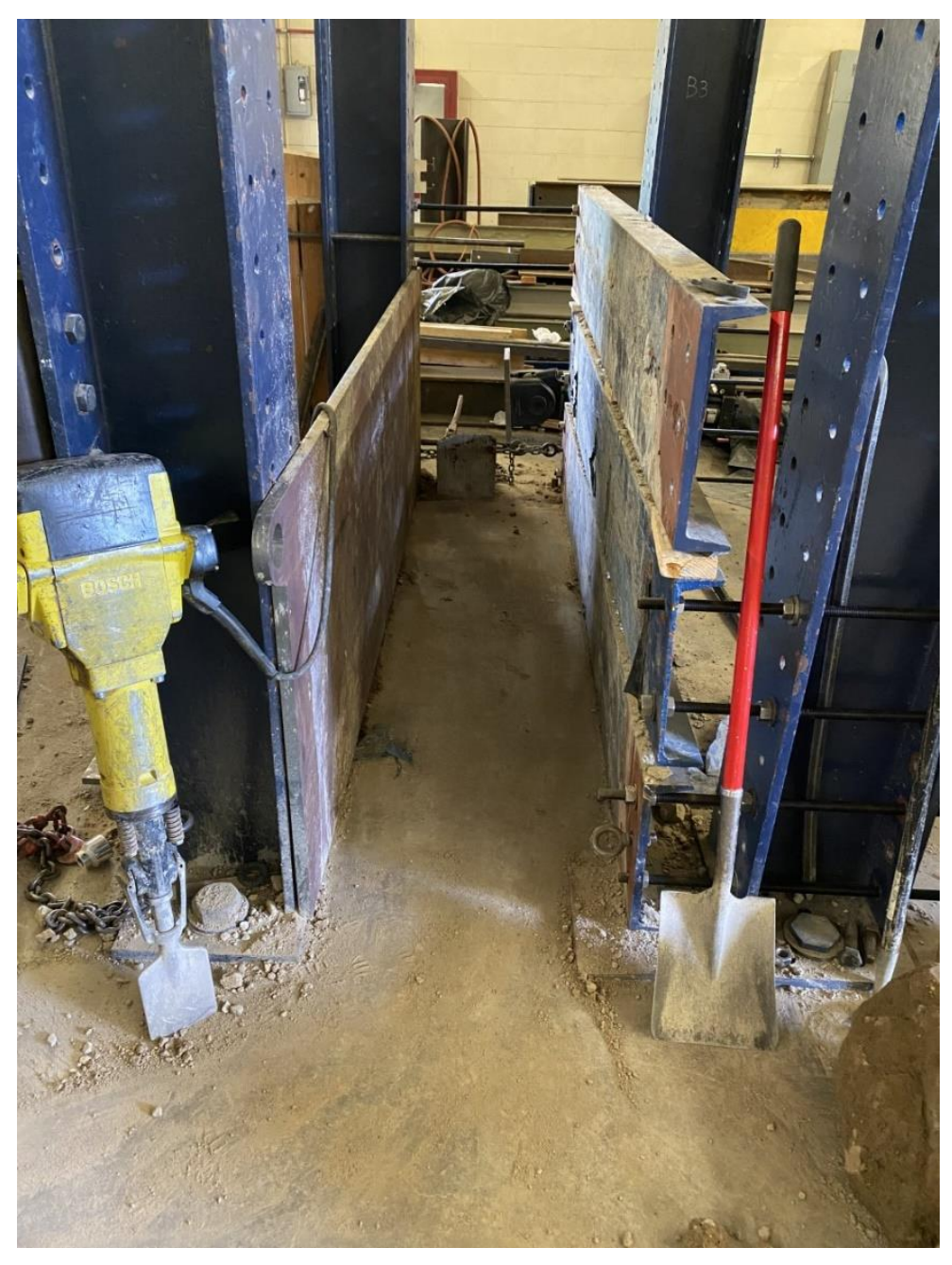

Figure 4. 18:Testing Bin Side Profile

A total of four constructed Series 1580 sheet piles provided by Creative Composites Group were tested in the final test setup configuration. The load and deflection results are displayed in Figure 4.19. There were no changes to test procedure during testing except for the height at which load was applied. Three of the sheet pile specimens constructed had a total height of 13 feet. The wale sections were attached so that load was applied at a height of 12 feet 6 inches from the bottom of the sheet pile. One set of sheet pile segments received from the manufacturer had a total height of 12 feet. Test 4 had load applied at 11 feet 6 inches ( 1 foot less than others). 


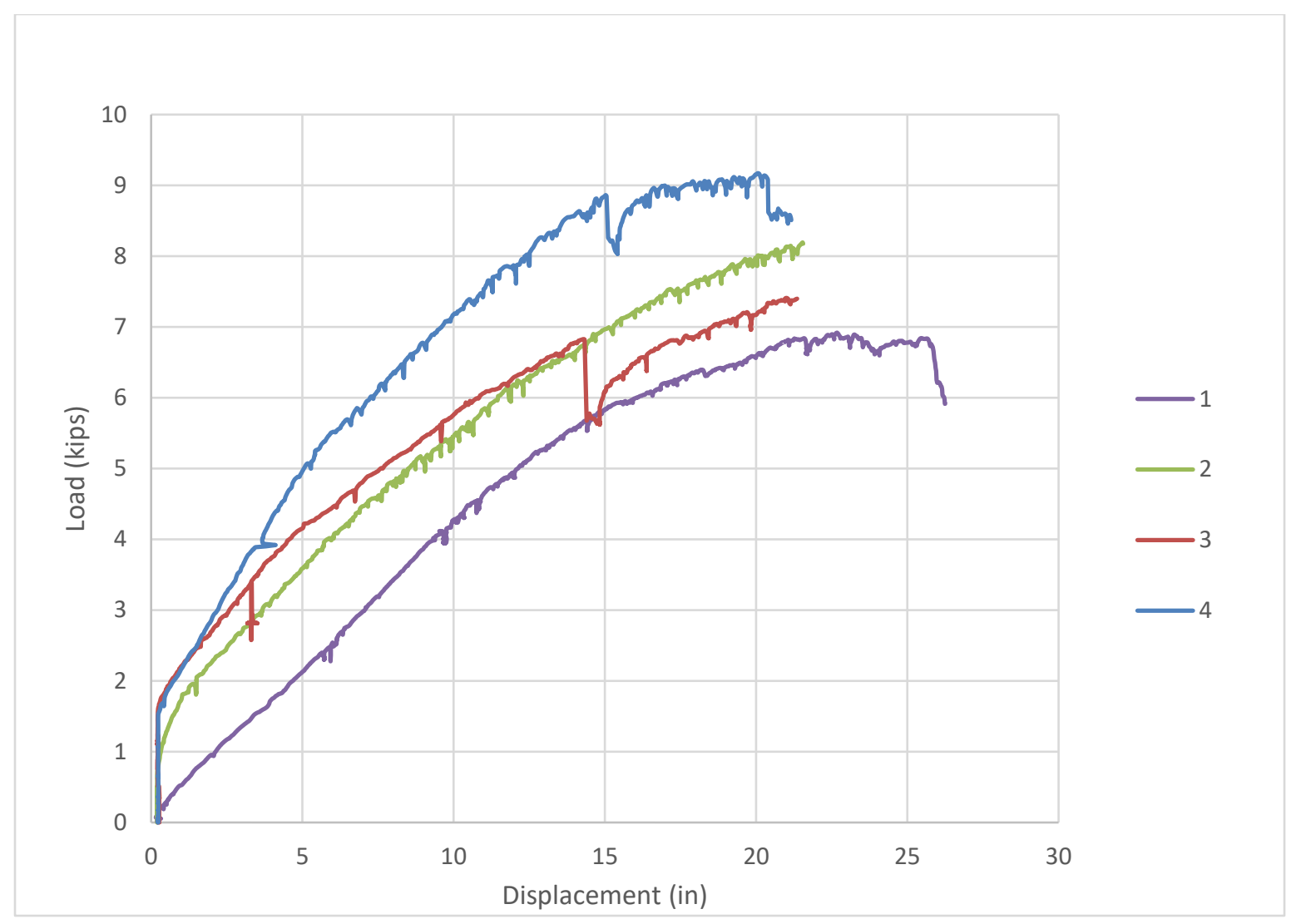

Figure 4. 19:Final Test Configuration Load vs Deflection

Tests 1, 2, and 3 projected similar behavior and results in terms of load and deflection rate with a lever arm of 12.5 feet. Test 4 differed slightly as a result of a decreased lever arm (11.5 feet). Figure 4.21 shows the strain data from above the dredge line. Tests 2, 3, and 4 required between 1 and 2 kips of load to be applied prior to any pile response. Test 1 responded immediately to load application. This is the case because more force was applied prior to starting the test than with other experiments Figure 4.20 shows a version of the load vs. displacement plot where all values have been adjusted so that $(0,0)$ is the initial point when a response is measured. 


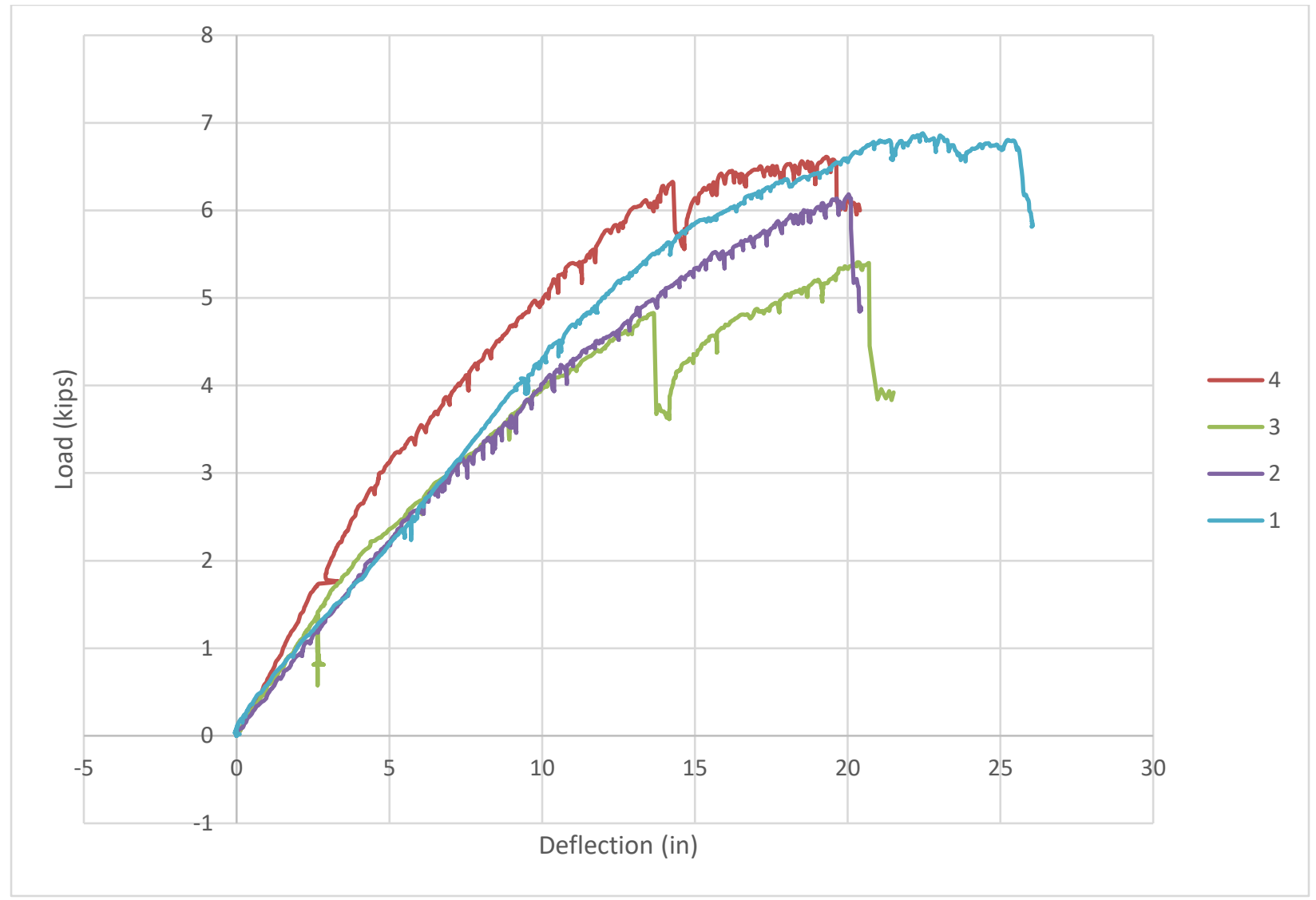

Figure 4. 20:Corrected Load vs Deflection

The results from Figure 4.20 clearly show the degree of similarity in load-deflection response between each test. Strain data shown in Figure 4.21 and Figure 4.22 provide additional evidence of the consistency that was observed with each of the final tests. 


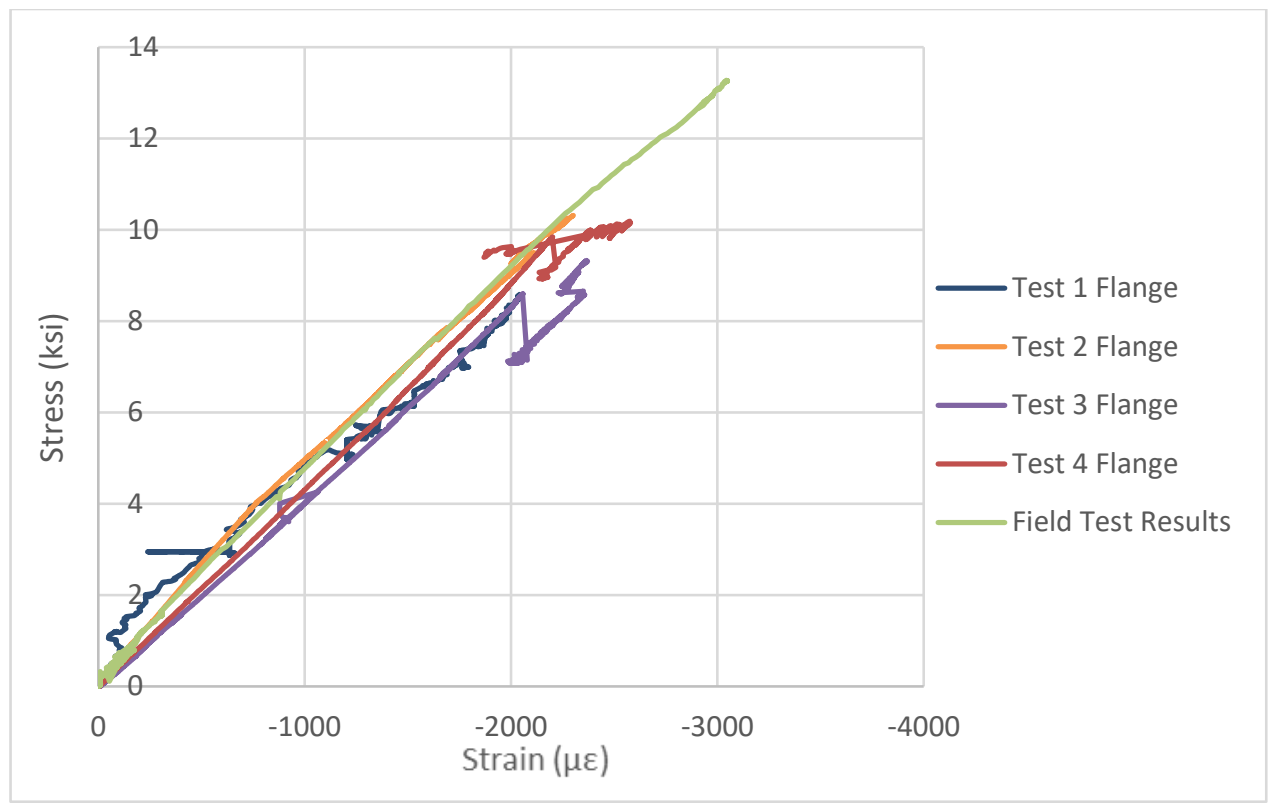

Figure 4. 21:Flange Strain Comparison

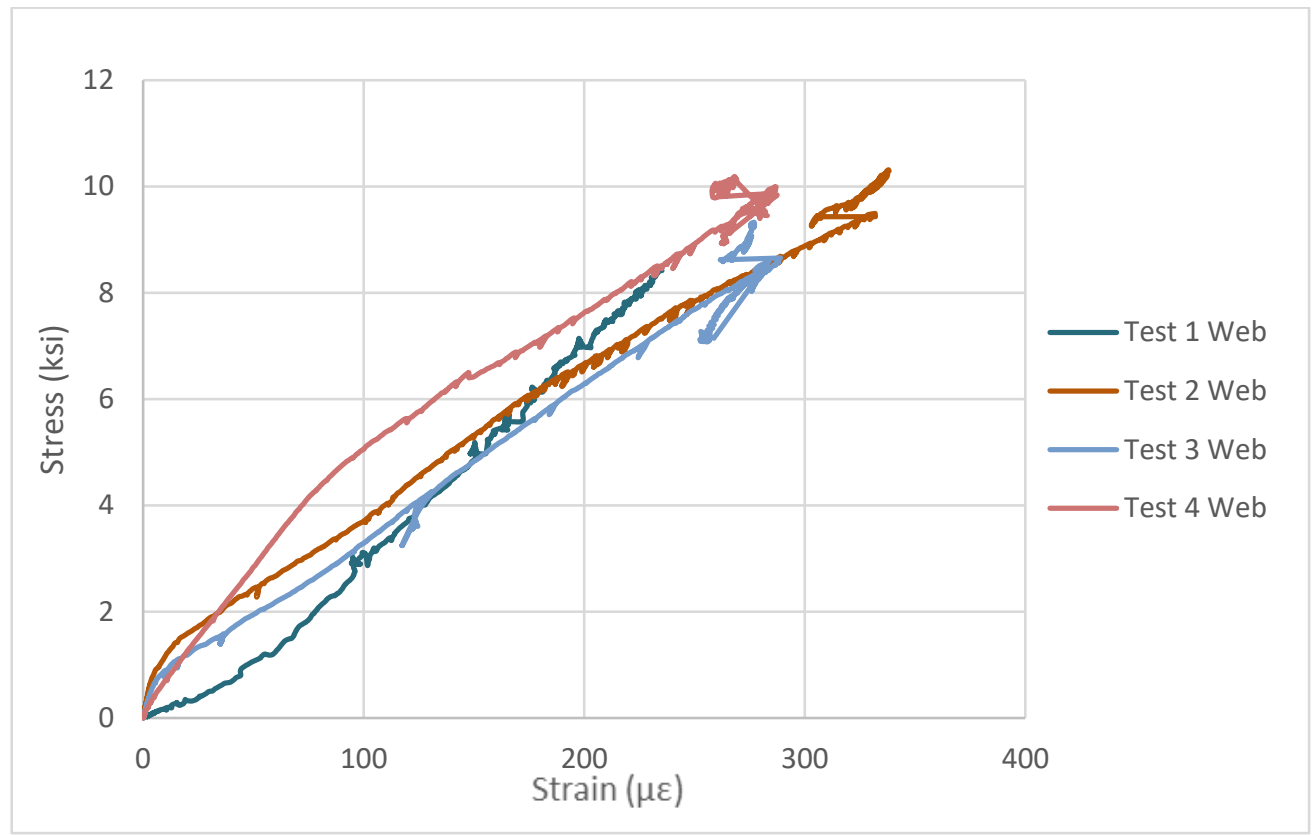

Figure 4. 22Web Strain Comparison

Figure 4.21 and Figure 4.22 show the longitudinal strains (compression zone) occurring on interior flange and web sections for each of the four trials. Figure 4.21 indicates field testing stress-strain data from the same location. The gages were all placed 1 foot above the dredge line surface. This location indicates the influence that the embedment material has on the test specimen. A slope in the stress-strain curve that is 
similar to the field testing results signifies that the sheet pile was responding as it would in field conditions without extreme amounts of influence from embedment material. Figure 4.23 an image of failure from Test 3.

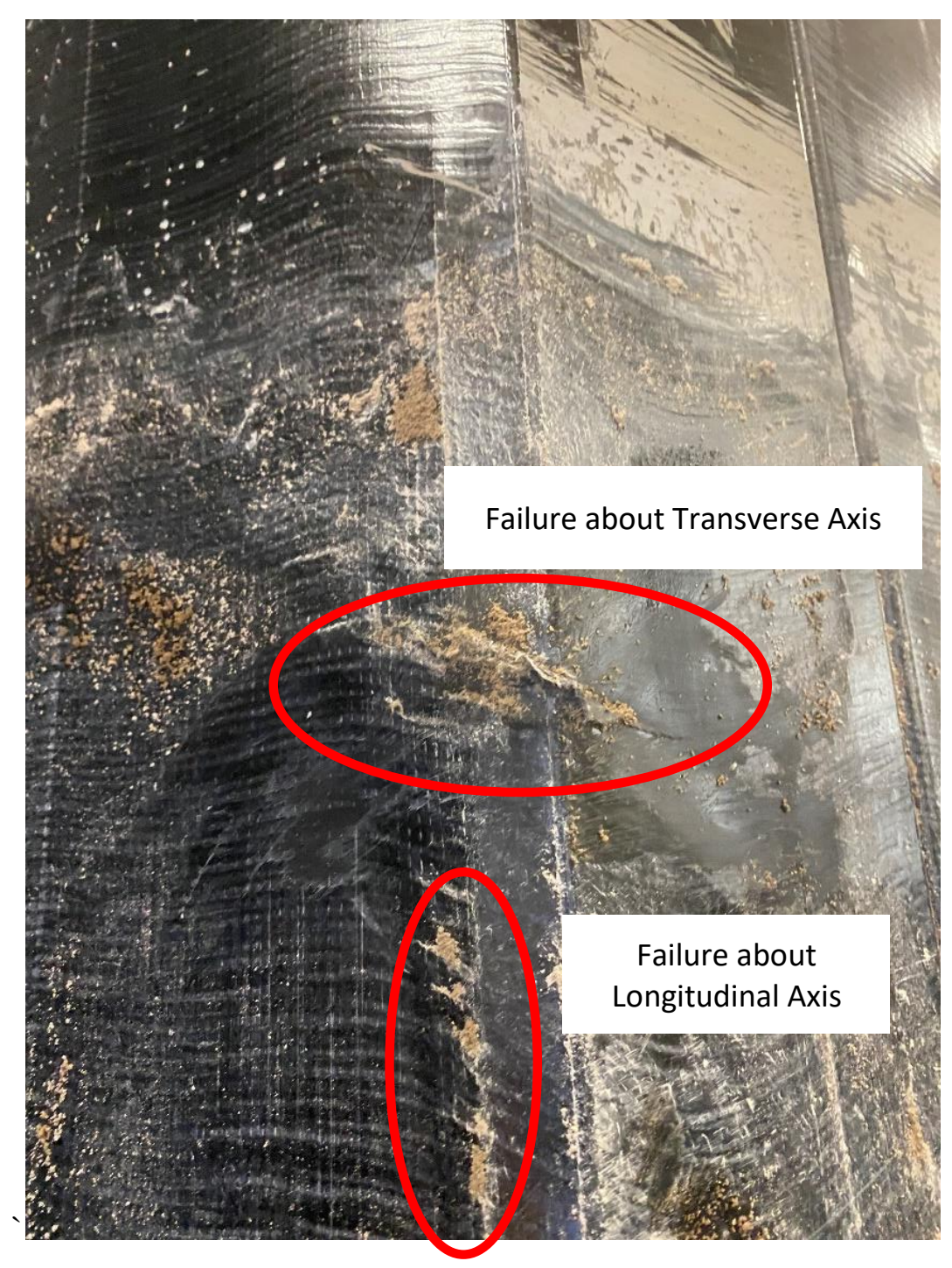

Figure 4. 23:Sheet Pile Failure

Although Figure 4.23 is from Test 3, it is representative of Tests 1 to Test 4's failure modes. Each experiment showed clear signs of failure about the weak axis of the pile as well as longitudinal separation at lower depths. An example of this was documented in Figure 4.23, at the bottom of the image. Fibers separated creating a rupture in the material, parallel to the longitudinal axis. The low transverse modulus is the cause of this failure, although if it was reinforced, failure would still occur within the longitudinal axis (also seen in Figure 4.23). 


\subsection{Variability in Sheet Pile Cross Section}

The moment capacity test for FRP sheet piles was designed to compare the maximum moment capacity of different sheet piles to one another and obtain the maximum load that can be applied to a sheet pile. In order to achieve the goals set for the test, new specimens had to be tested within the confines of the testing configuration. Two sheet pile profiles, separate from the Series 1580 Seawall Profile sheet pile were tested. The test denoted as V-Test 1 features 4 sections of the EverComp 26.1 sheet pile profile (Figure 4.24) joined together. This sheet pile is very similar to the Series 1580 Seawall Profile sheet pile tested in previous tests and the provided dimensions are shown in Table 4.1. The test denoted as V-Test 2 is comprised of two EverComp 47.5 sections (Figure 4.25).

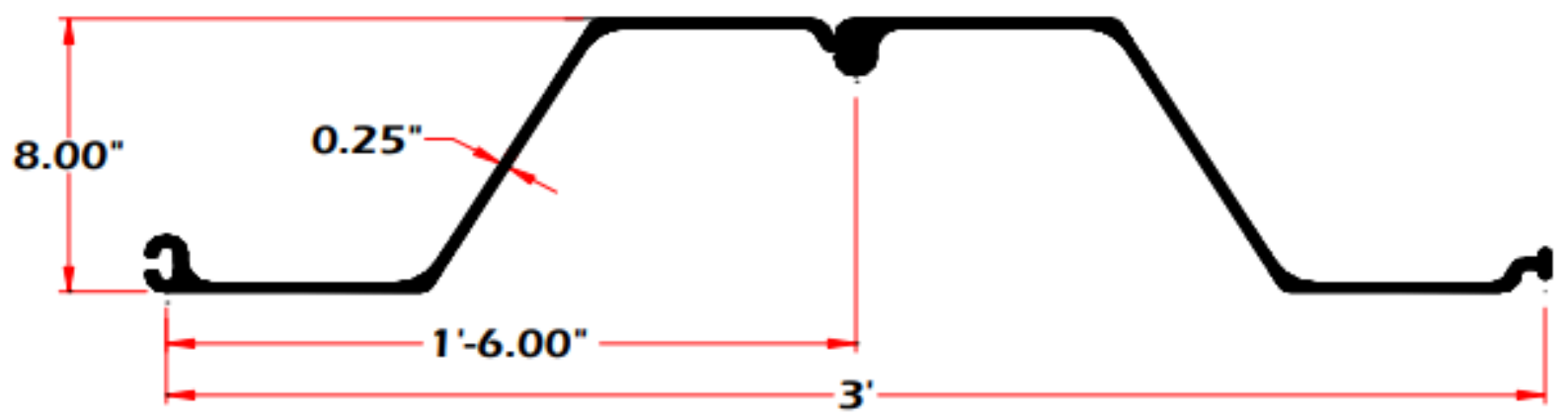

Figure 4. 24:EverComp 26.1 Sheet Pile Cross Section

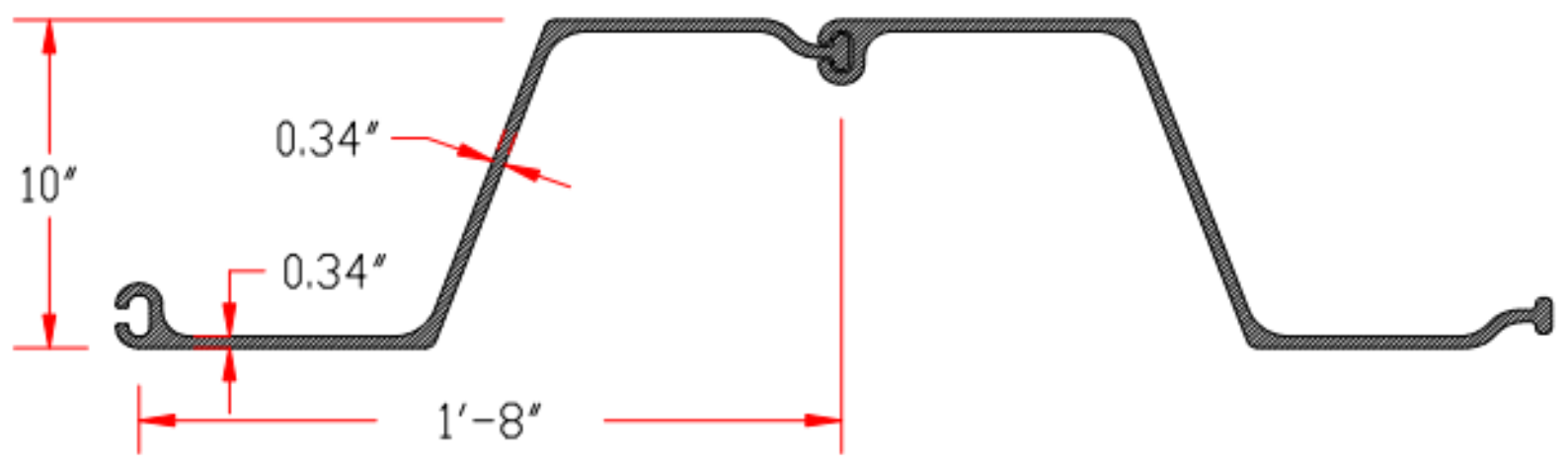

Figure 4. 25:EverComp 47.5 Sheet Pile Cross Section 
Table 4. 1: EverComp Sheet Pile Properties

\begin{tabular}{|c|c|c|}
\hline Property & V-Test 1 & V-Test 2 \\
\hline Longitudinal Modulus (psi) & $4.2 \times 10^{6}$ & $3.6 \times 10^{6}$ \\
\hline Transverse Modulus (psi) & $1.7 \times 10^{6}$ & $1.4 \times 10^{6}$ \\
\hline Longitudinal I $\left(\frac{\mathrm{in}^{4}}{\mathrm{ft}}\right)$ & 52 & 114 \\
\hline $\mathrm{c}$ (in) & 4 & 5 \\
\hline
\end{tabular}

\subsubsection{V-Test 1}

The first test conducted in the constructed test apparatus (V-Test 1) was nearly identical to the sheet pile from previous tests. The pile was pulled from a height of 13 feet and encapsulated in 3 feet of the sandconcrete media. Figure 4.26 shows the specimen prior to testing. The same test procedure was followed and results are shown in Figure 4.27 and Figure 4.28.

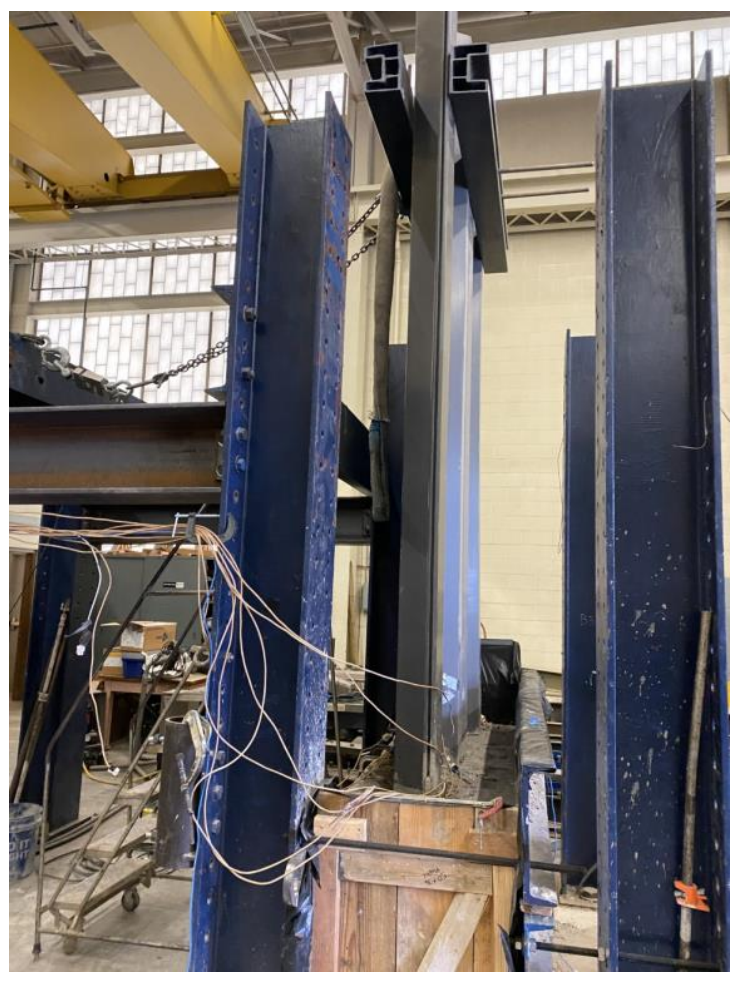

Figure 4. 26:V-Test 1 


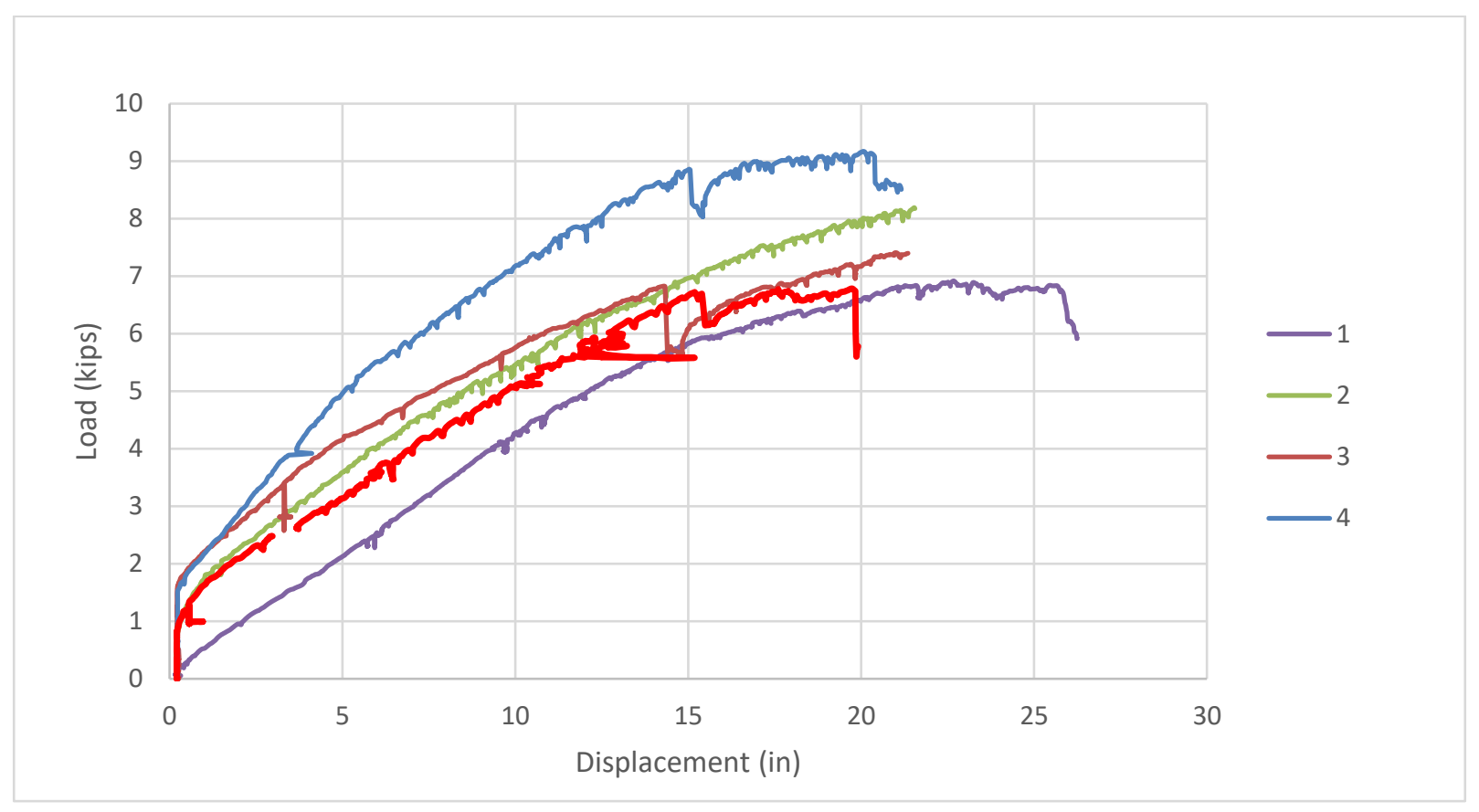

Figure 4. 27:Load vs Displacement Comparison

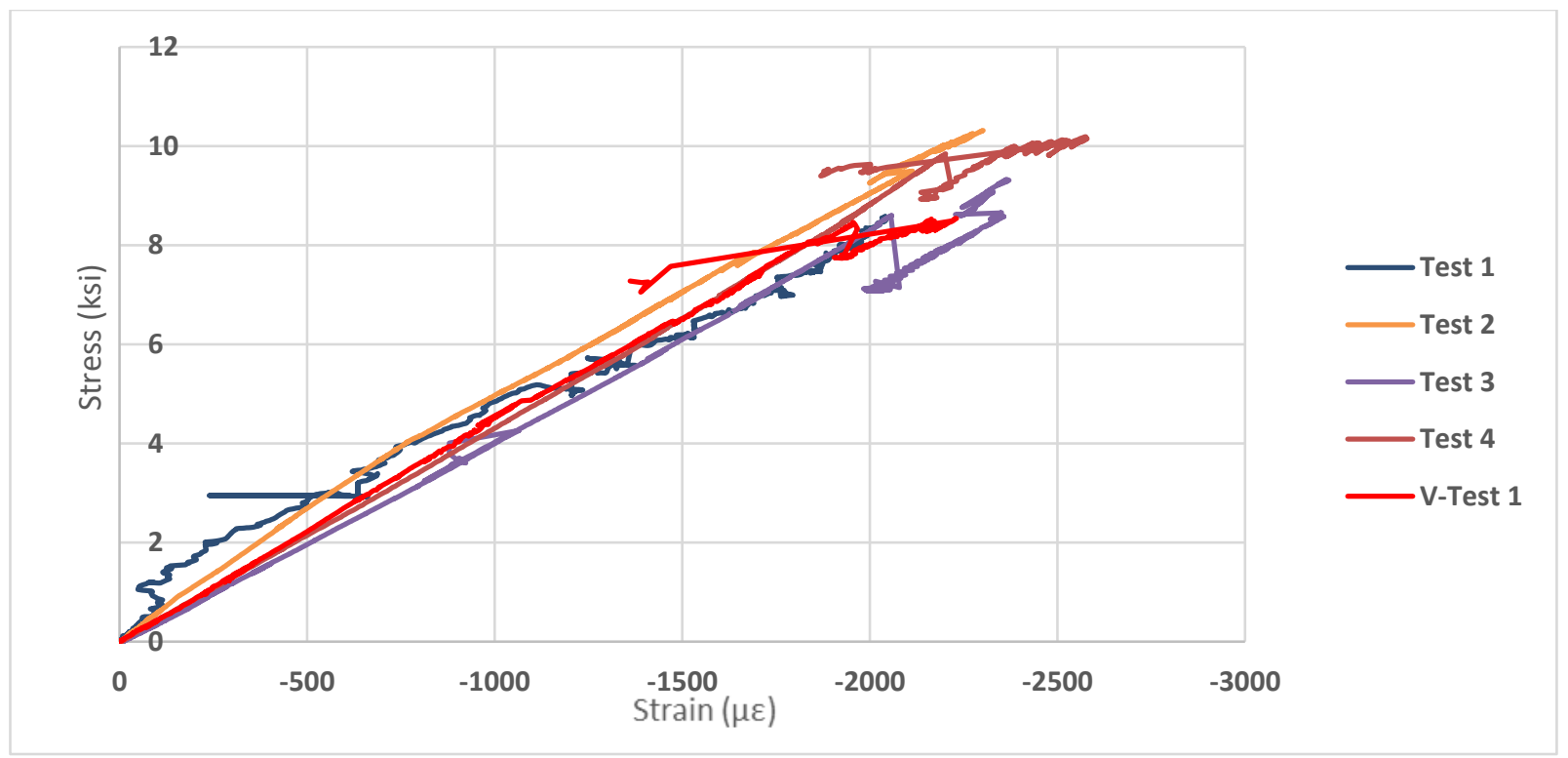

Figure 4. 28:Longitudinal Flange Strain Comparison

Figure 4.27 shows a comparison of load and displacement of the four Series 1580 sheet pile specimens as well as the V-Test 1 specimen. Testing revealed that the similar properties led to similar results both above the mudline (strain) and load capacity. Figure 4.29 shows the failure of V-Test 1's specimen. 


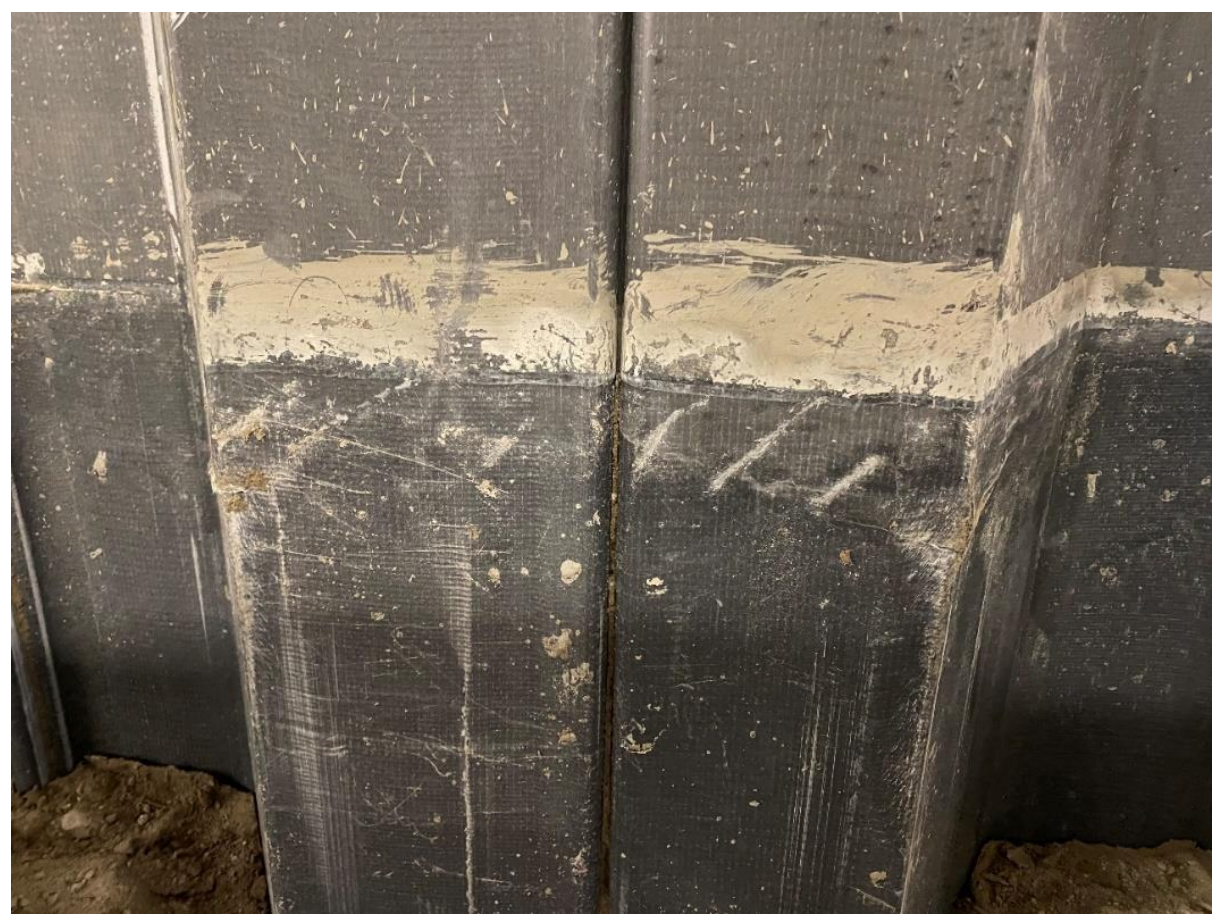

Figure 4. 29:V-Test 1 Failure

The failure documented in Figure 4.29 was similar to those seen in Tests 1-4. The pile has shown that the low transverse modulus cannot withstand the bending moment exerted on it from soil reaction, and is consistently the initial form of failure.

\subsubsection{V-Test 2}

The second of the two sheet piles from a different manufacturer was tested in the same fashion as all of the other specimens. This sheet pile however, featured only two segments. The segments (Figure 4.25) were the first specimens to feature a considerable amount of variability in material properties. Figure 4.30 shows an image of the V-Test 2 specimen under load and Figure 4.31 shows the resulting load vs displacement graph from the experiment. 


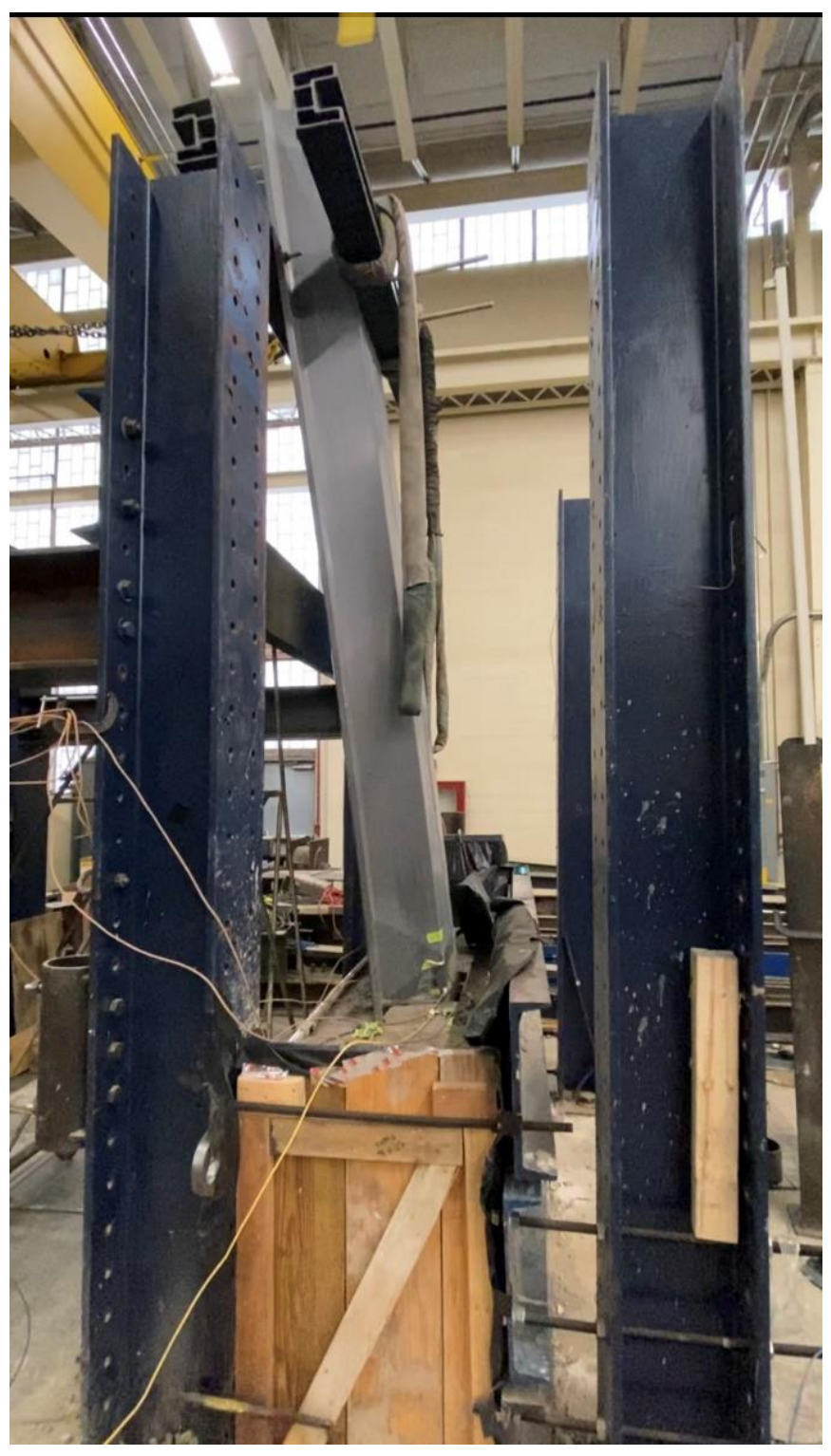

Figure 4. 30:V-Test 2 


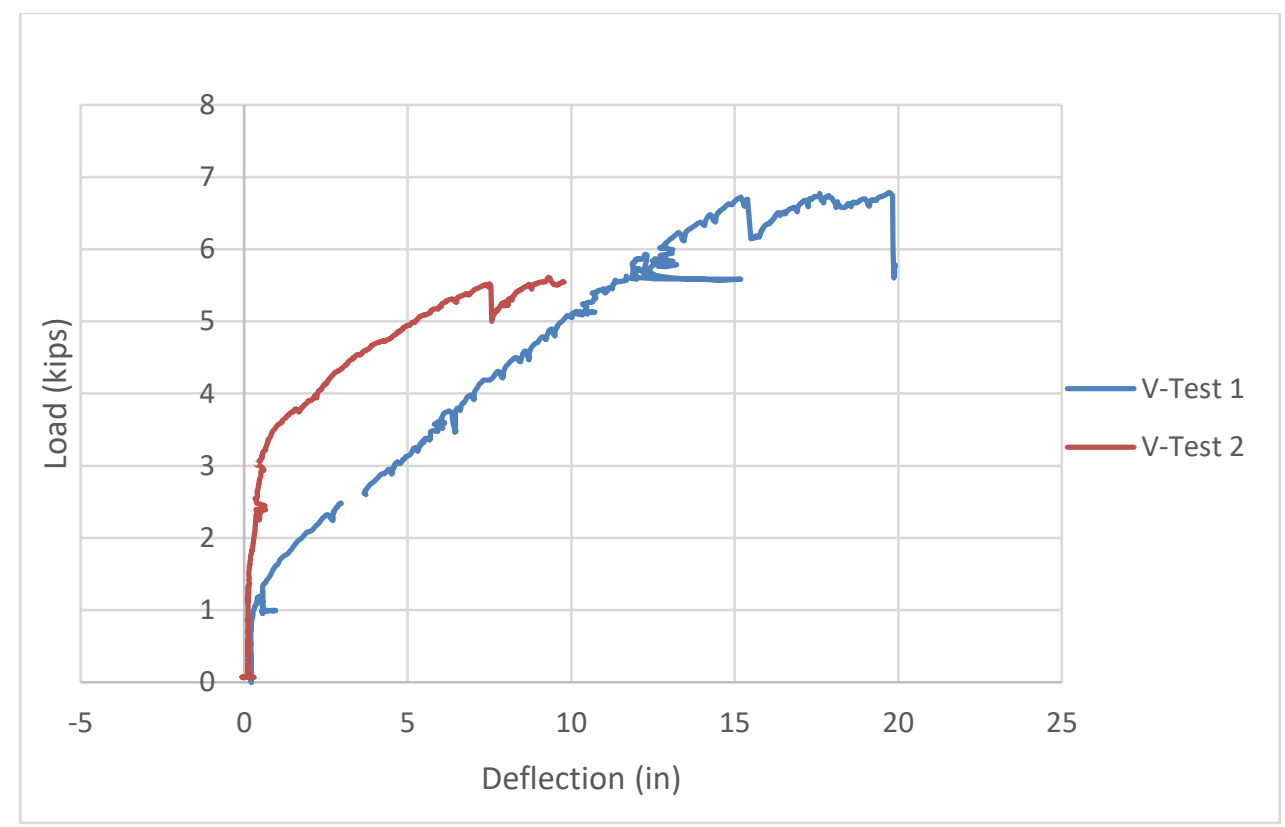

Figure 4. 31:V-Test Load vs Deflection Comparison

Figure 4.31 compares the load and displacement results from the two V-Tests that were conducted. The increase in flexural rigidity from V-Test 1 to V-Test 2 is apparent in the graphs. Nearly 3 kips of load are required to displace V-Test 2. Figure 4.32 compares the strain (horizontal direction) at 1 foot above the dredge line from V-Test 1 and V-Test 2.

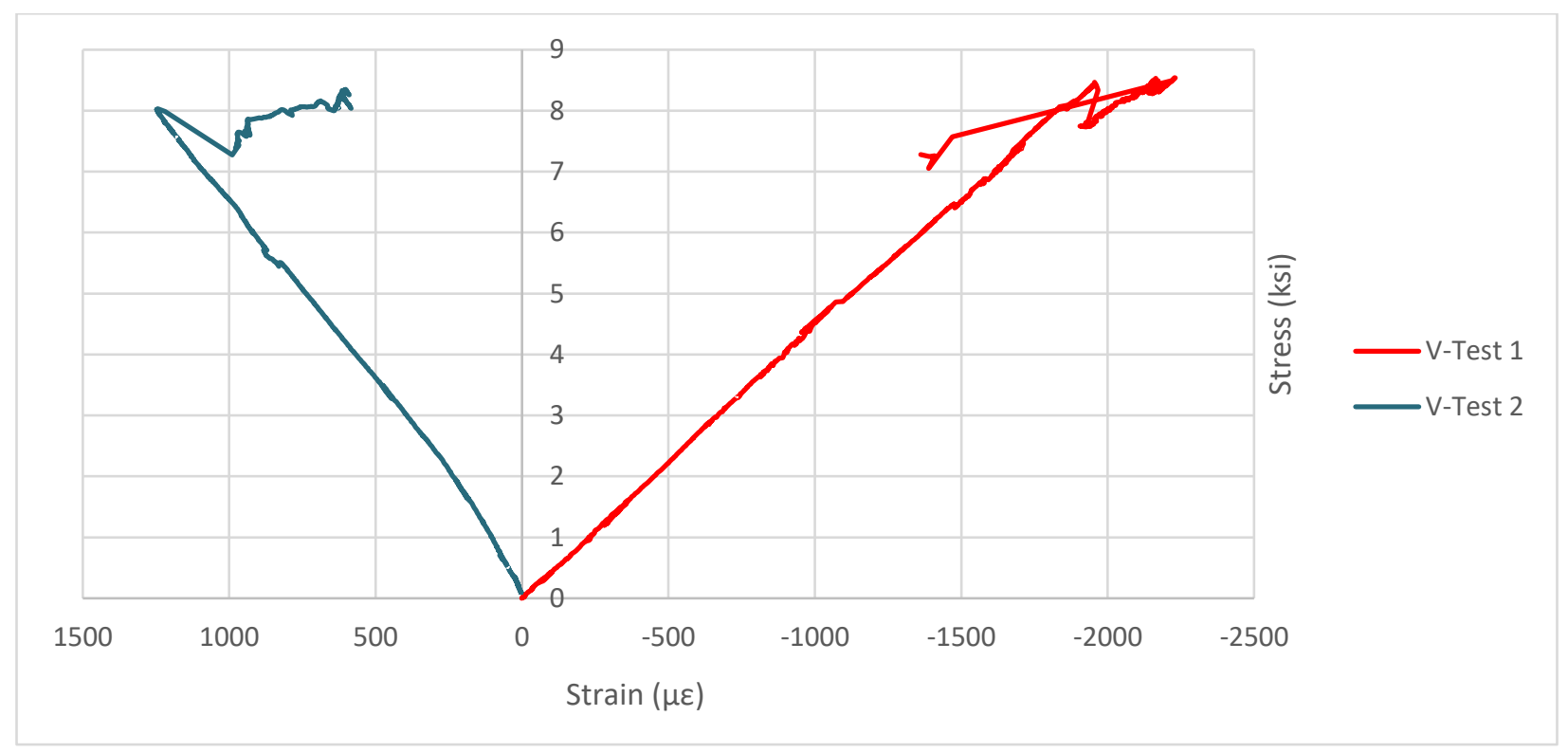

Figure 4. 32:Longitudinal Strain 1-foot Above Dredge Line

The gage responses under loading used in V-Test 1 and V-Test 2 are displayed in Figure 4.32 are both placed on a flange, on the compression side of the pile, but on separate sides of the neutral axis. The differed 
location with respect to the neutral axis leads to opposing signage, but the values recorded are still useful. Less strain was exhibited on V-Test 2 and the pile showed a slightly higher slope on the stress-strain curve. Figure 4.33 and Figure 4.34 show images of failures that had occurred on V-Test 2's specimen.

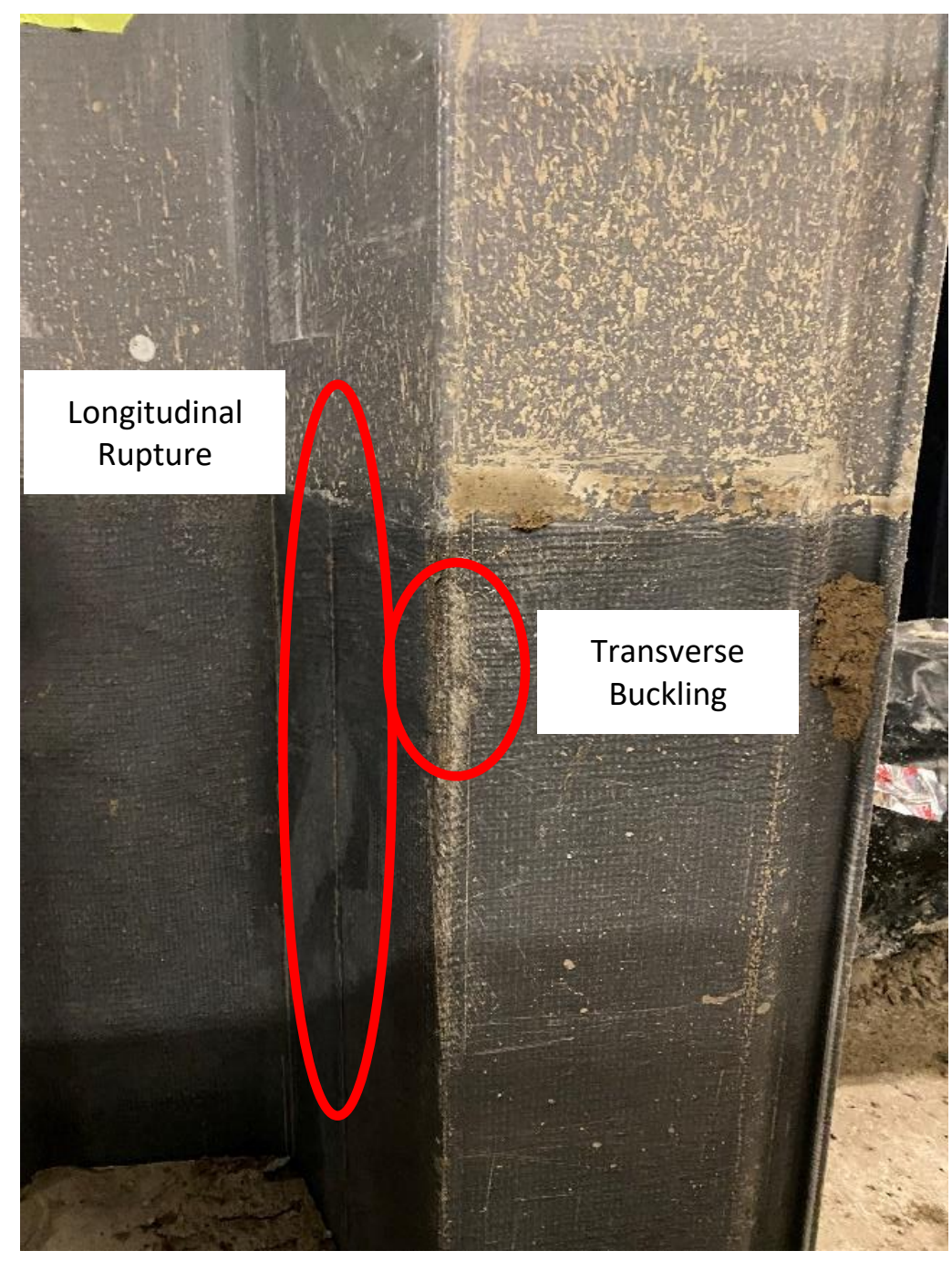

Figure 4. 33:V-Test 2 Horizontal and Vertical Failure 


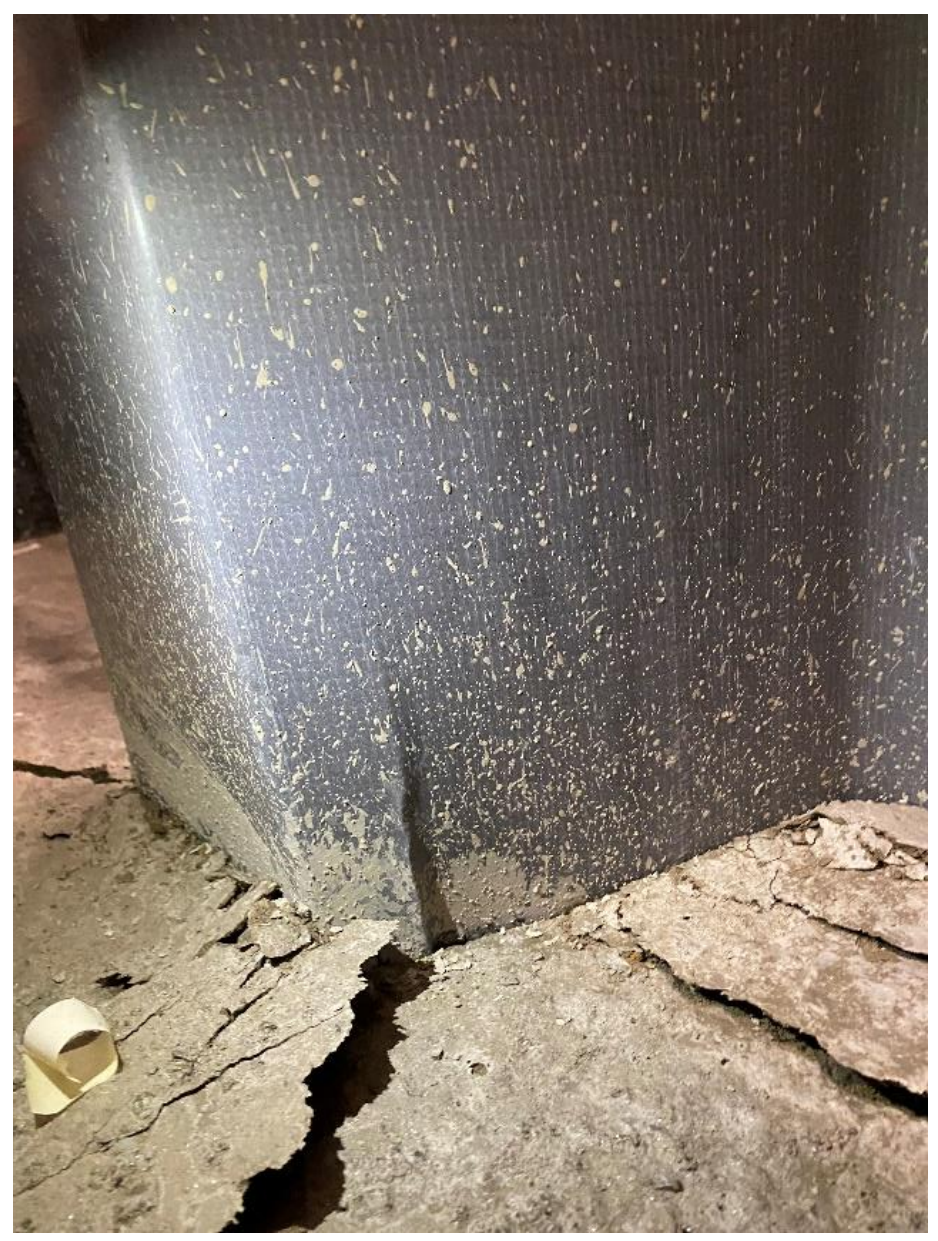

Figure 4. 34:V-Test 2 Stress Concentration

\subsection{Summary}

Following several iterations of testing, a final configuration has been established and proven consistent. Over the course of experimentation, a few major points continued to arise:

- An embedment material with sufficient shear strength must be established. Load applied to the sheet pile generated large reactionary forces at the base of the pile, if the media surrounding the test specimen does not have adequate shear strength, the sheet pile will never reach a load in which it will fail.

- Different degrees of fixity occurred as a result of embedment materials with different properties. Sheet piles derive their stability from pressures generated within the soil when horizontal force is applied, and they require a degree of freedom to deflect as shown in the diagram that is presented in Figure 2.4. This was especially apparent in Section 4.3, where the test specimen was embedded 
in reinforced concrete. The concrete had exceptionally high compressive strength (4000 psi) when compared with other materials and showed no signs of cracking after 8.6 kips of load was applied to a test specimenFigure 4.35 shows the stress-strain plot of tests from the final testing configuration, field testing results, and reinforced concrete test.

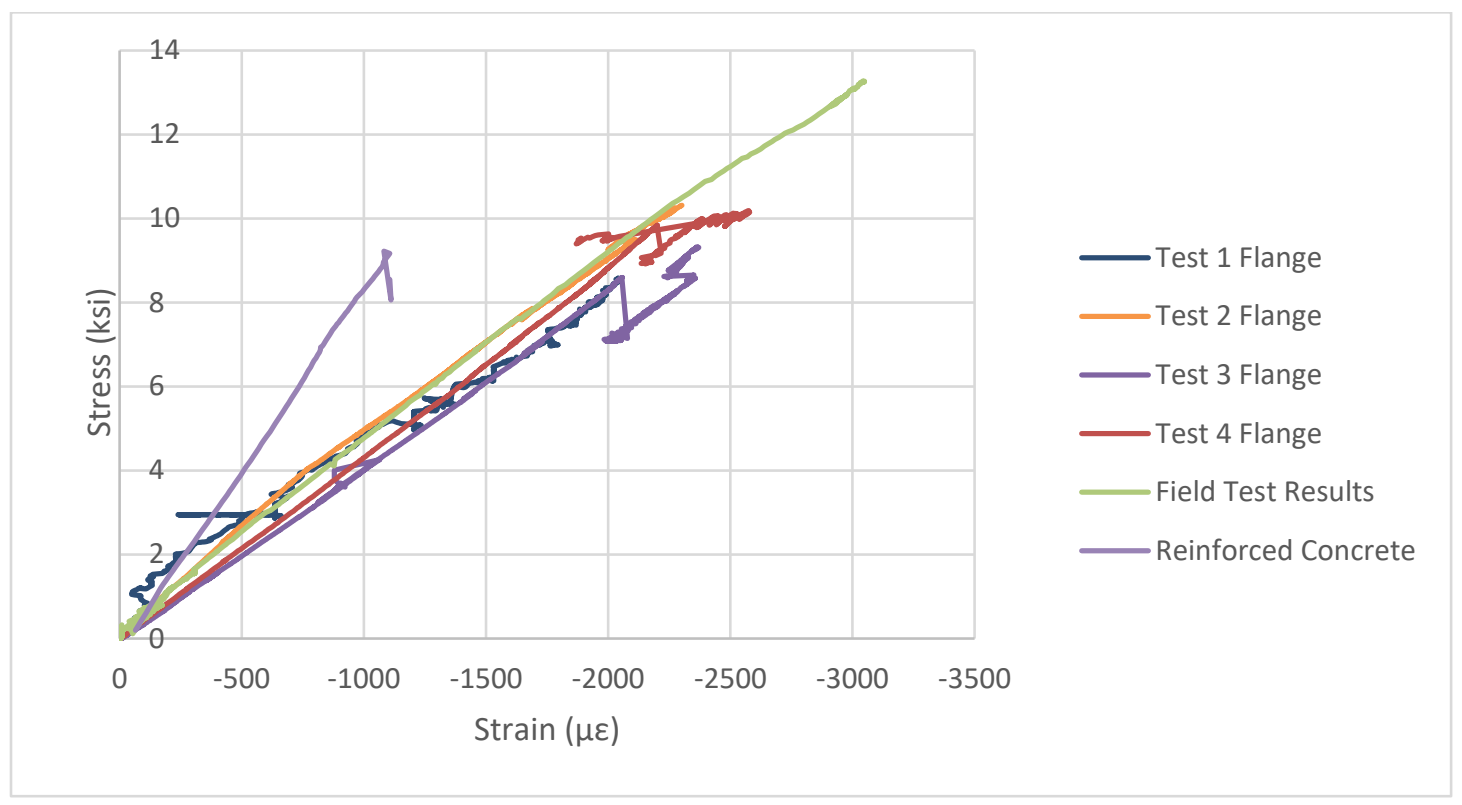

Figure 4. 35:Stress Strain Comparison

Figure 4.35 shows a discrepancy between each test's results and the stress-strain response of the sheet pile in reinforced concrete. A slope that is higher signifies a greater modulus. An increase in modulus from test to test of this degree is impossible because all tests shown Figure 4.35 are conducted with identical specimens. The reinforced concrete provided considerably more fixity for the sheet pile than any other embedment material. Another example of this was the lower strain at failure. By definition, less strain equates to less deformation. This is characteristic of a fixed cantilever as opposed to a sheet pile embedded in soil.

- Stress concentrations occur at the corners of the web and flange sections, leading to corner failures. While the dominant mode of failure may have occurred about the transverse axis for most specimens, nearly all tests showed signs of separation in the corners (Figure 4.36) 

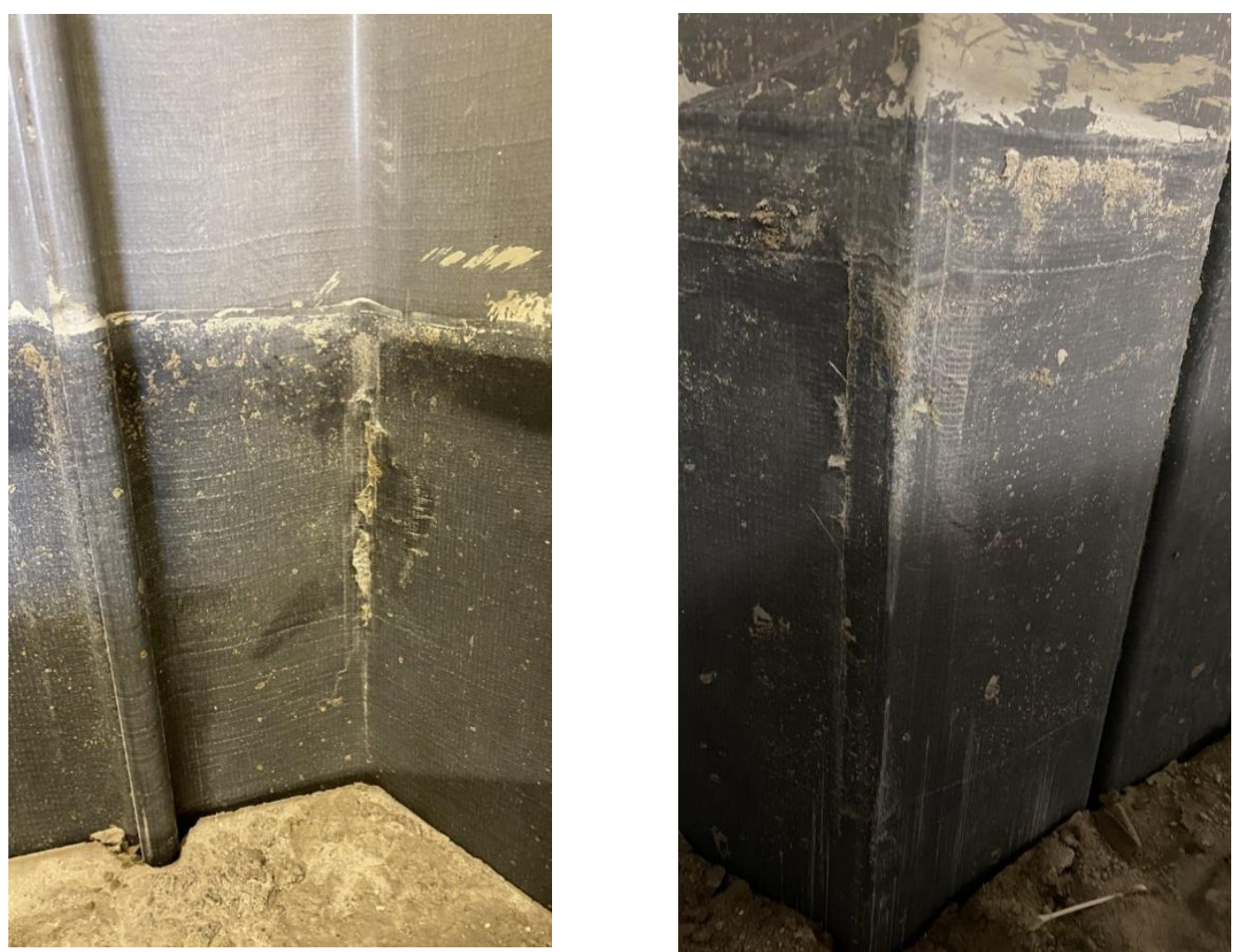

Figure 4. 36:Longitudinal Failures due to Stress Concentrations

Upon the observance of the phenomenon occurring in Figure 4.36, strain gages were placed on the specimen near the dredge line to confirm the assumption that stress concentrations are present. Figure 4.37 shows the strain response in the corner of the web and flange, 6 inches below the dredge line. 


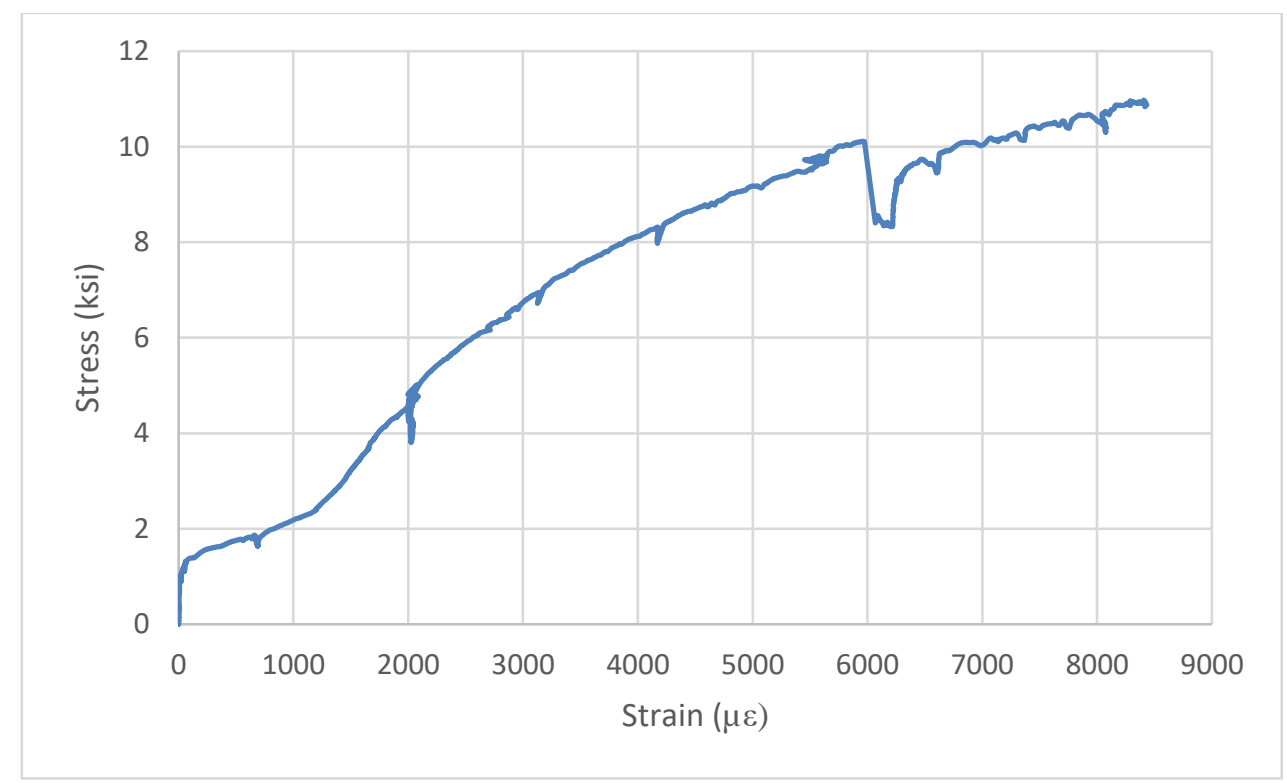

Figure 4. 37:Flange-Web Interface Strain

The results shown in Figure 4.37 reveal that the strain at locations near where stress concentrations are assumed to be is significantly higher than strain measured in the center of web or flanges throughout the specimen (maximum $3500 \mu \varepsilon$ ). It is apparent that after $2.3 \mathrm{ksi}$, there was geometric nonlinearity. The slope of the graph then increased linearly until $5 \mathrm{ksi}$ of stress was reached. Prior to $5 \mathrm{ksi}$ of stress, the strain responded elastically, but after $5 \mathrm{ksi}$, the response was viscoelastic. This signifies that ideally, a strain at this location should not exceed $2000 \mu \varepsilon$ because a higher strain would lead to deformation that could not be reversed. Despite the former claim, the structure still resisted close to an additional $6 \mathrm{ksi}$ of stress, therefore a failure strain of conservatively chosen for future calculations at $5000 \mu \varepsilon$. A strain of higher magnitude at that location indicated that deformation is occurring and the region is subject to an earlier failure than other locations. 


\section{THEORETICAL AND EXPERIMENTAL EVALUATION OF SHEET Pile Capacity}

The sheet pile capacity has been evaluated herein through a deterministic approach, assigning realistic material resistance values to soil type as well as FRP sheet piles in both the longitudinal and transverse directions. Prior to any installation, a soil-pile pressure interaction diagram similar to the one shown in Figure 5.1 is assumed as an idealization. This diagram displays the net lateral earth pressures acting on a sheet pile. Once the force or pressure distribution acting on the sheet pile is defined, the pile can be designed as a cantilever beam to establish maximum moment capacity based on sheet pile materials and geometric properties. This section compares the resultant forces and moments derived from the pressure diagram created below the dredge line in relation with laboratory testing data to well established methods for the design of sheet piles.

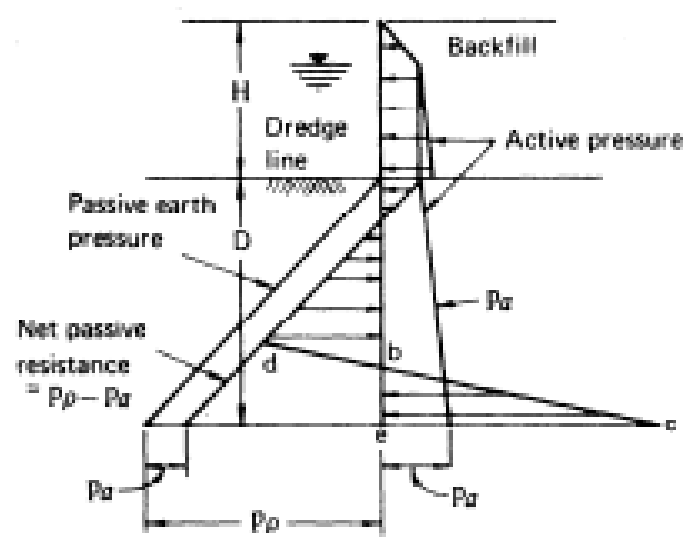

Figure 5. 1: Sheet Pile Pressure Distribution

\subsection{Theoretical Evaluation of Ultimate Moment Capacity}

Experimental data from each test provided valuable information, useful to calculate flexural or shear stresses that may control a failure mode. Strain gages were strategically placed at predetermnined varying depths beneath the dredge line (surface of sand-concrete mixture) in the final test configuration so that the data could be used to generate a net pressure distribution diagram. Several FRP composite material properties of the test specimen have been experimentally evaluated at coupon level so that these properties 
can be used to arrive at a net pressure distribution of the soil, exerting pressure onto sheet pile flanges and webs.

\subsubsection{Material Properties}

The test specimen was constructed from four FRP segments with Z-shape profiles and web angle of $60^{\circ}$ from the horizontal flange, which is similar to the one shown in Figure 5.2. Each section of pultruded sheet pile featured two flanges and one web.

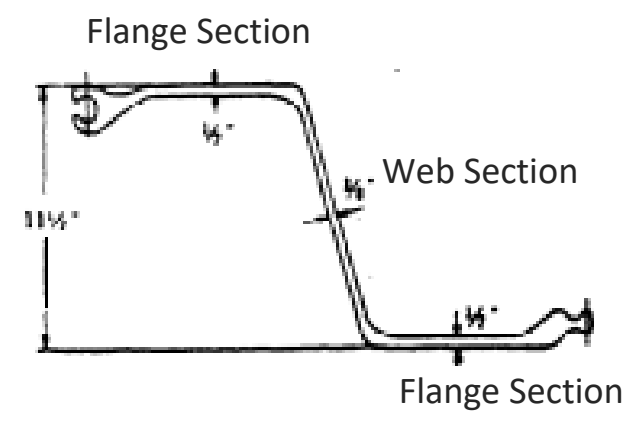

Figure 5. 2:Sheet Pile Z-Section

The interlocking mechanism (Figure 5.2) used to connect the four sections together to create one sheet pile test system creates a boundary condition at the center of the tension/compression face with a rotational degree of freedom. For analysis purposes, this boundary creates a hinge, therefore each section where two flanges connect is considered two flanges as opposed to one conjoined flange. Figure 3.2 indicates the setup for sheet pile specimen in which consists of 4 web and 6 flange sections.

\subsubsection{Effective Width}

Figure 5.3 shows a sheet pile test specimen under load. In the image it can be observed that the exterior flange nearest to the front of the image is not parallel with the interior flanges on the compression side of the sheet pile. The exterior flange is being restrained by the same material as the interior flange, but due to uneven load distribution and a lack of restraint on one side, the exterior flanges on each side of the specimen are considered herein as ineffective at resisting load. As a result, an effective width was established in a way that effective regions of the sheet pile specimen resist the majority of the applied load. For simplicity, the effective, load bearing region exists within the inner flanges and webs. 6 inches of flange length is 
subtracted from either side of the test specimen to account for the exterior flanges. The final effective width used for the theoretical analysis and design is 60 inches, i.e., 4 webs and 6 flanges in our test setup.

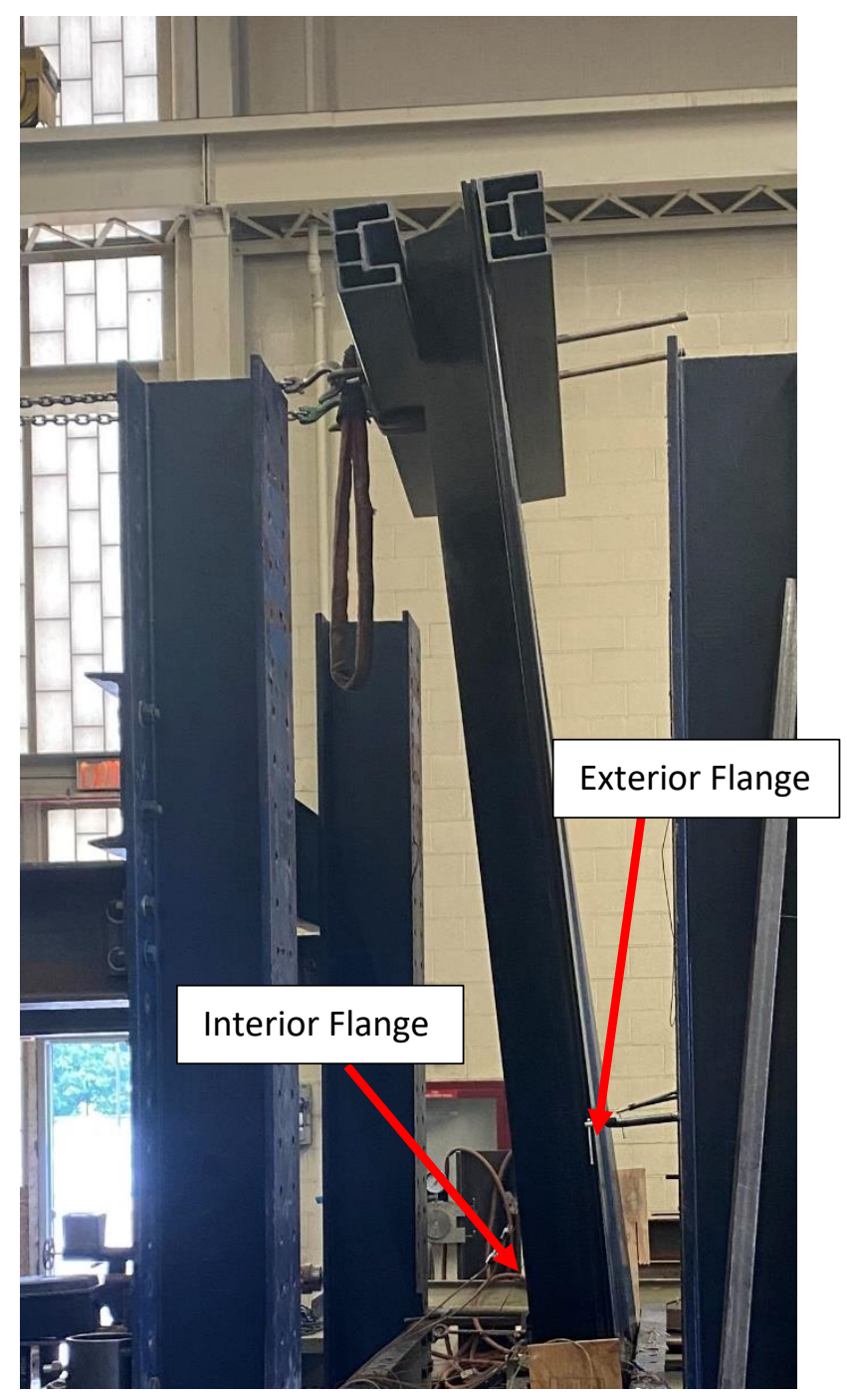

Figure 5. 3:Effective Length of Test Specimens

\subsubsection{Area Moment of Inertia}

The dimension to find moment of inertia was calculated for a rectangular section with a width of 1 inch and a thickness of 0.265 inch. The distance from the neutral axis of both the web and flange sections to the outermost fiber of the sheet pile is 0.1325 inch. A width of 1 inch is used so that the value can be used as an unit width of the bent system in the horizontal direction of the bent pile. This unit width was used for both the flange and web section while accounting for their varying span lengths in the horizontal direction. 
Each individual flange and web sections on the sheet pile are assumed to be undergoing a phenomenon known as cylindrical bending as described by Timoshenko (Theory of Plates and Shells, 1940). Figure 5.4 shows the span at which the unit width was considered.

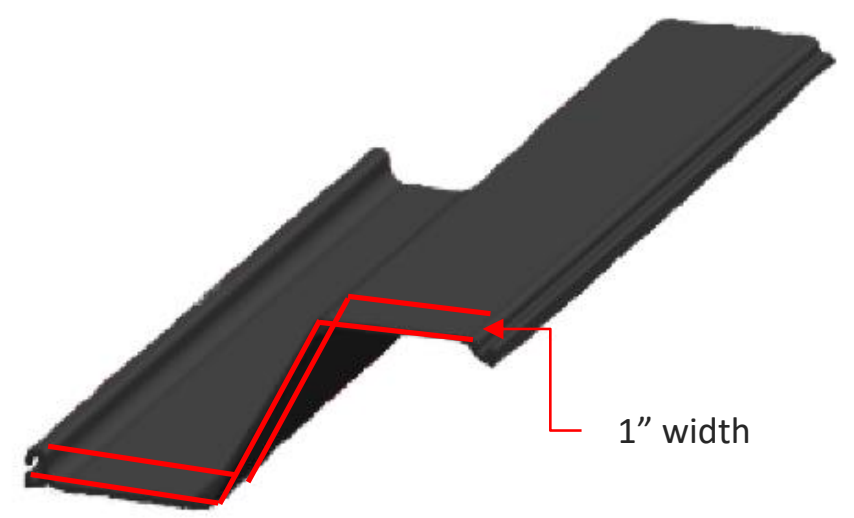

Figure 5. 4: Transverse Width Diagram

\subsection{Cylindrical Bending}

Thin plates with low bending rigidity (EI) in the horizontal direction characteristically deflect a relatively large amount without overstrain when load is applied perpendicular to the face of the pile. Cylindrical bending is a method of quantifying deflection of a long rectangular plate of narrow width (length to width ratio greater than 50/6) with a small thickness is subjected to a uniform transverse load across the length of the plate. Laboratory testing and strain monitoring showed uniform transverse bending across the length of each flange and web specimen. When each section is considered to be a simply supported plate which is uniformly loaded, as is occurring when load is applied, flexural rigidity (EI) remains constant (Timoshenko, 1959). This is because the width of the plate (flange or web) can be considered a bar. The bar's cross section remained planar when load is applied and only undergoes a deformation with respect to the neutral axis. Figure 5.5 shows a representation of what is considered to have occurred on the test specimen's web and flange sections. The specified dimensions were taken so that the moment of inertia is representative of the transverse/weak axis due to the piles' failure about this axis. Equation 5.1 was used 
to calculate a moment of inertia of of $0.0016 \mathrm{in}^{4} / \mathbf{i n}$, with 1 " (unit) width along the pile length or pultruded direction and a height of 0.26 ".

$$
I=\frac{b h^{3}}{12}
$$

$\mathrm{I}=$ Area Moment of Inertia (in $\left.{ }^{4}\right)$

$\mathrm{b}=$ width (in)

$\mathrm{h}=$ height (in)

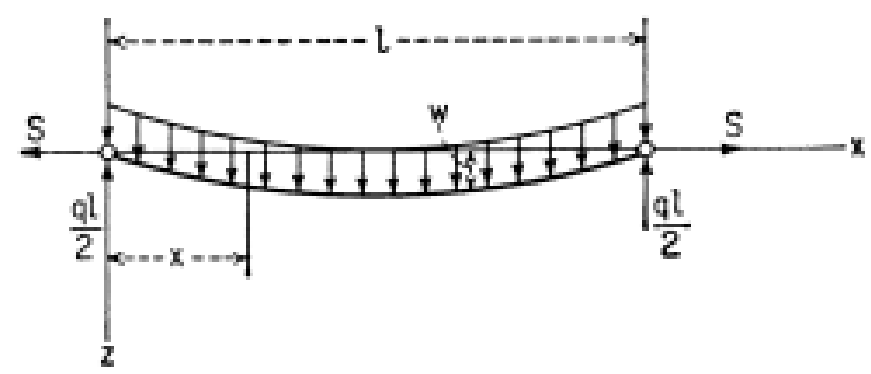

Figure 5. 5:Cylindrical Bending

\subsubsection{Modulus}

\subsection{Longitudinal Modulus}

The longitudinal axis of the test specimen used for experimentation was considered to be parallel with the pultrusion direction of the specimen, and was vertical when the specimen was placed vertically in the testing configuration. The longitudinal modulus as reported by Creative Composites Group was 4,250 ksi. This value was used in calculations to understand various modes of failure. Evidence of failure (Figure 5.6) was observed after several experiments on different test specimens. The failure occured as a result of large deformations and an induced moment about the transverse axis, which is parallel to the short span direction i.e., between the hinge mechanisms of the flanges and the flange-web junction. 


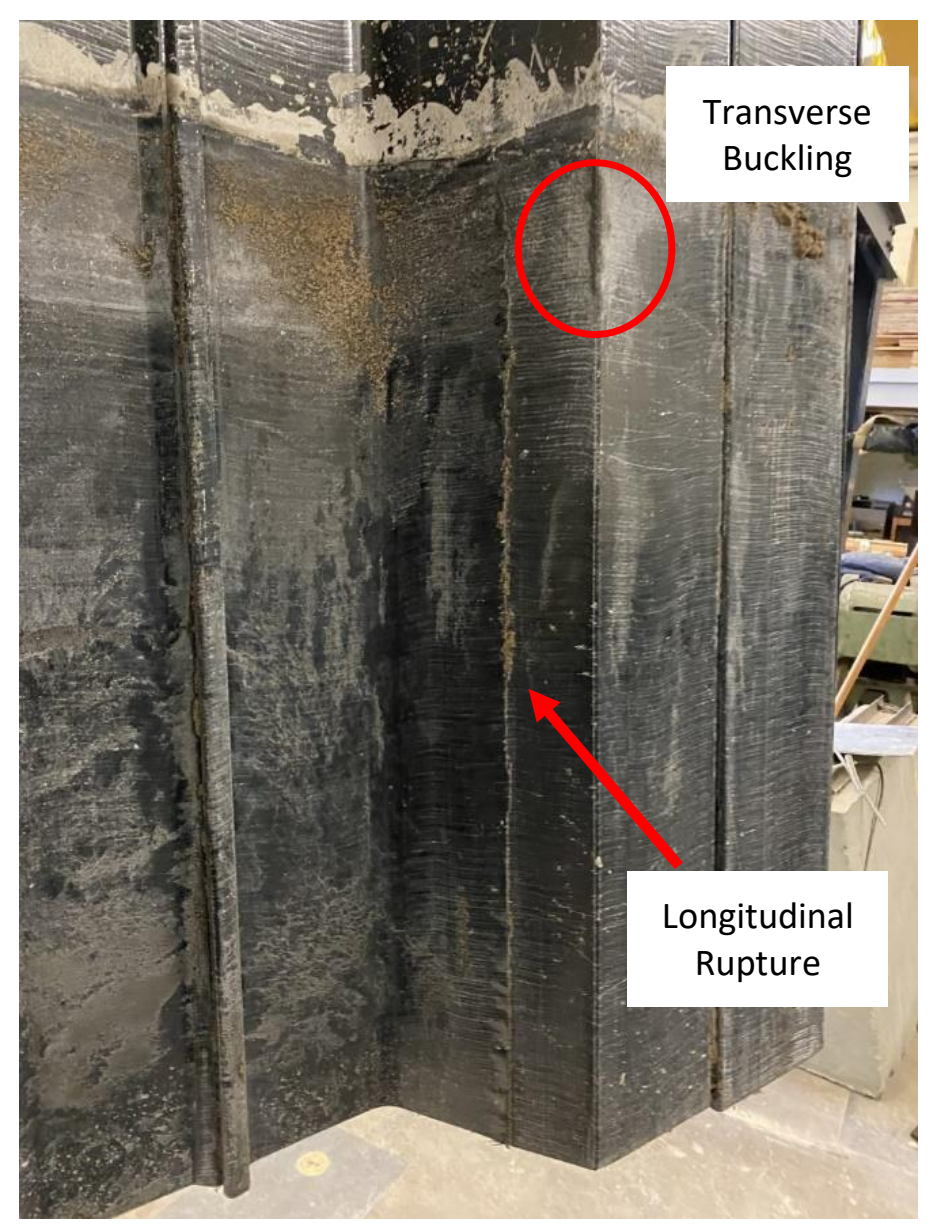

Figure 5. 6:Longitudinal Failure

\subsection{Transverse Modulus}

The transverse direction of the test specimen is perpendicular to the height of the sheet pile, or along the pultrusion direction of the pile. Figure 5.7 shows the test specimen bending about the transverse axis. The load applied directly resulted in the specimen longitudinally bending, resulting in failure about the transverse axis due to earth pressure, exerting in a transverse direction to the pile face. Buckling was observed (Figure 5.6) across the transverse axis in each of the final four tests, as well as V-Test 1 and VTest 2. As it was observed that failure would consistently occur about the transverse axis, coupon testing was conducted on a specimen (Figure 3.5) to verify the transverse modulus provided by Creative Composites Group (1,300 ksi). Coupon testing was conducted as per ASTM D790-17 and resulted in a modulus of 1,400 ksi including the effects of shear deformation. However subtracting the shear influence, the transverse modulus was found to be 1,600 ksi. Due to consistent failure in the transverse direction, 
calculations conducted to find the maximum failure moment were done so using the transverse modulus, because of transverse bending, i.e. about the weak (transverse) axis of the pile.

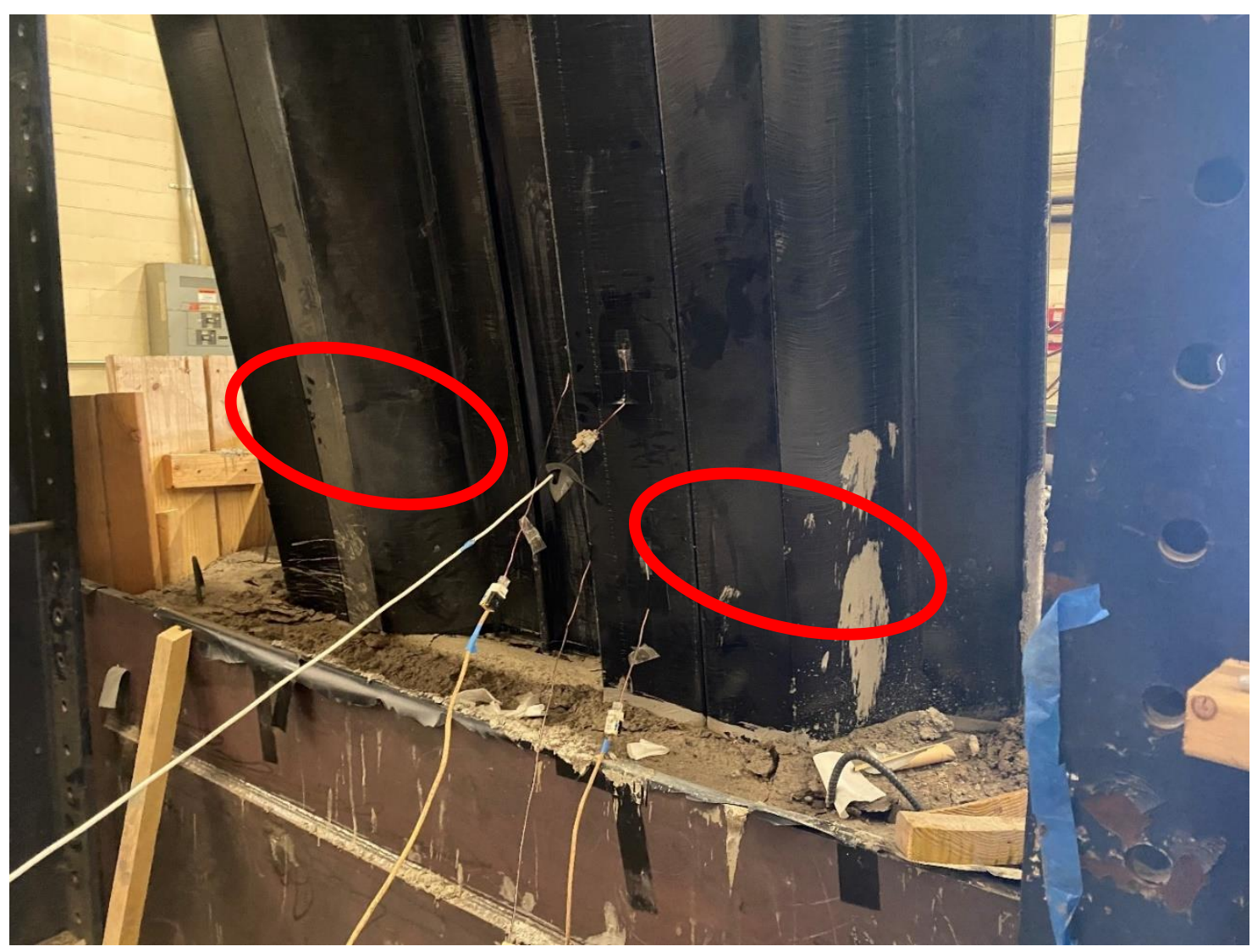

Figure 5. 7:Sheet Pile Under Longitudinal Bending about Transverse Axis 


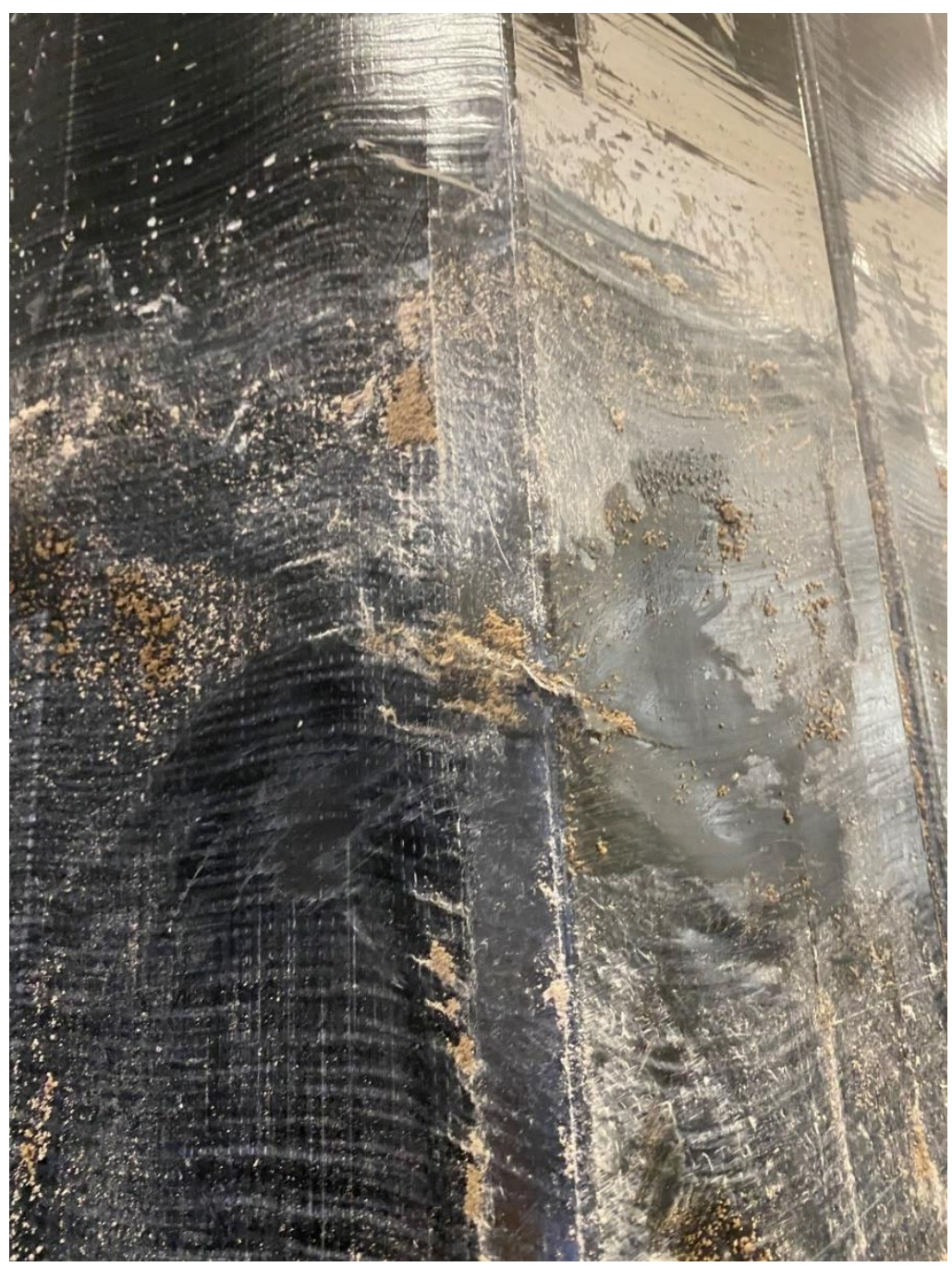

Figure 5. 8:Buckling about Transverse Axis

\subsubsection{Strain at Failure}

Preliminary results for final test configuration were highlighted in Section 4.6. Each of the tests conducted in the final procedure featured strain gages placed at the exact same location in order to ensure consistency. Table 5.1 shows the average strain recorded at failure for each location that gages were placed. Failure was acknowledged when the load dropped by 15 percent or more, or a noticeable deformation had been observed. In some instances, strain gages provided faulty data. This is believed to have resulted from the infiltration of moisture (from sand-concrete mixture) into the barrier created with a butyl rubber sealant. The readings that have been deemed faulty have been eliminated from the 
evaluations and analyses of data. The data shown in Table 5.1 is used in Section 5.1.2 to calculate the pressure exerted onto the pile.

Table 5. 1:Average Strain Results at Sheet Pile Failure

\begin{tabular}{|c|c|c|}
\hline Depth (in) & $\begin{array}{c}\text { Flange (Vertical) } \\
\text { Strain }(\boldsymbol{\mu \epsilon})\end{array}$ & $\begin{array}{c}\text { Web (Horizontal) } \\
\text { Strain }(\boldsymbol{\mu} \boldsymbol{\epsilon})\end{array}$ \\
\hline 0 & 1250 & 1400 \\
\hline 16 & 800 & 1000 \\
\hline 26 & 2800 & 3025 \\
\hline 33 & -600 & -700 \\
\hline
\end{tabular}

*Note: depth is in inch(es) beneath dredge line

Table 5.1 documents the failure strains used to calculate the pressure at each location. The strain was taken from gages at peak load for all depths along the web and for a depth of 0 inches along the flange. The remaining flange locations were assumed to be the values that are provided. The assumed values were obtained by interpolating for the results with results from the web and flange locations above the dredge line.

\subsubsection{Experimental Data Analysis}

Using Hooke's Law, Equation 5.2 was implemented, and the known moduli, strain, and material properties were used to obtain the positive and negative pressures acting on the compression and tension zones of sheet pile, respectively, at varying locations. The transverse modulus was chosen in Equation 5.2 because of the experimental results reported in Chapter 4; consistent failures on the transverse axis were observed. With the strain and transverse modulus known, the procedure to back-calculate shear force (interchangeable with net pressure) acting on the pile is possible.

$$
E_{T}=\frac{\sigma_{F}}{\varepsilon}
$$


where,

$E_{T}=$ Young's Modulus of the Transverse Axis

$\sigma_{F}=$ Flexural Stress about the Transverse Axis

$\varepsilon=$ Strain Reading from Gage (experiments)

Equation 5.3 shows the formula used to calculate flexural stress.

$$
\sigma_{f}=\frac{M c}{I}
$$

where,

$\sigma_{f}=$ Flexural Stress about the Transverse Axis (psi)

$\mathrm{M}=$ The Bending Moment (in-lbs)

$\mathrm{c}=$ the maximum distance from the neutral axis to the outermost fiber (in)

$\mathrm{I}=$ Area Moment of Inertia $\left(\mathrm{in}^{4}\right)$

Equation 5.3 further separated variables by providing a formula to calculate the bending moment about the transverse axis. Equation 5.4 (Kassimali, 2015) was taken as the bending moment at the fixed end of a beam which is simply supported at the other end under uniform loading. The beam shown in Figure 5.9 was the basis for this assumption, and the moment distribution method was used to calculate the moment with just one fixed end and the other end pinned.

$$
M=\frac{w l^{2}}{8}
$$

where,

$\mathrm{M}=$ Bending Moment (in-lbs)

$l=$ length of flange or web (in)

$\mathrm{W}=$ Pressure exerted on the sheet pile (lb/in)) 


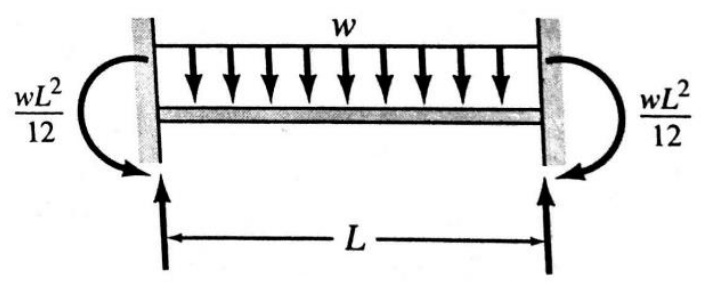

Figure 5. 9: Beam with Fixed Ends

The beam shown in Figutr 5.9 does not properly represent the test specimen because of partial fixity observed in test specimens where two contiguous flanges of pile sections are hinged together. It is impossible to achieve full fixity (Equation 5.4) and the lack of fixity was especially prominent in laboratory tests. The soil media surrounding the test specimen allowed for a small degree of movement and rotation. In order to account for this partial fixity, the moment distribution method (Kassimali, 2015) was used, and it was determined that Equation 5.5 would be used to express the bending moment at locations beneath the sandy concrete media surrounding the test specimen. This is a reasonable assumption because of webs at the end of the flange work as a partial moment restraint, resulting in a connection that has properties in between those of a fixed and a pinned connection. A denominator for Equation 5.5 could have ranged from a value of 8 (fixed) to 14 (pinned). 10 was chosen as a conservative value for the denominator, while still accounting condition present. The visible and logical lack of fixity has been accounted for.

\section{Bending Moment for Partial Fixity}

$$
M=\frac{w l^{2}}{10}
$$

Where,

$\mathrm{M}=$ Bending Moment (lbs*in)

$l=$ lateral length of flange or web (in)

$\mathrm{w}=$ Pressure exerted on the sheet pile $(\mathrm{psi})$ 
Through the combination of the Equations 5.2, 5.3, and 5.5, Equation 5.6 was expressed to solve for the force acting at a location relative to where the strain gage is placed.

$$
w_{f, w}=\frac{1}{\frac{l_{f, w}{ }^{2} c}{10 E_{T} I \varepsilon_{f, w}}}
$$

where,

$$
\begin{aligned}
& w_{f}=\text { Uniform pressure on flange (lb/in/in) } \\
& w_{w}=\text { Uniform pressure on web (lb/in/in) } \\
& l_{f}=\text { Length of flange (in) } \\
& l_{w}=\text { Length of web (in) } \\
& \mathrm{c}=\text { distance from neutral axis to furthermost fiber (in) } \\
& \mathrm{E}=\text { Bending Modulus (psi) } \\
& \left.\mathrm{I}=\text { Unit Area Moment of Inertia } \frac{\left(i n^{4}\right.}{i n}\right) \\
& \varepsilon_{f}=\text { Flange strain at peak load }(\mu \varepsilon) \\
& \varepsilon_{w}=\text { Web strain at peak load }(\mu \varepsilon)
\end{aligned}
$$

Table 5.2 establishes the values used for each variable and Table 5.1displays strain data that were used to find the pressures at different depths.

Table 5. 2:Test Specimen Properties

\begin{tabular}{|c|c|c|}
\hline & Flange & Web \\
\hline I (in) & 6.9 & 8.9 \\
\hline $\mathrm{c}$ (in) & 0.1325 & 0.1325 \\
\hline $\mathrm{E}(\mathrm{psi})$ & $1.6^{*} 10^{6}$ & $1.6^{*} 10^{6}$ \\
\hline $\mathrm{b}(\mathrm{in})$ & 1 & 1 \\
\hline $\mathrm{h}(\mathrm{in})$ & 0.265 & 0.265 \\
\hline $\mathrm{I}\left(\frac{\text { in }^{4}}{\text { in }}\right)$ & 0.0016 & 0.0016 \\
\hline
\end{tabular}

Table 5.1 and Table 5.2 were inserted into Equation 5.5 and the results were shown at their respective depths in Table 5.3. An example was shown to further show the process for obtaining the uniform 
pressure. A depth of zero was chosen for the examples where failure strain in the web was $1400 \mu \boldsymbol{\varepsilon}$ and failure strain in the flange was $1,250 \mu \varepsilon$.

Web

$$
w=\frac{1}{\frac{l_{w}{ }^{2} c}{10 E I \varepsilon}}=\frac{1}{\frac{8.9 \mathrm{in}^{2} 0.1325 \mathrm{in}}{10\left(1.6 * 10^{6} p s i\right)\left(0.0016 \mathrm{in}^{4}\right)\left(1400 * 10^{-6}\right)}}=3.4 \mathrm{lb} / \mathrm{in}
$$

Flange

$$
w=\frac{1}{\frac{l^{2} c}{10 E I \varepsilon}}=\frac{1}{\frac{6.9 \mathrm{in}^{2} 0.1325 \mathrm{in}}{10\left(1.6 * 10^{6} p s i\right)\left(0.0016 \mathrm{in}^{4}\right)\left(1250 * 10^{-6}\right)}}=5.1 \mathrm{lb} / \mathrm{in}
$$

Table 5. 3:Uniform Pressure Results

\begin{tabular}{|c|c|c|}
\hline $\begin{array}{c}\text { Depth (inches beneath ground } \\
\text { line) }\end{array}$ & $\begin{array}{c}\text { Uniform Pressure per } \\
\text { Flange Section (lb/in) }\end{array}$ & $\begin{array}{c}\text { Uniform Pressure per } \\
\text { Web Section (lb/in) }\end{array}$ \\
\hline 0 & 5.1 & 3.4 \\
\hline 16 & 3.2 & 2.4 \\
\hline 26 & 11.36 & 7.4 \\
\hline 33 & -2.4 & -1.7 \\
\hline
\end{tabular}

The pressures documented in Table 5.3 are uniform across each flange and web, and act perpendicularly on them. The web angle of 120 degrees must be accounted for so that the pressure that is occurring perpendicularly to the test specimen (globally) is recorded. Figure 5.10 (a) shows the direction of resultant pressures (5.3) calculated on the flange and web sections, whereas, Figure 5.10(b) shows the direction of resultant pressures that were calculated in Table 5.4. 


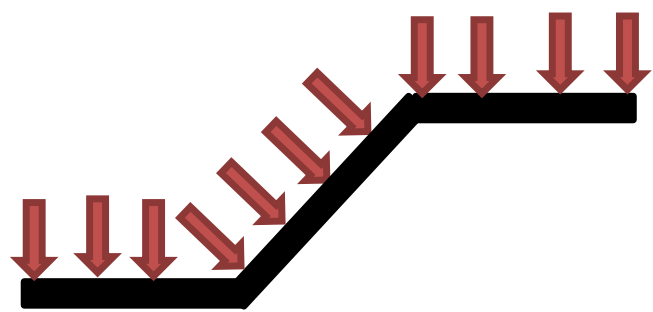

(a)

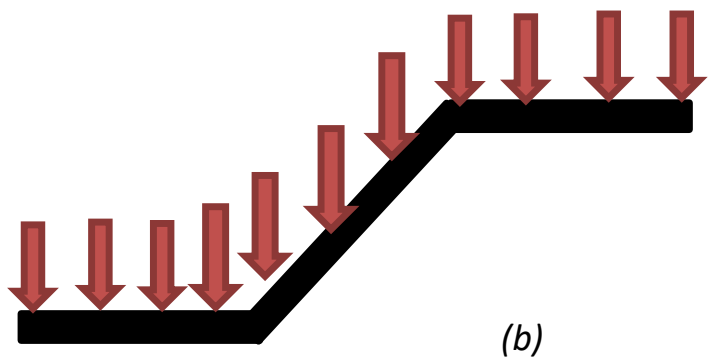

(b)

Figure 5. 10:Pressure Distributions

The process at which values were translated to show force distribution uniformly perpendicular to pultrusion direction is shown for a depth of 0 inches:

The uniform load is translated to a point load.

$$
\left(\frac{3.4 \frac{l b}{i n}}{i n}\right) * 8.9 \mathrm{in}=30.4 \mathrm{lb}
$$

The point load was then translated to a point load in the desired direction

$$
\sin (60) * 30.4 l b=26.3 l b
$$

The desired point load was then converted to a uniform load across the horizontal length of the web section (4 inches):

$$
\frac{26.3 \mathrm{lb}}{4 \mathrm{in}}=\frac{6.6 \frac{\mathrm{lb}}{\mathrm{in}}}{\mathrm{in}}
$$

Table 5. 4:Global Horizontal Pressure Results

\begin{tabular}{|c|c|c|}
\hline $\begin{array}{c}\text { Depth (inches beneath ground } \\
\text { line) }\end{array}$ & $\begin{array}{c}\text { Uniform Pressure per } \\
\text { Flange Section (lb/in/in) }\end{array}$ & $\begin{array}{c}\text { Uniform Pressure per } \\
\text { Web Section (lb/in/in) }\end{array}$ \\
\hline 0 & 5.1 & 6.6 \\
\hline 16 & 3.2 & 4.7 \\
\hline 26 & 11.4 & 14.2 \\
\hline 33 & -2.4 & -3.3 \\
\hline
\end{tabular}


The resultant forces at each location were then solved for using

$$
F_{R}=\left(w_{f} * N_{f} * l_{f}\right)+\left(w_{w} * N_{w} * l_{w}\right)
$$

where,

$F_{r}=$ Maximum Load at specified depth (lb/in)

$w_{f}=$ Uniform pressure parallel with load application on flange (lb/in)

$w_{w}^{\prime}=$ Uniform pressure parallel with load application on web (lb/in)

$l_{f}=$ Horizontal length of web (in)

$l_{w}$ '= Horizontal length of web (in)

$N_{f}=$ Number of effective flange sections

$N_{w}=$ Number of effective web sections

$$
F_{R}=\left(5.1 \frac{\mathrm{lb}}{\mathrm{in}} * 6 \text { sections } * 6.9 \mathrm{in}\right)+\left(6.6 \frac{\mathrm{lb}}{\mathrm{in}} * 4 \text { sections } * 4 \mathrm{in}\right)=317 \mathrm{lb} / \mathrm{in}
$$

Table 5. 5:Resultant Forces at Respective Depths

\begin{tabular}{|c|c|c|c|}
\hline $\begin{array}{c}\text { Depth (inches beneath ground } \\
\text { line) }\end{array}$ & $\begin{array}{c}\text { Force Flange } \\
(\mathbf{l b} / \mathbf{i n})\end{array}$ & $\begin{array}{c}\text { Force Web } \\
(\mathbf{l b} / \mathbf{i n})\end{array}$ & $\begin{array}{c}\text { Total horizontal Force } \\
(\mathbf{l b} / \mathbf{i n})\end{array}$ \\
\hline 0 & 211.14 & 105.6 & 316.7 \\
\hline 16 & 132.48 & 75.2 & 207.7 \\
\hline 26 & 471.96 & 227.2 & 699.2 \\
\hline 33 & -99.36 & -52.8 & -152.2 \\
\hline
\end{tabular}

With experimental data used to derive pressures acting on the test specimen at various locations, Table 5.5 was created to show the total horizontal force acting in each at each measured location. A plot (Figure 5.11) was then created to show the net pressure distribution on the test specimen. This plot replicates those seen in literature and textbooks, i.e., showing pressures derived from active and 
passive forces within the soil. The figure is created so that 0 inches is the dredge line, or the surface of the embedment material. The pile then extends 36 inches beneath the surface to the laboratory floor.

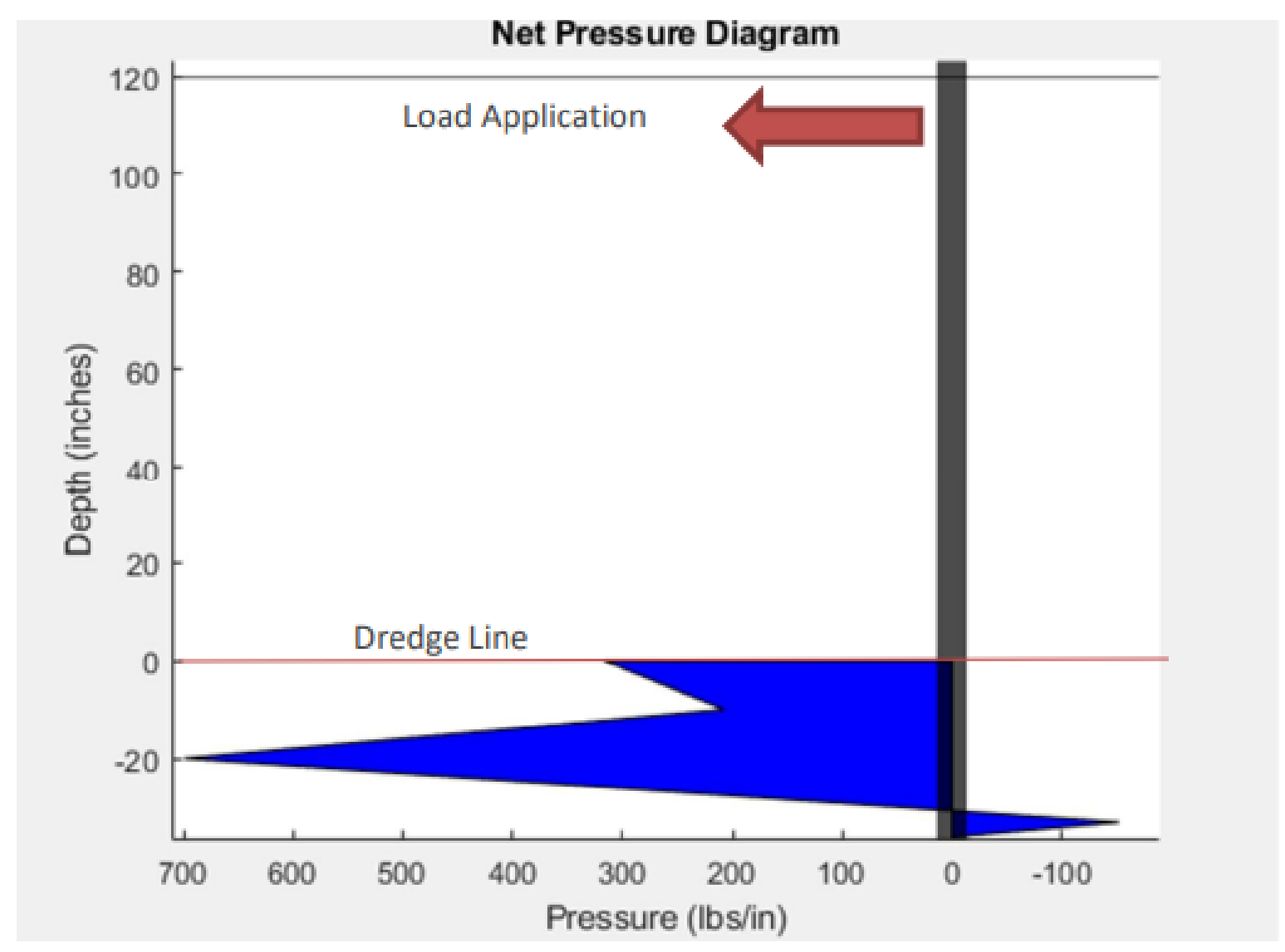

Figure 5. 11:Net Pressure Diagram

Sheet pile net pressure diagrams are often displayed in a trapezoidal manner as observed in Figure 5.11. Realistically the pressure is distributed in a parabolic fashion, however due to a small (negligible) difference in the equilibrium of forces when using either method, the trapezoidal method of displaying pressure distribution is the industry standard due to its simplicity (Das and Sivakugan, 2017). With the pressure distribution established, a force equilibrium approach was taken to solve for the reaction at the bottom of the specimen (-36 inches). Using the information in Figure 5.11 and the force equilibrium 
approach (Kassimali, 2015) a reactionary force of 3155 pounds was solved for at the laboratory floor level. This force was arrived at when the free body diagram (Figure 5.12) of the test specimen was created to satisfy the force equilibrium.

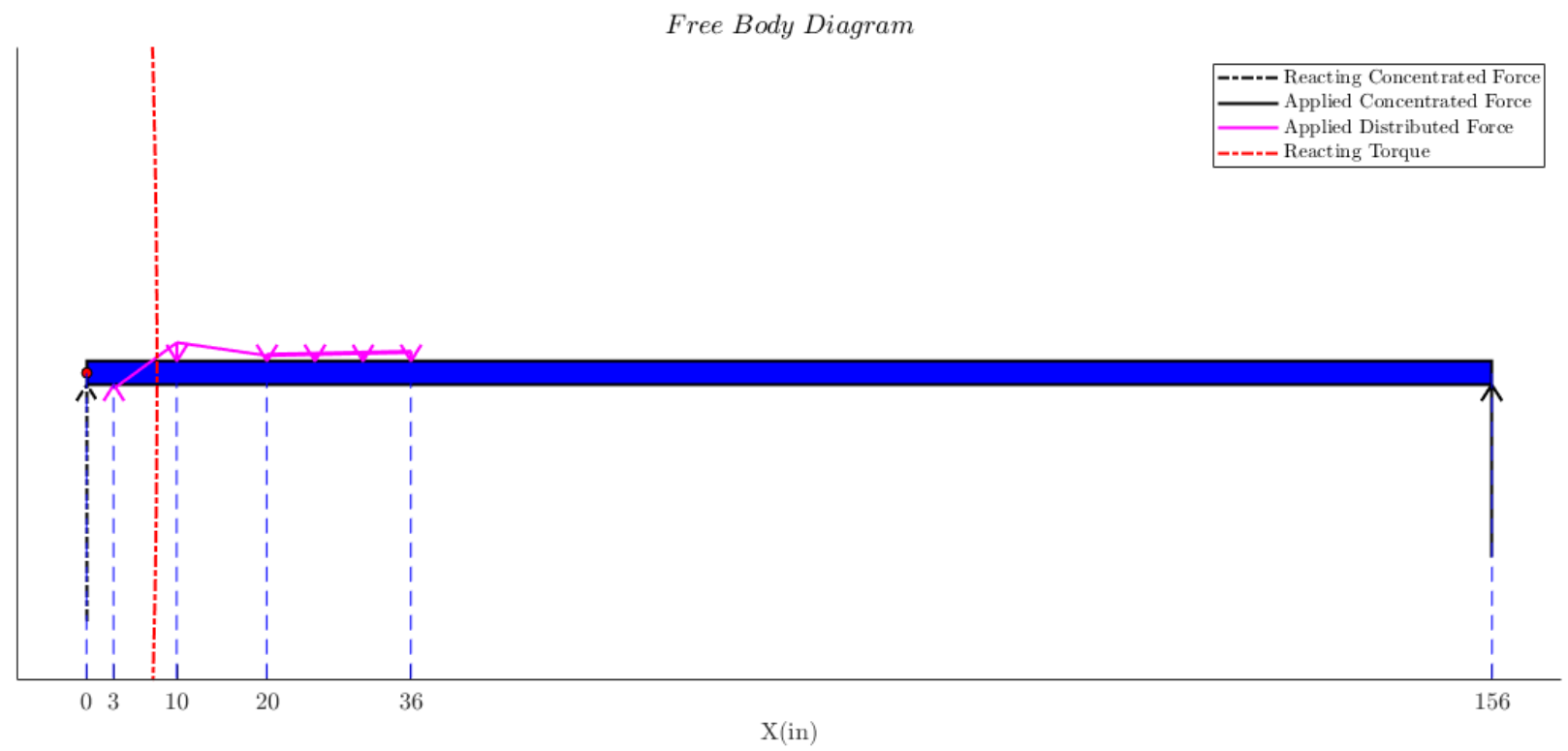

Figure 5. 12:Free Body Diagram

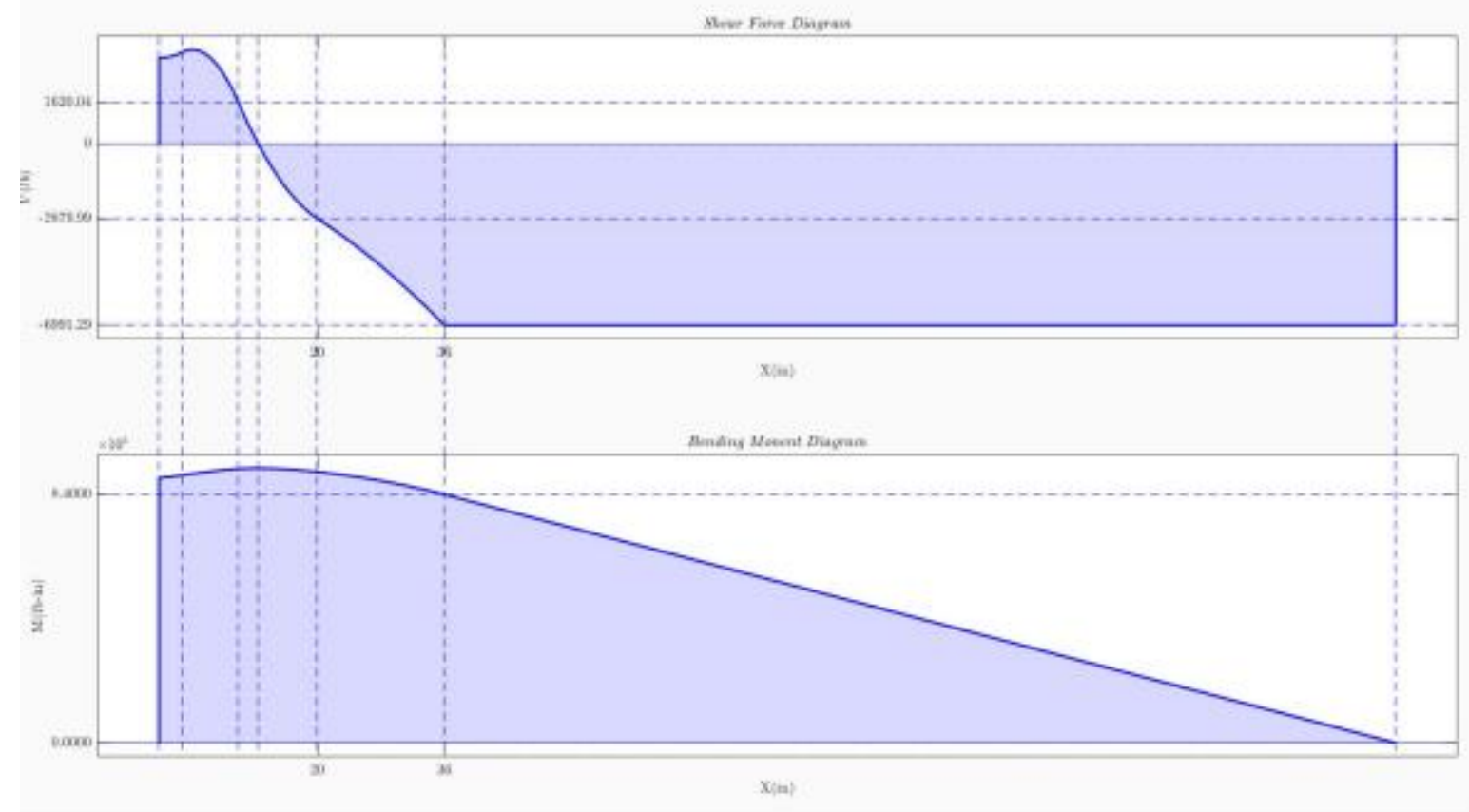

Figure 5. 13:Shear and Moment Diagrams 
The free body diagram shown in Figure 5.12 was used to properly analyze the sheet pile as a cantilever beam. The specimen was analyzed with Matlab and results were confirmed through solid mechanics approach. Figure 5.13 shows the resulting shear force and bending moment diagrams of the specimen, respectively. The specimen was analyzed on a scale from 0 to 156 inches. The point $(0,0)$ represents the bottom of the pile, while $(156,0)$ represents the 13 -foot height of the pile, while recognizing that the horizontal load was applied at $12.5^{\prime}$ (150”) from the laboratory floor.

The shear force and bending moment diagrams shown in Figure 5.13 were used to establish a maximum moment occurring on the sheet pile when a maximum load of 7 kips is applied at the top of the test specimen. 7 kips was chosen as the designated failure load because in Figure 4.19 two of the four tests were in the process of failing, and the average of the other two specimens failure load was approximately 7 kips. Based on experimental data, The maximum moment occurs at 16 inches based on experimental data above the laboratory floor and has a magnitude of $\mathbf{7 7 . 4 1}$ kip-ft. When the effective width, as established in Section 5.1.1.1 (5 ft) of the pile is accounted for, the resulting moment is $\mathbf{1 5 . 4 8} \mathbf{~ k i p} * \mathbf{f t} / \mathbf{f t}$.

\subsubsection{Simplified Analysis Approach}

The approach established in Section 5.1.2 is successful in obtaining the maximum bending moment which a test specimen can withstand, however, the decrease in pressure seen in figure 5.11 from the dredge line to the 16 inches beneath the surface is not characteristic of pressure distribution plots for granular or cohesive soils (Das and Sivakugan, 2017). The assumed cohesion present in the material presents the logic that immediately beneath the dredge line, the pressure should remain constant, similarly to Figure 2.13. It was assumed that the material had a higher intensity of reaction at the dredge line due to its rigidity. This resulted in a slight increase in strain at the dredge line. The simplified approach accounted for this increase in strain by averaging the results at the dredge line and the results 16 inches beneath the dredge line for a constant amount of pressure. Table 5.6 shows the resultant pressures assuming a constant pressure is acting until a depth of 16 inches and Figure 5.14 shows them in a graphical representation. 
Table 5. 6:Simplified Method Horizontal Forces

\begin{tabular}{|c|c|}
\hline Depth (inches beneath dredge line) & Horizontal Force (lb) \\
\hline 0 & 262.2 \\
\hline 16 & 262.2 \\
\hline 26 & 699.3 \\
\hline 33 & -152.98 \\
\hline
\end{tabular}

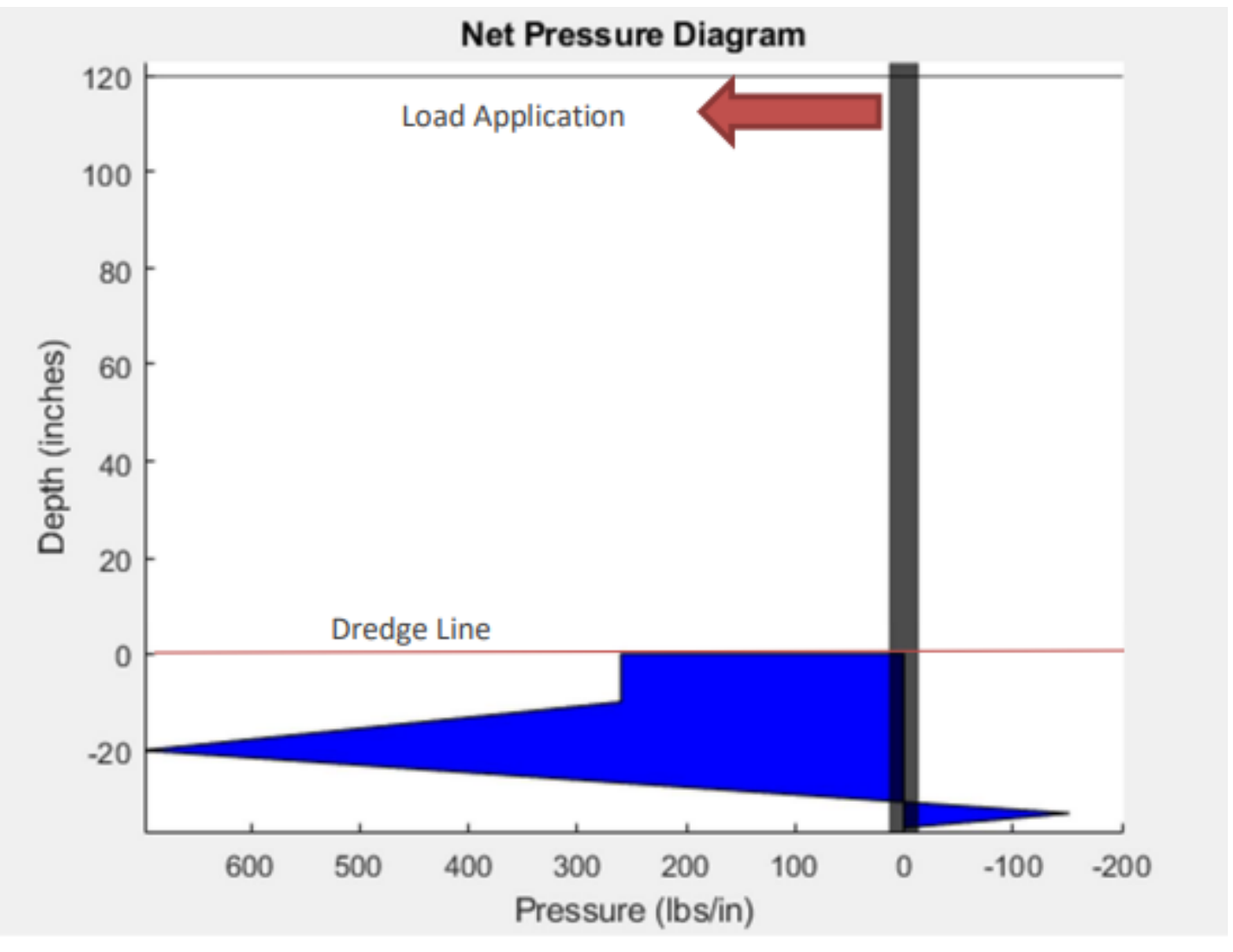

Figure 5. 14:Simplified Pressure Distribution 
Using a force equilibrium approach, a resultant force of 3665 pounds that occurred at the bottom of the test specimen when 7000 pounds were applied. With all forces considered Figure 5.15 was created to visualize the maximum moment.

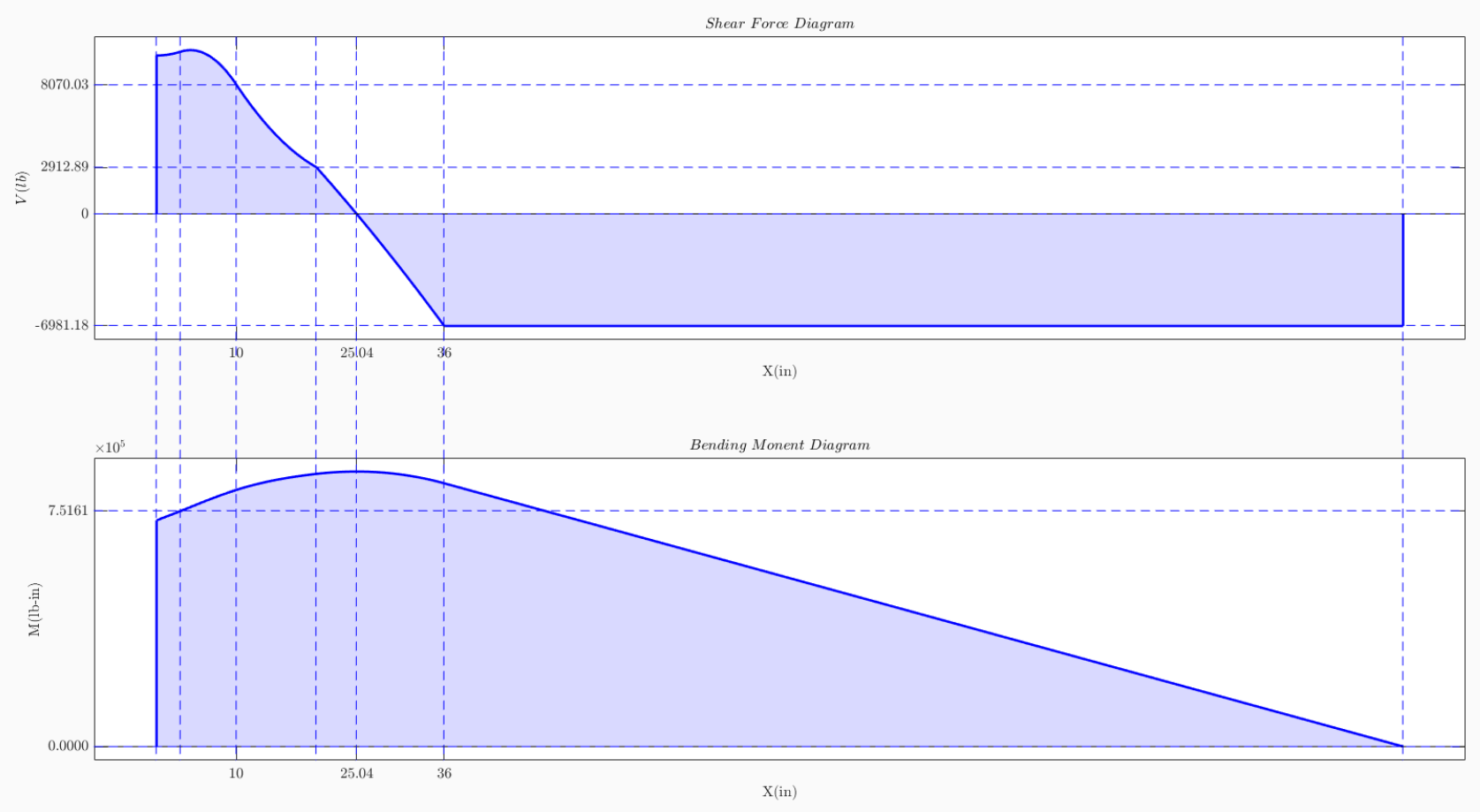

Figure 5. 15:Simplified Method Shear and Moment Diagrams

The resultant maximum moment from Figure 5.15 is $\mathbf{7 7 . 3 5} \mathbf{f t - k i p s}$ or $\mathbf{1 5 . 4 9} \mathbf{f t - k i p s / f t . ~ T h e ~ s i m p l i f i e d ~}$ analysis approach resulted in a bending moment capacity that differed from the original analysis approach by less than 0.06 percent. Not only was the simplified approach effective at calculating the maximum bending moment capacity, but it simplified the pressure distribution diagram.

\subsection{Theoretical Evaluation of Different Failure Modes}

Although the primary mode of failure documented in the testing was failure about the transverse axis, a variety of other failure modes could have occurred. The failure mode of the test specimen was dependent on FRP material properties and the quality of fiber. A failure about the transverse (weak) axis would likely occur in the event of longitudinal bending and a failure about the longitudinal (strong) axis most likely would occur as a result of transverse bending which is further accentuated due to stress concentration factors at corners or due to change in fiber/fabric configurations or voids. When poor quality embedment material 
was used, the material experienced failure prior to the sheet pile. This section studies the other failure modes that were possible with the Series 1580 Seawall Profile sheet pile. In order to calculate the maximum load.

\subsubsection{Lever Arm}

Throughout each trial, the location of the lever arm was observed within the test specimen,justified with data. The final testing configuration had a pivot point located about 6 inches (Figure 5.11) from the laboratory floor. This equated to a lever arm of 12 feet for the final configuration test specimens. Meanwhile, no strain measurements were taken in the reinforced concrete, but due to the fixity documented in Figure 4.35 the lever arm is assumed to be located directly at the dredge line, or 7.5 feet (Figure 3.1) for the test conducted. If any other specimens were to be tested in an extremely rigid material with properties similar to reinforced concrete, the lever arm would be equivalent to the distance of load application to dredge line due to the fixity. Additionally, in trials that were conducted in the sand medium, the strain readings shown in Figure 4.4 indicate that the pivot point was located beneath a depth of 4 feet (testing bin was 5 feet deep). This was the case because the strain measurements were all taken on the tensile side of the pile and had positive (tension) readings. Directly above the bottom of the pile, a negative reading is assumed to have occurred as a result of the pivot point and passive pressure. A pivot point at a depth of 4.5 feet beneath the sand, combined with a load application height 4.5 feet above the sand resulted in a lever arm of 9 feet. Table 5.7 stated the lever arms for the different trials. 
Table 5. 7:Lever Arm Values

\begin{tabular}{|c|c|c|c|}
\hline Experiment & $\begin{array}{l}\text { Final } \\
\text { Configuration }\end{array}$ & Reinforced Concrete & \\
\hline Lever Arm (ft) & 12 & 7.5 & 9.5 \\
\hline $\begin{array}{c}\text { Height of Load } \\
\text { Application (ft) }\end{array}$ & 12.5 & 9.5 & 5 \\
\hline $\begin{array}{c}\text { Depth of Embedment (ft) } \\
\text { Defthes }\end{array}$ & 3 & 2 & \\
\hline
\end{tabular}

Initial findings from Table 5.7 indicated that when embedment material was not extremely rigid, the pivot point will be located close to the laboratory floor. The pivot point is located near 6 inches for both the tests conducted in sand-concrete media and the test conducted in sand. As a result, if there is less than 5 feet of embedment material, the lever arm can be assumed to be located between 6 inches and 1 foot above the laboratory floor.

\subsubsection{Transverse Axis Failure}

Failure is possible in either the longitudinal or transverse direction of any sheet pile. Design checks must be done to ensure that sufficient loading can be done prior to the failure of any kind for the specimen. This is done through using a maximum failure strain obtained during coupon testing. The strain must be obtained through coupon testing for this procedure to ensure that a material failure strain is obtained. Using Hooke's law, a rearrangement of Equation 5.6 shows how the strain was converted to obtain the maximum moment. This calculation must be done for both the flange and the web sections.

$$
\varepsilon_{f}=\frac{\sigma}{E}=\frac{\frac{M_{\max } c}{I}}{E_{T}}=\frac{\left(\frac{w l^{2}}{10}\right) c}{E_{T} I}=\left(w l^{2} c\right) /\left(10\left(E_{L}, E_{T}\right) I\right)
$$

where, $\varepsilon_{f}=$ Failure Strain of Flange $(\mu \varepsilon)$ 
$\sigma=$ Bending Stress (ksi)

$E_{L}=$ Longitudinal Modulus (ksi)

$E_{T}=$ Transverse Modulus (ksi)

$c=$ Distance from neutral axis to exterior fiber (in)

$I=$ Area Moment of Inertia $\left(\right.$ in $\left.^{4}\right)$

$M_{\max }=$ Maximum bending moment (ft-kips)

$w=$ Pressure (lb/in)

$l=$ length of specimen (in)

Failure strain was taken from Figure 5.16. The gage used to provide the corresponding strain data was placed horizontally and inherently registered strain across the transverse axis. A value of $1400 \mu \varepsilon$ was used for both the flange and web axis to determine the corresponding pressures. Following the data shown in the graph, the strain moved significantly in the negative direction, implying that a failure had occurred. Strain continued to increase in the negative direction while load decreased. A strain at peak load conditions is ideal to calculate load capacity because strain will continually increase in magnitude after a specimen has failed.

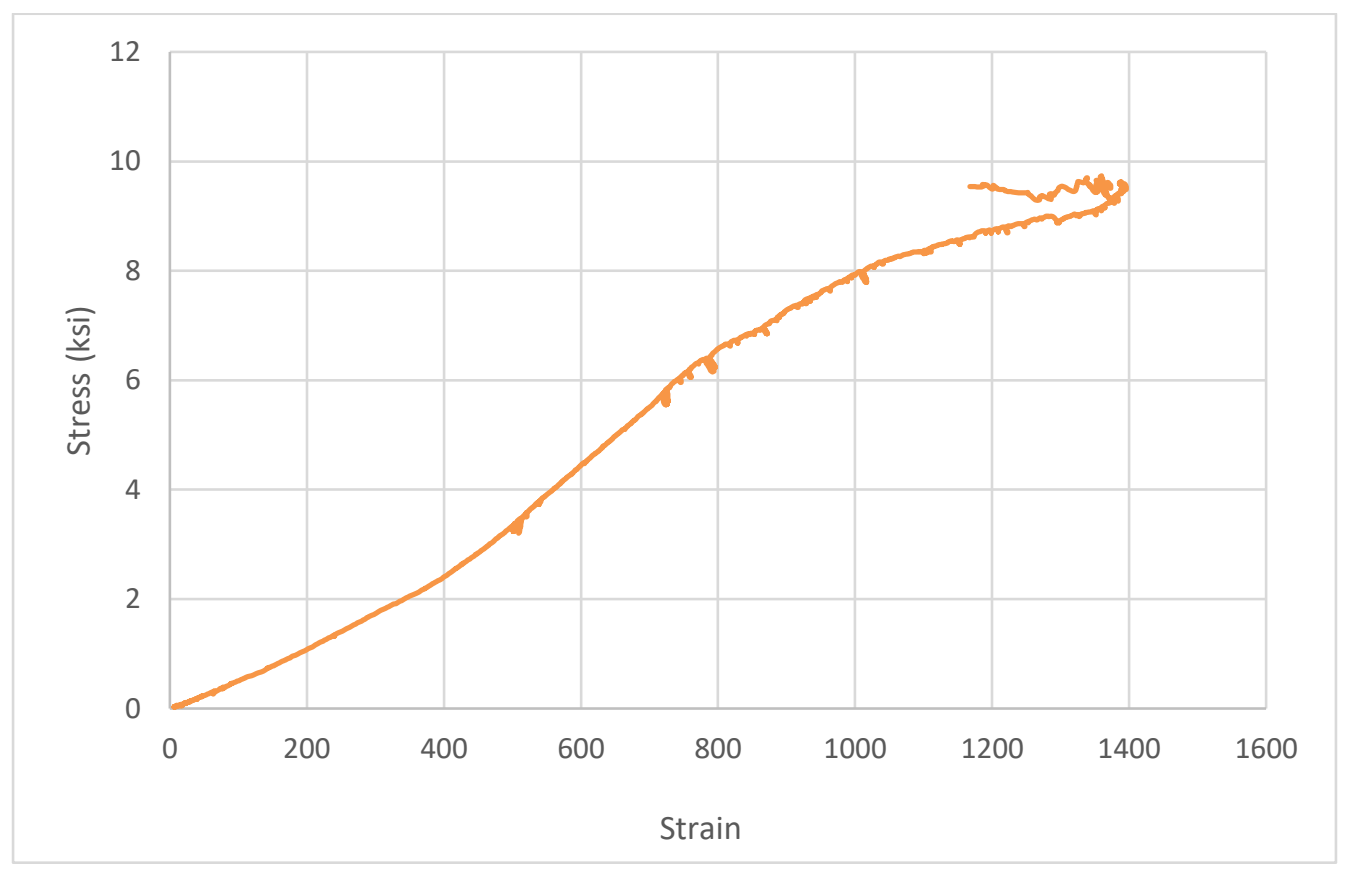

Figure 5. 16:Stress-Strain at Ground Level 
Flange:

$$
\begin{gathered}
1400 \mu \varepsilon=\frac{\frac{M_{\max } 0.1325 \mathrm{in}}{.0016 \frac{\mathrm{in}^{4}}{\mathrm{in}}}}{1600 \mathrm{ksi}}=\left(w * 6.9^{2} \mathrm{in.} 1325 \mathrm{in}\right) /\left(10 * 1600 \mathrm{ksi} * .0016 \mathrm{in}^{4}\right) \\
w_{F}=\frac{5.7 \frac{\mathrm{lb}}{\mathrm{in}}}{i} n
\end{gathered}
$$

Web:

$$
\begin{gathered}
1400 \mu \varepsilon=\frac{\frac{M_{\max } 0.1325 \mathrm{in}}{.0016 \frac{\mathrm{in}^{4}}{\mathrm{in}}}}{1600 \mathrm{ksi}}=\frac{w * 8.9 \mathrm{in}^{2} .1325 \mathrm{in}}{10 * 1600 \mathrm{ksi} * .0016 \mathrm{in}^{4}} \\
w_{w}=\frac{3.4 \frac{\mathrm{lb}}{\mathrm{in}}}{\mathrm{in}}
\end{gathered}
$$

The uniform pressure was then converted so that it was acting perpendicular to the entire test specimen, as opposed to acting perpendicularly to the web section. An angle of 60 degrees was used according to the geometry of the specimen.

$$
w_{W}^{\prime}=\frac{\left(w_{w}\left(l_{W}\right)\right)(\sin (60))}{l_{W}^{\prime}}=\frac{\frac{3.4 \frac{l b}{i n}}{i n(8.9 i n)(\sin (60))}}{4 \mathrm{in}}=\frac{6.58 \frac{\mathrm{lb}}{\mathrm{in}}}{\mathrm{in}}
$$

Each pressure was converted to the maximum moment acting per inch of area, and then multiplied by the effective width and depth to obtain the total moment on the compression side of the specimen. As seen in Figure 5.11, there is pressure applied to the tension side of the pile, just

$$
\begin{gathered}
P_{\max }=\left(\left(w_{f} * N_{f} * l_{f}\right)+\left(w_{w}{ }^{\prime} * N_{w} * l_{w}{ }^{\prime}\right)\right) D \\
\left(\left(\frac{5.7 \frac{\mathrm{lb}}{\mathrm{in}}}{\text { in }} * 6 \text { sections } * 6.9 \mathrm{in}\right)+\left(\frac{6.58 \frac{\mathrm{lb}}{\mathrm{in}}}{\mathrm{in}} * 4 \text { sections } * 4 \mathrm{in}\right)\right) 30 \mathrm{in}=10,237.8 \mathrm{lb}
\end{gathered}
$$


where,

$P_{\text {max }}=$ Maximum load capacity $(\mathrm{lb})$

$N_{F}=$ Number of flange sections

$l_{F}=$ Length of flange section (in)

$w_{F}=$ Pressure on flange $(\mathrm{lb} / \mathrm{in})$

$M_{W}=$ Moment of web (in.lb)

$N_{W}=$ Number of web sections

$l_{W}^{\prime}=$ Horizontal length of web section (in)

$w_{W}^{\prime}=$ Horizontal pressure on web (lb/in)

$$
P_{\text {max }}=10,237.8 \mathrm{lb}=10.2 \mathrm{kips}
$$

A maximum load of 10.2 kips will result from pressure on the compressive face of the test specimen. An additional force will be exerted on the specimen's tension side beneath the pivot point. By definition, the pivot point is the location within the embedment material that the sheet pile rotates about. Therefore, beneath the pivot point, pressure was observed through strain gage data to be in the opposite direction.

The same procedure used to calculate resultant load above the pivot point was used once more, to calculate the resultant load below the pivot point. With force application in the opposing direction and a failure strain of $700 \mu \varepsilon$ (average strain at peak load from three separate tests) was used, the pressure beneath the pivot point was calculated.

Flange:

$$
\begin{gathered}
700 \mu \varepsilon=\frac{\frac{M_{\max } 0.1325 \mathrm{in}}{.0016 \frac{\mathrm{in}^{4}}{\mathrm{in}}}}{1600 \mathrm{ksi}}=\left(w * 6.9^{2} \mathrm{in} .1325 \mathrm{in}\right) /\left(10 * 1600 \mathrm{ksi} * .0016 \mathrm{in}^{4}\right) \\
w_{F}=\frac{2.84 \frac{\mathrm{lb}}{\mathrm{in}}}{\mathrm{in}}
\end{gathered}
$$

Web: 


$$
\begin{aligned}
& 700 \mu \varepsilon=\frac{\frac{M_{\max } 0.1325 \mathrm{in}}{.0016 \frac{\mathrm{in}}{\mathrm{in}}}}{1600 \mathrm{ksi}}=\frac{w * 8.9 \mathrm{in}^{2} .1325 \mathrm{in}}{10 * 1600 \mathrm{ksi} * .0016 \mathrm{in}^{4}} \\
& w_{w}=\frac{1.71 \frac{l b}{i n}}{i n} \\
& w_{W}^{\prime}=\frac{\left(w_{w}\left(l_{W}\right)\right)(\sin (60))}{l_{W}^{\prime}}=\frac{\frac{1.71 \frac{\mathrm{lb}}{\mathrm{in}}}{\mathrm{in}}}{4 \mathrm{in}(8.9 \mathrm{in})(\sin (60))}=3.29 \frac{\frac{\mathrm{lb}}{\mathrm{in}}}{\mathrm{in}} \\
& P_{\max }=\left(\left(w_{f} * N_{f} * l_{f}\right)+\left(w_{w}{ }^{\prime} * N_{w} * l_{w}{ }^{\prime}\right)\right) D \\
& \left(\left(\frac{2.84 \frac{\mathrm{lb}}{\mathrm{in}}}{\mathrm{in}} * 6 \text { sections } * 6.9 \mathrm{in}\right)+\left(\frac{3.29 \frac{\mathrm{lb}}{\mathrm{in}}}{\mathrm{in}} * 4 \text { sections } * 4 \mathrm{in}\right)\right) 6 \mathrm{in}=1021.30 \mathrm{lb}
\end{aligned}
$$

With resistance by the testing configuration accounted for, a force equilibrium approach was used to solve for the maximum load applied to the specimen.

$$
10,237 l b-1,021 l b=9,216 l b=9.2 \text { kips }
$$

A failure load of 9.2 kips is slightly greater than failure loads observed during testing. This discrepancy was attributed to the existence of stress concentrations within the corners (web-flange interface) of the specimen. Stress concentrations can be further accounted for through the use of a stress concentration factor. A factor of safety was also incorporated into the design procedure as shown below.

$$
P_{\text {all }}=\frac{9.2}{3}=3.1 \text { kips }
$$

\subsubsection{Longitudinal Axis Failure}

Failure along the longitudinal axis was calculated using Hooke's law. Equation 5.8 was used to solve for the maximum moment, however because transverse bending leads to longitudinal failure, the moment is 
calculated about the transverse axis. Table 3.2 defines the test specimen properties as provided by the manufacturer. The dimensions are shown in Figure 3.2. A range of failure strain about the transverse axis of 4,000 - 5,000 $\mu \varepsilon$ was taken from the horizontal web 6 inches beneath the ground line, shown in Figure 4.37. This range was utilized because it represented the maximum strain at peak loading in coupon testing. This strain will occur within the test specimen at the failure location, when the peak load is applied.

This obtained strain value was used to solve for the maximum moment using a version of Equation 5.6 was used as an effective width of the specimen.

$$
\begin{gathered}
\varepsilon=\frac{\sigma}{E}=\frac{\frac{M_{\max } c}{I}}{E_{L}}=\frac{M_{\max } c}{E_{L} I} \\
4000-5000 \mu \varepsilon=\frac{M_{\max }(4 \mathrm{in})}{4250 \mathrm{ksi}\left(54.1 \frac{\mathrm{in}^{4}}{f t}\right)(5 \mathrm{ft})} \\
M_{\max }=95.75-120 \mathrm{ft} . \mathrm{kip}
\end{gathered}
$$

A lever arm of $12 \mathrm{ft}$ was present during this trial, therefore:

$$
\begin{gathered}
95.75-120 \text { ft. kip }=P(12 f t) \\
\boldsymbol{P}=\mathbf{8 . 0}-\mathbf{1 0 . 0} \text { kips } \\
\boldsymbol{P}_{\text {all }}=\frac{\mathbf{8}-\mathbf{1 0}}{\mathbf{3}}=\mathbf{2 . 6 6 7}-\mathbf{3 . 3 3} \text { kips }
\end{gathered}
$$

A range from 8 to 10 kips was established as the failure criteria in the longitudinal direction. The prescence of a range in this instance exists due to the complex and unpredictable nature of stress concentrations. With a factor of safety incorporated, a design load of 2.667 to 3.33 kips of load may be applied.

\subsubsection{Embedment Material Failure}

The material surrounding the test specimen was extremely important for each experiment conducted. The response of the test specimen differed greatly in the final testing configuration than it did in preliminary trials. 


\subsubsection{Final Test Embedment Material}

Laboratory testing within the final configuration used a sand-concrete mixture with a ratio of $\mathbf{0 . 7 5}$ parts 3000 psi concrete to 2 parts sand. The concrete mix that totals $33 \%$ of the mixture has a $1: 5$ ratio of cement to fine and coarse aggregate, therefore the material surrounding the sheet pile consists of $6.6 \%$ cement and $92.5 \%$ sand/aggregate materials. Sample material from each test was saved in 6-inch diameter by 12 inch long cylinders and underwent unconfined compressive testing on the day of the corresponding experiment to analyze the compressive strength. Figure 5.17 shows a tested cylinder.

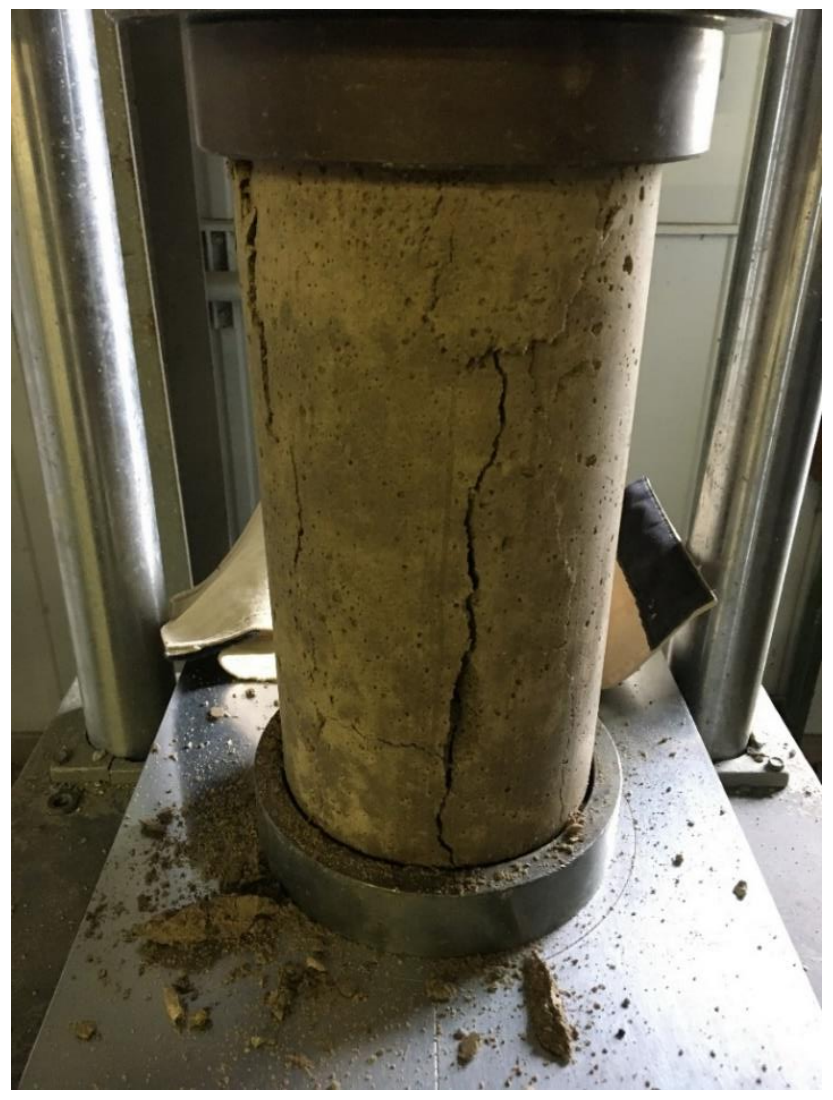

Figure 5. 17:Embedment Material Compression Test

The material shown in Figure 5.17 failed in a columnar like manner. Splitting in this vertical manner has been seen in mortar or cement paste but is not common in concrete specimens. The compressive testing provided a compressive strength of the material that was 70 psi. Using Equation 5.9, the cohesion of the material was established (Das and Sobhan 2017).

$$
c_{u}=\frac{\sigma_{1}}{2}
$$


where,

$q_{u}=$ Normal Stress $(\mathrm{psi})$

$c_{u}=$ Cohesion $(\mathrm{psi})$

Equation 5.9 is only valid for an unconfined compression test. The cohesion of the sand-concrete mixture surrounding the base of the test specimen was 35 psi. The material consists of sand and concrete, however the shear strength is similar to that of a hard clay (Das and Sobhan, 2017). Further efforts were then made to verify the material's properties and Figure 5.18 can be used to assign a similar cohesion value to the material.

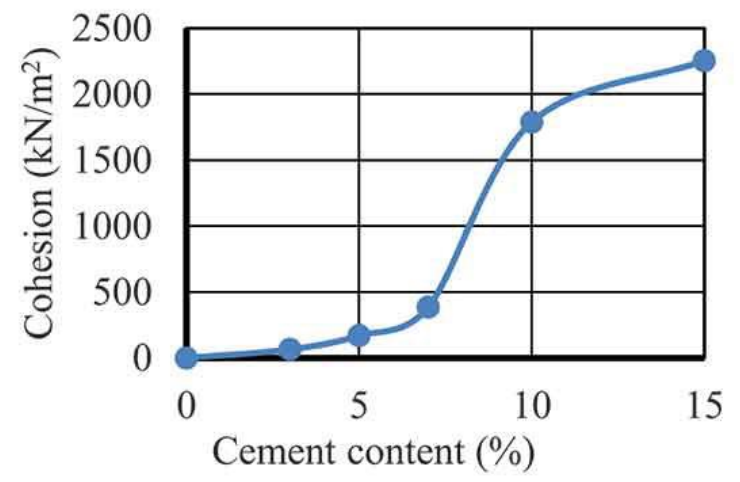

(a)

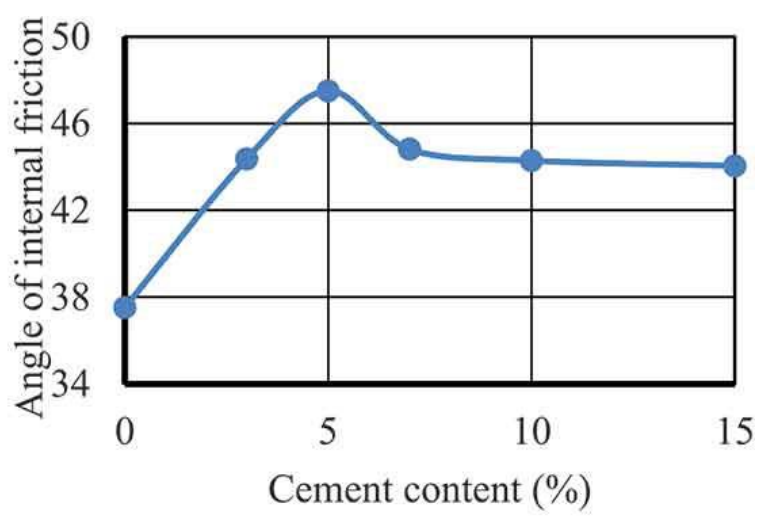

(b)

Figure 5. 18:Cemented Sand Test Results (El-Hanafy and AbdelAziz, 2021)

Figure 5.18 (a) shows a graph created with results from results of several direct shear tests on cemented sands with varying cement content percentages. The material used to test sheet piles with featured cement content of $6.6 \%$. According to Figure 5.18 (a) a cement content of $6.6 \%$ has a cohesion value near 400 $\mathrm{kN} / \mathrm{m}^{2}$ which translates to 58.2 psi. Additionally, from Figure $5.18($ b) a cement content of $6.6 \%$ results in an angle of internal friction of 45 degrees. Using the cohesion value, the shear stress was calculated in Equation 5.12. 


$$
\tau_{f}=c+\sigma \tan \Phi
$$

where,

$\tau_{f}=$ Shear Strength (psi)

$\mathrm{c}=$ Cohesion (psi)

$\sigma=$ Normal Stress on the Failure Plane (psi)

$\Phi=$ Angle of Internal Friction

An extremely conservative approach was taken in which only the cohesive strength was used to obtain the maximum shear strength. This shear strength was most likely greater than just the strength from cohesion, however calculations proved that the strength derived from cohesion was enough to withstand loading. A material with either a cohesive value or concrete is required as an embedment material. If an embedment soil does not have cohesive properties, in a confined region, the soil on and near the surface will fail quickly as its strength would be dependent on the normal force (function of depth). Upon completion of testing, there are no signs of degradation within the material other than small surface cracks. Figure 5.19 shows a top view of the material after a test had been conducted on the specimen with test specimen V-Test 2. 


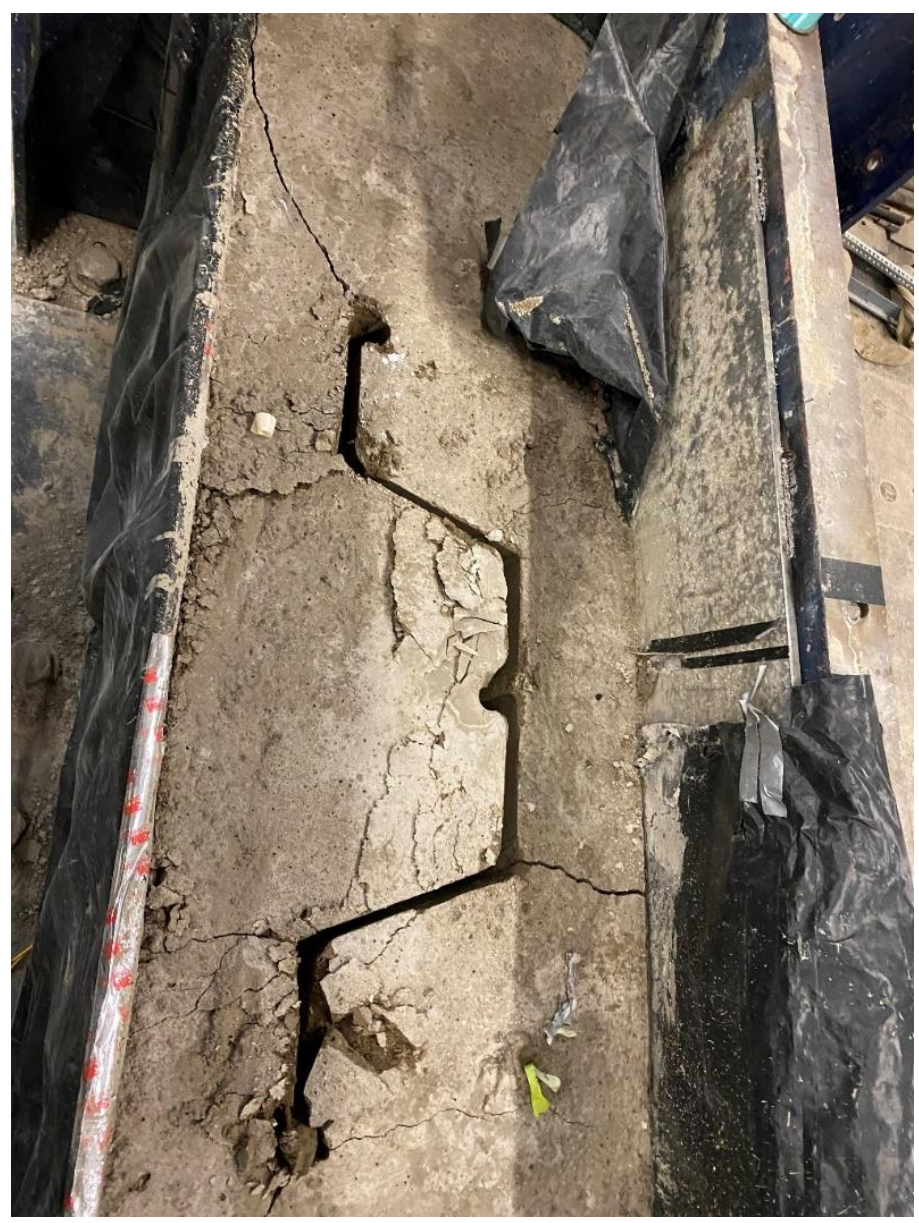

Figure 5. 19:Embedment Material Post-Test

\subsubsection{Alternative Material Shear Strength Properties}

The variance in embedment material throughout the course of testing provided insightful data. A proper test configuration accounts for the shear strength of the embedment material to ensure that the material encapsulating the sheet pile will not fail prior to the sheet pile itself. If soil is surrounding the test specimen, Equation 5.12 can be used to calculate the maximum shear stress that can be resisted by the soil (Coulomb, 1776).

Equation 5.12 was used as a conservative estimation to calculate the shear strength.

$$
\begin{gathered}
1.9 \sqrt{f_{c}^{\prime}}\left(b_{w} d\right) \leq V_{c} \leq 3.5 \sqrt{f_{c}^{\prime}}\left(b_{w} d\right) \\
V_{c}=2.5 \sqrt{f_{c}^{\prime}}\left(b_{w} d\right)
\end{gathered}
$$


where,

$V_{c}=$ Concrete Shear Capacity $(\mathrm{lb})$

$f_{c}^{\prime}=$ Concrete Compressive Strength (psi)

$b_{w}=$ web width of section (in)

$\mathrm{d}=$ distance from extreme compression fiber to centroid of tension reinforcement (in)

\subsubsection{Application of Shear Strength}

The shear strength of the material (35 psi) used in the final testing configuration was studied to ensure that it would provide sufficient resistance for the test specimen. Equation 5.13 was used to solve for the maximum moment that the material could withstand, which was then used to determine the maximum load that can be applied.

$$
\begin{gathered}
w_{s} b d=P \\
35 p s i * 72 \text { in } * 36 \text { in } * 144 \text { in }=P(144 \mathrm{in}) \\
P=90,720 \mathrm{lb}
\end{gathered}
$$

where,

$M_{\max }=$ Maximum Moment (ft-lb)

$w_{s}=$ Maximum Shear Pressure (psi)

$\mathrm{b}=$ Width of specimen (in)

$\mathrm{d}=$ Depth of material (in)

The safety factor of 3 is then accounted for.

$$
P_{\text {allow }}=\frac{90,720}{3}=30,240 \mathrm{lbs}
$$

An allowable load of 30,240 lbs signified that the embedment material would not fail prior to the sheet pile and a test can be conducted knowing that the sheet pile failure will occur.

\subsection{ASTM DESIGN GUIDE}

An established procedure to calculate the maximum load allowed was established in the fashion of an ASTM procedure. Design examples were then created in this section to demonstrate the usability of the 
design guideline. Several variables that effect a sheet pile's stability, including soil properties, lever arm, and embedment depth were accounted for in the guideline. Using equations from Chapter 5, the guideline for analyzing experimental results as well as design examples was presented in the following chapter.

\section{Scope}

1.1 This method determines both the load and bending moment capacities of corrugated FRP sheet piles, including z-sections.

1.1.1 Test Procedure is the procedure created to test the load and bending capacities of FRP composite sheet piles

1.1.2 Procedure $A$ is an analysis of failure about the transverse axis of a test specimen to determine the maximum resisting load and bending moment.

1.1.3 Procedure $B$ is an analysis of failure about the longitudinal axis of a test specimen to determine the maximum resisting load and bending moment.

1.1.4 Procedure $C$ is an analysis of the soil properties and their ability to resist a rotational failure when a load is incurred on a sheet pile wall embedded in the soil.

1.2 For comparison purposes, data must be analyzed within each procedure $(\mathrm{A}, \mathrm{B}, \mathrm{C})$ so that the lowest ultimate load will be accepted as the failure load of the test specimen.

1.3 The lowest ultimate load is used to find the maximum allowable load through the implementation of a factor of safety.

1.4 This standard does not purport to address all of the safety concerns, if any, associated with its use. It is the responsibility of the user of this standard to establish appropriate safety and health practices and determine the applicability of regulatory limitations prior to use.

\section{Referenced Documents}


ASTM Standards:

ASTM D2850.380331-1

ASTM D3080.380331-1

ASTM D4767

ASTM A328/A328M-13a(2018)

ASTM D7264/D7264M-07

Other Documents:

EM 1110-2-2504

US Steel Sheet Pile Design Manual

\subsection{Terminology}

3.1 Definitions - Terminology D3878 defines the terms relating to high modulus fibers and their composites.

Sheet pile wall: A continuous row of interlocking, vertically installed pile segments that form a wall, retaining soil and/or water thrust against the sheet pile wall. The plan dimension of the wall is sufficiently large so that its behavior may be considered as one unit.

Cantilever wall: A sheet pile wall which derives its support through interaction with surrounding embedment material and surrounding soil.

Free Cantilever wall: Version of a cantilever wall where a portion of the sheet pile remains free-standing above the ground with no backfill or soil present.

Pivot Point: Location within embedded material where cantilever sheet pile walls rotate as a result of active and passive forces.

Dredge Line: Term used to describe the top of the soil material that a sheet pile wall is embedded in.

3.3 Symbols:

$w_{f}=$ Uniform pressure on flange $(\mathrm{lb} / \mathrm{in})$ 

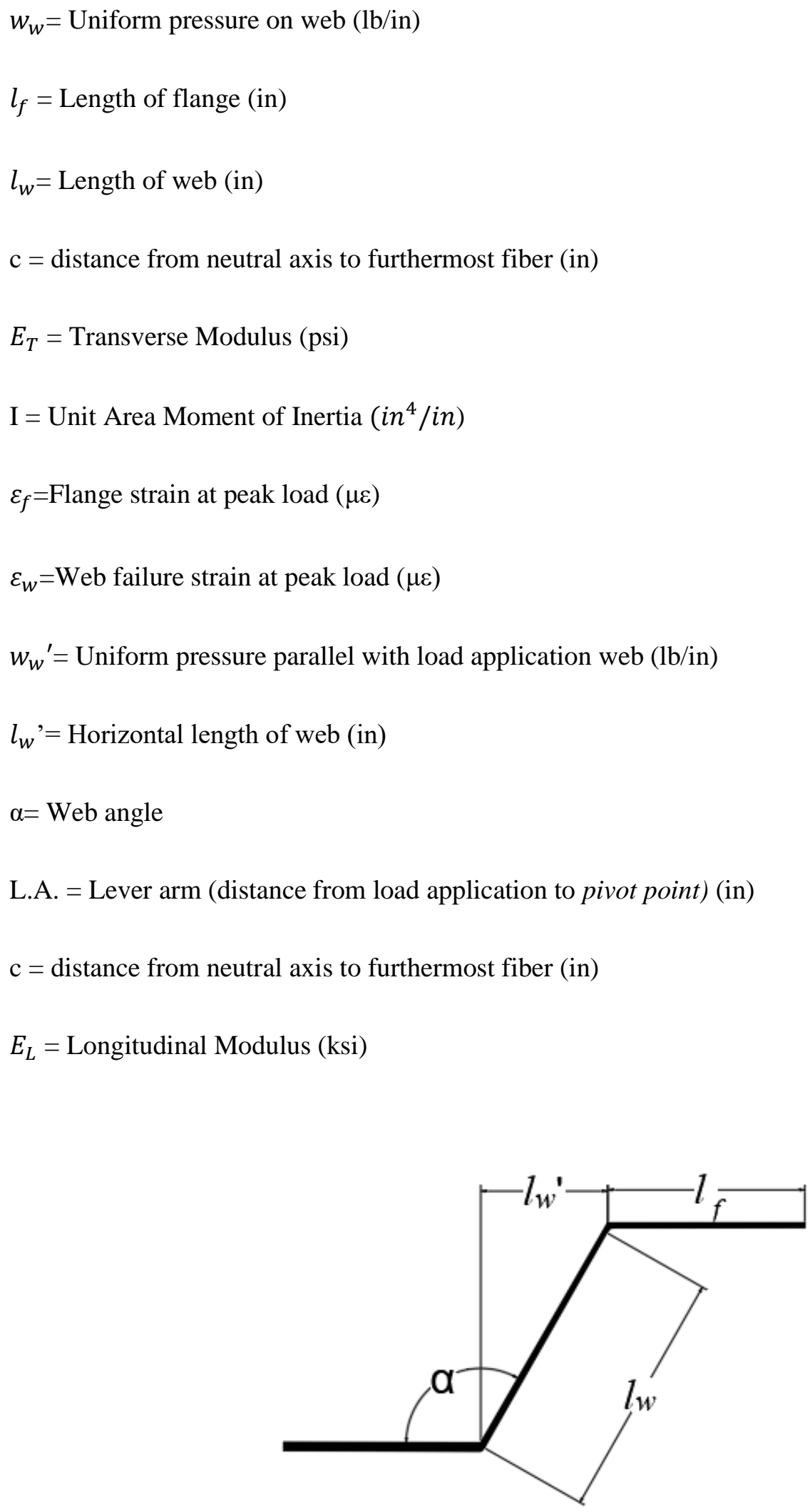

Figure 5. 20:Property Identification 


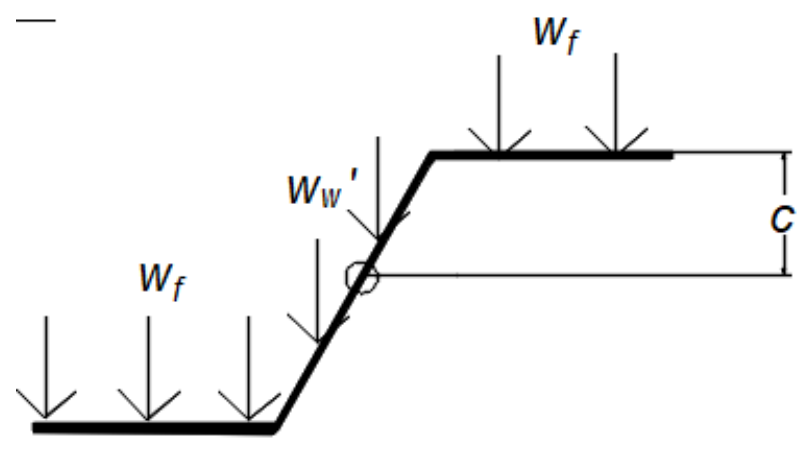

Figure 5. 21:Load Direction

\subsection{Summary of Test Method}

Test Procedure-The test procedure to calculate the load capacity of an FRP composite sheet pile is described. Procedure A can be used to determine the load required to cause a failure about the transverse axis of a test specimen. Procedure B can determine the load required to cause a failure about the longitudinal axis of a test specimen. Procedure $C$ determines if the soil at the location of sheet pile installation has the shear strength to prevent rotational failuire.

\section{Significance and Use}

5.1 This test method determines the maximum bending moment and load capacity of FRP composite sheet piles under the conditions defined. This method was developed for optimum use with continuous fiber and/or fabric or mat reinforced polymer matrix composite sheet piles and differs in several respects from other sheet pile test methods.

5.2 Results from this procedure can be used to design sheet pile retaining walls with FRP composite sheet piles.

5.3 These procedures may also be used to confirm/compare engineering properties of the structure such as the modulus.

\section{Apparatus}

7.1 Testing Container: A rectangular container must be constructed so that embedment material can be filled to the desired height around the base of a test specimen. This material will provide the necessary 
support for the sheet pile so that load can be applied at the free end of the cantilever until failure. The container must be constructed from steel and fastened to a structural foundation so that there is no rotation when load is applied. The majority of strength derived from the box needs to be derived from the compression and tension sides of the test specimen. The walls that are parallel with load application need to be able to contain embedment material, and resist tensile forces generated by the sheet pile under bending loads acting at the free end of embedded cantilever sheet pile system, but there is no additional strength needed.

7.2 Load Connection: Horizontal wale sections must be fastened to the desired height of load application on either side of the sheet pile wall, interconnecting several sheet pile modules/sections. The wale section will distribute load so that a horizontal line load is acting on the sheet pile specimen. Bolts must extend from the wale section on the load side of the specimen so that the loading device can be connected to the wale section.

7.3 Load Application: Load must be applied using an actuator. The actuator must be mounted at the desired height of load application and pull the test specimen at a 90-degree angle to the sheet piles' major bending axis.

7.4 Deflection Measurement: The measurement of deflection during testing is optional and can provide additional information. A string pot can be set on the ground on the tension side of the test specimen and through the use of a pulley attached to an extended arm, be connected perpendicularly to the wale section.

\section{Test Specimens}

8.1 Specimen Preparation: Individual sheet pile segments must be connected to a desired size so that there is an even number of segments and the specimen is symmetric across the neutral axis. There must be a minimum of 6 inches on either side from the test specimen to the side walls of the test bin which has the compacted soil and embedded sheet pile. Additionally, a minimum of span of 8 inches is required to exist from the face of the sheet pile on either side to the steel walls. Once the sheet pile wall is constructed, a wale section must be attached at the desired height of load application, with bolts extending from the wale section that can be fastened to the actuator. 
8.2 Specimen Size: Each sheet pile segment comprising a test specimen should be pultruded to the desired length. A taller specimen with a greater distance from loading to the dredge line will fail at a lower load. This is important to consider if limit load application is a constraint. Specimen size is chosen such that there is a reduced ratio of total width to effective width. All or part of the exterior flange sections (that are unreinforced without contiguous sheet piles) on any open-faced Z-section sheet pile test specimen will be

ineffective at resisting load and in turn the length of the flanges must be negated from the overall width of the test specimen for analysis purposes. Therefore, a test specimen with four sheet pile segments has a reduced effect from the effective width than a specimen with two sheet pile segments.

8.3 Pivot Point: During Test Procedure, the pivot point can be assumed to be at a depth equivalent to 85 percent of the total embedment depth. When Procedure B is used to design a sheet pile in the field, a guideline for creating a pressure distribution plot which can locate the pivot point is provided in EM

\section{0-2-2504.}

\section{Embedment Material}

9.1 Sand-Concrete Mixture-- An embedment material must be placed around the base of the sheet pile so that adequate stability is achieved for a test to be conducted. A sand-concrete mixture is to be used due to its high shear strength properties (similar to those of a stiff clay). A combination of 0.75 parts concrete (3000 psi) and 2 parts sand can be used. This results in a ratio of 1 part cement: 60 parts sand: 10 parts stone. Materials with exceptionally high shear strength like reinforced concrete alter the behavior of the sheet pile mode of failure and provide results that misrepresent sheet pile behavior.

9.2 Quality Control--Compressive tests must be conducted on the embedment material so that quality can be assured. A compressive strength ranging from 20 psi to 100 psi should be documented with the recommended embedment material. Upon the installment of the sand-concrete mixture, a concrete vibrator must be used to consolidate the material prior to hardening to ensure a consistently low void content. 


\section{Laboratory Test Procedure}

10.1 Measure the height of test specimens/modules and ensure that load is applied perpendicularly to pultrusion direction. Record the specimen properties such as the width of the specimen, width of the flange sections, and width of the web sections.

10.2 Speed of Testing: Set the speed of load application within a range of 1 kip of load (within 10\% margin of error) per minute.

10.3 Apply the force to the specimen at the specified rate. Measure and record force data so that a minimum of 100 data points comprise the results.

10.4 Failure Modes - To obtain valid maximum load, it is necessary that failure occurs within the sheet pile test specimen as opposed to the embedment material. A failure about the transverse or longitudinal axis will occur in a successful test and should be documented. Failure on the compression surface will likely be either local buckling about the transverse axis or rupture about the longitudinal axis at a location where stress concentrations exist.

\section{Calculation}

11.1 Test Procedure - Each test conducted on a specimen will provide a failure load at which the specimen will show signs of failure and loading will decrease. The maximum load prior to a significant

drop in load can be considered the failure load. This load should be used as a maximum load for the sheet pile to be designed for and can be used more effectively for design purposes when divided by effective width (pounds/width of wall).

11.1.1 Test Procedure Failure Moment Resistance-With a failure load established, the maximum moment that a test specimen can withstand can be defined as:

$$
M_{\max }=P(\text { L.A. })
$$

where,

$M_{\max }=$ Maximum Moment (ft-lbs/ft effective width of test specimen)

$\mathrm{P}=$ Maximum load (lbs/ft effective width of test specimen)

L.A.= Lever Arm (ft) (Assumed to be Load Height - (6-12 inches) when tested in less than 5 feet of embement material 
11.1.2 Test Procedure: Embedment Material Check -- Embedment material surrounding a sheet pile at its base must have a shear strength greater than that of the reaction stress at the base of the test specimen, when the specimen naturally fails. Shear strength of the embedment material is calculated using:

where,

$$
\tau_{f}=c+\sigma \tan \Phi
$$

$\tau_{f}=$ Shear Strength (psi)

$\mathrm{c}=$ Cohesion (psi)

$\sigma=$ Normal Stress on the Failure Plane (psi)

$\Phi=$ Angle of Internal Friction

ASTM D2850.380331-1, ASTM D3080.380331-1, and ASTM D4767 can be used to obtain soil properties if a different material is used to embed the test specimen. The shear strength of the soil can then be used to determine the point at which the soil can be expected to fail:

$$
\tau_{f} b d=P_{\max }
$$

where,

$\tau_{f}=$ Shear Strength (psi)

$\mathrm{b}=$ Width of embedment material (in)

$\mathrm{d}=$ Depth of embedment material (in)

11.1 Maximum Bending Moment Procedure A-When a FRP composite sheet pile test specimen is placed as a free cantilever and exerted with applied load and failure is observed to be rupture about the transverse axis, the uniform pressure acting on the sheet pile from the embedment material that is transferred to the flange or web sections can be calculated as Equation 4 . This equation accounts for partial fixity of soil as an embedment material, as opposed to a fixed condition by reducing the moment value to $\frac{w l^{2}}{10}$.

$$
w_{f, w}=\frac{1}{\frac{l_{f, w}{ }^{2} c}{10 E_{T} I \varepsilon_{f, w}}}
$$


where,

$w_{f}=$ Uniform pressure on flange (lb/in)

$w_{w}=$ Uniform pressure on web (lb/in)

$l_{f}=$ Length of flange (in)

$l_{w}=$ Length of web (in)

$\mathrm{c}=$ distance from neutral axis to furthermost fiber (in)

$\mathrm{E}=$ Bending Modulus (psi)

$\mathrm{I}=$ Unit Area Moment of Inertia $\left(i n^{4} /\right.$ in $)$

$\varepsilon_{f}=$ Flange strain at peak load provided by manufacturer $(\mu \varepsilon)$

$\varepsilon_{w}=$ Web strain at peak load provided by manufacturer $(\mu \varepsilon)$

The calculated pressure must be accounted for in a direction perpendicular to pultrusion. For standard Zsection sheet pile segments, the pressure calculated in equation can be converted with the following equation:

$$
w_{w}{ }^{\prime}=\left(\left(w_{w} * l_{w}\right) \sin (180-\alpha)\right) / l_{w}{ }^{\prime}
$$

where,

$w_{w}=$ Uniform pressure perpendicular to web (lb/in)

$w_{w}{ }^{\prime}=$ Uniform pressure parallel with load application web (lb/in)

$l_{w}=$ Length of web (in)

$l_{w}{ }^{\prime}=$ Horizontal length of web (in)

$\alpha=$ Web angle

The overall load capacity that the test specimen can withstand is:

$$
P_{\max }=\left(\left(w_{f} * N_{f} * l_{f}\right)+\left(w_{w}{ }^{\prime} * N_{w} * l_{w}{ }^{\prime}\right)\right) D
$$

where,

$P_{\text {max }}=$ Maximum Load (lb)

$w_{f}=$ Uniform pressure parallel with load application on flange (lb/in)

$w_{w}{ }^{\prime}=$ Uniform pressure parallel with load application on web (lb/in)

$l_{f}=$ Horizontal length of web (in) 
$l_{w}{ }^{\prime}=$ Horizontal length of web (in)

$N_{f}=$ Number of effective flange sections

$N_{w}=$ Number of effective web sections

$\mathrm{D}=$ Length of interface at which passive force is present (in)

Equation 6 is valid because it takes the sheet pile pressure distribution plot into consideration. The strains fluctuate until the pivot point is reached (D), however, the triangular fashion of shear force distribution when pressure increases results in a similar (negligible difference proved in Section 5.3) total force resistance to a uniform pressure across the entire depth until the pivot point is reached.

11.2 Maximum Bending Moment Procedure B (crack developing in the transverse direction) - FRP composite sheet piles can demonstrate failure about the longitudinal axis when a sufficient amount of load is applied. The maximum load that the test specimen can withstand is defined as:

$$
P_{\max }=\frac{1}{\frac{(L . A .) c}{E_{L} I \varepsilon}}
$$

where,

$P_{\text {max }}=$ Maximum load (lb)

L.A. = Lever arm (distance from load application point to pivot point) (in)

$\mathrm{c}=$ distance from neutral axis to furthermost fiber (in)

$E_{L}=$ Longitudinal Modulus (ksi)

$I=$ Section area moment of inertia $\left(\mathrm{in}^{4}\right)$

$\varepsilon=$ strain at peak load about transverse axis as provided by manufacturer $(\mu \varepsilon)$

11.3 Design for Rotational Stability —Cantilever sheet pile walls rely on stability from soil. Proper analysis of the soil is needed to determine that there is rotational stability. With known soil properties, one can calculate the pressures exerted onto the pile and use a force equilibrium approach to determine the driving depth. Per EM-1110-2-2504 it can be assumed that a cantilever wall rotates about a pivot point due to applied loads that present themselves in the form of active and passive pressures. The typical 
distribution of active and passive pressures onto a sheet pile embedded in granular material is shown in Figure 5.22.

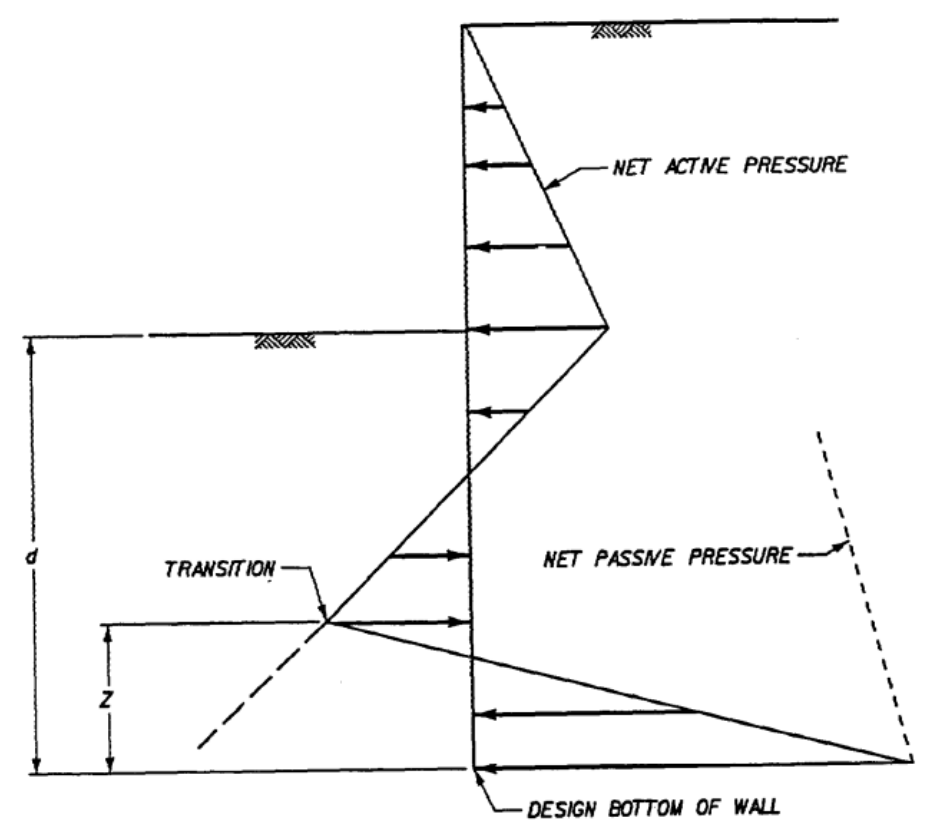

Figure 5. 22:Net Pressure Distribution Plot

The first step to obtaining the active or passive pressure at a given location is to define the normal stress at that location:

$$
\sigma=\Upsilon L
$$

where,

$\sigma=$ Normal Stress $\left(\mathrm{lb} / \mathrm{ft}^{2}\right)$

$\Upsilon=$ Unit weight of soil $\left(\mathrm{lb} / \mathrm{ft}^{3}\right)$

$\mathrm{L}=$ Distance from surface $(\mathrm{ft})$

Regardless of the in-situ material, active force can be defined as:

$$
\sigma_{a}=\sigma K_{a}
$$

where,

$\sigma_{a}=$ Active pressure $\left(\mathrm{lb} / \mathrm{ft}^{2}\right)$

$K_{a}=$ Active earth pressure coefficient

Passive force is equivalent to:

$$
\sigma_{p}=\sigma K_{p}
$$


where,

$\sigma_{p}=$ Passive pressure $\left(\mathrm{lb} / \mathrm{ft}^{2}\right)$

$K_{p}=$ Passive earth pressure coefficient

Active and Passive coefficients can be obtained from Figure B-4 located in the appendix. A diagram shown in Figure 23 must be created using calculated active and passive forces along the depth of the cantilever sheet pile wall.

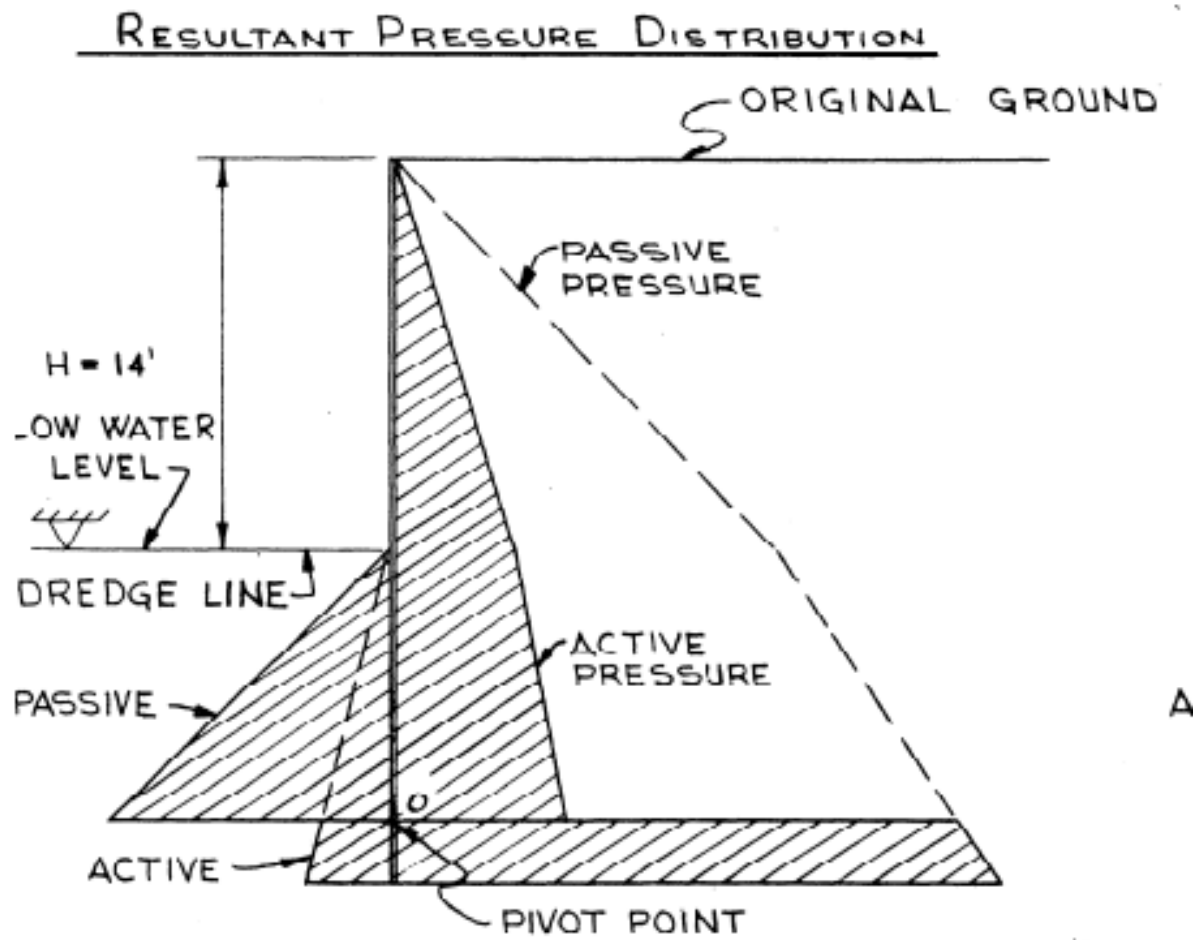

Figure 5. 23:Sheet Pile Total Pressure Distribution

The total pressure distribution plot must be deduced to a net pressure distribution plot as shown in Figure 5.22. The depth of penetration is assumed (reasonable value for a sheet pile wall, typically $1.5(\mathrm{H})$ initially) in order to calculate moment about the bottom of the sheet pile (theoretically zero). If a negligible value is obtained (less than 1,000 ft-lb), the assumed depth is accepted. To assure a margin of safety, D may be increased by 20 to $40 \%$ (US Steel Design Manual, 1984) 


\section{Validation}

12.1 Values for maximum load and moment capacity obtained through Test Procedure shall not be used for design purposes for any specimen that breaks at some obvious, fortuitous flaw, unless such flaw constitute a variable being studied. Results from experiments where test specimens fail in an unacceptable failure mode shall not be used.

\section{Report}

13.1 Report the following information, or references pointing to other documentation containing this information, to the maximum extent applicable if Test Procedure is used to obtain the maximum load capacity of a sheet pile test speciemn. (Reporting of items beyond the control of a given testing laboratory, such as might occur with material details of panel fabrication parameters, shall be the responsibility of the requestor):

13.1.1 The revision level or date of issue of the test method used.

13.1.2 The date(s) and location(s) of the testing.

13.1.3 The name(s) of the test operator(s).

13.1.5 Any variations to this test method, embedment material properties, anomalies noticed during testing, or equipment problems occurring during testing.

13.1.6 Identification of the material tested, including: material specification, material type, material designation, manufacturer, manufacturer's lot or batch number, source (if not from the manufacturer), date of certification, expiration of certification, filament diameter, tow or yarn filament count and twist, sizing, form or weave, fiber areal weight, matrix type, prepreg matrix content, and prepreg volatiles content

13.1.7 Identification of test specimen size and cross section, including: total length of specimen, width of each flange section, width of each web section, angle of web section, thickness test specimen.

13.1.8 Identification and inclusion of effective width.

13.1.9 Manufacturer material specifications including but not limited to : longitudinal modulus, transverse modulus and strain recorded at peak load conditions about each axis. 
13.1.10 Failure mode and location of failure for each specimen.

\section{Precision and Bias}

15.1 Precision - The data required for the development of precision is not currently available for this test method.

15.2 Bias - Bias cannot be determined for this test method as no acceptable reference standard exists.

\section{Keywords}

15.1 fiber reinforced composites, flexural properties, sheet piles, retaining walls, design guide, strength, stiffness, experimental procedure, load capacity

\section{Design Example 1}

The following example was created to show the effects of a soil with weak shear strength surrounding the base of a test specimen.

A test is to be conducted on a Series 1580 Seawall Profile Sheet Pile. The material properties of this specimen are shown in Table 6. The test specimen is pulled from a height of 10 feet. Poorly graded, loose, dry sand $(\Phi=27$ degrees, $\mathrm{V}=102 \mathrm{pcf}, \mathrm{c}=0)$ is used as the material to surround the pile. The sand is poured so that the test specimen has an embedment depth of 5 feet. The pivot point exists 4 feet beneath the dredge line. Calculate the maximum load that can be applied before the sand experiences a failure.

Table 6 Test Specimen Properties

\begin{tabular}{|l|r|r|}
\hline & \multicolumn{1}{|l|}{ Flange } & \multicolumn{1}{l|}{ Web } \\
\hline l (in) & 6.6 & 4 \\
\hline $\mathrm{c}$ (in) & 0.1325 & 0.1325 \\
\hline $\mathrm{E}$ (psi) & $1.6^{*} 10^{6}$ & $1.6^{*} 10^{6}$ \\
\hline $\mathrm{b}$ (in) & 1 & 1 \\
\hline $\mathrm{h}$ (in) & 0.265 & 0.265 \\
\hline $\mathrm{I}\left(\right.$ in $\left.^{4}\right)$ & 0.0016 & 0.0016 \\
\hline
\end{tabular}

The shear strength of the sand must be calculated using Equation 5.12. An average $\sigma$ (Normal Stress) is taken throughout the depth of embedment:

$$
\tau_{f}=c+\sigma \tan \Phi
$$




$$
\tau_{f}=0+\frac{102 \frac{l b s}{f t^{3}} * 4 f t}{2}=104 \frac{l b s}{f t^{2}}=0.72 p s i
$$

The moment capacity (exerted onto soil by sheet pile) is calculated using Equation 10. The lever arm is calculated using the depth of embedment and pivot point location provided in the problem statement.

$$
\begin{gathered}
w_{s} b d(\text { L.A. })=P(\text { L.A. }) \\
0.72 \text { psi } * 72 \text { in } * 60 \text { in } * 108 \text { in }=P * 108 \text { in } \\
P=\mathbf{3}, \mathbf{1 1 0} \text { lbs }
\end{gathered}
$$

The sand would show signs of failure when 3,110 pounds of load were applied to the top of the test specimen. Based on experimental findings, this would be premature and the test specimen would not have failed.

\section{Design Example 2}

\section{Peak Failure strain}

A test is to be conducted on a Series 1580 Seawall Profile Sheet Pile. The material properties of this specimen are shown in Table 6 . The test specimen is pulled from a height of 12.5 feet. A sandy concrete mixture that featured less cement than experimental testing (compressive strength $=40 \mathrm{psi}$ ) was poured to a depth of 3 feet is used as the embedment material. The pivot point is located 2 feet beneath the dredge line. Coupon testing of the material revealed a failure strain of $5000 \mu \varepsilon$ on the transverse axis, and it was revealed that strains along the transverse axis of the test specimen at the dredge line were approximately $1500 \mu \varepsilon$. A pivot point is located 5 inches above the bottom of the test specimen. At 2.5 inches above the ground, the strain was approximately $550 \mu \varepsilon$. What is the maximum load that can be applied to the test specimen?

The shear strength of the embedment material must be conservatively calculated using Equation 5.9:

$$
\tau_{f}=\frac{\sigma_{1}}{2}=\frac{40}{2}=20 p s i
$$

Equation 5.10 is then used to determine embedment material load capacity:

$$
w_{S} b d(L . A .)=P(\text { L.A. })
$$




$$
\begin{gathered}
20 \text { psi } * 36 \text { in } * 72 \text { in } * 138 \text { in }=P * 138 \text { in } \\
P_{\max }=\mathbf{5 1 , 8 4 0 ~ l b s}
\end{gathered}
$$

Accounting for the factor of safety, the maximum allowable load for the embedment material is:

$$
P_{\text {allow }}=\frac{P_{\text {max }}}{3}=\frac{51,840}{3}=17,280 \text { lbs }=17.28 \text { kips }
$$

Sheet pile capacity must now be checked in the horizontal and longitudinal directions. Equation 5.6 was used to find the pressure (w) exerted onto the flange and web sections of the sheet pile.

$$
\begin{gathered}
w_{f, w}=\frac{1}{\frac{l_{f, w}{ }^{2} c}{10 E_{T} I \varepsilon_{f, w}}} \\
w_{f}=\frac{1}{\frac{6.9^{2} \mathrm{in} 0.13 \mathrm{in}}{10(1600 \mathrm{ksi})\left(0.0016 \mathrm{in}^{4}\right)(1500 \mu \varepsilon)}}=6.1 \frac{\mathrm{lb}}{\mathrm{in}} / \mathrm{in} \\
w_{w}=\frac{1}{\frac{8.9^{2} \mathrm{in} 0.13 \mathrm{in}}{10(1600 \mathrm{ksi})\left(0.0016 \mathrm{in}^{4}\right)(1500 \mu \varepsilon)}}=3.7 \frac{\mathrm{lb}}{\mathrm{in}} / \mathrm{in}
\end{gathered}
$$

Web pressure direction must then be converted so that it is acting perpendicular to the pultrusion direction.

$$
\begin{gathered}
w_{w}^{\prime}=\left(\left(w_{w} * l_{w}\right) \sin (180-\alpha)\right) / l_{w}{ }^{\prime} \\
\left.w_{w}^{\prime}=(3.7 * 8.9 \mathrm{in}) \sin (180-120)\right) / 4 \mathrm{in}=7.0 \mathrm{lb} / \mathrm{in} / \mathrm{in}
\end{gathered}
$$

The resultant force is then calculated to be:

$$
\begin{gathered}
F_{R}=\left(\left(w_{f} * N_{f} * l_{f}\right)+\left(w_{w}{ }^{\prime} * N_{w} * l_{w}{ }^{\prime}\right)\right) D \\
F_{R}=\left(\left(6.1 \frac{l b}{\text { in }} / \text { in } * 6 * 6.9 \text { in }\right)+\left(7.0 \frac{l b}{\text { in }} / \text { in } * 4 * 4 \text { in }\right)\right) 31 \text { in }=11,300 \mathrm{lb}
\end{gathered}
$$

The pressures and resultant force beneath the pivot point must now be calculated:

$$
w_{f}=\frac{1}{\frac{6.9^{2} \text { in } 0.13 \mathrm{in}}{10(1600 \mathrm{ksi})\left(0.0016 \mathrm{in}^{4}\right)(550 \mu \varepsilon)}}=2.2 \frac{\mathrm{lb}}{\mathrm{in}} / \mathrm{in}
$$




$$
\begin{gathered}
w_{w}=\frac{1}{\frac{8.9^{2} \mathrm{in} 0.13 \mathrm{in}}{10(1600 \mathrm{ksi})\left(0.0016 \mathrm{in}^{4}\right)(550 \mu \mathrm{\varepsilon})}}=1.3 \frac{\mathrm{lb}}{\mathrm{in}} / \mathrm{in} \\
\left.w_{w}^{\prime}=(1.3 * 8.9 \mathrm{in}) \sin (180-120)\right) / 4 \mathrm{in}=2.6 \mathrm{lb} / \mathrm{in} / \mathrm{in} \\
F_{R}=\left(\left(2.2 \frac{\mathrm{lb}}{\mathrm{in}} / \mathrm{in} * 6 * 6.9 \mathrm{in}\right)+\left(1.3 \frac{\mathrm{lb}}{\mathrm{in}} / \mathrm{in} * 4 * 4 \mathrm{in}\right)\right) 5 \mathrm{in}=559.4 \mathrm{lb} \\
P_{\max }=11,300 \mathrm{lb}-559.4 \mathrm{lb}=10,740 \mathrm{lb}
\end{gathered}
$$

The maximum load capacity of the transverse axis is $10,740 \mathrm{lb}$.

Longitudinal failure is then accounted for:

$$
\begin{gathered}
\varepsilon_{f}=\frac{\sigma}{E}=\frac{\frac{M_{\max } c}{I}}{E_{L}}=\frac{M_{\max } c}{E_{L} I} \\
5000 \mu \varepsilon=\frac{M_{\max }(4 \mathrm{in})}{4250 \mathrm{ksi}\left(54.1 \frac{\mathrm{in}}{f t} * 5 f t\right)} \\
M_{\max }=1437.03 \text { in. kips }
\end{gathered}
$$

Maximum load was obtained:

$$
\begin{gathered}
M_{\max }=P(\text { L.A. }) \\
1437.03 \text { in. kips }=P(138 \mathrm{in}) \\
P_{\max }=10.41 \text { kips }
\end{gathered}
$$

As a result of the three computations, longitudinal failure due to transverse bending of FRP sheet pile was the lowest value. This signified that the failure would occur in this method and a factor of safety can be added to this failure mode to create an allowable design load.

$$
P_{\text {allow }}=\frac{P_{\text {max }}}{3}=\frac{10.41}{3}=3.47 \mathrm{kips}
$$




\section{Design Example 3 (US Steel Sheet Pile Design Manual, 1984)}

\section{Rotational Stability}

Using soil properties properties defined in Table 7 create a pressure distribution plot of the sheet pile wall shown in Figure 5.24 (US Steel Sheet Pile Design Manual, 1984) and obtain the required depth of penetration for the wall. Figure B-4 provided earth pressure coefficients.

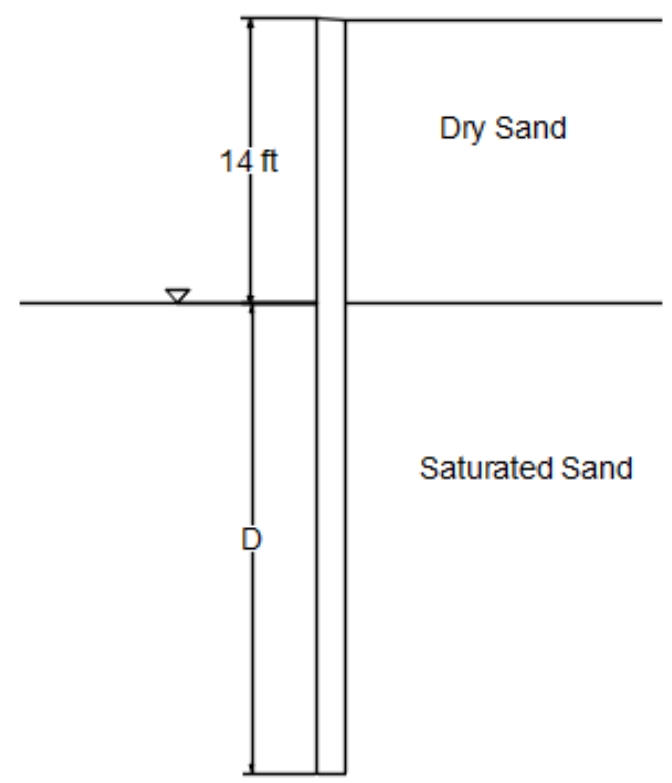

Figure 5. 24:Sheet Pile Example Problem

Table 7: Example 3 Soil Properties

\begin{tabular}{|c|c|}
\hline Property & Value \\
\hline Dry Unit Weight (Y) & $115 \mathrm{lb} / \mathrm{ft}^{3}$ \\
\hline Saturated Unit Weight (Y') & $65 \mathrm{lb} / \mathrm{ft}^{3}$ \\
\hline Angle of Friction ( $\phi)$ & $35^{\circ}$ \\
\hline$K_{a}$ & 0.27 \\
\hline$K_{p}$ & 6.56 \\
\hline
\end{tabular}


Wall pressures at each location shown in Figure 5.25 must be calculated.

PA1 (only active pressure (Equation 9) above dredge line):

$$
P A 1=115 \frac{l b}{f t^{3}} * 14 f t * 0.27=435 \frac{l b}{f t^{2}}
$$

Active pressure beneath the dredge line (PA2) can be calculated as:

$$
P A 2=P A 1+Y^{\prime} \frac{l b}{f t^{3}} * D * K_{a}=P A 1+65 \frac{l b}{f t^{3}} * 0.27=435 \frac{l b}{f t^{2}}+17.6 D
$$

Total Pressure at PE can be obtained by using the slope of the pressure plot from A1 to E

$$
\begin{gathered}
P E=\Upsilon^{\prime} \frac{l b}{f t^{3}} * D\left(K_{p}-K_{a}\right)-P A 1=65 \frac{l b}{f t^{3}} * D(3.69-0.27)-435 \frac{l b}{f t^{2}} \\
P E=408.9 D-435 \frac{l b}{f t^{2}}
\end{gathered}
$$

Total pressure at PJ can be obtained through a similar method, with the same slope added to the passive pressure from above the dredge line..

$$
\begin{gathered}
P J=\Upsilon^{\prime} D\left(K_{p}-K_{a}\right)+\sigma_{P} \\
P J=65 \frac{l b}{f t^{3}} * D(3.69-0.27)+115 \frac{l b}{f t^{3}} * 14 f t * K_{p}=408.9 D+5908.7 \frac{l b}{f t^{2}}
\end{gathered}
$$




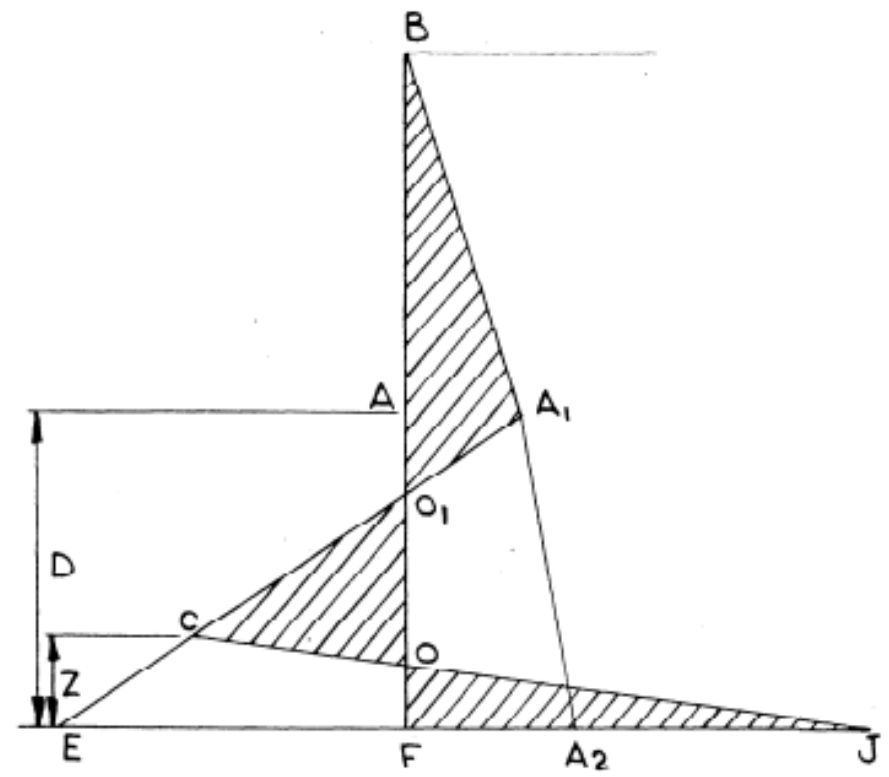

Figure 5. 25:Example Net Pressure

From statics, the following terms must be satisfied:

The sum of forces in terms of areas in Figure 5.25 must be equivalent to zero. Therefore:

$$
0.5(H) P A 1+(P A 1+P A 2)\left(\frac{D}{2}\right)+(P E+P J)\left(\frac{Z}{2}\right)-(P E+P A 2)\left(\frac{D}{2}\right)=0
$$

The equation derived by the force equilibrium approach can be used to solve for $\mathrm{z}$, when a depth (D) is assumed. In this instance, a depth of 10.5 feet is selected for use.

$$
z=((P E-P A 1) D-H P A 1) /(P E+P J)
$$

With a depth of 10.5 feet assumed, $\mathrm{z}$ is equivalent to 1.60 feet. The moment at the base of the pile can be assumed to be zero. The moment is calculated about the base (point F) and a value of $728 \mathrm{ft}-\mathrm{lb}$ is obtained. This is considered acceptable due to its relative low value. To ensure that the structure is conservatively designed, D can be increased $20-40 \%$. In this instance, D was increased to 13.5 feet. Figure 5.26 shows how the maximum moment is calculated. 


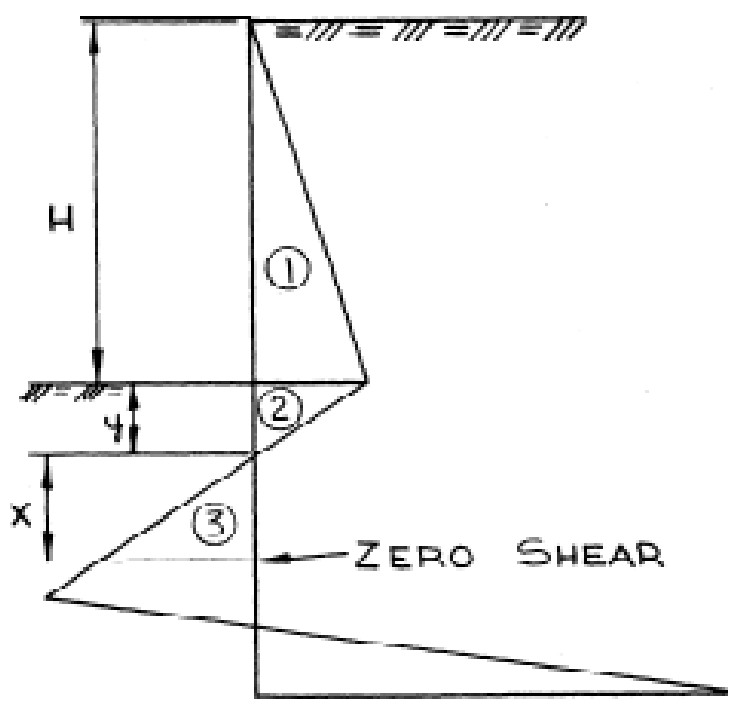

Figure 5. 26:Maximum Moment Calculation

The point of zero shear is calculated using Figure 5.26. Initially, y (from Figure 5.26) must be obtained.

$$
y=P A 1 /\left(\Upsilon^{\prime}\left(K_{p}-K_{a}\right)\right)=\frac{435 \frac{l b}{f t^{2}}}{65 \frac{l b}{f t^{2}} * 6.29}=1.0 f t
$$

The resultant forces from sections 1 and 2 in Figure 5.26 can then be calculated as:

$$
\begin{aligned}
& P 1=0.5 * 435 \frac{l b}{f t^{2}} * 14 f t=3040 \mathrm{lb} / f t \\
& P 2=0.5 * 435 \frac{l b}{f t^{2}} * 1.0 f t=218 \mathrm{lb} / \mathrm{ft}
\end{aligned}
$$

Therefore,

$$
\begin{gathered}
P 1+P 2=0.5 * \Upsilon^{\prime}\left(K_{p}-K_{a}\right) x^{2}=\left(3040 \frac{l b}{f t}+218 \frac{l b}{f t}\right)=0.5 * 65 \frac{l b}{f t^{2}} *(6.29) x^{2} \\
x=4.0 \text { feet }
\end{gathered}
$$

With $\mathrm{x}$ (distance from pivot point to maximum moment) obtained, the resultant force from section 3 can be calculated:

$$
P 3=0.5 * \Upsilon^{\prime}\left(K_{p}-K_{a}\right) * x^{2} f t=3280 \mathrm{lb} / f t
$$


The moment is taken about the point of zero shear, where the maximum moment will occur within the sheet pile.

$$
M_{\max }=\mathrm{P} 1 \mathrm{~L} 1+\mathrm{P} 2 \mathrm{~L} 2-\mathrm{P} 3 \mathrm{~L} 3=29,300 \mathrm{ft} . \mathrm{lbs}+1030 \mathrm{ft} . \mathrm{lbs}-4360 \mathrm{ft} . \mathrm{lbs}=26,000 \mathrm{ft} . \mathrm{lbs}
$$

The maximum moment that the sheet pile will have to withstand in this design, is $\mathbf{2 6 , 0 0 0} \mathbf{f t . l b s}$. 


\section{CONCLUSIONS AND RECOMMENDATIONS}

\subsection{Conclusions}

The primary objectives of this report were to establish a bending moment and load capacity test procedure for FRP composite sheet piles, analyse experimental data to determine the maximum load capacity of sheet piles tests, and establish equations to calculate failure loads for the tested sheet piles. A total of 12 preliminary tests and 6 final tests were conducted at the West Virginia University Constructed Facilities Center (WVU-CFC) to develop and affirm the final test configuration. Strain, load, deflection, and failure modes were documented from each tests so that conclusions could be drawn from the data. Three separate modes of failure were observed including, failure due to transverse bending, failure due to longitudinal bending, and failure of the embedment material (only observed in preliminary testing). Upon the completion of testing, an extensive analysis was conducted on the tested sheet pile using strain results from the final tests. The analysis proved the specimens moment capacity and allowed for a more theoretical evaluation of the sheet pile's loading response. Equations were derived for each of the three noted failure modes and when compared with actual testing results, proved to be accurate.

\subsubsection{Experimental Conclusions}

Through extensive testing, a final procedure to test bending moment and load capacity on FRP composite sheet piles had been created. Prior to the establishment of a final testing configuration, several tests with varying load application devices, embement materials, embedment depths, and locations of load application were conducted. Extensive review on the positive and negative aspects of each trial resulted in a replicable procedure to test FRP composite sheet piles. Figure 6.1 shows a perspective on the testing configuration that highlights the final load application method. 


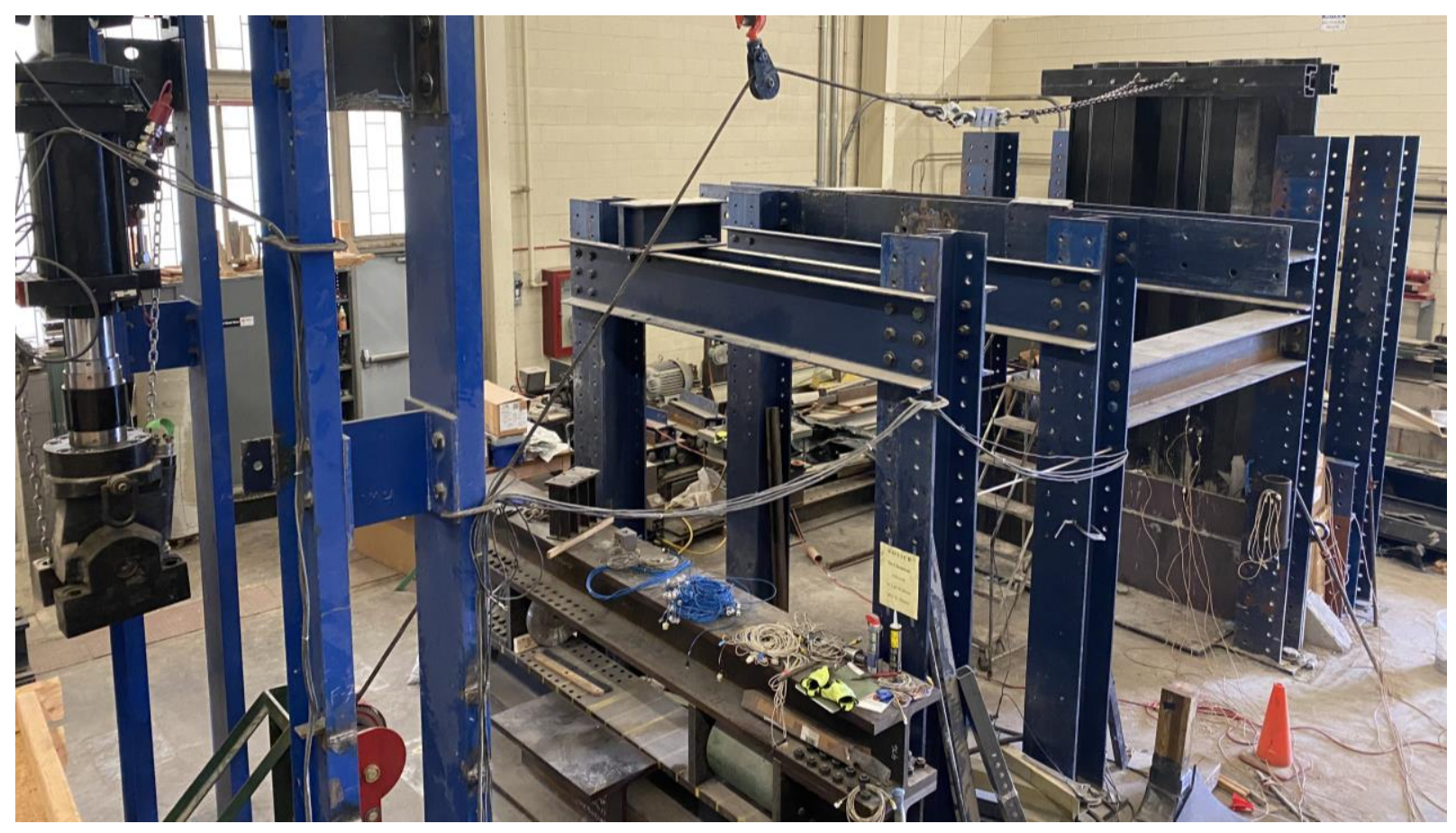

Figure 6.1: Final Test Procedure

Key observations from experimental testing include:

- Parital fixity of the sheet pile specimen within the embedment material was observed by watching a test conducted, and further expanded on through analysis. A lower degree of fixity than a true cantilever beam caused a slight adjustment in calculations to obtain the maximum moment.

- The prescence of an effective width was observed and documented throughout testing and analysis. Due to the lack of resraints on either side of the test specimen, the exterior flange did not resist load at the same rate as interior flange and web sections. As a result, an effective width (total width subtracted by ineffective flange sections) was used for calculations.

- Cylindrical bending was used to quantify deflection along each web and flange section (long, thin, rectangular plate) when each specimen was accounted for along the transverse axis. This assumption resulted in a constant flexural rigidity of FRP along the transverse axis.

\subsubsection{Experimental Results}

Knowledge pertaining to FRP sheet pile behavior and the testing configuration was gained during each test that was conducted. Failure methods were consistently the same (transverse and longitudinal), and documented for each test. Strain recorded at strategic locations was used to calculate pressure acting on the sheet pile. The results were used to create a net pressure distribution diagram that was then 
converted into a moment distribution diagram. From the moment distribution diagram, a maximum moment along the sheet pile test specimen was equivalent to $15.48 \mathrm{ft} . \mathrm{kip} / \mathrm{ft}$ width of wall.

\subsubsection{Theoretical Analysis}

An in depth analysis on strain at several locations on the sheet pile provided key insight to the failure behavior of the sheet pile. Strain results near the corners of the sheet pile cross section revealed that strain readings were approximately 3-4 times higher than strain readings at the same height on the center of the web or flange section. Formulas were developed to utilize strains taken from strategic locations to create design equation for both the longitudinal and transverse axis. Additionally, a procedure was created to analyze the shear capacity of the material used to retain the sheet pile in the final test configuration. The established equations in Chapter 5 have the capability to analyze testing results as well as design functional sheet pile retaining walls.

\subsection{Recommendations}

Test results shown throughout this document are promising due to their consistency and high degree of precision when compared with design equations. Although the data was promising, further evaluations into the optimal embedment material should be done. An ideal embedment material would experience shear failure at or slightly above the failure load required to cause failure in the test specimen. Additionally, more testing should be done with different sheet pile cross sections. Only three cross sections were tested over the course of testing with little variability. Further exploration into the effect of stress concentrations, especially at the corner/interface of the web and flange sections. 


\section{REFERENCES}

ACI Committee 318. (1995). Building code requirements for structural concrete : (ACI 318-95) ; and commentary (ACI 318R-95). Farmington Hills, MI :American Concrete Institute

Washington State Department of Transportation . Design manual (M 22-01.19). Olympia, WA, 2020. https://wsdot.wa.gov/publications/manuals/fulltext/M22-01/730.pdf

Das, B. M., \& Sivakugan, N. (2018). Principles of foundation engineering. Cengage learning.

Bilgin, Ö. (2010). Numerical studies of anchored sheet pile wall behavior constructed in cut and fill conditions. Computers and Geotechnics, 37(3), 399-407.

Murthy, V. N. S. (2002). Geotechnical engineering: principles and practices of soil mechanics and foundation engineering. CRC press.

Das, B. M. (2017). Principles of geotechnical engineering. Cengage learning.

El-Hanafy, A. M., \& AbdelAziz, M. H. (2021). Effect of using cemented sand as a replacement layer beneath a strip footing. HBRC Journal, 17(1), 1-17.

GuhaRay, A., \& Baidya, D. K. (2015). Reliability-based analysis of cantilever sheet pile walls backfilled with different soil types using the finite-element approach. International journal of Geomechanics, 15(6), 06015001.

Technical Supplement 14R Design and Use of Sheet Pile Walls in Stream Restoration and Stabilization Projects, Stream Restoration Design, National Engineering HandbookVolume 654, Pages 31

Choudhury, Deepankar \& Singh, Shailesh \& Goel, Shubhra. (2011). New approach for analysis of cantilever sheet pile with line load. Canadian Geotechnical Journal. 43. 540-549. 10.1139/t06-018.

GangaRao, H. V., \& Prachasaree, W. (2021). FRP Composite Structures: Theory, Fundamentals, and Design.

USACE. EM 1110-2-2504: Design of Sheet Pile Walls. US Army Corps of Engineers, 1994.

Reclamation, B. O. (1998). Earth Manual, US Department Of The Interior.

Das, B. M. (1979). Introduction to soil mechanics. Iowa State University Press..

Reclamation, B. O. (2019). E-7 Seismic Evaluation of Retaining Walls, US Department Of The Interior.

Lambe, T. W., \& Whitman, R. V. (1991). Soil mechanics (Vol. 10). John Wiley \& Sons. 
King, G. J. W. (1995). Analysis of cantilever sheet-pile walls in cohesionless soil. Journal of geotechnical engineering, 121(9), 629-635.

Terzaghi, K. (1934a). "Large retaining wall tests. I. Pressure of dry sand.” Eng. News-Rec., 136140

Gopal Madabhushi, S. P., \& Chandrasekaran, V. S. (2005). Rotation of cantilever sheet pile walls. Journal of geotechnical and geoenvironmental engineering, 131(2), 202-212.

Timoshenko, S., \& Woinowsky-Krieger, S. (1959). Theory of plates and shells.

Rajak, D. K., Pagar, D. D., Menezes, P. L., \& Linul, E. (2019). Fiber-reinforced polymer composites: Manufacturing, properties, and applications. Polymers, 11(10), 1667.

Giroux, C., \& Shao, Y. (2003). Flexural and shear rigidity of composite sheet piles. Journal of Composites for Construction, 7(4), 348-355.

Wang, J., Liu, W., Liang, R., GangaRao, H., \& Wan, L. (2016). Analytical and experimental study on flexural behavior of pultruded fibre reinforced polymer sheet piles. Journal of Composite Materials, 50(24), 3415-3429. 


\section{APPENDiX A: ResUlts From FinAl TeST Configuration}

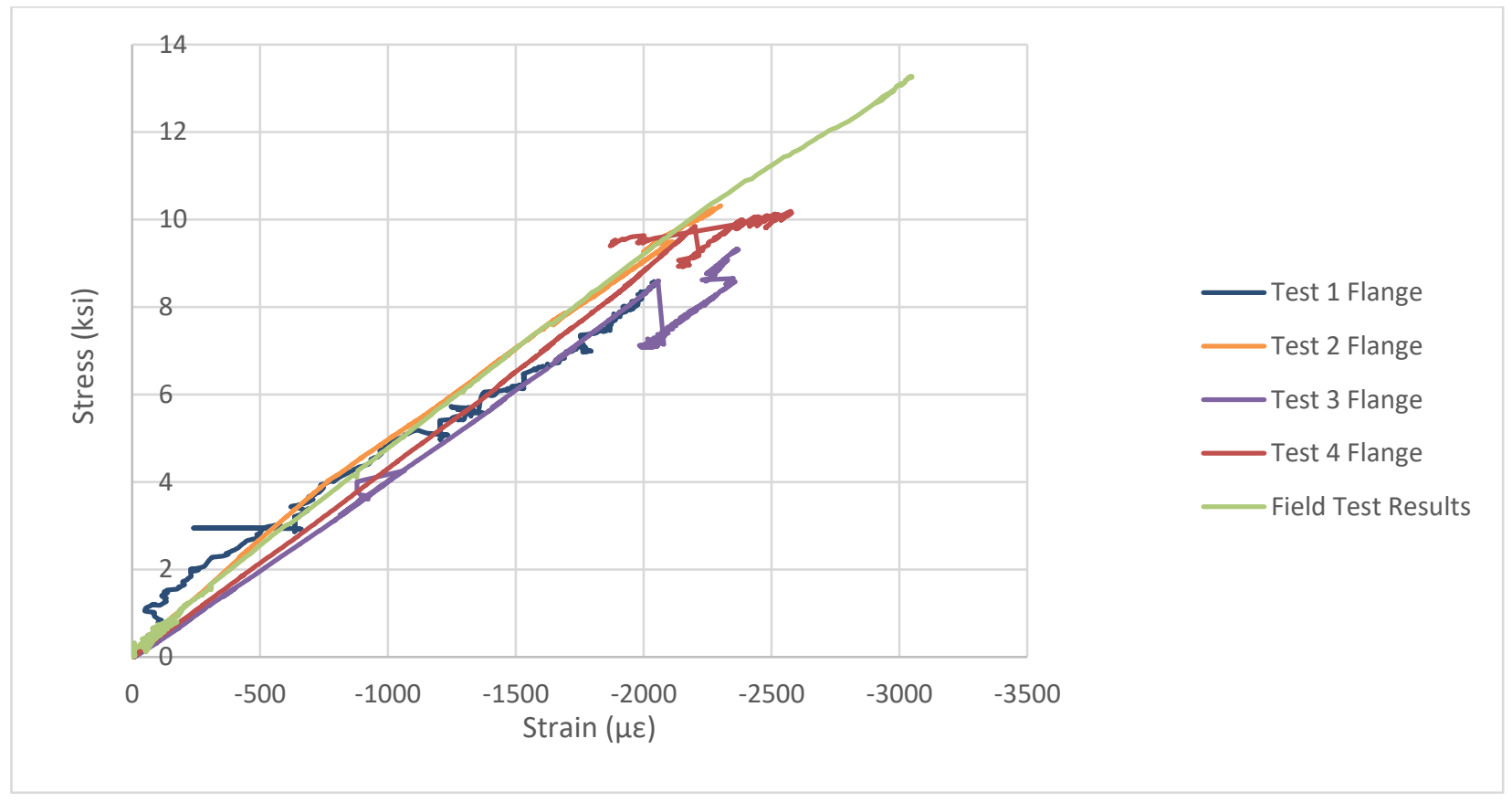

Figure A- 1: 1-Foot Above Dredge Line Flange Vertical Strain

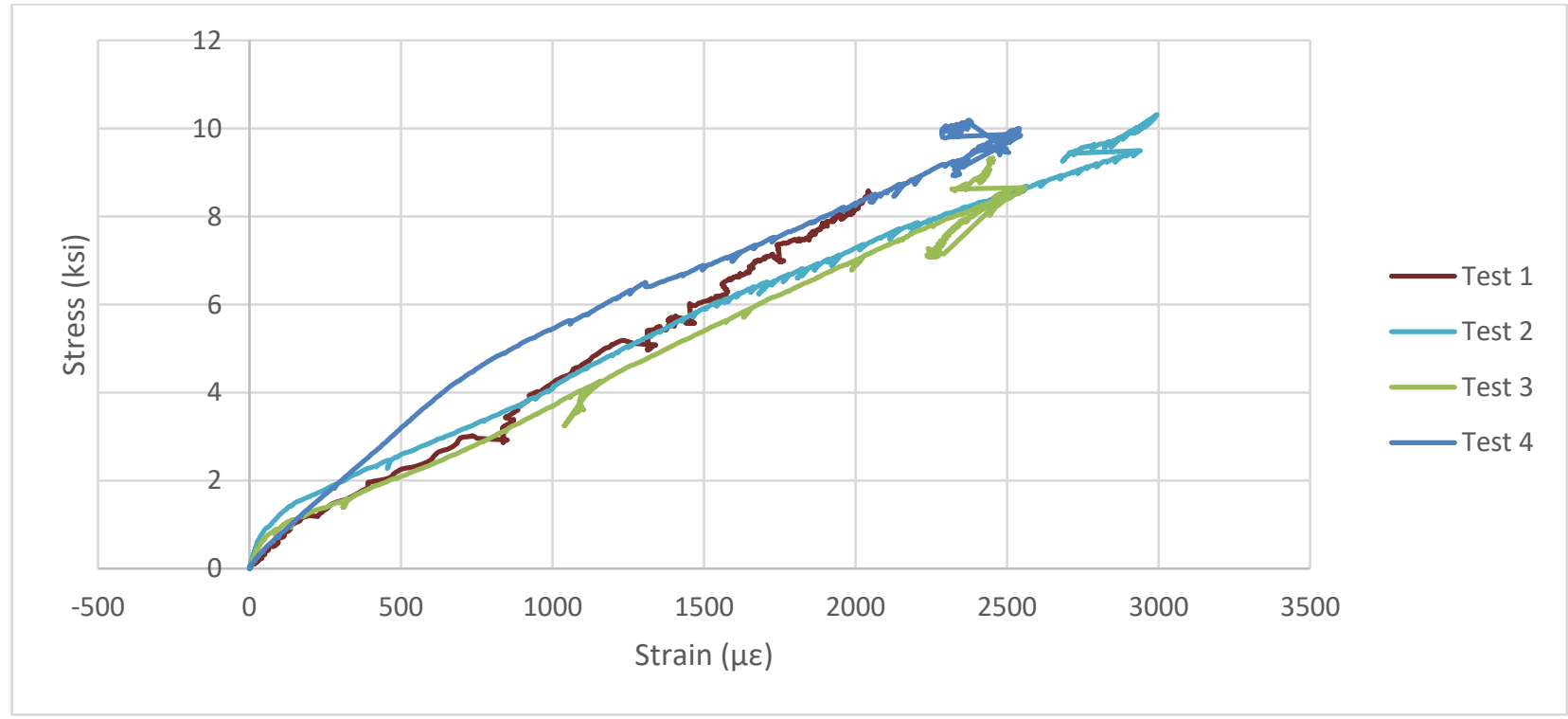

Figure A- 2:1-Foot Above Dredge Line Web Horizontal Strain 


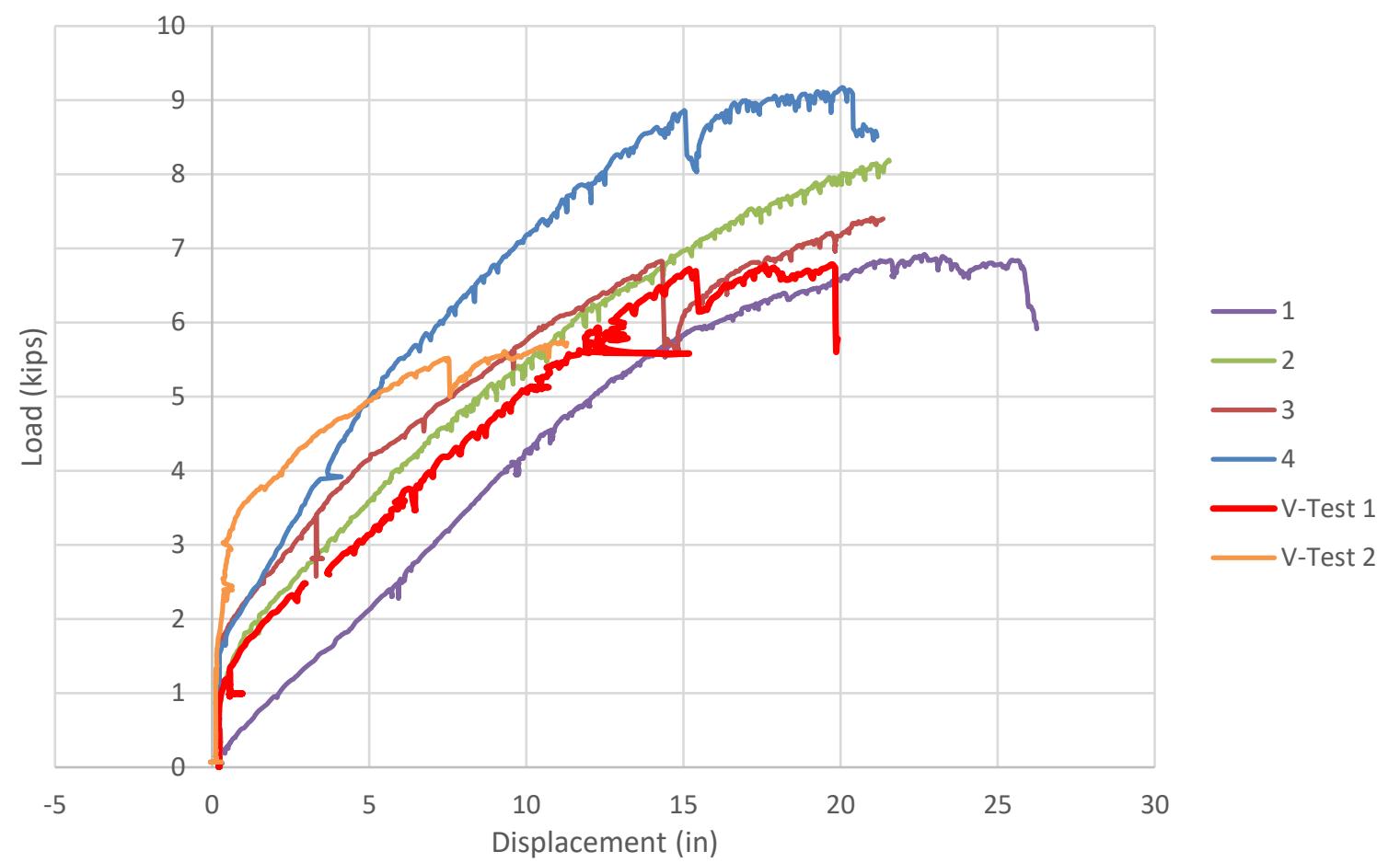

Figure A- 3: Load vs Deflection Comparison

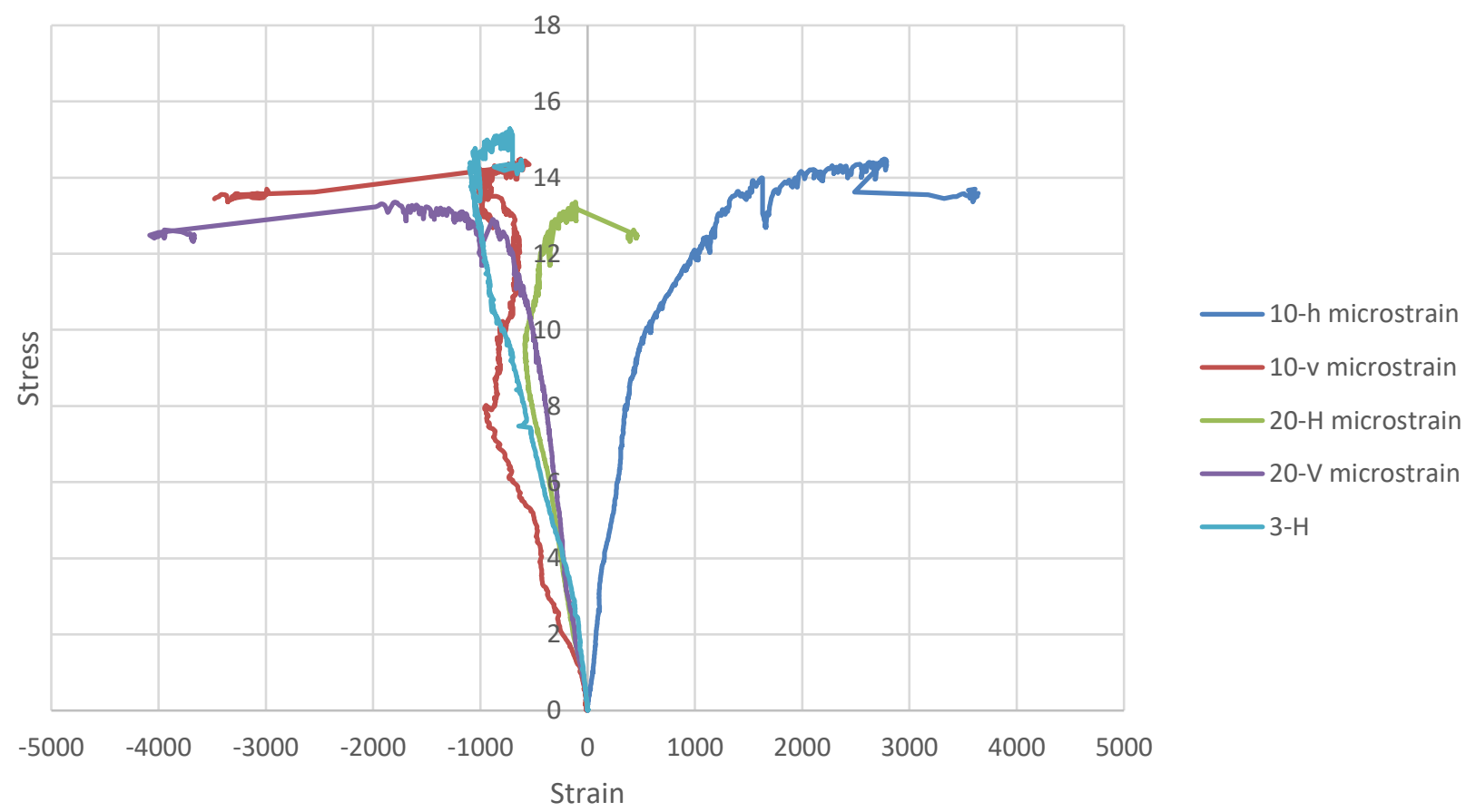

Figure A- 4: Test 4 Embedded Gages 


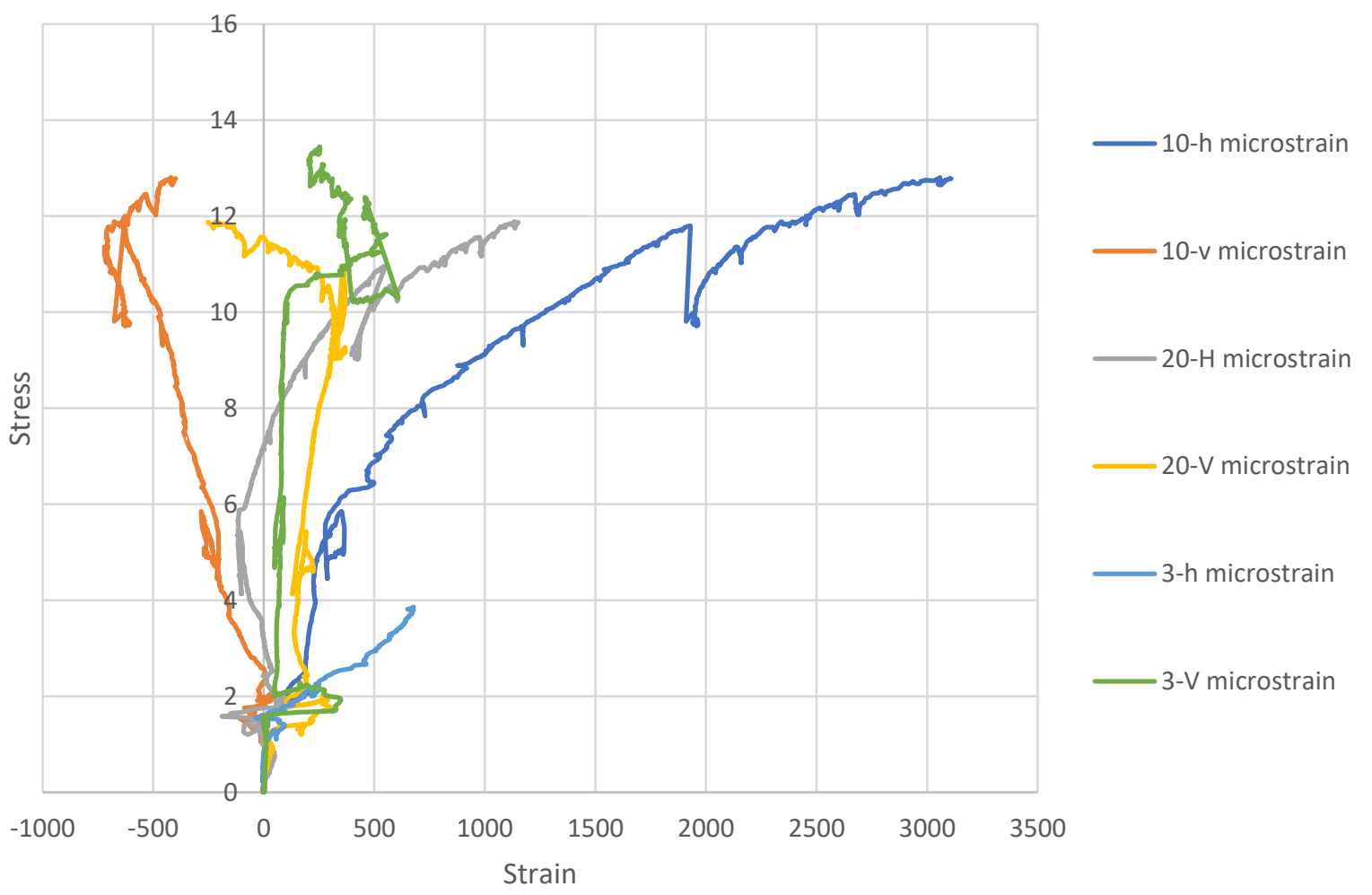

Figure A- 5: Test 3 Embedded Gages

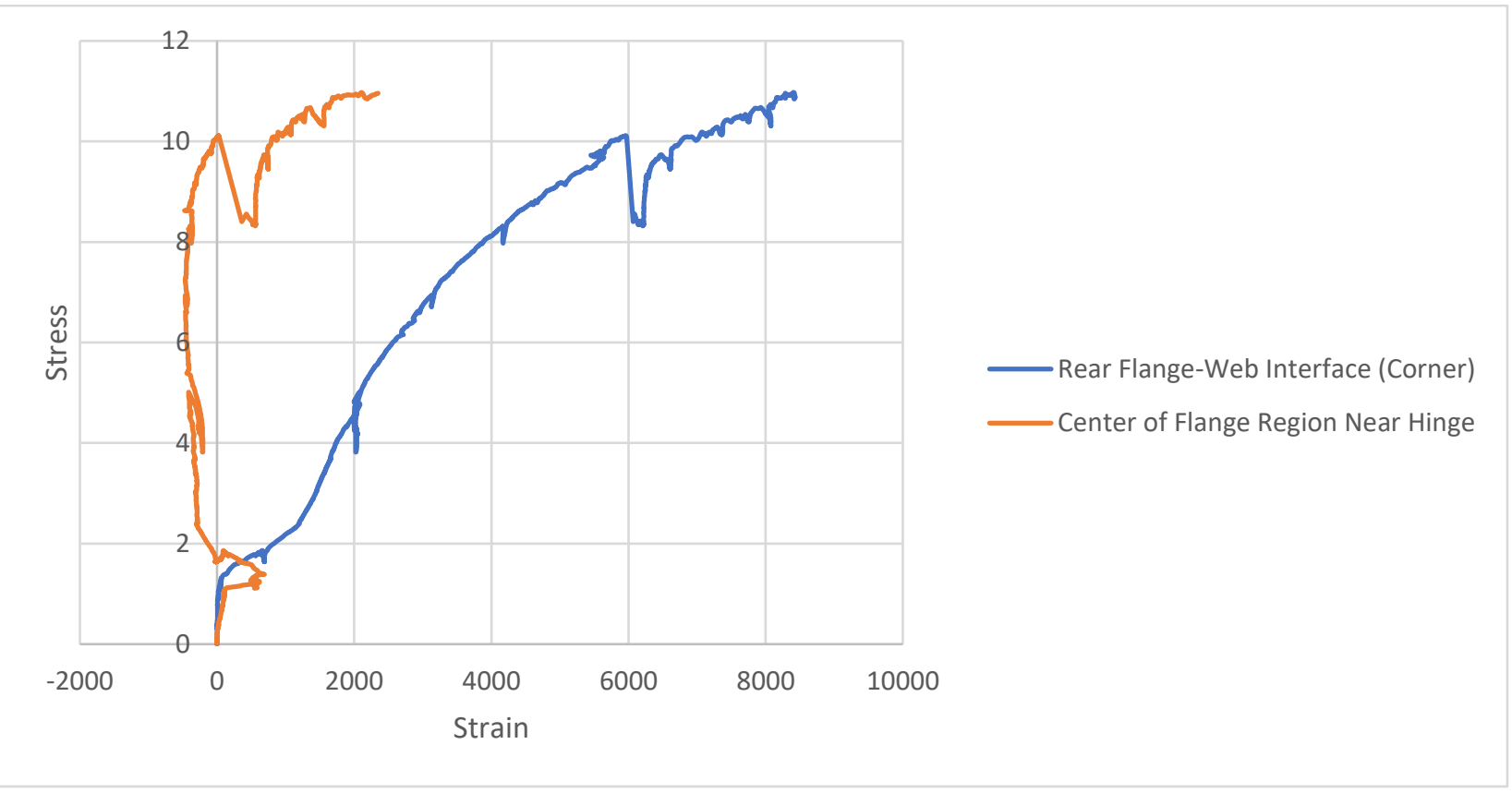

Figure A- 6: Test 3 6-Inches Beneath Dredge Line 


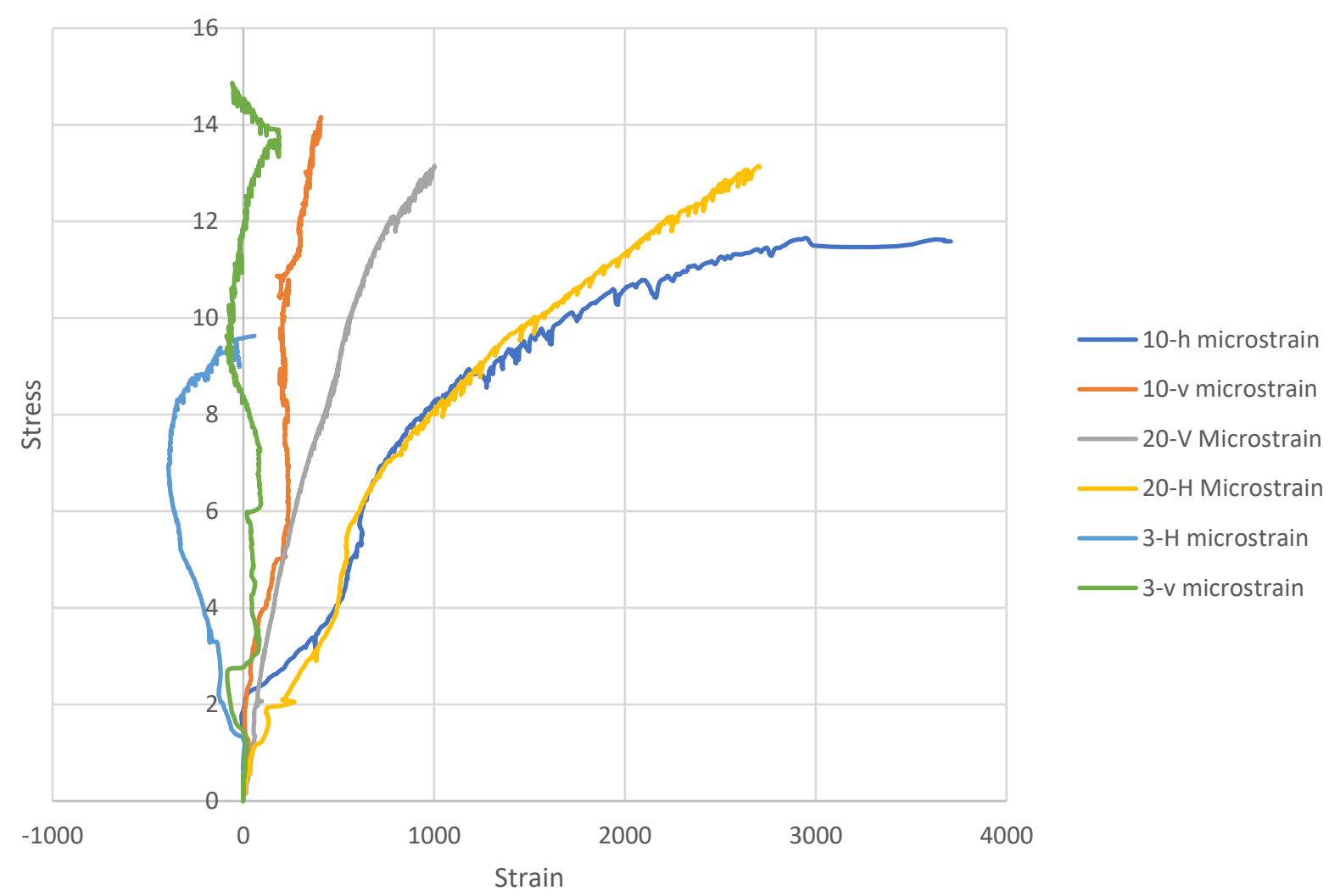

Figure A- 7: Test 2 Embedded Gages

\begin{tabular}{|c|c|c|c|c|c|}
\hline & \multicolumn{4}{|c|}{ Failure Strains } & \multirow[b]{2}{*}{ Average } \\
\hline & 7-Oct & 21-Sep & 15-Sep & 7-Sep & \\
\hline $3-\mathrm{H}$ & -1000 & 700 & -400 & & -700 \\
\hline $10-\mathrm{H}$ & 2800 & 3000 & 3500 & 2800 & 3025 \\
\hline $20-\mathrm{H}$ & -100 & 1000 & 1000 & & 1000 \\
\hline $\mathrm{FCl}$ & -2400 & -2350 & -2300 & -2000 & -2262.5 \\
\hline FW1 & 2500 & 2500 & 3000 & 2000 & 2500 \\
\hline $\mathrm{FC} 2$ & & & -2000 & -1750 & -1875 \\
\hline FW2 & & & 3000 & 2200 & 2600 \\
\hline $3-V$ & & & -100 & & -100 \\
\hline $10-\mathrm{V}$ & -1000 & -650 & 400 & & \\
\hline $20-\mathrm{V}$ & -1800 & -300 & 2600 & & \\
\hline Front Ground Web & & & & 1400 & \\
\hline Front Ground Flange & & & & -1250 & \\
\hline Rea Connection & & 0 & & & \\
\hline Rea Flange-Webcor ne & & 6000 & & & \\
\hline $\mathrm{L}$ (from load to mudline & 9 & 10 & 10 & 10 & \\
\hline LOAD & 9 & 6.9 & 8 & 6.9 & \\
\hline
\end{tabular}

Figure A- 8: Failure Strains From Final Test Configuration 


\section{Appendix B: Referenced Documents}

$E_{H_{t}}=E_{L_{w w}}=4250 \mathrm{ksi}$

Longitudinal modulus

$\mathbf{E}_{\mathrm{T}, \mathrm{t}}=\mathbf{E}_{\mathrm{T}, \mathrm{w}}=1300 \mathrm{ksi}$

Transverse modulus

$\mathbf{G}_{\mathrm{UI}}=500 \mathrm{ksi}$

In-plane shear modulus

$\mathbf{v u r}=0.3$

Longitudinal Poisson's ratio

$\mathbf{b}_{\mathbf{t}}=13.8$ in

Full width of flange

$\mathrm{t}_{\mathrm{f}}=\mathrm{t}_{\mathrm{w}}=0.265 \mathrm{in}$

Thickness of flange

$\mathbf{h}=8$ in

Full height of member

$\mathbf{I}=54 . \mathrm{lin}^{4}$

Moment of inertia of the profile

about the axis of bending

\section{Analysis}

An Analysis was conducted using the Pre-Standard rectangular fube design equations and FEA. Coupon level testing had been conducted to determine the nominal and characteristic material properties and strengths as specified within the PreStandard. Nominal material properties were used for the analysis to compare to the full section physical testing. In an effort of conservativeness in the calculation, the minimum value of each property was chosen from the available test results (tension/compression, flange/web).

\section{Pre-Standard Calculation}

The capacity of the panel was calculated using the flexural loading of a rectangular tube section of the Pre-Standard. The rectangular tube model was chosen because this most closely represents the interaction of the web-flange interface.

Section 5.2.3.4 of the Pre-Standard provides the equations used for the analysis of the panel. The calculation resulted in a critical compression flange local buckling value of $12,843 \mathrm{psi}$. This value correlates to a predicted failure moment of $13.998 \mathrm{ft}$ $\mathrm{lb} / \mathrm{ft}$ of wall. Standard cantilever beam calculations predict the failure load of the full section test to be $8.764 \mathrm{lb}$ at a deflection of $3.221 "$.

The coupon level compression strength for the part was measure to have an average value of $70,160 \mathrm{psi}$. Therefore, the panel is predicted to buckle well below the material rupture strength.

Equations for Square and

Rectangular Box Members

$f_{c r}=\frac{4 \pi^{2} t_{f}^{2}}{b_{f}^{2}}\left(\frac{\sqrt{\left(E_{L, f} E_{T, f}\right)(1+4.1 \xi)}}{6}+\left(2+0.62 \xi^{2}\right)\left(\frac{E_{T, f^{\prime}} v_{L T}}{12}+\frac{G_{L T}}{6}\right)\right.$

with

$$
\begin{aligned}
& \xi=\frac{1}{1+\frac{4 E_{T, f} t_{f}^{3}}{5 k, b f}} \\
& k_{r}=\frac{E_{T, w} t_{w}^{3}}{3 h}\left(I-\left[\left(\frac{2 t_{f}^{2} h^{2} E_{L, f}}{11.1 b_{f}^{2} t_{w}^{2} E_{L, f}}\right)\left(\frac{\sqrt{E_{L, f} E_{T, f}}+E_{T, f^{\prime} v_{L T}}+2 G_{L T}}{1.25 \sqrt{E_{L, w} E_{T, w}}+E_{T, w} v_{L T}+2 G_{L T}}\right)\right]\right)
\end{aligned}
$$

(b) Web local buckling

$f_{c r}=\frac{11.1 \pi^{2} t_{w}^{2}}{6 h^{2}}\left(1.25 \sqrt{E_{L, w} E_{T, w}}+E_{T, w} v_{L T}+2 G_{L T}\right)$

Figure B- 1: Series 1580 Sheet Pile Properties 


\begin{tabular}{|c|c|c|c|c|}
\hline \multirow{2}{*}{$\begin{array}{l}\text { AL - Along length of sheet pile } \\
\text { |Property }\end{array}$} & \multicolumn{4}{|c|}{ Aws - Along width of sheet pile } \\
\hline & Symbol & Units & Results & ASTM Test Method \\
\hline Primary Resin System: & & & Polyurethane & \\
\hline \multicolumn{5}{|l|}{ Flexural Stress: } \\
\hline Ültimate (AL) & $\sigma_{\text {UISAL }}$ & psi & $\overline{100 \overline{c o}} \overline{0}$ & D790-03 \\
\hline Recommended Allowablè Stress](AL) & $\sigma_{\text {all }}$ & psì & 25,000 & \\
\hline Möodulus of Elasticity (ĀL) & $E_{A L}$ & psi & $4,200,000$ & D̄ं9̄ō-03 \\
\hline Ultimate (AW/S) & $\sigma_{\text {ult }}$ & psi & 27,000 & D 790-03 \\
\hline MođaüTưs of ETästicitity [AW/ST & $E_{\text {Aurs }}$ & psi & $1,700,000$ & $0790-03$ \\
\hline \multicolumn{5}{|l|}{ Tensile Stress: } \\
\hline Üitimate $(\bar{A} \mathrm{~L})$ & ğ & psi & $9 \overline{5}, 0 \overline{0} 0 \overline{]}$ & D638-03 \\
\hline Recommended Allowablè Stress][AL] & oallis & psì & 25,000 & \\
\hline Modulus of Elasticity $(\bar{A} \bar{L})$ & $E_{A L}$ & psi & $4,600,000 \overline{0}$ & D $638-03$ \\
\hline Ultimate (AWS) & $\sigma$ ult Aws & psi & 10,000 & D 638-03 \\
\hline Modüiūs of Elásticity [AW/ST & $E_{\text {AWS }}$ & psi & $2,000,000$ & - 633803 \\
\hline \multicolumn{5}{|l|}{ Shear Stress: } \\
\hline Ültimate $(\mathrm{AL})$ & TultAl & psi & $5,40 \overline{0}$ & D-3846-02 \\
\hline Recömmended Allowablè Stress](AL) & $\mathrm{T}_{\text {afllA }}$ & psì & 2,700 & 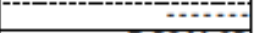 \\
\hline Ultimate (AWS) & $\sigma$ vit Aurs & psi & 6,200 & D 3846-02 \\
\hline \multicolumn{5}{|l|}{ Compression Stress: } \\
\hline Uttímàte $] \mathrm{AL} \mathrm{L}^{-}$ & 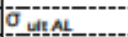 & psì & 56,000 & Б6 $695-02 a$ \\
\hline Recommended Äilowable stress (AL) & $\sigma_{\text {allAL }}$ & psi & $18,6 \overline{0}$ & \\
\hline 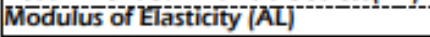 & $E_{A L}^{-a-2}$ & psì & 806,000 & D6 $695-02 a$ \\
\hline Ultimate (AWS) & 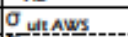 & psì- & $\mathbf{2 2}, 000$ & D6 $695-02 a$ \\
\hline Módülüs of ETasticity [AWUST & $\mathrm{E}_{\text {AWS }}$ & psi & 641,000 & D695-02a \\
\hline \multicolumn{5}{|l|}{ Impact Strength: } \\
\hline Izod & & $\mathrm{ft}-\mathrm{b}$ foinch & 59 & D256-05 \\
\hline izod $(A \bar{W} / \bar{S})$ & & $\mathrm{ft}-\mathrm{lb}$ f/inch & 20 & D 256-05 \\
\hline
\end{tabular}

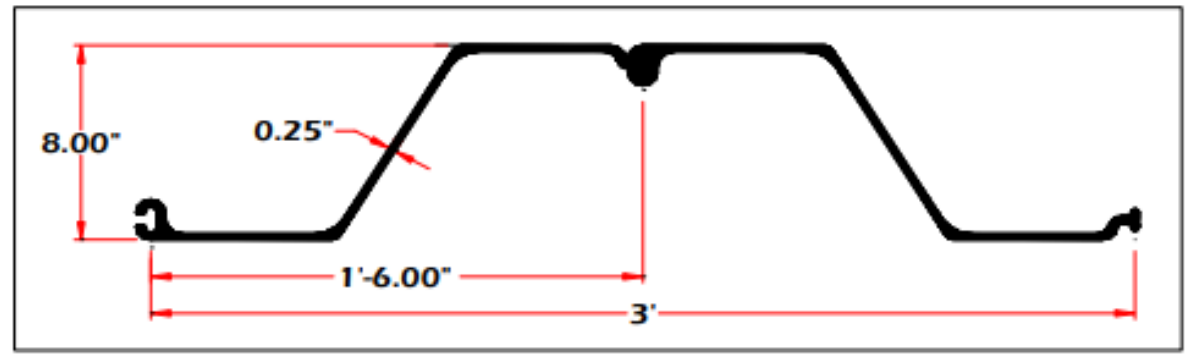

\begin{tabular}{|c|c|c|c|c|}
\hline \multicolumn{5}{|l|}{ Properties of Sheet Plle: } \\
\hline $\bar{w}$ idth & $\overline{\mathbf{W}}^{-}$ & inches & 18 & (n) \\
\hline Depth & $\overline{1}$ & inches & -8 & 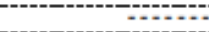 \\
\hline Tihickness & $\bar{t}^{-}$ & inches & $0 . \overline{2} \overline{5}$ & D̄79̄ō-03 \\
\hline Section Modulus & $\bar{z}$ & $\operatorname{in}^{3-1}$ & 13 & D 790-03 \\
\hline Moment of Inertia & $i$ & in $^{4}$ & 52 & D790-03 \\
\hline Radius of Gyration (pair) & $r$ & inches & 3.29 & (n........ \\
\hline Ärea of Web & $A_{w}$ & $\operatorname{in}^{2}$ & 2.33 & (n) \\
\hline İnteriock Strength & & tibf/in & $225-251$ & D4884-96(2003) \\
\hline
\end{tabular}

The values shown are averages and may very. No warrantes of any kind are made as to the suitability of ESP sheet piling for particular applications

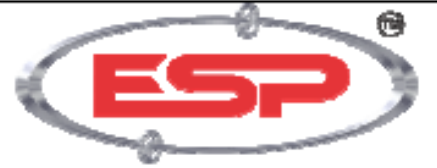

Everlast Synthetic Products, UC 1000 W/yngate Plkwy, S-100 Woodstock, GA 30189 800-687-0036 www.everlastseawalls.com

Figure B- 2: EverComp 26.1 Sheet Pile Properties 


\begin{tabular}{|c|c|c|c|c|}
\hline & & & & \\
\hline Property & symbor & Units & Results & Astim Test Method \\
\hline \multicolumn{5}{|l|}{ Flexural Stress: } \\
\hline Ultimate (AL) & O & psi & 85,000 & D 790-03 \\
\hline Recommended Allowable Stress $(\mathrm{AL})$ & o & psi & 21,250 & (n)..... \\
\hline Modulus of Elasticity (AL) & $\mathbf{E}_{\text {AL }}$ & psi & $3,600,000$ & D 790-03 \\
\hline Ultimate (AW/S) & $\sigma_{\text {ut }}$ aWs & psi & 23,000 & D 790-03 \\
\hline Modulus of Elasticity (ĀW/S) & $E_{\text {Aws }}$ & psi & $1,400,000$ & D $790-03$ \\
\hline \multicolumn{5}{|l|}{ Tensile Stress: } \\
\hline Ultimate (AL) & o & psi & 80,000 & D 638-03 \\
\hline Recommended Allowable Stress (AL) & GallAL. & psi & 21,250 & (n) \\
\hline Modulus of Elasticity (AL) & $\mathbf{E}_{\text {ML }}$ & psi & $3,900,000$ & D $638-03$ \\
\hline Ultimate (AW/S) & O uavs & psi & 8,500 & D 638-03 \\
\hline Modulus of Elasticity (AW/S) & $E_{\text {aws }}$ & psi & $1,700,000$ & $\mathrm{D} 63 \overline{8}-03$ \\
\hline \multicolumn{5}{|l|}{ Shear Stress: } \\
\hline Ultimate (AL) & Tut스. & psi & 4,600 & $\mathrm{D} 3846-02$ \\
\hline Recommended Allowable Stress(AL) & TatAL & psi & 2,300 & (n........ \\
\hline Ultimate (AWS) & $\sigma_{\text {ut Aws }}$ & psi & 5,300 & D 3846-02 \\
\hline
\end{tabular}

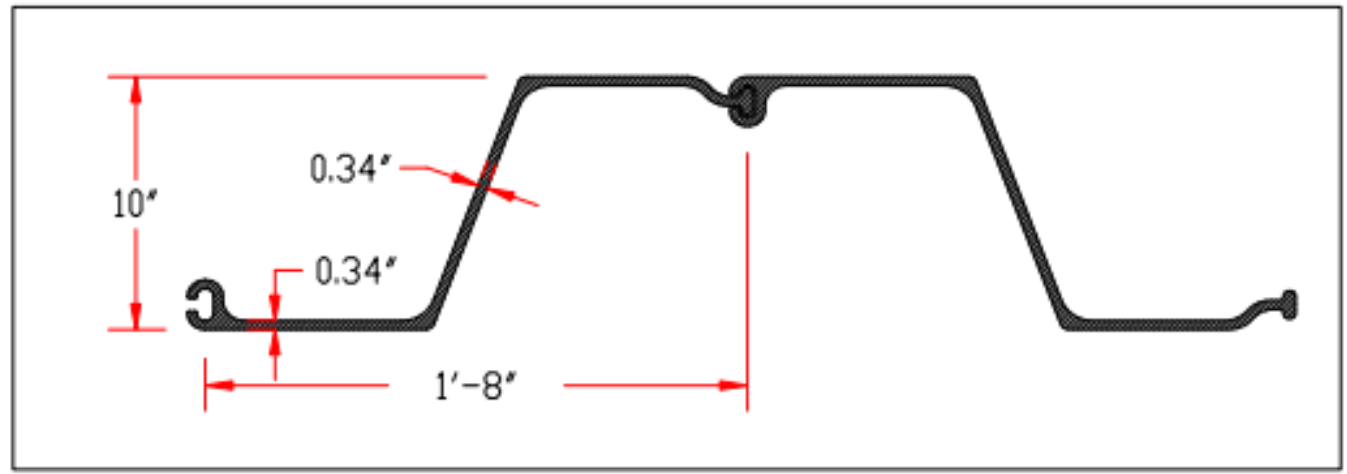

\begin{tabular}{|c|c|c|c|c|}
\hline Properties of Sheet Pile: & & & & \\
\hline Width & $w$ & inches & 20 & ......... \\
\hline Depth & D & inches & 10 & ......... \\
\hline Thickness & t & inches & 0.34 & $\cdots$ \\
\hline Section Modulus & $z$ & $\mathrm{in}^{3} / \mathrm{ft}$ & 23 & $\cdots$ \\
\hline Moment of Inertia & 1 & $\mathrm{in}^{4} / \mathrm{ft}$ & 114 & - \\
\hline Radius of Gyration (pair) & $r$ & inches & 4.12 & $\ldots$ \\
\hline Area of Web & $A_{W W}$ & in $^{2}$ & 3.60 & $\ldots$ \\
\hline
\end{tabular}

The values shown are averages and may vary. No warranties of any kind are made as to the suitability of ESP sheet pling for particular applications

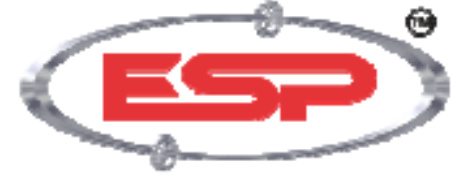

Everlast Synthetic Products, $\amalg C$ 1000 W/yngate Pkwy, S-100 Woodstock, GA 30189 800-687-0036 800-687-0048 fax www.everlastseawalls.com

Figure B- 3: EverComp 47.5 Sheet Pile Properties 


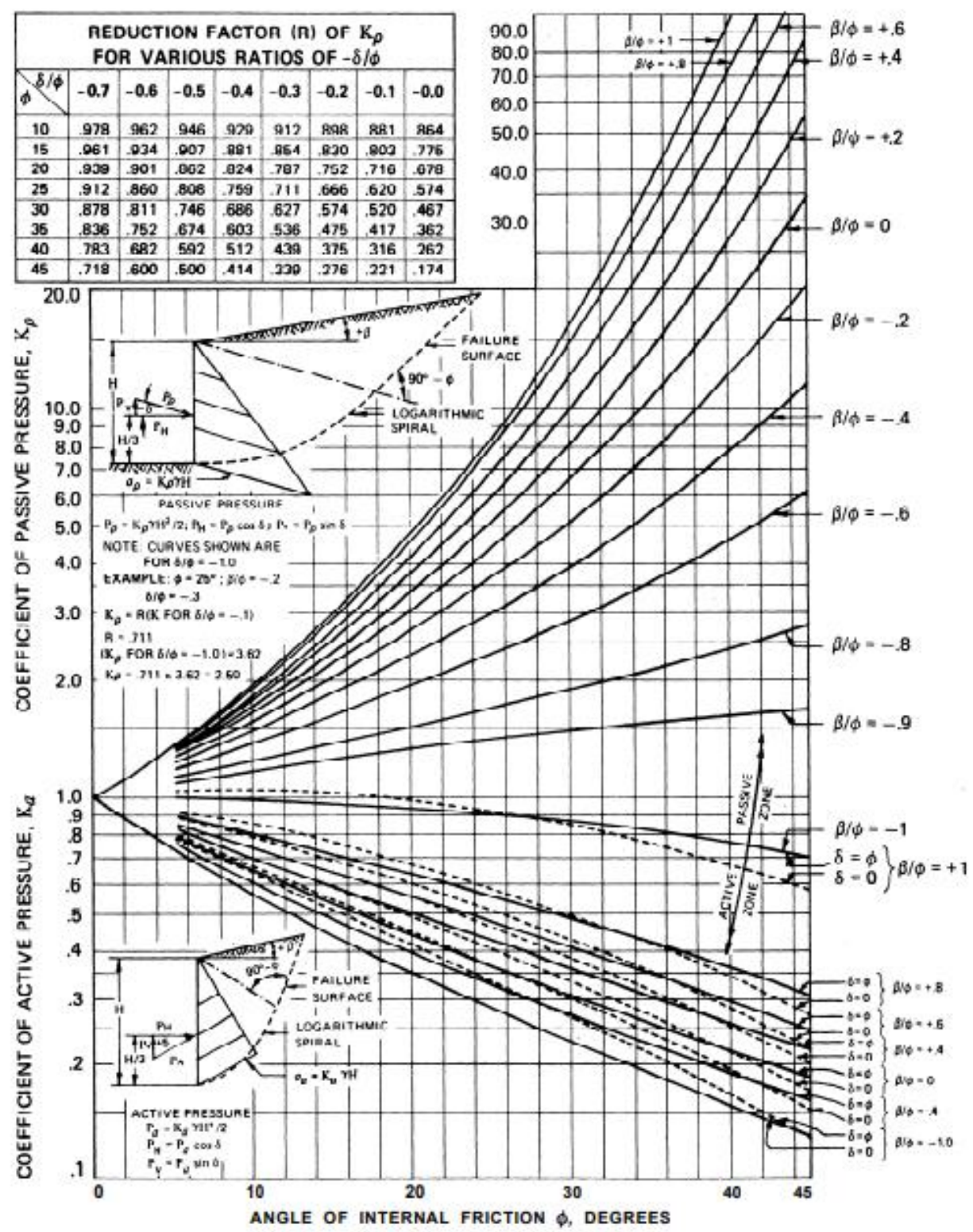

Fig. 5(a) - Active and passive coefficients with wall friction (sloping backfill) (after Caquot and Kerisel ${ }^{21}$ )

Figure B- 4: Earth Pressure Chart 
(Na1) DESIGN OF CANTILEVERED SHEET PILE WALL - GRANULAR SOIL

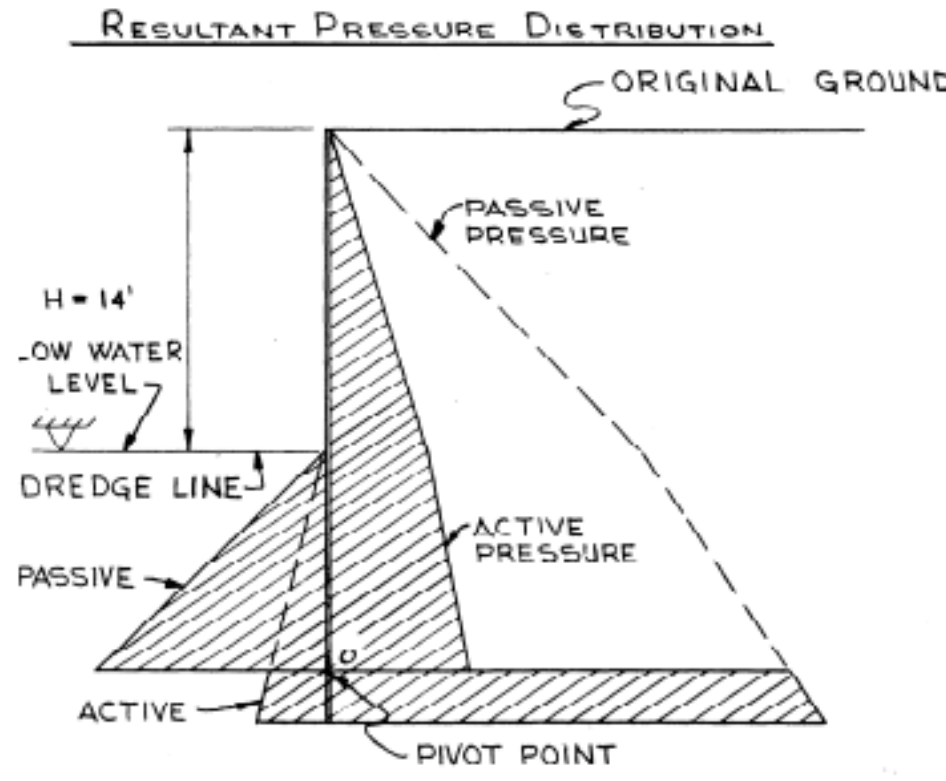

$$
\begin{aligned}
& \text { MEDIUM SAND } \\
& 8=115 \text { PCF } \\
& 8^{\prime}=65 \mathrm{PCF} \\
& \phi=35^{\circ} \\
& 8 / \phi=-0.5 \\
& \left.\mathrm{~K}_{a}=0.27\right\} \text { EEE } \\
& \left.K_{P}=6.56\right\} \text { FIG. 5A }
\end{aligned}
$$

CONVENTIONAL ASSUMED PRESSURE DIAGRAM

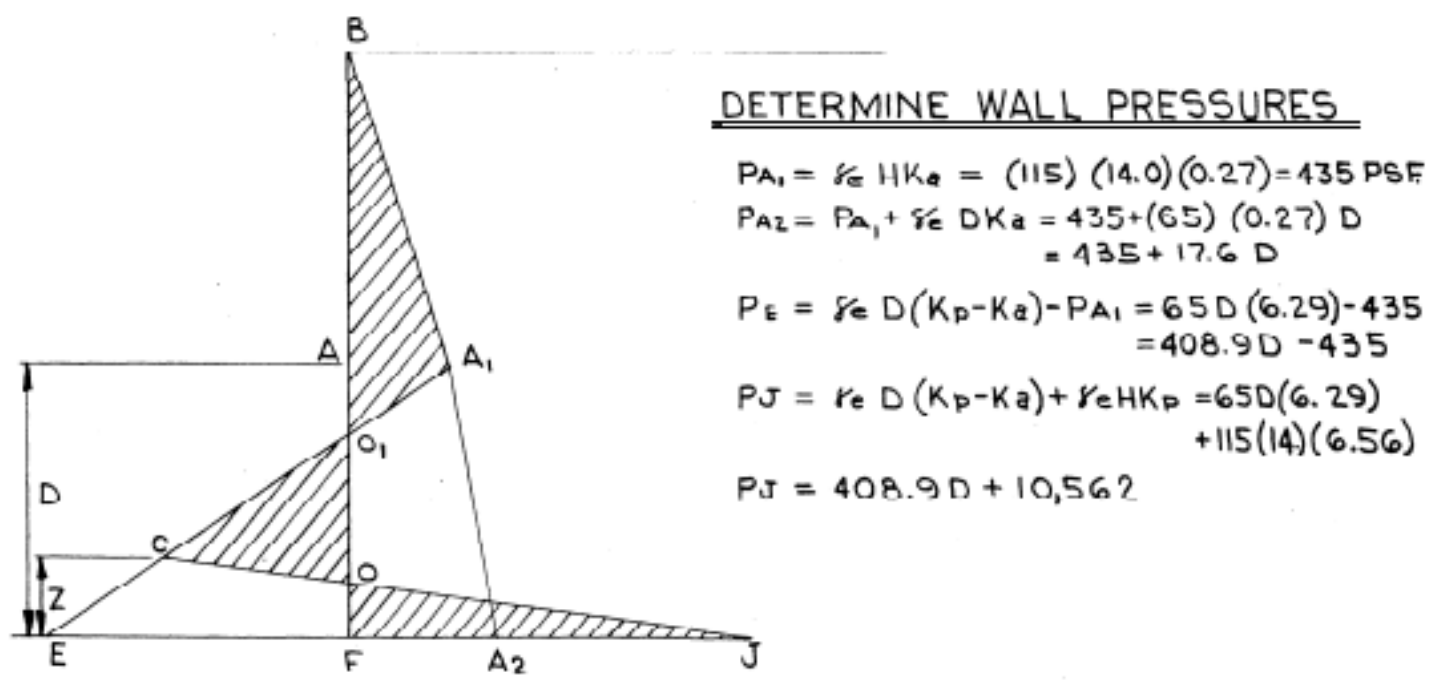

Figure B- 5 
From statics. The Following Conditions Must Be Satisfied

(1) $\sum F_{H}=0$ IN TERMS OF AREAS:

OR

AREA $\left(B A A_{1}\right)+\operatorname{ArEA}\left(A A_{1} A_{2} F\right)+\operatorname{ArEA}(E C U)-\operatorname{ArEA}\left(E A_{1} A_{2}\right)=0$

$\frac{1}{2}(H) P A_{1}+\left(P A_{1}+P A_{2}\right) \frac{D}{2}+(P E+P J) \frac{Z}{2}-\left(P E+P A_{2}\right) \frac{D}{2}=0$

SOLVING FOR Z:

$$
Z=\frac{\left(P E-P_{A_{1}}\right) D-H P_{A_{1}}}{P_{E}+P_{I}}
$$

(2) $\sum M$ ABOUT ANY POINT IS ZERO

$$
\Sigma M_{F}=\frac{1}{2}(H) P_{A_{1}}\left(D+\frac{H}{3}\right)+\left(P_{A_{1}}\right) \frac{D^{2}}{2}+(P E+P J) \frac{Z^{2}}{6}-\left(P E+P A_{2}\right) \frac{D^{2}}{6}
$$

METHOD OF SOLUTION: $+\left(P A_{2}-P A_{1}\right) \frac{D^{2}}{6}=0$

1. Assume A Depth Of Penetration, D

2. Calculate $Z$

S SUBSTITUTE $z$ InTO EMF ANo CheCK If Zero. AOUUST $D$ and Recalculate. if necessary.

TRT D $=10.5 \mathrm{FT}$.

$P A_{1}=435$ PSF $P A_{2}=620$ PSF. $P J=14,855$ PSF. $\quad P E=3858 \mathrm{PSF}$

$z=\frac{(3858-435)(10.5)-(14)(435)}{14.855+3858}=\frac{29852}{18713}=1.60 \mathrm{FT}$.

$\sum M_{F}=\frac{1}{2}(14)(435)(10.5+4.67)+(435) \frac{(10.5)^{2}}{2}+\frac{(620-435) \frac{(10.5)^{2}}{6}}{6}$

$$
+(3858+14,855) \frac{(160)^{2}}{6}-(3858+620) \frac{(10.5)^{2}}{6}
$$

$\Sigma M_{F}=46,193+23,979+3399+7984-82,283$

$E M_{F}=-728$ FT. - LB. SAY O.K. USE D-10.5 FT.

Figure B- 6 
To ASSURE A MARGin OF SAFETY, D MAY BE INCREASED BY

20 TO $40 \%$ OR, ALternately, A Reduceu Passive Earth

Pressure Coefficient COULd Be Used.

USE D $=13.5 \mathrm{FT} . \quad$ (INCREASE $=28.5 \%$ )

MOXIMUM MOMENT ANR SHEET PILE SIZE

LOCATE POINT OF ZERO SHEAR

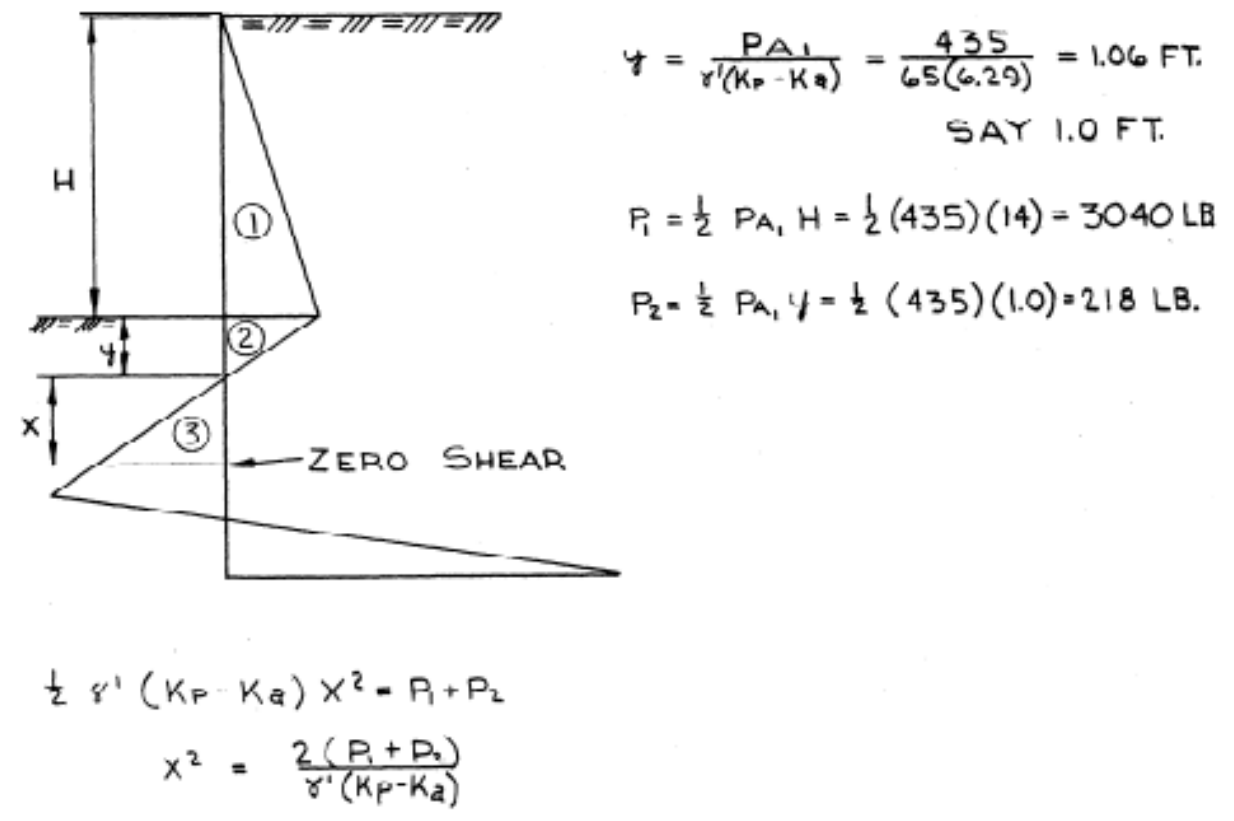

Figure B- 7 


$$
\begin{gathered}
X 2=\frac{2(3040+218)}{65(6.29)}=\frac{2(3258)}{407}=16 \\
X=4.0 \text { FEET }
\end{gathered}
$$

MAXIMUM MOMENT

$$
P_{3}=\frac{1}{2} \gamma^{\prime}\left(K_{P}-K_{a}\right) 4^{2}-P_{1}+P_{2}=3280 L B \text {. }
$$

$$
\begin{aligned}
M_{\max } & =P_{1} e_{1}+P_{2} e_{2}-P_{3} l_{3} & & l_{1}=\left(\frac{H}{3}+y+x\right) \\
M_{\max } & =3040\left(\frac{14}{3}+1.0+4.0\right) & & \ell_{2}=\left(\frac{2 y}{3}+x\right) \\
& +218\left(\frac{2(1)}{3}+4.0\right) & & \ell_{3}=\frac{x}{3} \\
& =3280\left(\frac{4.0}{3}\right) & &
\end{aligned}
$$

$M_{\operatorname{MAX}}=29,300+1030-4360=26,000 \mathrm{FT}$. LBS.

TRT REgULAR CARBON GRADE; $f_{5}=25 \mathrm{KS} 1$ REQUIRED SECTION MODULUS - $\frac{M}{f_{5}}=\frac{26000 \times 12}{25000}=12.5 \mathrm{IN}^{3}$ MUST USE PZ-27-TRYEXTEN 45 STEEL; $f_{5}=29 \mathrm{KSI}$ REQ'D. $S=\frac{26,000 \times 12}{29,000}=10.76 \mathrm{IN}^{3} \bigcup_{\text {(ALTERNATE SECTION) }}^{\text {SE PDA-27 }} S=10.7 \mathrm{IN}^{3}$

CHECK USING FIG. 18 (DESIGH CURVE)

$$
K_{P} / K_{2}=\frac{6.56}{0.27}=24.2 \quad \alpha=\frac{14.0}{14.0}=1.0
$$

FROM CURVES $\frac{D}{H}=0.8 \quad \frac{M_{\max }}{\gamma^{1} K_{2} H^{3}}=0.65$

Figure B- 8 